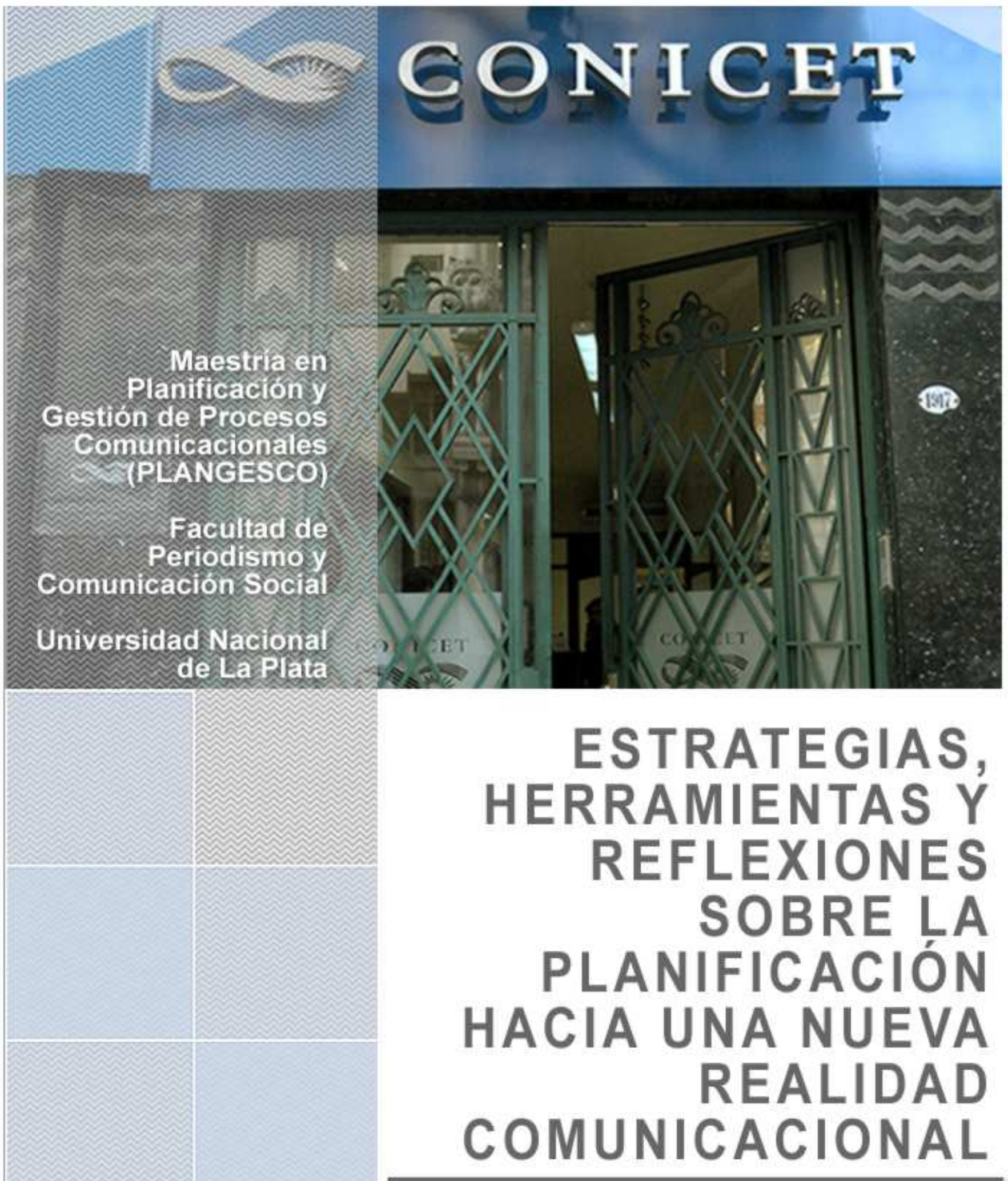

El lugar de la comunicación

Tesista Lic. Mario Migliorati Julio de 2015 institucional en procesos de gestión en el Estado desde el análisis de la Dirección de Relaciones Institucionales del CONICET 
TESIS DE MAESTRÍA

\section{ESTRATEGIAS, HERRAMIENTAS Y REFLEXIONES SOBRE LA PLANIFICACIÓN HACIA UNA NUEVA REALIDAD COMUNICACIONAL}

El lugar de la comunicación institucional en procesos de gestión en el Estado desde el análisis de la Dirección de Relaciones Institucionales del CONICET

Tesista: Lic. Mario Andrés Migliorati

Director: Mg. Cecilia Ceraso

Maestría en Planificación y Gestión de Procesos Comunicacionales (PLANGESCO)

Facultad de Periodismo y Comunicación Social

Universidad Nacional de La Plata

Julio de 2015 
Página 2 de 205 


\section{CAPÍTULO I}

\section{CAPÍTULO II}




\section{CAPÍTULO III}

\section{CAPÍTULO IV}




\section{CAPÍTULO V}

EI eje investigación/producción/gestión de nuevos lineamientos comunicacionales

El marco inicial o punto de partida. Consideraciones iniciales en el diagnóstico

El diagnóstico como posibilidad de comprender la realidad

\section{CAPÍTULO VI}

Seis puntos hacia una redefinición de la Dirección de Relaciones

Institucionales 
Punto 2: Del diagnóstico

Punto 3: Desarrollos

Punto 4: Configuración

Punto 5: Preguntas críticas

Punto 6: Agendas de gestión

\section{CAPÍTULO VII}

Diagnóstico de la comunicación en la Red Institucional

La comunicación en la Red Institucional

121

-Aspectos observados sobre la comunicación

122

-Estrategias de difusión

123

-Tecnologías disponibles

125

-Perspectivas

126

Red Institucional de comunicadores

126

CAPÍTULO VIII 
Programas y proyecciones

El Programa de Promoción de Vocaciones Científicas

Aportes del Programa VocAr

El Buque Oceanográfico Puerto Deseado integrado a VocAr

País Ciencia

Eventos, Ceremonial y Protocolo

Las condiciones de producción

Conceptualizaciones y convergencia

\section{Capítulo IX}


Respuestas hacia la sustentabilidad comunicacional

Comunicación en acto

Otras respuestas a las preguntas iniciales

Bibliografía 
Página 10 de 205 
"La comodidad y el bienestar de los hombres no depende tanto del progreso industrial y científico, sino de la justicia social. Si por hacer exposiciones automovilísticas, se descuida la justa distribución de las ganancias de la empresa constructora, entre patrones y obreros, de nada servirá que el hombre vaya a la Luna o coma estrellas fritas o escuche por inalambrana las músicas seráficas en cuerda viva".

Cesar Vallejo "El salón del automóvil de París" (1926).

\section{Introducción}

Esta tesis surgió de primeros encuentros, debates, experiencias y elecciones generados en momentos en que me encontraba cursando la Maestría de Planificación y Gestión de Procesos Comunicacionales (PLANGESCO). Y si bien se trató de un proceso de búsqueda que aún continúa, aquellas reflexiones alcanzadas y posteriores tránsitos en ámbitos institucionales me llevaron a establecer primeras preguntas acerca de cómo sería trabajar la comunicación en una institución científica, a partir de diagnosticar la comunicación y proponer la construcción de un conjunto de herramientas comunicacionales predefinidas para la intervención operativa y la gestión.

Constituyendo es sí mismas una línea de discusión, esas preguntas pudieron plasmarse en una intervención desde la comunicación que hoy da lugar a esta tesis. Y se trata de un aporte a la vinculación del comunicador en una institución del sistema científico nacional que, si bien se origina sobre procesos reconocidos desde distintas contribuciones teóricas sobre este campo de conocimiento, se presenta como una experiencia sostenible y comunicable desde la interrelación operativa. Esta propuesta concreta de intervención es también un evidente 
trabajo de adecuación de herramientas comunicacionales para la gestión de la comunicación institucional.

Esta preocupación acerca de la comunicación en organizaciones científicas experimentó un itinerario personal desde diversos roles de la gestión comunicacional que facilitaron este proceso reflexivo desde prácticas y saberes en distintos proyectos institucionales.

Fortalecida esta idea con el tiempo, sobre teorías y lecturas de la complejidad, desde los inicios en la PLANGESCO (2003-2006) y por otros desarrollos investigativos como becario ${ }^{1}$ y en el ámbito de la docencia ${ }^{2}$, aparece la formulación de la hipótesis sobre la que comienzo a dar cuenta en 2012, cuando ya en la Dirección de Relaciones Institucionales (DRI) del Consejo Nacional de Investigaciones Científicas y Técnicas (CONICET) pude concebir las herramientas comunicacionales y llevarlas a la práctica.

De aquí en más lo que se constituye como un estudio de caso único transcurre durante un período de tiempo de tres años que concluye en el año 2014 para su posterior sistematización. Durante este tiempo haber tenido la posibilidad de gestionar la comunicación me permitió delinear lo que primero fue un plan para la acción para pasar a un recorrido que contempló herramientas diagnósticas, estrategias de comunicación e instancias de intervención comunicacional en y desde este organismo.

Por su parte, fue necesario acercarme a un universo de interacciones en red y de dinámicas para entender el proceso que experimentó la Institución en estos últimos años, hecho del que se irá dando cuenta. Y entender porqué fue necesario llevar adelante estos componentes y llegar a desarrollarlos, desde líneas de reflexión que invitan a pensar las instancias de comunicación desde enfoques y aportes críticos situados desde la mirada disciplinar.

Este abordaje cualitativo que incluye aportes historizantes y reflexiones, empleo de conceptos y metodologías, en un marco de aportes y acciones propositivas, está orientado a conocer el qué y el cómo de la comunicación institucional en un caso único en particular. Y sobre este caso observar lo interno y lo externo, lo singular, su despliegue en espacios y tiempos

\footnotetext{
${ }^{1}$ Del año 2004 al 2006 accedí por concurso a la Beca de Iniciación en la Investigación Científica y Tecnológica de la Universidad Nacional de La Plata. La investigación se tituló: "Prácticas y saberes comunicacionales en programas de educación superior bajo entornos virtuales". Su continuación fue del 2006 al 2008, con la Beca de Perfeccionamiento en la Investigación Científica y Tecnológica. La investigación se tituló: "La educación a distancia para la planificación de producción y gestión de información comunitaria". Del 2008 al 2010 , a la Beca de Formación Superior en la Investigación Científica y Tecnológica. La investigación se tituló: "La planificación estratégica hacia una nueva realidad comunicacional".

${ }^{2}$ Profesor Adjunto del Seminario Permanente de Tesis de la Facultad de Periodismo y Comunicación Social de la UNLP.
} 
determinados, con críticas y reconocimientos sobre las prácticas, y establecer no solo los marcos que permitieron aplicar las herramientas comunicacionales sino llegar a profundizar en la relación entre profesionalización y prácticas respecto de las condiciones de producción en un organismo de ciencia y tecnología.

En consecuencia, ha sido de vital importancia recuperar la memoria institucional y el modo de acercamiento a la realidad para entender los cambios generados en más de una década de constante crecimiento de la ciencia y la tecnología nacional.

Este estudio describe, involucra y considera los emergentes tanto de la realización de diagnósticos, de procesos de evaluación permanentes para alcanzar el desarrollo de acciones producto de la aplicación de las herramientas comunicacionales, como de la profundización del conocimiento acerca de las propuestas de un plan de acciones comunicativas generadas durante el trienio. De este manera la comunicación propuestas desde sus objetivos involucró la integración efectiva de los actores institucionales identificados en la Red Institucional ${ }^{3}$.

La consolidación del sistema científico argentino y el lugar destacado del CONICET delinean nuevas trayectorias en un país que, desde la gestión ejecutiva nacional y las políticas de Estado desde el año 2003, se encuentra en pleno proceso de consolidación de la investigación y desarrollo científico en un mundo cada vez más globalizado y cambiante. Apuntando al desarrollo sostenido en la materia por considerarlas esenciales y primordiales para el desarrollo nacional.

En los mismos términos, en esta tesis se reconoce la capacidad de los estados y sociedades latinoamericanas para producir, difundir y utilizar conocimientos tendientes a orientar procesos de desarrollo, en este caso, socio-educativos-científicos. Una concepción del Estado presente y garante, que piensa la educación y la ciencia y tecnología en clave de derecho para todos. Con claras definiciones de una política pública de carácter universal que garantiza en

\footnotetext{
${ }^{3}$ El relevamiento que realiza la Gerencia de RR.HH. del CONICET considera y define distintos tipos de lugares de trabajo. Las entidades que llevan a cabo actividades investigación y desarrollo, comprenden la Red Institucional del CONICET, las universidades nacionales, los organismos de ciencia y técnica, las universidades privadas y otros.

La Red Institucional del CONICET considera a los institutos de investigación y desarrollo que son propios del Consejo Nacional o por convenio con otras instituciones. Incluye: Centros Científicos Tecnológicos (CCT), Unidades Ejecutoras (UE), Unidades en Red, Grupos vinculados y Unidades Asociadas.

Organismos de Ciencia y Técnica que corresponden a otros Organismos Nacionales dedicados total o parcialmente a la ciencia y la tecnología. En este grupo se incluyen a CNEA, CONAE, INTA, INTI, INIDEP e INVAP. Asimismo considera el vínculo con asociaciones, sociedades, hospitales, empresas y fundaciones que realizan algún tipo de actividad ciencia y tecnología, así como organismos dependientes de gobierno nacional, provincial y municipal, no incluidos en las categorías anteriores.
} 
primer término el derecho a una educación de calidad acorde a la realidad de los jóvenes y al desarrollo del país en términos económicos, sociales, culturales y políticos.

Tras lo dicho, se avanzará en la lectura de una tesis que ahonda en el desarrollo de una temática de la comunicación en un organismo encargado de instrumentar las políticas científicas, para lo cual se considera como necesario relacionar y considerar la dimensión comunicacional en los términos que se llevó adelante. Asimismo, para el análisis de las herramientas comunicacionales como de las modalidades de la comunicación institucional junto a otros enfoques, es prioritario dar cuenta de las políticas institucionales que permitieron orientar la intervención en un contexto de producción comunicacional de alcance nacional.

En la necesidad de reconocer los diferentes estadios que componen la propuesta de comunicación institucional para la DRI fue necesario un amplio conocimiento tanto de la Institución que albergó y posibilitó las condiciones de trabajo en la misma, tanto como lo fue la necesidad de conocimiento de aspectos teóricos, planificación y gestión de la comunicación institucional. Y de aquí que el título de la tesis plantee estrategias, herramientas y reflexiones enfocadas hacia una nueva realidad comunicacional. 


\section{CAPÍTULO I}

\section{Intervención en la comunicación institucional}

En virtud de lo hasta aquí expresado es preciso asumir que el caso que aquí se presenta debe relacionarse y entenderse como instancia donde se trabajó la dimensión comunicacional y, como toda intervención, se construyó en plena relación con otros actores sociales guardando este proceso de interacción una propuesta de comunicación implícita, motivo más que suficiente para darla a conocer porque produce y valida sentido social.

Para el estudio de caso coincidimos con la posición de Robert Stake ${ }^{4}$ acerca de "no pretendo describir el mundo, ni siquiera describir el caso por completo. Busco dar sentido a determinadas observaciones del caso, mediante el estudio más atento y la reflexión más profunda de que soy capaz. Es algo muy subjetivo. Lo defiendo porque no conozco otra forma de dar sentido a las complejidades de mi caso. Reconozco que mi forma de actuar no es 'la forma correcta'". Y agrega que "mediante la experiencia y la reflexión, cada investigador debe encontrar las formas de análisis que a él le sean de utilidad".

De los estudios cualitativos de casos se esperan descripciones abiertas, comprensión mediante la experiencia y realidades múltiples. No es posible sencillamente diseñar la búsqueda de significados complejos, ni alcanzarlos de forma retrospectiva tal como lo plantean Norman Denzin y Yvonna Lincoln ${ }^{5}$.

Este conocimiento de la comunicación sobre prácticas y saberes en instituciones de ciencia y tecnología, mientras que puede ser leído como un problema teórico y de investigación, también resulta una línea de reflexión que merece ser considerada en el análisis de los procesos que involucran la dimensión comunicacional en investigación y desarrollo como parte de la constitución de la vida social y política en condiciones históricas específicas.

Del mismo modo, analizar las condiciones de planificación y gestión como factores considerados necesarios en las instituciones admite desde el campo disciplinar concebir el

\footnotetext{
${ }^{4}$ STAKE, Robert (1999). "La investigación con estudio de casos". 2da. ed. Ediciones Morata. Madrid.

${ }^{5}$ DENZIN, Norman y LINCOLN, Yvonna (Eds.) (1994). "The Sage Handbook of Qualitative Research". Los Ángeles. SAGE.
} 
carácter no solo prescriptivo normativo ${ }^{6}$ sino elaborador de condiciones de cambio de las prácticas comunicacionales.

En consecuencia se reconoce, traza y sitúa un recorrido realizado durante tres años que sistematiza lo desarrollado durante ese tiempo en la organización y gestión de la comunicación y la realización de prácticas profesionales como director de la Dirección de Relaciones Institucionales (DRI) ${ }^{7}$ del Consejo Nacional de Investigaciones Científicas y Técnicas (CONICET) $)^{8}$.

En tal sentido, es reflejo de los diversos avances y abordajes en ámbitos de la Institución ${ }^{9}$ donde se trabajó priorizando el intercambio de pareceres acerca de la tarea propuesta, la solución de conflictos y la planificación ${ }^{10}$.

\footnotetext{
${ }^{6}$ Al respecto, según lo destaca Silvia Delfino "los estudios culturales han destacado el carácter no solo normativo prescriptivo sino elaborador de condiciones de cambios de las regulaciones cultuales o de las prácticas institucionales. De este modo, lo institucional no constituye solo un área de profesionalización sino también parte de los desafíos más recientes planteados por las teorías que vinculan lo comunicacional con las políticas culturales implicadas en su conceptualización".

En DELFINO, Silvia (1998). "La relación entre producción e investigación de procesos comunicacionales en los planes de estudio de las carreras de comunicación social". Trabajo presentado en las Primeras Jornadas sobre Comunicación y Ciencias Sociales. Facultad de Ciencias Políticas y Relaciones Internacionales de la Universidad Nacional de Rosario. Rosario. Septiembre.

- Otras lecturas para referir a la importancia que tiene el pasaje de la noción de institución, desde el entendimiento de un conjunto de normas prescriptivas basadas en la estabilidad y previsibilidad, al concepto de hegemonía como lucha y articulación de los conflictos y crisis de cambio histórico en términos de autoridad y poder, pueden hacerse en DELFINO, Silvia (2009). "Investigación y activismo en el vínculo entre teorias de género, identidad de géneros y luchas politicas". $\mathrm{N}^{\circ} 66$. julio-agosto. Revista Tram[p]as de la Comunicación y la Cultura. Facultad de Periodismo y Comunicación Social. UNLP. La Plata.

${ }^{7}$ Es preciso mencionar que mi nombramiento como Director de Relaciones Institucionales se resolvió a través de la Resolución de Directorio $\mathrm{N}^{\circ}$ 936, fechada el 15 de marzo de 2012, y de acuerdo al Expediente $\mathrm{N}^{\circ}$ 1265/12 del registro del Consejo Nacional de Investigaciones Científicas y Técnicas (CONICET). Por su parte, es preciso determinar que las iniciativas, nuevos modos de organización en la DRI (espacio central al tema de las nuevas herramientas impulsadas y de reconocimientos de actores sociales) y las cuestiones que hacen a los debates, como el de la comunicación en el CONICET, quedan comprendidos desde el 15 de marzo de 2012 hasta diciembre de 2014 a los fines de poder sistematizar lo producido y como propósito que moviliza esta tesis.

${ }^{8}$ El CONICET fue creado el 5 de febrero de 1958. Su primer presidente fue Bernardo Houssay, premio Nobel de Fisiología y Medicina. Asimismo, es preciso señalar que su creación se remonta a la década del ' 50 y como primer antecedente se destaca, en el año 1951, la creación del Consejo Nacional de Investigaciones Técnicas y Científicas (CONITYC), un organismo que 7 años más tarde daría lugar al CONICET. A partir de la revisión de referencias históricas es posible sostener y argumentar el concepto de que la creación de los principales organismos de ciencia y tecnología encuentran su génesis en esa década, durante el gobierno de Juan Domingo Perón. Al respecto, en el año 1948 es creado el Instituto Nacional de Investigación de las Ciencias Naturales, de acuerdo al Boletín Oficial del 13 de diciembre de 1948; así como el Decreto 우 9695 del 17 de mayo de 1951 dio lugar a la institucionalización del CONITYC para ser posteriormente reemplazado, mediante Decreto $\mathrm{N}^{\circ} 1291$, por el CONICET durante la dictadura cívico- militar encabezado por el general Pedro Eugenio Aramburu. En 1961 se crea la Carrera del Investigador Científico del CONICET.

${ }^{9}$ Cada vez que aparezca empleado el término Institución con "I" en mayúscula debe leerse como sinónimo de CONICET. En esta concepto se recuperan los procesos que desarrolla la práctica, es el contexto donde se generan además relaciones con actores sociales e institucionales, con referentes de organizaciones, sujetos sociales, gerentes y directores, coordinadores de proyectos y programas; con investigadores, profesionales y estudiantes de posgrados, dirigentes políticos y sociales. Considera la posibilidad de una multiplicidad y transversalidad de relaciones y permite compartir y reconocer a todos los sujetos en sus roles, responsabilidades y sus vínculos; a los sujetos de conocimiento en sus diferentes contextos, diversidad de espacios así como actores en diferentes encuadres en la construcción de sus relaciones. Lo cual permite pensar que la Institución posibilita poner en juego diferentes registros y modos de vincularse.

${ }^{10} \mathrm{La}$ intención es abordar una primera definición acerca del rol del comunicador planificador para posteriormente avanzar en la manera en que la planificación permite el desarrollo de procesos desde una mirada integral de la realidad. Para alcanzar ese lugar, y como un hecho primario por testimoniar desde el rol, el comunicador debe elegir; esa decisión-elección en nuestro caso nos pone en la vereda de enfrente de la planificación instrumental porque elegimos desde las experiencias y conceptualizaciones que llevan a reconocernos en una mirada de la planificación que se organiza en la flexibilidad del movimiento desde el profundo casos de sentidos que habita nuestra realidad. Al respecto, sobre estas últimas palabras y las que compartimos a continuación, en claro acuerdo con Cecilia Ceraso, decimos que planificar es "introducir organización y racionalidad en la acción; la idea de la planificación se encuentra vinculada a las Ciencias Sociales, a la organización de la sociedad y al Estado como planificador".

CERASO, Cecilia (2002). "El rol del planificador", en "Sembrando mi tierra de futuro. Comunicación, Planificación y Desarrollo Local". Ediciones de la Unidad de Prácticas y Producción de Conocimiento de la Facultad de Periodismo y Comunicación Social. UNLP.
} 
Recupera la experiencia del diálogo constante y sistemático entre teoría y práctica que se vincula con todos los aspectos del proceso de investigación, y especialmente con el planteo del proyecto, ya que a medida que se define y delimita el objeto de estudio también se construyen y revisan las herramientas teóricas, diseñan y ajustan la metodología, se repiensa la pregunta de investigación y acota el universo de estudio ${ }^{11}$.

Al respecto, asumiendo lo que señalan desde la antropología Rosana Guber y Ana Rosato ${ }^{12}$, quienes retoman a Pierre Bourdieu, la construcción del objeto de estudio implica poner en relación la práctica teórica con la realidad. Esta vinculación, entre la realidad objetiva del fenómeno investigado y las descripciones conceptuales que se hacen de ella, se desarrolla en un proceso que es sistemático pero a la vez lábil y variable.

Resulta entonces que este estudio es tanto una oportunidad para repensar las prácticas como para apelar una vez más al conocimiento, saberes, experiencias y recursos, y para potenciar de manera eficiente la acción comunicacional en las instituciones. Y destacar que el recorrido permitió el relacionamiento y el involucramiento con profesionales de diversas especialidades, compartir criterios e interactuar con los distintos actores que conforman la Institución en todo el país.

Además, este estudio demuestra su necesidad a partir de los resultados alcanzados pero más importante aún en cuanto a las nuevas preguntas que como tal despierta y las definiciones alcanzadas; las cuáles se proponen no como recomendaciones, sino que se busca revisar las estrategias y la implementación de las herramientas en el territorio que recogen en su diseño los elementos fundamentales para la organización y dirección de la actividad científica y tecnológica que se fomenta en la institución, y en la cual se integran indisolublemente: su esencia, enfoque y contenido.

\footnotetext{
${ }^{11}$ SOUZA, María Silvina, GIORDANO, Carlos y MIGLIORATI, Mario (Comp.) (2012). "Hacia la Tesis. Itinerarios conceptuales y metodológicos para la investigación en comunicación". En Cap. V: "El referente empírico". Verónica Vidarte Asorey. 1.a ed. - La Plata: Universidad Nacional de La Plata. Argentina.

${ }^{12}$ GUBER, Rosana y ROSATO, Ana. (1986). "La construcción del objeto de investigación en Antropología Social: una aproximación", Congreso Argentino de Antropología Social, Buenos Aires. Argentina.
} 


\section{Sobre el qué y el cómo proceder en las instituciones}

Para lograr mejores resultados y un funcionamiento efectivo de la comunicación se traza este recorrido que busca alcanzar un mayor y mejor entendimiento sobre las estrategias y las herramientas flexibles que se incorporaron, sus ajustes y las correcciones en el rumbo de la programación, sobre la organización y la gestión de las mismas adecuadas al momento que atravesaba el CONICET y a los cambios de escenarios científicos tecnológicos, socioeconómicos, políticos y productivos que se fueron sucediendo en la Argentina desde el año 2012 hasta fines del 2014.

En este rumbo, desde la gestión de la comunicación se partió de un diagnóstico de la comunicación como indagación descriptivo y analítica que dio lugar a trabajar sobre un informe de situación válido y una caracterización epistemológica de la que damos cuenta; a su vez, se consideró el contexto histórico y político desde el CONICET ${ }^{13}$, comprendido desde una mirada más integral de la situación de la ciencia y la tecnología e involucrado en un período de transformaciones sociales relevantes en Argentina.

Desde el punto de la inclusión social y la profundización de la democratización a nivel local y latinoamericano, sin lugar a dudas, marca un cambio en el país desde el año 2003 en adelante. Se plantea la organización social y la aplicación de políticas públicas con carácter sustancial y transformador, donde es posible imaginar escenarios que permiten pensar a la educación, la cultura y la ciencia como ejes dinamizadores de la igualdad de oportunidades y del desarrollo social y económico. Pero también, políticas públicas desde el Estado que pusieron en el centro del debate el conocimiento científico y tecnológico aplicado al desarrollo productivo.

\footnotetext{
13 El CONICET es posterior a la creación del Instituto Nacional de Tecnología Agropecuaria (INTA) y a la Comisión Nacional de Energía Atómica (CNEA), ambas en 1956, y al Instituto Nacional de Tecnología Industrial (INTI) en 1957.

En HURTADO, Diego (2010). "La ciencia Argentina: un proyecto inconcluso: 1930-2000". 1ra. ed. Buenos Aires, Edhasa.

*Para los autores Rozenwurcel y Bezchinsky, este complejo de instituciones que comenzó a desarrollarse durante los años cincuenta se trató de una política pública destinada a formar recursos humanos, desarrollar la ciencia básica e intervenir de manera directa en ciertos sectores basados en una tecnología entendida como de punta o clave (nuclear o aeroespacial). Según estos autores, no existía una verdadera articulación entre las actividades o instituciones existentes. La mejora de las capacidades tecnológicas de las empresas no aparecía como un objetivo explicito de la política de ciencia y tecnología. En 1967 se crea la Secretaría de Ciencia y Técnica (SECyT), con el objetivo de convertirse en el organismo rector del sistema, encargado de definir las políticas y los mecanismos de coordinación y articulación entre sus distintos componentes.

En ROZENWURCEL, Guillermo y BEZCHINSKY, Gabriel (2007). "Economía del conocimiento, innovación y politicas públicas en Argentina". Escuela de Gobierno y Política. Universidad Nacional de General San Martín. Buenos Aires. Documento de Trabajo N²5.
} 
Esto le permitió al país alcanzar innovaciones de productos y crecer en procesos pero, centralmente, redimensionar el conocimiento científico tecnológico ${ }^{14}$.

En síntesis, este estudio comprende la realización de un diagnóstico (revisión de propuestas, estrategias comunicacionales y procesos desarrollados por la DRI en la aplicación de herramientas comunicacionales y el accionar de otras unidades que comprenden la Red Institucional, el lugar de las decisiones significativas y debates internos desde los espacios de decisión) y, a partir del mismo, de la disposición de estrategias y herramientas comunicacionales tendientes a lograr que exista una adecuada comunicación y una integración efectiva de la Institución en todo el país.

\section{El proceso que da cuenta de la práctica profesional}

Esta investigación, si bien no se constituye en un primer estudio acerca del CONICET $^{15}$, principalmente en lo institucional, se puede considerar sí que tiene carácter iniciático en relación a la comunicación ya que pone de relieve preguntas acerca de la importancia de gestionar adecuadamente los procesos de comunicación en investigación y desarrollo como transferencia e innovación tecnológica.

A partir de experiencias como la vivenciada podemos decir que la comunicación como campo tiene un fuerte potencial transformador en diversas experiencias concretas. La comunicación como disciplina enmarcada dentro de las ciencias sociales se ha definido como un campo y no por la construcción de un objeto de estudio único. Se caracteriza por

\footnotetext{
${ }^{14}$ MIGLIORATI, Mario. (2013). "La politica transformó la ciencia y la tecnología". Ponencia leída en la mesa: "La comunicación de la ciencia como política pública". Congreso de Popularización de la Ciencia (COPUCI). Ciudad de Rosario, provincia de Santa Fe.

${ }^{15}$ A partir del Estado del Arte hemos relevado la existencia del artículo titulado: "Dossier Ciencia, Tecnología y Sociedad. La dinámica de la relación entre CONICET y dos universidades nacionales argentinas", cuyas autoras son María Soledad Oregioni y Nerina Sarthou. En este trabajo del año 2012 (como becarias doctorales del CONICET) exploran la relación reciente entre el CONICET con la UNLP y la UNCPBA. A partir de identificar determinadas dimensiones de análisis, las autoras relevaron las principales iniciativas impulsadas por el organismo y se describieron la relación que mantiene con estas universidades a con el objetivo de detectar sus características y aquellos factores parecen incidir en la misma.

Disponible en: http://www.scielo.org.ar/scielo.php?script=sci_arttext\&pid=S1851-17162013000100002\&lng=es\&nrm=iso

Vale una aclaración acerca de trabajar el Estado del Arte o de la cuestión. Hacerlo aporta luz acerca de cómo funciona este objeto de investigación puntual y no se trata de redescubrir lo ya dicho, sino que a nuestro entender realza la importancia de una revisión y de un diálogo crítico con los aportes previamente existentes de un conocimiento en el sentido de un diálogo con otros trabajos y el que desarrollamos o nos proponemos.
} 
conservar una perspectiva múltiple que sostiene una variedad de metodologías y formas de validación del conocimiento obtenido. Resulta pertinente agregar, con respecto al campo, que éste se constituye desde experiencias y conceptualizaciones para hacer importantes aportes a la producción de nuevos sentidos sobre el desarrollo y la gestión de la comunicación en instituciones.

Desde nuestro modo de entender, la comunicación busca fortalecer los procesos de dinamización de la realidad y generar nuevos sentidos a las propuestas de desarrollo. Estas no pueden ir en contra de las políticas públicas en general y de las sociales en particular, ya que deben permitir entablar entre el Estado y la sociedad una relación desde la cual es posible inferir la inclusión de los ciudadanos en tanto sujetos de derechos y deberes, obligaciones y responsabilidades.

Todos estos elementos considerados clave se consideraron en este diseño estratégico de la comunicación impulsada en el trienio para la DRI, fundados desde una lectura de la realidad y en la dimensión política que la acción suponía.

Tras lo dicho es necesario precisar que de aquí en adelante todo lo expuesto no puede leerse por fuera del lugar de responsabilidad que implica ser comunicador ni desconocer el ámbito de actuación, donde en cada acción hay una clara identificación con el posicionamiento político: una razón válida y esencial que no podemos perder de vista, ya que todas nuestras acciones suponen una elección en este orden.

La acción comunicacional requiere asumir un rol que demanda una mirada prospectiva ${ }^{16}$ y planificación estratégica para orientar los cambios, lo cual confirma al mismo tiempo una clara conciencia del sentido político sobre nuestro hacer. Los ámbitos de actuación nos exigen posicionamientos tanto éticos como políticos y por esta razón es esencial reconocerlo con el fin de dar sustento a los escenarios posibles y habilitar los desafíos que enfrenta la Institución.

Consideración que permite reafirmar que la implementación de las herramientas para la gestión de la comunicación institucional se efectuó en el marco de los recursos disponibles

\footnotetext{
${ }^{16}$ Una primera aproximación al planteo prospectivo, ya que será desarrollada conceptualmente más avanzada la tesis, resume la concepción desde donde pensamos e impulsa el conjunto de tareas a llevar adelante. Como proceso implica el conocimiento y la reflexión en términos diagnósticos, la decisión y también la acción. La prospectiva involucra poner en diálogo una conceptualización del tiempo, a la relación que se establece entre el pasado, el presente y el futuro; pero, además, involucra instancias que tienen que ver con la toma de decisiones y que como tales están basadas en opciones posibles permitidas por la construcción de escenarios prospectivos. Para ello requerimos contar información y conocimiento para poder reflexionar, es decir, para poder establecer escenarios prospectivos y tener opciones.
} 
por la institución, principalmente, desde el nivel de las capacidades y de los recursos humanos, la historia, interpretando las políticas acordadas que contribuyen a la actividad científica de la institución como a las condiciones económicas. Es evidente que al hablar de este marco de posibilidades hay que destacar que el mismo es posible en cuanto a que se cuenta con un Estado presente que ha garantizado y garantiza desde hace más de una década no solo la posibilidad de impulsar estas medidas sino, como hecho central, la promoción de políticas públicas que generaron nuevas posibilidades para los Argentinos.

A partir del año 2003, con el gobierno de ex presidente Néstor Kirchner, se comienzan a delinear nuevas tendencias como fueron la generación de normativas que buscaron revertir las políticas educativas neoliberales de los años '90, como la Ley de Educación Nacional, Ley de Financiamiento Educativo y Ley de Educación Técnica Profesional.

Otras políticas públicas se dictaron para la expansión del sistema científico y tecnológico argentino, con el aumento de recursos para la investigación, repatriación de investigadores y fortalecimiento de su gestión creando el Ministerio de Ciencia, Tecnología e Innovación Productiva de la Nación.

Eje de estas políticas fue la promoción del vínculo entre educación, ciencia y desarrollo productivo, mediante la orientación de la matrícula universitaria hacia carreras tecnológicas y el especial financiamiento de líneas de investigación estratégicas desde el punto de vista económico. La promoción también se centró en la inclusión social y educativa a través de Planes de Mejora para las escuelas y programas específicos, como el Programa Conectar Igualdad donde se entregaron más de 5 millones de netbooks.

Un aspecto esencial a reconocer y que suma a lo descrito para este período es que la organización, el Consejo Nacional, evolucionó y fue atravesada por procesos de cambio en sus estructuras a lo largo de este tiempo, como sus adaptaciones frente a los cambios que se sucedieron en el entorno.

Una razón más que válida para hablar en este trabajo de la historia y sostener que en sus más de 57 años de existencia este aspecto no puede ser dejado de lado. En consecuencia, se dialoga y se traza en una línea espacial/temporal que ayuda a interpretar al CONICET según los distintos contextos nacionales haciendo foco, $\mathrm{o}$, mejor dicho, centrándonos en el trienio ya mencionado. 
Es indudable que frente a este desarrollo resta aclarar qué se entiende por políticas públicas. Si bien pueden existir diferencias que corresponden al programa de acción o al resultado de una actividad de poder público y legitimidad gubernamental, esencialmente las políticas públicas requieren de un largo desarrollo en el que se le asigna un papel central al Estado.

En estos últimos años las políticas públicas en ciencia y tecnología han tenido cursos de acción relacionados con un objetivo público definido claramente para el bienestar de la sociedad. Y en cada nivel político de la administración del Estado, en organismos integrantes del Sistema Nacional de Ciencia, Tecnología e Innovación se ha requerido del fortalecimiento de las estructuras de gestión, del diseño y la evaluación en todos los aspectos de las políticas públicas impulsadas.

Los organismos del sistema nacional como parte de ese diseño y gestión, de interacciones para alcanzar procesos y resultados, avanzaron en torno a finalidades y propósitos para lograr metas de orden ministerial, objetivos administrativos y también presupuestarios.

Entretanto aparece como una necesidad, para mejorar la capacidad y las orientaciones de las políticas públicas, que puedan:

-ser vistas y trabajadas desde la comunicación desde su formulación y como posibilidades de diálogo entre sectores, como acciones que abren un campo de declaraciones y encuadres -en contextos históricos y sociales cambiantes-, de seguimientos en su ejecución y de cumplimientos de metas y objetivos; en cuanto comprometen acciones y recursos y se caracterizan en su cumplimiento por la diversidad de actores que intervienen;

-en ese orden, las posibilidades de acción de un Estado contribuye en generar externalidades, información y señales a una sociedad informada, donde las tecnologías de la información y las comunicaciones incorporadas por los organismos han contribuido a mejor el acceso a la información y a la configuración de las orientaciones de los temas en cuanto a los sectores sociales identificados como destinatarios;

-concentrar los esfuerzos entre organismos públicos y privados permite aumentar la participación. La integración de esfuerzos conlleva a que se incremente la posibilidad 
de participación del sector privado en la puesta en práctica de diversas políticas públicas;

-la existencia de las tan solicitadas políticas para el sector de investigación y desarrollo, que tuvieron lugar a partir del año 2003, y fueron sostenidas en los sucesivos gobiernos, comprometieron financiamiento, objetivos e instrumentos en una secuencia donde las políticas públicas ocuparon el terreno antes privativo de la retórica política;

-las propuestas que no incorporan un amplio proceso de discusión, diseño, gestión y evaluación pueden tender a eclipsar la política por la tecnocracia y subsumir a la comunicación en los efectos y la inmediatez de lo mediático faltando a las condiciones deseables para una política pública;

-y agregar que en los últimos años la aplicación de la ciencia al sector público, en un proceso que aún está en marcha y tiende a profundizarse en los organismos, ha promovido un cambio en la administración de la gestión, de la información, de la comunicación y de las políticas públicas.

En orden a lo señalado, interpretamos que la búsqueda de todo cambio debe intervenir en la horizontalidad de las movilizaciones sociales y en la verticalidad de una transformación del Estado. Y desde este lugar es imposible abandonar las particularidades, así como la dificultad de pensar en un nosotros que no incluya a todos.

Los cambios sucedidos en ciencia y tecnología, impulsados desde la política, se dieron de una manera que totalizaron al conjunto de la sociedad. Un proyecto de cambio como el acontecido, en educación-ciencia y tecnología, solo es posible por una política pluralista y democrática.

Para ello es necesario entender las diferencias y la heterogeneidad social. Y aquí es donde debe ampliarse el horizonte del comunicador para pensar, entender y discutir a las sociedades, a partir de cómo explicar al mundo y a las maneras posibles de cambiarlo. Es decir, tener desde el campo disciplinar la capacidad para interpretar la historia y los caminos que brinda el presente para influir en los futuros posibles. 


\section{La necesidad de leer e interpretar en términos de comunicación}

En todo ámbito institucional los procesos comunicacionales nos llevan a identificar diferentes actores, ya sean individuos y comunidades discursivas, con los cuales se negocia en forma desigual acerca del modo de hacer y de percibir la realidad; es decir, al intervenir sobre espacios de la realidad hay una clara identificación del poder de constituir la realidad. Al respecto, compartimos con Guillermo Orozco Gómez ${ }^{17}$ que este es un mercado de lo simbólico, donde se hacen presente las desigualdades y las negociaciones. Estas negociaciones que se dan en su interior "tienen el carácter de lucha por el poder discursivo. Como toda lucha, esto implica conflictos y debates, pero también alianzas, acuerdos y sinergias".

Decididamente toda intervención persigue fines que persiguen poder generar los cambios deseados y propuestos, hecho que requiere de una clara conciencia política, de una mirada atenta sobre las nociones y problemas diagnosticados y de una definición precisa del sentido político del cambio, ya que las acciones propuestas no deben contradecir el sentido que se pretenda dar al cambio.

Frente a este escenario la propuesta de intervención atendió especialmente a los contextos, a las capacidades institucionales, a los objetivos y las acciones institucionales y, especialmente, al lugar de los actores institucionales considerando la diversidad.

${ }^{17}$ OROZCO GOMEZ, Guillermo. (1994). " Al rescate de los medios. Desafio democrático para los comunicadores". Univ. Iberoamericana / Fundación Manuel Buendía: México. 


\section{CAPÍTULO II}

\section{El sistema científico y sus instituciones}

Esta tesis compone no solo un estudio que busca vincular la relación posible y poco explorada, tratada en oportunidades como vinculación casual entre comunicación, ciencia y tecnología. Aborda y profundiza la relación causal al focalizar, desde la comunicación, en el análisis de la relación compleja con la ciencia y tecnología, cultura y sociedad, un puente necesario desde diversas disciplinas, campos de reflexión y convivencia en la temática.

A partir de esta aproximación puede tomarse como punto de partida lo obtenido para el sector en la década, hecho que se plasma en cifras en el documento titulado "CONICET, 30 años de democracia"18. Así como los años '90 sirvieron de escenario para las reformas del Estado. Con similares matices, políticas y alcances, discursos en pugna y discusiones, entre los años 1999 a 2001 el CONICET y las Universidades públicas fueron parte del debate sobre el futuro del sistema científico argentino, perspectiva que puede leerse en documentos sobre el tema y en la prensa escrita ${ }^{19}$.

Para referir al desarrollo de las instituciones de ciencia y tecnología en este período ${ }^{20}$ es preciso reconocer que el sistema científico nacional estuvo marcado por la inestabilidad política y económica que derivó en concurrentes crisis macroeconómicas y golpes de Estado cívicos-militares. En la década del '60 y más precisamente en el año 1966, comenzó un proceso de persecución política sobre importantes sectores de la comunidad científica y

\footnotetext{
18 Documento publicado por el CONICET con motivo de conmemorarse 30 Años de Democracia. Disponible en: http://www.conicet.gov.ar/wp-content/uploads/2013/09/CONICET-55-a\%C3\%B1os-Discurso-Roberto-Salvarezza.pdf

${ }^{19}$ La incertidumbre sobre el destino del CONICET se refleja en el artículo publicado en el diario La Nación, el 7 de noviembre de 1999 , titulado: El futuro del CONICET, "Bajo pronóstico reservado". Disponible en: http://www.lanacion.com.ar/209736-bajo-pronosticoreservado

Al año siguiente, el 6 de agosto del 2000, el mismo diario titulaba: "La segunda muerte de Houssay", en referencia al intento de hacer desaparecer la Carrera del Investigador Científico y Tecnológico. Disponible en: http://www.lanacion.com.ar/27637-la-segunda-muerte-dehoussay

${ }^{20}$ En el marco de la creación de estos organismos se da la nueva institucionalización del sistema mundial con la creación del Banco Mundial (BM) en 1944, el Fondo Monetario Internacional (FMI) y la Organización de las Naciones Unidas (ONU) en 1945, y el Acuerdo General sobre Aranceles Aduaneros y Comercio (GATT) en 1947. En Latinoamérica se materializó con la creación del Tratado Interamericano de Asistencia Recíproca (TIAR) en 1947, la Organización de los Estados Americanos (OEA) en 1948, el Banco Interamericano de Desarrollo (BID) en 1959 y la Alianza para el Progreso (ALPRO) en 1961.

En CARRIZO, Érica y ALFONSO, Victoria (2013). "Las politicas de CyTy el estilo de desarrollo: un proyecto inconcluso". En Voces en el Fénix. Año 4, Núm. 24.
} 
universitaria. La "noche de los bastones largos"21 marca la ruptura de buena parte de las tradiciones científicas. En el CONICET ${ }^{22}$ se generaron hechos de persecución de científicos mientras que la conducción del Consejo Nacional intentó mantener la neutralidad ${ }^{23}$.

El CONICET sufrió procesos de depuración y expulsión de investigadores a través de mecanismos jurídicos y desde el punto de vista de su organización interna, se produjo un proceso de recambio de agentes a partir del cual la conducción del mismo quedó en manos de un reducido grupo de investigadores que fueron acumulando cargos directivos en el Directorio, en Comisiones Asesoras, en la dirección de institutos y programas ${ }^{24}$.

Entre 1975 y 1983 la orientación de los recursos asignados a ciencia y técnica reflejan un quiebre institucional, particularmente el distanciamiento del CONICET y las universidades, con la asignación creciente de recursos de investigación hacia ámbitos extrauniversitarios y en especial la multiplicación y consolidación de institutos ubicados bajo la jurisdicción directa del Consejo Nacional ${ }^{25}$.

Este organismo fue destinatario de un aumento significativo en su presupuesto, proveniente del Estado nacional y también de préstamos internacionales, cuyo destino fue la incorporación de investigadores, personal de apoyo a la investigación, becarios internos y externos, y la creación de una vasta cantidad de centros, programas e institutos bajo su jurisdicción, dando lugar a un significativo proceso de crecimiento y descentralización geográfica en su interior.

\footnotetext{
21 "La noche de los bastones largos, 47 años después".

Disponible en http://www.conicet.gov.ar/la-noche-de-los-bastones-largos-47-anos-despues/

${ }^{22}$ CONICET (2006). "Ciencia y tecnología para el desarrollo". lra. ed. Edición Nacional Editora \& Impresora. Buenos Aires. Al respecto de este libro es preciso realizar una aclaración que no puede pasarse por alto y hace a la continuidad de la lectura del mismo en cuanto a que refiere a decisiones asumidas al momento en que fue realizada esta producción por el CONICET. Esto tiene que ver con el Capítulo II, Origen y trayectoria institucional. En su apertura se presenta una foto referida a la Sesión constitutiva del Consejo Nacional de Investigaciones Científicas y Técnicas, el 5 de febrero de 1958, donde integrante de la dictadura cívico-militar y presidente en ese año Pedro Eugenio Aramburu aparece junto a Bernardo Houssay, Rolando García, Eduardo Braun Menéndez, Luis Federico Leloir, entre otros científicos. En el texto que acompaña a la foto se señala: "En el año 1958, bajo el gobierno de facto del general Aramburu, se pone en vigencia el Decreto-Ley Nro. 1291/58...". La otra referencia que aparece en todo el libro se encuentra en el Capítulo IV (página 100) donde se señala: "El impacto de las diversas coyunturas políticas nacionales durante el siglo XX dejaba su impronta negativa en el desarrollo de la vida universitaria y en las instituciones científicas. Durante el período comprendido entre el gobierno de facto de mediados de la década del cincuenta hasta fines de la última dictadura militar, a principios de los ochenta, hubo momentos en los que era muy difícil encarar proyectos científicos desde las universidades sin que estos sufrieran los condicionamientos de la dirigencia política de turno".

${ }^{23}$ GORDON, Ariel (2013). "El sistema de innovación argentino en perspectiva histórica. Historia institucional y políticas públicas". En SUAREZ, Diana (Comp.). "El sistema argentino de innovación: instituciones, empresa y redes: el desafio de la creación y apropiación de conocimiento". 1a. ed. Los Polvorines, Universidad Nacional de General Sarmiento.

${ }_{24}^{4}$ BEKERMAN, Fabiana (2009). "El campo científico argentino en los años de plomo: desplazamientos y reorientación de los recursos". Sociohistórica. Cuadernos del Centro de Investigaciones Sociohistóricas. N ${ }^{\circ} 26$, segundo semestre. Facultad de Humanidades y Ciencias de la Educación. Universidad Nacional de La Plata. La Plata.

${ }_{25}$ OTEIZA, Enrique (1992). "La politica de investigación científica y tecnológica en Argentina". Historias y Perspectivas. Centro Editor de América Latina. Buenos Aires.
} 
Se inició un período que durará unos 17 años hasta el regreso a la democracia donde la investigación científica estuvo fuertemente afectada por la inestabilidad política e importantes sectores de la comunidad científica padecieron la persecución política, el exilio y otros miles fueron detenidos y desaparecidos.

Afectadas las capacidades del país en lo que hacía a investigación y desarrollo, se vivieron momentos donde la pérdida de la industrialización alcanzada a mediados de los '60 se tradujo en la caída de la industrialización por sustitución de importaciones. La falta de demanda del mercado local de investigación y desarrollo, la compra llave en mano de tecnología extranjera, una alta volatilidad económica donde la especulación y el rol del sistema financiera crearon condiciones para la desinversión industrial privada en el largo plazo y la ausencia de políticas públicas estatales.

Hubo pocas excepciones en esta caracterización que se convirtieron en casos de éxito como fue el desarrollo de la energía nuclear que contó con estabilidad institucional y económica ${ }^{26}$.

Las instituciones de investigación en los períodos de inestabilidad social y políticas tuvieron además poca vinculación con la transferencia de conocimiento en el orden social y productivo; aunque organismos como el Instituto Nacional de Tecnología Agropecuaria (INTA) continuaron desarrollando tareas de extensión agropecuaria, pero parte de ese personal fue cesanteado, detenido o desaparecido durante el período 1976-1983 ${ }^{27}$. El desmantelamiento que la dictadura provocó sobre la figura del extensionista un nuevo perfil de "consultor" científico tecnológico que tuvo sus consecuencias en el proceso de despoblamiento rural, de escisión del discurso institucional de la práctica de extensión y del pase del agrónomo de terreno a la transferencia de tecnología para el sector privado que sobrevino de la mano de esa lógica. La investigación se focalizó en el desarrollo de tecnologías para la agricultura pampeana de exportación y en la generación y transferencia de paquetes tecnológicos de los cultivos claves.

Simultáneamente, en el mundo la ciencia y la tecnología tuvo su reorientación en lo que se denominó la revolución científico tecnológica ${ }^{28}$. Se instaura un nuevo orden mundial sobre la

\footnotetext{
${ }^{26}$ HURTADO, Diego (2014). "El sueño de la Argentina atómica: política, tecnología nuclear y desarrollo nacional. 1945-2006". 1era. ed. Edhasa. Ciudad Autónoma de Buenos Aires.

${ }^{27}$ GARGANO, Cecilia (2013). "Ciencia y dictadura: producción pública y apropiación privada de conocimiento cientifico-tecnológico. Dinámicas de cooptación y transferencia en el ámbito del Instituto Nacional de Tecnología Agropecuaria (INTA) durante la última dictadura cívico-militar". Crítica y Emancipación. Revista Latinoamericana de Ciencias Sociales.

${ }^{28}$ ARGUMEDO, Alcira (2005). "Crisis de las Ciencias Sociales de la Argentina en Crisis". Prometeo Libros. Buenos Aires.
} 
ciencia y la tecnología con hegemonía estadounidense, tras la salida del modelo de industrialización y la crisis de los países de la órbita soviética. Se avanza en el desarrollo de nuevas tecnologías de información que provocarán una convergencia que dará lugar a una nueva matriz tecnológica y productiva que traerá aparejado el aumento de la producción, la reducción de costos de manufactura, la transferencia de las problemáticas ambientales a los países manufactureros y el crecimiento de las ganancias de las empresas multinacionales.

Es a mediados de los '70, con el surgimiento de políticas neoliberales, donde la Argentina y los países de la región vieron afectadas sus capacidades institucionales y organizacionales para impulsar el desarrollo científico y tecnológico con grados de autonomía, con capacidad para articular con ámbitos de la vida social y generar aportes para impedir a la transnacionalización y primarización de la producción.

El retorno a la democracia estuvo marcado por la pesada herencia económica y la crisis social y las derivaciones de la Guerra de Malvinas.

Desde lo científico el año $1983^{29}$ se inicia un período de democratización de las instituciones y en el caso del CONICET el eje se centró en las políticas científicas y el fortalecimiento de los vínculos con las universidades nacionales. Entre mediados y fines de la dictadura cívicomilitar, institutos de investigación que habían pertenecido a las universidades nacionales habían sido trasladados a la órbita del CONICET.

Durante la dictadura cívico-militar en el Consejo Nacional aconteció el mayor período de crecimiento al que le seguirán, posteriormente y ya en democracia, 30 años de desinversión. A partir del 2003 un nuevo capítulo quedará evidenciado desde las políticas de Estado orientados en lo científico-universitario y científico-tecnológica. Esta políticas contribuirán a revertir la fractura en el campo científico-académico y cerrar la escisión entre investigación y docencia; profundas marcas que dejó la dictadura y que afectaron la investigación en el

\footnotetext{
${ }^{29}$ Con motivo de la Celebración de los 55 años del CONICET en Tecnópolis, el 10 de septiembre de 2013, se generó un debate en torno al tono del mismo lo que generó un cruce de notas en el diario La Nación entre Hilda Sábato y el presidente del CONICET, Roberto Salvarezza. La nota de Sábato se titulaba: "Historia sesgada: La épica del relato llegó a la ciencia" (19 de septiembre de 2013, edición impresa. Disponible en: http://www.lanacion.com.ar/1621221-la-epica-del-relato-llego-a-la-ciencia). En la misma se hace referencia al video institucional del organismo presentado en ese marco y se señala que "resulta un ejercicio más de propaganda oficial, que ofrece una visión distorsionada del pasado del Conicet, a la vez que desdibuja el papel de la institución y de los científicos en esa historia", entre otros argumentos. Por su parte, el presidente del CONICET respondió a esos dichos en el mismo diario bajo el título: "Un Conicet Fortalecido" (11 de octubre de 2013, edición impresa. Disponible en: http://www.lanacion.com.ar/1627963-un-conicet-fortalecido. En la nota se expresa: "Las cifras destacan los esfuerzos sin precedentes realizados a partir del año 2003 que significaron sin duda la refundación de nuestra institución. En este contexto, festejamos en Tecnópolis no solo nuestros 55 años sino también estos 10 años de políticas ininterrumpidas de crecimiento del Conicet".

Por su parte, en el diario Clarín (12-3-2013) se publicó al respecto: "Aniversario del CONICET. Queja Radical por la omisión de Alfonsín en un video".
} 
ámbito universitario, en un momento donde se favoreció un trasvase de los grupos de investigación calificados hacia el CONICET.

Con el regreso a la democracia finaliza un período iniciado en 1976 por el golpe de estado, autodenominado "Proceso de Reorganización Nacional", que abrió una de las etapas más sombrías para el campo académico y científico argentino. Las universidades nacionales fueron intervenidas militarmente y se desplegaron acciones de terror material y simbólico.

Las políticas impulsadas durante la dictadura cívico-militar comenzaron a ser revertidas y algunos de los programas de interés militar, como el Proyecto Cóndor, destinado al desarrollo de misiles, fueron cancelados y el programa nuclear fue reducido. Asimismo, lentamente las universidades públicas comenzaron a recuperar la capacidad para realizar investigación, transferencia e innovación.

La implementación de políticas públicas en los años '90 sobre la base de las reformas estructurales neoliberales, en sintonía con el denominado acuerdo de Washington, consistieron en medidas que impulsaron un drástico programa de reformas estructurales en el Estado que afectaron al sistema científico y las universidades nacionales ${ }^{30}$, destacándose por la liberalización de los mercados de productos que afectaron a la industria nacional, la apertura comercial y la privatización de las empresas públicas. Con el plan de convertibilidad se inició un proceso de reconversión de algunos sectores del sistema productivo con un fuerte crecimiento del desempleo y la pobreza.

Fueron estas políticas económicas neoliberales puestas en práctica y rigurosamente ejecutadas en la década de los noventa y que tuvieron su profundización en 2001-2002, centradas en la apertura de la economía y la estabilidad macroeconómica, las que conspiraron contra la trayectoria tecnológica de las empresas argentinas y restaron interés a la capacidad de producir localmente conocimientos científicos y tecnológicos relevantes y que además provocaron la mayor crisis política, económica y social de la historia nacional. Las que además tuvieron un particular correlato en las políticas de ciencia y tecnología acentuando su

\footnotetext{
${ }^{30}$ En 1995 se aplica la Ley de Educación Superior y el Programa de Reforma de la Educación Superior.
} 
crisis y con un Estado en emergencia en el plano presupuestario, en lo relativo a su misión, a sus orientaciones y su funcionamiento ${ }^{31}$.

Se llegó al $54 \%$ de pobreza ${ }^{32}$ en el país y a contar con un sector productivo en crisis, las universidades con problemas de financiamiento y las instituciones científicas distancias de la actividad tecnológica con investigadores que contaban con sueldos y recursos que estaban entre los más bajos del mundo. El sistema científico y tecnológico nacional era testigo del segundo éxodo ${ }^{33}$, después de la dictadura pero por motivos diferentes, de científicos y profesionales jóvenes calificados que emigraban al exterior.

En 2003, con un nuevo contexto político y económico se inicia un crecimiento del país, donde estuvo en foco la ampliación de las políticas científicas, educativas y sociales. Este año será el inicio de una nueva etapa en las políticas científicas argentinas orientadas en torno a la ampliación de la inversión pública en investigación y desarrollo, la ampliación de la base de recursos humanos para la investigación, de becarios y de infraestructura, y el fortalecimiento institucional de los organismos del sector científico y tecnológico.

Este proceso de recuperación institucional tuvo al CONICET como actor destacado en un período que se inició con posterioridad al 2002 y que significó el proceso de ampliación y fortalecimiento del organismo más importante en investigación y desarrollo del país.

\section{Cuatro momentos de la ciencia en democracia}

En el plano de la ciencia y la tecnología se pueden establecer cuatro períodos a partir de 1983 pero con la imposibilidad de dar cuenta de lo acontecido sin considerar los siete años previos de dictadura cívico militar y terrorismo de Estado. En un marco social y económico

\footnotetext{
31 ALBORNOZ, Mario y GORDON, Ariel (2011). "La politica de ciencia y tecnología en Argentina desde la recuperación de la democracias 1983-2009)". En ALBORNOZ, Mario y SEBASTIÁN, Jesús. "Trayectorias de politicas cientificas y universitarias de Argentina y España". Madrid: CSIC.

32 Según el Instituto Nacional de Estadísticas y Censos (INDEC), la incidencia de la pobreza medida por insuficiencia de ingresos en el primer semestre del año 200,3 según mediciones realizadas en 28 aglomerados, alcanzaba al 54\% de la población en un equivalente a 12.510.000 personas aproximadamente.

${ }^{33}$ ALBORNOZ, Mario, FERNÁNDEZ POLCUCH, Ernesto y ALFARAZ, Claudio. (2002). " Hacia una nueva estimación de la 'fuga de cerebros'". Buenos Aires: Centro Redes.
} 
dominado por una perspectiva económica donde los intereses eran claramente agroexportadores, en un proceso de industrialización inconcluso bajo un patrón de apertura de mercados, desregulación y valorización financiera, y un Estado débil.

Estas condiciones explican -en parte- la ausencia de actividades de producción de conocimiento y sobre todo la falta de identificación de la sociedad con la investigación y desarrollo tecnológico, debiéndose aún hoy trabajar en lograr que la ciencia y la tecnología sean comprendidas como parte de la identidad como país.

En lo que respecta a las políticas públicas desde el Estado, los organismos del sistema científico argentino atravesaron los últimos 30 años en medio de una sucesión de cambios de rumbo. Desde intentos de política desarrollistas seguidas por la desregulación propia del pensamiento neoliberal y, en ya más de una década, una nueva etapa de políticas con mayor protagonismo estatal donde el contexto internacional fue favorable, más allá de las crisis financieras que se abatieron en el mundo ${ }^{34}$.

Los cuatro momentos pueden ser caracterizados por las políticas para el sector que prefiguraron el legado de cada uno de los gobiernos democráticos desde 1983 en adelante.

Enfoques que permiten identificar las formulación de las políticas científicas hasta 1989, en el caso del gobierno de Raúl Alfonsín, en un claro proceso signado por la reconstrucción democrática, donde la política científica estuvo vinculada al proceso de democratización. Aquí aparece con gran protagonismo en la escena de la política científica la permanente necesidad de superar conflictos institucionales desde una lógica de la democratización con la asignación de prioridades en investigación y desarrollo, y la recuperación y la generación de las condiciones básicas en las universidades para impulsarlas a ocupar un lugar de protagonismo en la investigación científica y tecnológica.

En los posteriores dos mandatos presidenciales de Carlos Menem, entre los años 1989 a 1999, es posible distinguir dos etapas distintivas y, a su vez, contradictorias. Durante el transcurso de su primer mandato presidencial se generó una reacción que marcó el regreso a la gestión de investigadores que habían compartido las políticas e intervenido en funciones durante la dictadura cívico militar. Hasta 1994 el gobierno de Menem emprendió una reforma

\footnotetext{
${ }^{34}$ ALBORNOZ, Mario y GORDON, Ariel (2011). "La politica de ciencia y tecnología en Argentina desde la recuperación de la democracias 1983-2009)". En ALBORNOZ, Mario y SEBASTIÁN, Jesús. "Trayectorias de políticas científicas y universitarias de Argentina y España". Madrid: CSIC.
} 
estructural, con apertura y desregulación de la economía y un programa de privatización de las principales empresas estatales y la concesión de los servicios públicos a empresas en su mayoría extranjeras. Como en el resto de las reparticiones públicas nacionales, en el área de ciencia y tecnología se produjo la reducción del tamaño de las instituciones.

Por su parte, las políticas desregulación durante el primer gobierno y las económicas impulsadas a partir de la segunda presidencia, que también tuvieron en foco al sector de la ciencia y la tecnología (por citar un ejemplo, la Comisión de Ciencia y Técnica y la Comisión de Industria de la Cámara de Diputados de la Nación, a mediados de 1990 interpeló a las autoridades del INTI sobre su continuidad. Si bien el INTI no fue cerrado, el personal se redujo a menos de la mitad respecto de mediados de los años '80), se sustentaron en una clara identificación y proximidad con los dictados de los organismos de financiamiento internacional (Fondo Monetario Internacional -FMI- y Banco Mundial -BM-).

Las reformas impulsadas en el Estado ${ }^{35}$ se produjeron en el contexto político neoliberal y desde un rediseño del entramado institucional del sector sobre nuevas competencias a las existentes. En este marco de reformas se sucedieron hechos de confrontación con investigadores y docentes de las universidades nacionales debido al avance que estas significaban sobre la autonomía y la pérdida del rol del Estado en sus competencias para delinear las políticas orientadas a las actividades científicas y tecnológicas.

La crisis desatada a finales del período 1999-2001, encuentra al gobierno de Fernando De la Rúa enfrentado a los investigadores por la instrumentación de políticas de orden económico que incidieron en el plano de la política científica y tecnológica. Los investigadores llegaron a cobrar un sueldo promedio de 50 dólares mensuales en el $\mathrm{CONICET}^{36}$, en momentos en que la crisis económica afectaba a toda la sociedad.

Entre medio se genera un pasaje que va de la profunda crisis institucional que desencadenará los acontecimientos del 19 y 20 de diciembre del 2001, a la sucesión de 5 presidentes, y el inicio de una posterior recuperación en 2002.

\footnotetext{
${ }^{35}$ A mediados de 1996, se creó la Agencia Nacional de Promoción Científica y Tecnológica (ANPCyT). Esta iniciativa modificó drásticamente el panorama institucional y los mecanismos de financiamiento de la investigación en la Argentina. En HURTADO, Diego (2010). "Organización de las instituciones científicas en la Argentina (1933-1996). Una Visión Panorámica". 1ra. ed. Cuadernos ICES 3. Buenos Aires.

${ }^{36}$ El ministro de Ciencia, Tecnología e Innovación Productiva de la Nación, Lino Barañao, realizó esta afirmación durante la presentación de "Argentina Innovadora 2020: Plan Nacional de Ciencia, Tecnología e Innovación", evento celebrado en Casa Rosada el martes 12 de marzo de 2013. El ministro también repaso los avances logrados por el Ministerio.

El discurso se encuentra disponible en: http://www.mincyt.gob.ar/noticias/la-presidenta-presento-el-plan-nacional-de-ciencia-tecnologia-einnovacion-4775
} 
Y ya en 2003 con la gestión en el gobierno de Néstor Kirchner $^{37}$ comienza un período que se extenderá como continuidad de modelo de país hasta el presente. Con matices frente a los gobiernos que le sucedieron, Kirchner orientó las políticas públicas para el sector en una planificación de mediano plazo donde los organismos del sistema nacional fueron la referencia. La primera medida adoptada consistió en recuperar los sueldos de los investigadores y sumar al CONICET como institución clave en el encuadre de la políticas científicas.

El marco amplio de medidas, efectos y momentos políticos fue acompañado con un crecimiento presupuestario que impactó también en las universidades, en el sector de desarrollo aeroespacial, de las comunicaciones y nuclear pero, esencialmente, en la orientación de objetivos para la recomposición de instancias propias de la agricultura familiar y la transferencia de tecnología al sector productivo por parte del INTA y el INTI.

Por su parte, desde diciembre de 2007 y en sus dos mandatos consecutivos, el gobierno de Cristina Fernández de Kirchner no solo propuso la creación del Ministerio de Ciencia, Tecnología e Innovación Productiva sino que situó el alcance de las políticas públicas en la consolidación del sistema nacional de ciencia y tecnología (período del que damos cuenta en esta tesis más extensamente).

En el transcurso de estos más de 30 años el CONICET, y desde 2008 bajo la órbita del Ministerio de Ciencia y Tecnología, ha experimentado distintos procesos que, por un lado, tuvieron que ver con el aumento de la cantidad de institutos de investigación durante la dictadura cívico-militar. Entrado el año 1983 contaba con 116 institutos y 7 centros regionales. Y desde 2003 al 2014 pasar a contar con otros 108 centros e institutos de investigación para llegar a 226 y sumar 14 Centros Científicos y Tecnológicos (CCT) y 2 Centros de Investigación Multidisciplinarios (CADIC y CENPAT) ${ }^{38}$ (ver gráfico al final: Red Institucional del CONICET).

\footnotetext{
${ }^{37}$ Es importante recordar un hecho destacable en la vida institucional de los gobiernos de la región, en lo que fue el profundo rechazo que tuvo el proyecto estadounidense para crear el Área de Libre Comercio de las Américas (ALCA) que, tras ser negociado a lo largo de los años noventa con la pretensión de abarcar al hemisferio, llegó a su fin en noviembre del año 2005 en la IV Cumbre de las Américas en la ciudad de Mar del Plata. El ALCA, que también refería a visiones sobre la ciencia y la tecnología, designaba la expansión del Tratado de Libre Comercio de América del Norte con el resto de los estados del continente americano excluyendo a Cuba, aceptando una integración subordinada a la economía de los Estados Unidos. El no al ALCA fue el comienzo de un período de integración regional donde se comenzaron a profundizar aspectos referidos a ciencia y tecnología.

${ }^{38}$ Respecto de la Red Institucional será considerada en otros apartados.
} 
Con la finalidad de comprender los hechos se avanzó en la descripción de los antecedentes historiográficos ${ }^{39}$ más destacados como en los efectos de las políticas de Estado de orden científicas, económicas y sociales. Conocer este campo de articulación permitió activar y robustecer las memorias públicas, interpretar las orientaciones asumidas desde el CONICET durante estas etapas así como la impronta que los distintos gobiernos democráticos dejaron en éste y en otros organismos del sistema nacional de ciencia y tecnología.

Estos aspectos permiten dar cuenta de la estrecha vinculación entre la política científica y desarrollo institucional, necesarios para considerar los procesos comunicacionales y advertir la existencia de un espacio de intersección que explica ciertas tendencias y características del sistema científico y las posibilidades de intervención desde el campo de las ciencias sociales en la última época (sin este entendimiento hubiese sido aún más complejo poder interpretar el lugar que se le asignó a la comunicación).

Como se señaló al inicio de esta tesis, lo hasta aquí referido enriquece el proceso de trabajo de la comunicación en ámbitos institucionales de orden científico. Reconocer para poder decidir ha sido el objetivo, en cuanto a los impactos atribuibles sobre las estructuras institucionales, los cambios organizacionales o de políticas atribuibles ${ }^{40}$ a la experiencia adquirida en cada período y con cada gobierno y los cambios culturales en la comunidad científica o en el entorno social de la institución.

Las dimensiones a ser consideradas permiten comprender, en el caso del CONICET, la organización de red institucional y los marcos de colaboración actuales con las universidades, como estrategia para el abordaje de problemas complejos y el aprendizaje recíproco desde la comunicación (ver gráfico al final: Distribución geográfica de las instituciones de educación superior universitaria y unidades del CONICET al 2012).

Por tanto, para considerar el impacto sobre la difusión de los nuevos conocimientos, la comunicación y la cultura científica y tecnológica ha sido necesaria una evaluación sobre la

\footnotetext{
${ }^{39}$ PAGANO, Nora (2004). "Las ciencias sociales durante la dictadura argentina (1976-1981)". En DEVOTO, Fernando y PAGANO, Nora (Editores). "La historiografía académica y la historiografia militante en Argentina y Uruguay". Buenos Aires, Biblos.

-VESSURI, Hebe (1992). "Las ciencias sociales en la Argentina: diagnóstico y perspectivas". En OTEIZA, Enrique (Dir.). "La política de investigación cientifica y tecnológica en Argentina. Historias y perspectivas". Buenos Aires, Centro Editor de América Latina (CEAL). ${ }^{40}$ Lecturas de documentos oficiales:

-SECyT (2005). "Bases para un Plan Estratégico de Mediano Plazo en Ciencia, Tecnología e Innovación 2005-2015". Ciudad Autónoma de Buenos Aires.

-MINCyT (2006). "Plan estratégico nacional de Ciencia, Tecnología e Innovación "bicentenario" (2006-2010)". Ministerio de Ciencia, Tecnología e Innovación Productiva de la Nación. Ciudad Autónoma de Buenos Aires.

-MINCyT (2011). "Plan Nacional de Ciencia, Tecnología e Innovación 2012-2015". Secretaría de Planeamiento y Políticas en CTIP. Ministerio de Ciencia, Tecnología e Innovación Productiva de la Nación. Ciudad Autónoma de Buenos Aires.
} 
existencia de realidades que han conformado los cambios y los rasgos culturales de las comunidades científicas con respecto a la excelencia, a la atención a necesidades sociales y económicas, a la cooperación y la conformación de redes, así como a la propia evaluación del sistema científico. 


\section{Red Institucional del CONICET}

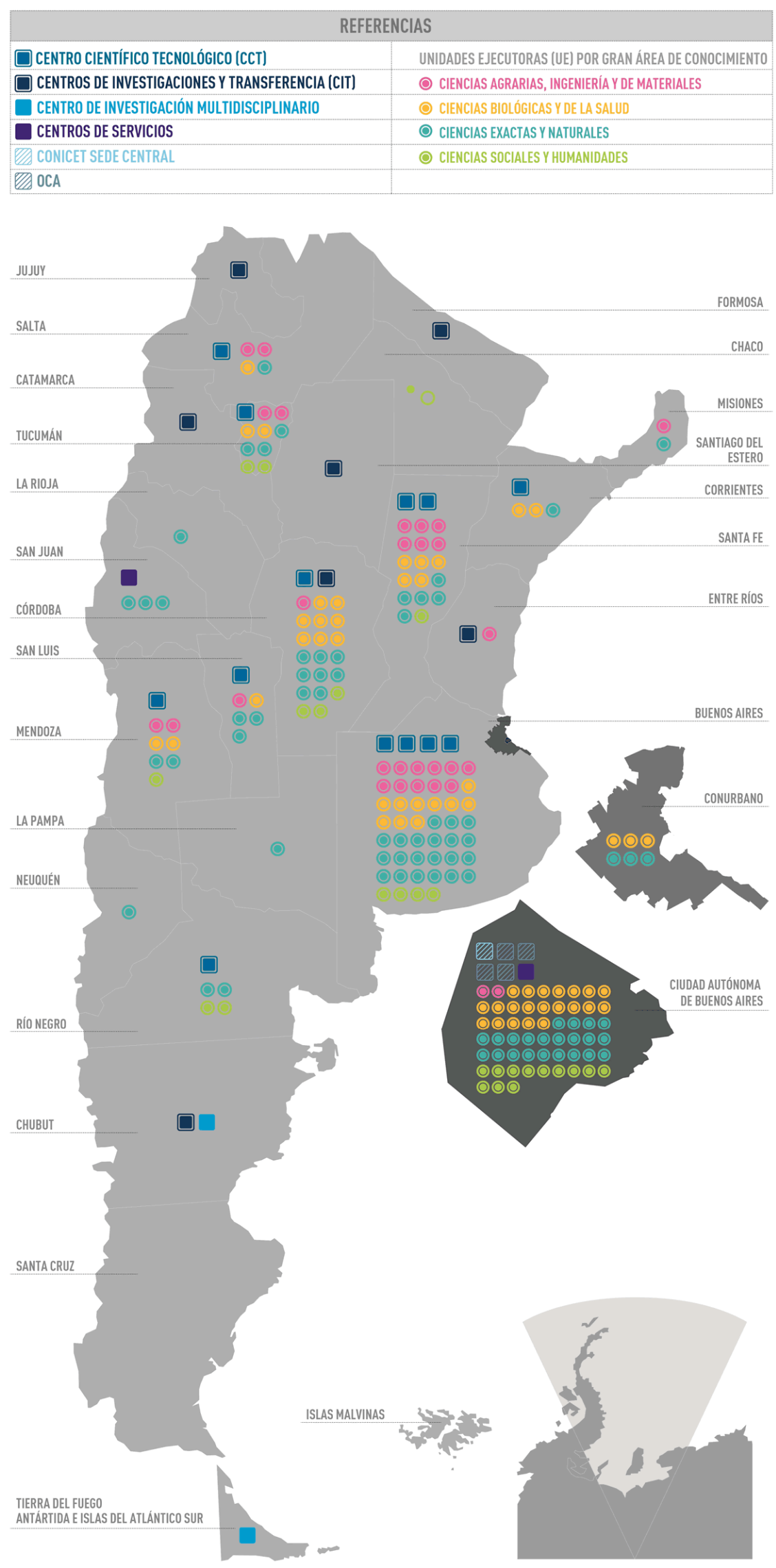

Página 36 de 205 


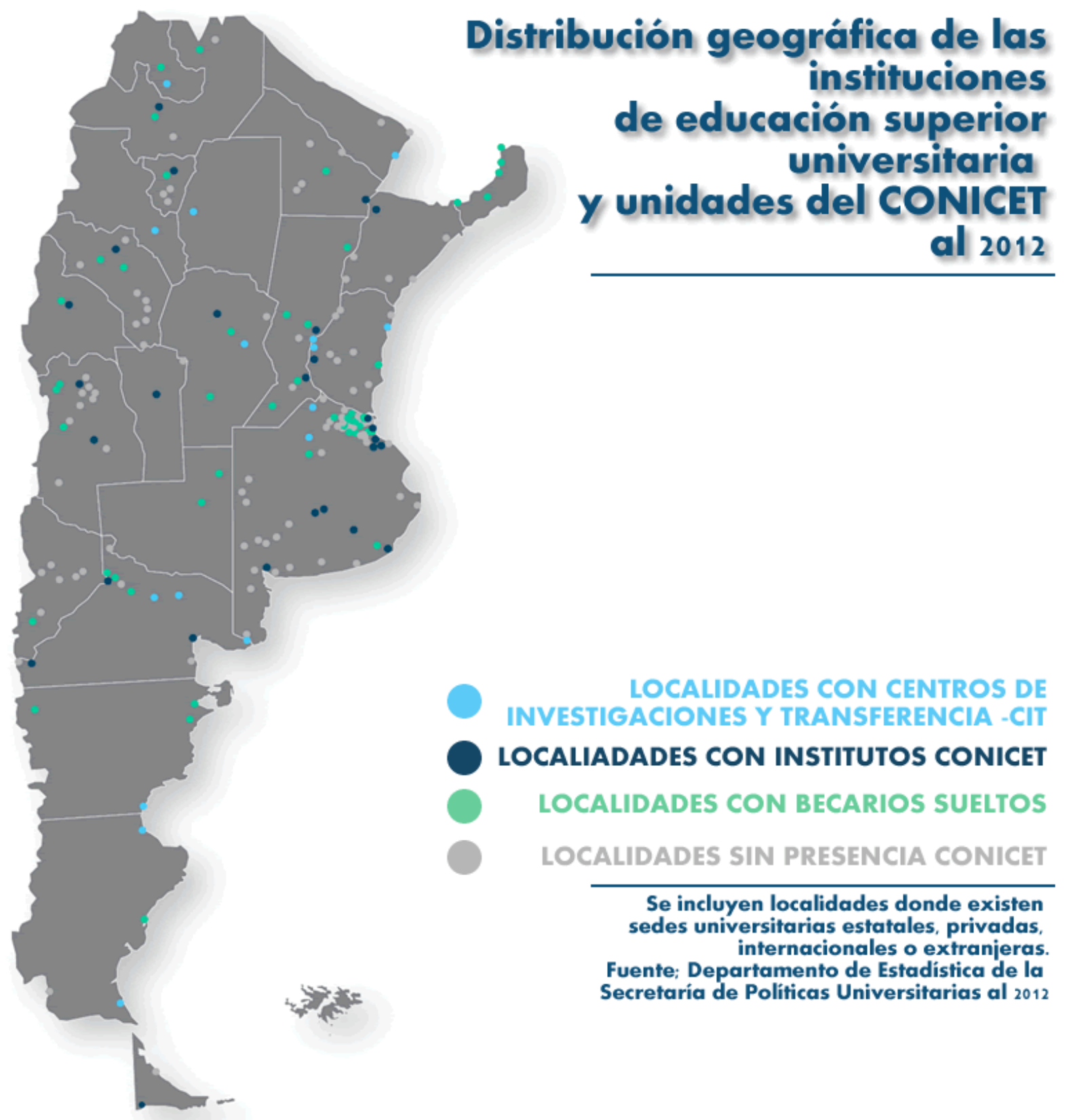




\section{La recuperación de la ciencia y tecnología}

En el escenario nacional el panorama económico y político no fue diferente a otros países de América Latina. Si se retoma el diálogo de los últimos 70 años, una y otra vez, se pueden situar como componentes principales y a revisión crítica a las dictaduras cívico-militares y los gobiernos democráticos neoliberales.

Visto así, y como ya fuera destacado en este último caso se trató de una sistemática y profunda aplicación del recetario neoliberal en la región a lo largo de los años ochenta y noventa del siglo pasado, que empujó al país a procesos de profundo cambio y ruptura de las cadenas productivas internas, de traslado del comando de la economía hacia las empresas transnacionales, la reducción de los espacios para definir estrategias de desarrollo y de acentuación de desigualdades de todo orden.

A finales de ese período comenzaron a surgir claras evidencias de agotamiento del neoliberalismo y el avance de distintos movimientos políticos y sociales de oposición al modelo imperante, así como triunfos electorales que abrieron paso a los llamados gobiernos progresistas en distintos países de la región.

Estas nuevas propuestas políticas fijaron una agenda de gobierno focalizada en lo social pero situada en la recomposición de las capacidades productivas, tecnológicas y científicas. Dieron lugar a revalorizar los intereses de los diversos actores económicos y sociales de los países de la región ${ }^{41}$, que han ido construyendo una amplia agenda de crítica y denuncia al neoliberalismo y de construcción de alternativas de diferente contenido y alcance.

Desde el año 2003 en adelante, considerando el corte temporal de esta tesis en 2014, se pueden distinguir dos etapas que coinciden con los dos últimos gobiernos, de Néstor Kirchner, primero, y de Cristina Fernández de Kirchner, posteriormente (en sus dos gestiones).

\footnotetext{
${ }^{41}$ Un hecho destacable durante este período fue el profundo rechazo que tuvo el proyecto estadounidense para crear el Área de Libre Comercio de las Américas (ALCA) que, tras ser negociado a lo largo de los años noventa con la pretensión de abarcar al hemisferio, llegó a su fin desde el año 2003. El mismo planteaba visiones sobre la ciencia y la tecnología.
} 
En referencia a la primera etapa el área de Ciencia y Tecnología todavía no era un Ministerio aunque dependía del Ministerio de Educación y Ciencia, y la instrumentación de la política científica estuvo en manos de la Secretaría de Ciencia y Tecnología hasta el año 2007. Por su parte, la segunda etapa se inició con la creación del Ministerio de Ciencia y Tecnología.

Esta secuencia de cambios institucionales mantuvo una continuidad de la política científica y gran parte de los instrumentos impulsados por Secretaría de Ciencia y Tecnología siguieron vigentes. En este sentido, el principal punto de continuidad está en la recuperación de la inversión pública en ciencia y tecnología que había caído drásticamente en los años 2001 y 2002. La inversión se recuperó en 2005 y ha tenido un crecimiento sostenido hasta llegar a los niveles más altos de la historia (ver gráficos al final: Presupuesto del CONICET 20032015; Presupuesto Nacional -para el período 2008-2015).

La creación del Ministerio de Ciencia y Tecnología le aportó una alta visibilidad al tema de las políticas científica y de la investigación científica a nivel de la opinión pública. Desde este lugar, la ciencia y la tecnología conforman un conjunto de actividades y de movimiento de instituciones que en términos sociales miden su impacto sobre la economía y sobre otras dimensiones de la construcción social.

Dada la continuidad en las políticas científicas en más de una década, se han generado nuevas herramientas y ha crecido la inversión en materia de ciencia y tecnología. También se han creado centros de investigación y el país cuenta con equipos de investigadores fortalecidos, cuya producción a nivel internacional comienza a ser competitiva. En ese marco, uno de los desafíos detallados por la cartera científica es lograr que esta inversión privada crezca. Entre otros aspectos se busca avanzar en la relación entre investigación y las diferentes necesidades de la sociedad.

En relación a la evolución de los indicadores ${ }^{42}$, América Latina evolucionó en materia de inversión científica y tecnológica. La inversión en Argentina, en el año 2001, era el 6,9\% de la inversión latinoamericana y la de Brasil el 65\%. En el año 2010, Argentina ya ocupaba el 10\% y aportaba el 0.62 del Producto Bruto Interno (PBI). En cuanto al porcentaje sobre el PBI en la Unión Europea la inversión científica y tecnológica significaba el 2\% del total del

\footnotetext{
${ }^{42}$ Los datos fueron conformados con información pública que corresponde al Ministerio de Ciencia, Tecnología e Innovación Productiva y al Programa Iberoamericano de Ciencia y Tecnología para el Desarrollo (CYTED).
} 
PBI. En Iberoamérica, por su parte, rondaba el 1\% y sin España el porcentaje se reducía al 0.75\%. La variación de inversión para el período $2000-2011$ fue del $47,42 \%{ }^{43}$.

En el caso de Argentina, la inversión científica y tecnológica en 2003 fue del $0.41 \%$ y en 2014 alcanzó el 0,65\% del PBI, sin considerar la inversión privada (que la lleva al 1\%).

\section{Presupuesto del CONICET 2003 - 2015}
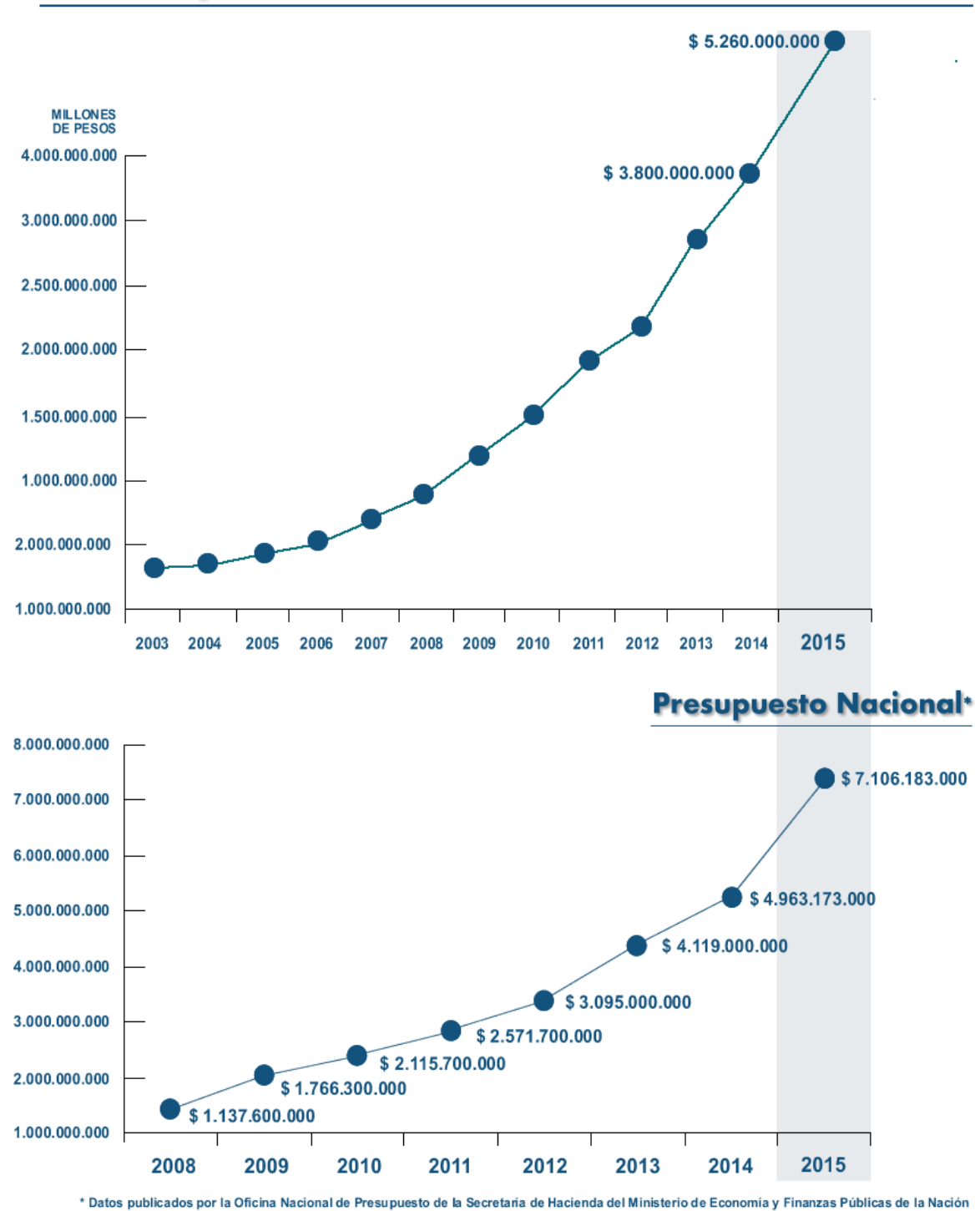

43 "Estado de la Ciencia 2014". Publicación de la Red de Indicadores de Ciencia y Tecnología - Iberoamericana e Interamericana (RICYT). Disponible en: http://www.ricyt.org/publicaciones 


\section{La ciencia y la tecnología en la agenda política}

Sin lugar a dudas hay un cambio desde el año 2003 en adelante. Se plantea la organización social y la aplicación de políticas de carácter sustancial que también pusieron en el centro del debate el conocimiento científico y tecnológico aplicado al desarrollo productivo. Esto le permitió al país alcanzar innovaciones de productos y crecer en procesos pero, centralmente, redimensionar el conocimiento científico tecnológico.

Desde la presidencia de Néstor Kirchner y en adelante se impulsaron todas aquellas actividades que derivaron en la regeneración del sistema productivo y con ello se generaron nuevos criterios en torno a la investigación científico tecnológica, con incentivos que permitieron reorientar la investigación y la transferencia a las necesidades actuales de las distintas regiones del país.

La creación del Ministerio de Ciencia y Tecnología bajo el primer gobierno de Cristina Fernández de Kirchner, a finales del año 2007 y la dotación al sistema científico y tecnológico de presupuesto, el cual se incremento 16 veces para el período 2003 - 2014 en el caso del CONICET, así como la articulación institucional y el reconocimiento sectorial, con sueldos de investigadores que crecieron en promedio por encima del $550 \%$, son evidencia y marcan un rol distintivo en la transformación de las capacidades tecnológicas previas frente a las políticas aplicadas en la última década.

Se trata de un acontecimiento que cambia las coordenadas de la realidad hacia nuevas posibilidades políticas. La ruptura con el estado anterior implicó necesariamente la emergencia de algo nuevo para la investigación y el desarrollo. Y esta nueva realidad debía de ser comunicada de manera cabal porque se comenzaron a impulsar políticas públicas para fortalecer su capacidad de gestionar el procesamiento social del conocimiento para mantener opciones de futuro, y fomentar en los jóvenes la aptitud para investigar y producir conocimiento localmente. 
En este período lo relevante de la ciencia, su valor primordial, se juega en torno de su valor de utilidad económica y social. Los cambios en los sistemas nacionales de ciencia y tecnología y en sus políticas, las estrategias pero también la integración y coordinación de acciones que incluyeron a todos aquellos actores e instituciones que participan o influyen en investigación, transferencia y procesos de innovación, permitieron avanzar en la elaboración de políticas públicas.

Es así que se pasó de 30 años sin inversión en infraestructura a contar con un Plan de Obras para la Ciencia y la Tecnología que plantea la construcción de $90 \mathrm{mil} \mathrm{m} 2$ en nuevos institutos, laboratorios y la modernización de instalaciones en diferentes puntos del país, destinados al CONICET y a las universidades (de los $193 \mathrm{mil} \mathrm{m} 2$ destinados a todo el sistema científico y tecnológico nacional).

En poco más de 6 años el CONICET duplicó el número de investigadores y cuadruplicó el de becarios, con una marcada mejoría de los estipendios en las becas y en los niveles salariales del personal científico y técnico, en sus diferentes categorías. Este crecimiento favoreció el retorno de científicos argentinos radicados en el exterior, en becas otorgadas. Los números dan cuenta de que el $80 \%$ del Programa de Formación se destina a financiar becas de postgrado para la obtención de doctorados en todas las disciplinas. Mientras que el $20 \%$ restante a fortalecer la capacidad de investigación de jóvenes doctores con becas postdoctorales, que experimentó un crecimiento del $500 \%$ en la última década (ver gráfico al final: Investigadores por año y área de conocimiento. Serie 2003-2007-2014; Becarios CONICET Serie 2003-2007-2014).

Estos elementos visibles son conclusivos de hacia dónde debe dirigirse una política que focaliza en el valor del conocimiento, que orienta la inversión social para ayudar a los individuos y se propone tomar ventaja de su potencial humano ubicando sus tendencias, principales problemas, grandes temas y núcleos socio productivos estratégicos. Para el caso estas políticas que apoyan la innovación, difusión e inversión subrayan que el país puede responder al acelerado cambio tecnológico; así como interpretar los factores que crean un ambiente que conduce a la innovación y que es receptivo acerca de la teoría de que el conocimiento permite incorporar valor. 


\section{Investigadores por año y área de conocimiento \\ Serie $2003=2007=2014$}

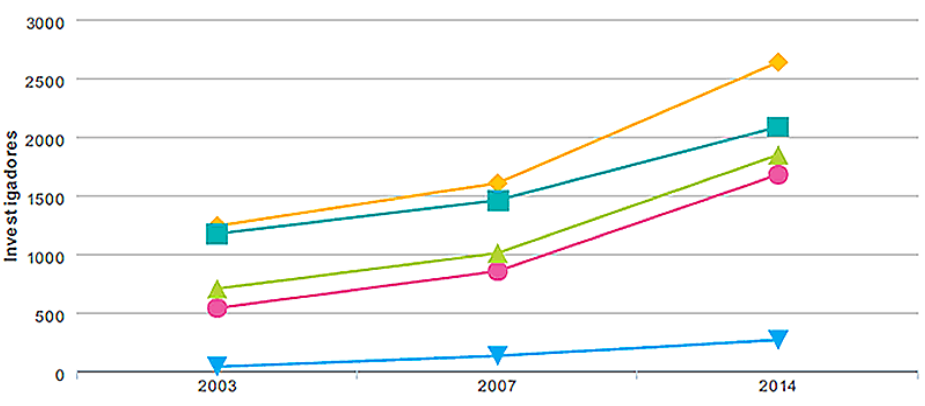

KA - Ciencias Agrarias. de la Ingeniería y de Materiales KB - Ciencias Biologicas y de la Salud KE - Ciencias Exactas y Naturales - KS - Ciencias Sociales y Humanidades - KT - Tecnología

\begin{tabular}{|c|c|c|c|}
\hline KA - Ciencias Agrarias, de la Ingeniería y & $\mathbf{2 0 0 3}$ & $\mathbf{2 0 0 7}$ & $\mathbf{2 0 1 4}$ \\
\hline $\begin{array}{c}\text { de Materiales } \\
\text { KB - Ciencias Biológicas y de la Salud }\end{array}$ & 1240 & 1605 & 1676 \\
\hline KE - Ciencias Exactas y Naturales & 1172 & 1458 & 2035 \\
\hline KS - Ciencias Sociales y Humanidades & 705 & 1008 & 1846 \\
\hline KT - Tecnología & 38 & 131 & 267 \\
\hline Total & $\mathbf{3 6 9 4}$ & $\mathbf{5 0 5 7}$ & $\mathbf{8 5 0 8}$ \\
\hline
\end{tabular}

\section{Becarios CONICET \\ Serie $2003=2007=2014$}

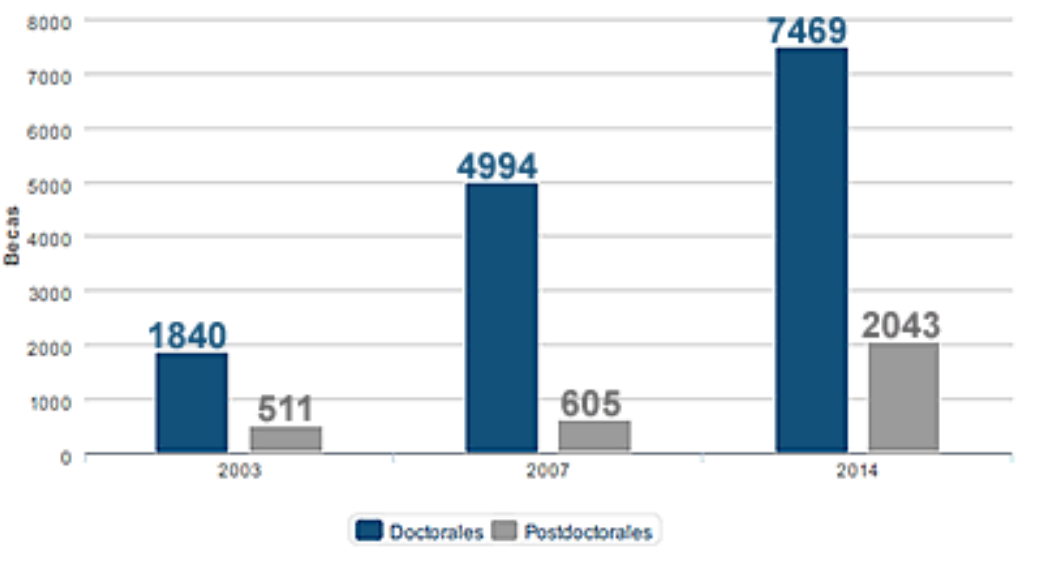

\begin{tabular}{|l|l|l|}
2003 & 2007 & 2014 \\
\hline
\end{tabular}

\begin{tabular}{|c|c|c|c|}
\hline Doctorales & 1840 & 4994 & 7464 \\
\hline Postdoctorales & 511 & 605 & 2043 \\
\hline Tot al & $\mathbf{2 3 5 1}$ & $\mathbf{5 5 9 9}$ & $\mathbf{9 5 0 7}$ \\
\hline
\end{tabular}

Página 43 de 205 


\section{La transformación requiere un proceso sostenido}

Uno de los puntos donde se sustenta un proceso de crecimiento sostenido de la ciencia y la tecnología está dado en el aumento de los niveles de inversión, aunque aún queda como materia pendiente según las estadísticas del Ministerio de Ciencia y Tecnología incrementar la inversión privada. Muestra de ello es el crecimiento de aportes en investigación y desarrollo en relación al Producto Bruto Interno (PBI). Para la Argentina el coeficiente de inversión pública en investigación y desarrollo supone un factor que incide claramente en el impulso dado a la actividad industrial y al conocimiento para incrementar la producción agrícola; estimulada a partir de la articulación de la investigación científica con el aparato productivo a través de los organismos como el INTA, el INTI y el CONICET.

Que la Argentina se haya trazado una decisiva política de estímulo a la actividad científica y tecnológica, está íntimamente asociada a los lineamientos generales que marcan el rumbo económico y social del país; y, además, es consecuencia de haber incorporado en la negociación a los ciudadanos acerca del sentido de Nación deseado, en un país que debe dar respuestas y sostener la actividad productiva frente a los mercados locales, regionales e internacionales.

\section{Pasado y presente}

Reparar en estos hechos de la vida institucional reciente, centrándonos particularmente en el CONICET, por su destacado lugar el Sistema Nacional de Ciencia, Tecnología e Innovación, permiten sumar elementos para comprender y entender las variables que componen la comunicación institucional en un proceso de planificación y gestión; ya que en este proceso, el estudio de la cultura de la organización refiere a su historia y al de sus personalidades, al 
sistema de valores traducidos en costumbres, ritos y estilos de administración y gestión, lenguajes y medios.

Se presenta así una lectura sobre la cual se puede identificar su especificidad que la diferencia de otra institución ${ }^{44}$, y que permite hacer visibles grados de cohesión organizativa como es posible también leer falta de identificación de los objetivos asumidos.

Y teniéndose en cuenta las diversidades culturales existentes en el CONICET e integrando las posibilidades de incertidumbre, riesgo, inestabilidad y cambio desde su creación en 1958 del CONICET, es necesario entender la relación entre ciencia y sociedad que trata de una responsabilidad a todos los organismos de ciencia y tecnología, indispensable para lograr que el conocimiento se transforme en un aporte imprescindible para la equidad social.

Este es el desafío al que se han sumado los organismos del sistema científico desde el 2003 en adelante: convertir a la ciencia en un factor y un instrumento de inclusión social y que aporte a la calidad de vida a la población.

Para lograr este propósito desde las ciencias sociales y desde los lugares que se asumen para la intervención, es posible al generar aportes sobre asuntos específicos y como insumos para la elaboración de políticas públicas. De aquí que la institución que pretende comunicar se abre hacia afuera y desde una adaptación de su funcionamiento al contexto cultural y político. Y en este diálogo o en todo diálogo de la institución con la comunicación tiene un componente político en el que se constituye la estrategia que contempla y articula valores, representaciones y poder.

Por esta razón, no reconocer los hilos de diálogo de la historia institucional y la política, desde la comunicación, impediría en parte la verdadera adecuación del proceso organizacional y comunicacional como un hecho que articula a la comunidad que la integra con su cultura, en un acto que necesariamente requiere de planificación y que a su vez trae implícita la gestión de la comunicación.

\footnotetext{
${ }^{44}$ Se han recuperado para el Estado de Arte a los fines de comprender los enfoques y los tratamientos dados, las siguientes tesis: -VINUESA, Juan Francisco (2012). "Politica Agraria y Comunicación. El INTA y su propuesta de intervención rural". PLANGESCO. Facultad de Periodismo y Comunicación Social. Universidad Nacional de La Plata. La Plata.

-TRÉSPIDI, Miguel Ángel (2009). "Universidad Nacional y Comunicación Institucional. Una gestión posible para alcanzar una universidad mejor comunicada". PLANGESCO. Facultad de Periodismo y Comunicación Social. Universidad Nacional de La Plata. La Plata.

-TAUBER, Fernando (2008). "La comunicación en la planificación y gestión para el desarrollo de las instituciones universitarias públicas argentinas: el caso de la Universidad Nacional de La Plata en el trienio junio 2004-mayo 2007". Tesis de doctorado. Facultad de Periodismo y Comunicación Social. Universidad Nacional de La Plata. La Plata.
} 
La comunicación institucional involucra y requiere diferentes miradas desde la comunicación donde se da cuenta de la evolución de la gestión, que identifica y refiere sobre la imagen institucional, que informa y divulga la evolución, la oferta y la integración institucional, y que propone una comunicación para la interacción de sus actores institucionales, con el medio social y productivo, con participación y generando oportunidades de proyectar intereses y visiones de los sectores que componen la institución para alcanzar objetivos y propiciar valor desde nuevas contribuciones.

Aquí yace la idea de complejidad y heterogeneidad de las realidades histórico-sociales, lo cual implica una crisis de las posibles explicaciones simples en una clara resistencia a la naturalización de este mundo institucional.

La Institución tiene su principal aporte en la construcción efectiva de una sociedad cuyas características se definen necesariamente en el plano de la política, como sujeto de transformación en las democracias.

Consecuentemente desde la comunicación en ese abordaje como fenómeno complejo, total, inserto en un sistema de prácticas y saberes, discursos y tradiciones que constituyen su identidad, se establece un acto de acuerdo con lógicas de intervención y de gestión institucional complejas desde este punto de análisis.

De aquí en adelante se plantean algunas cuestiones indisolubles que hacen a la posibilidad de intervención desde lo disciplinar, desde lo político y desde el lugar activo que adquieren las reflexiones plasmadas en esta tesis, que sirve en su doble sentido identitario e identificatorio.

$Y$ en vistas del tema emerge una primera caracterización del período signado de 2003 en adelante como de "reconstrucción" del sistema científico y tecnológico, pero además distinguido por la continuidad de un modelo político que asume una fuerte política de inclusión social de los sectores vulnerables, con una clara identificación con los derechos humanos, de promoción de leyes de reconocimiento de minorías sociales, de integración del país profundizando sus lazos con la región y Latinoamérica, de políticas que disminuyeron la pobreza y desocupación apuntando a la generación de empleo genuino, entre otros aspectos destacados. 
El conjunto de organismos que aplican en la ciencia básica hasta transferencia de tecnología (entendida como una instancia superior de investigación, desarrollo, e innovación; bajo la fórmula $\mathrm{I}+\mathrm{D}+\mathrm{i}$ ), pasando por una visión extensionista con una fuerte presencia en el territorio, sumado a la intervención y articulación en las cadenas agro productivas, permite actualmente destacar que la ciencia y la tecnología tienen un valor como motor de cambio y de valor agregado a todas la instancias socioprodutivas.

Así lo expresa en el Plan Nacional de Ciencia y Tecnología, Argentina 2020, creado por el Ministerio de Ciencia, Tecnología e Innovación Productiva de la Nación ${ }^{45}$. El documento establece los lineamientos de política científica, tecnológica y de innovación para el país en los próximos años y aspira a dar continuidad al crecimiento y consolidación de estas áreas consideradas puntales estratégicos del desarrollo nacional.

Los pilares sobre los que se elaboró el plan son el aprovechamiento pleno de las capacidades científicas nacionales; impulso a la cultura emprendedora y la innovación productiva, inclusiva y sustentable; mejoramiento de la calidad de vida de la población; y fomento de la competitividad de la economía.

Bajo estas pautas, la política pública en ciencia y tecnología es presentada para un sector que debe conformar una mayor articulación y definiciones respecto del lugar que se le otorga a los temas como: agroindustria, ambiente y desarrollo sustentable, desarrollo social, energía, industria y salud; así como el lugar que cada organismo asume respecto de los núcleos socioproductivos estratégicos de cara a un futuro inmediato.

Desde esta perspectiva, el tratamiento brindado a la ciencia y tecnología no solo refiere a la adopción de compromisos en el ámbito interinstitucional, sino que responde por primera vez a una política pública en ciencia y tecnología; al reconocer concepciones, patrones e intereses y cuya trayectoria y abordaje requiere considerar aquellos elementos más específicos además de la revisión que puede hacerse del documento y su tratamiento en profundidad.

La relevancia y alcance del Plan cobra sentido en esta tesis como fuente. Pero aportó a la definición y el delineamiento de una estrategia comunicacional enfocada en las tendencias y

\footnotetext{
${ }^{45}$ El Plan fue presentado el 12 de marzo de 2013 por el ministro de Ciencia, Tecnología e Innovación Productiva de la Nación, Lino Barañao, durante un acto presidido por le presidenta Cristina Fernández de Kirchner.

Disponible en: http://www.argentinainnovadora2020.mincyt.gob.ar/

Discurso del ministro de Ciencia y Tecnología. Disponible en: http:/www.mincyt.gob.ar/noticias/la-presidenta-presento-el-plan-nacionalde-ciencia-tecnologia-e-innovacion-4775
} 
relevancia otorgada a la ciencia y tecnología desde el Estado y cuya ámbito de aplicación fue la gestión de la comunicación institucional en el CONICET.

Pese a que se ha ido construyendo en cada organismo una agenda cada vez más amplia de trabajo, compartida con aciertos y desaciertos, y enfocada en las necesidades que plantea y dispara el Plan Argentina 2020, aún resta suficiente trabajo hacia la construcción de alternativas de diferente contenido y alcance para su efectiva aplicación.

En tanto, no surge evidencia suficiente acerca de una posición compartida en términos comunicacionales para relacionar y visualizar elementos de una estrategia de comunicación común, ya no compartida en referencia a sus alcances, sino al menos en cuanto a expresar los objetivos.

Como primer intento es conveniente destacar que el sistema científico y tecnológico nacional precisa de una mayor comprensión sobre los aportes de los distintos organismos para hacer viable esta política pero, además, y no por ello menos necesaria, requiere hablar de los factores y condicionantes sociopolíticos y culturales, analizados y contemplados para alcanzar una efectiva comprensión desde el lugar desde donde se interviene.

El necesario relacionamiento habilitará a definir una estrategia comunicacional de posible desarrollo, en cuanto a las políticas formuladas, las ideologías y los actores sociales involucrados.

De esta manera el presente estudio de caso se inscribe en la tendencia contemporánea que pretende revalorizar la posición de los organismos del Estado en la materia, como un aporte para proyectar nuevas formas de intervención comunicacional.

Por ello la necesidad de articular esta perspectiva con un análisis diacrónico del contexto institucional para la adecuada comprensión de la dimensión del sistema y el impacto de la ciencia y la tecnología. 


\section{EI CONICET en las políticas nacionales de ciencia y tecnología}

Con una clara incidencia del Estado Nacional en más de una década, se establecieron lineamientos de políticas en ciencia y tecnología y se fijaron, de manera integrada y coherente, metas de largo plazo que permitieron que las acciones implementadas se tradujeran en una política de Estado en la materia.

Sobre las necesidades y capacidades del sistema científico argentino se constituyó una base desde la cual fue posible plantear un modelo de país en que la ciencia y la tecnología (base de un proyecto nacional integrador que reafirma su modelo de país en el acceso a la educación, la cultura, al trabajo, las políticas sociales y de salud y los derechos humanos, por destacar solo algunos) constituyen uno de los pilares y motor del desarrollo económico y de la inclusión social.

En el proceso de la plena integración entre los diferentes elementos componentes de la ciencia y la tecnología y entre los diversos actores de la sociedad argentina en el ejercicio de esta esfera de actividad, se encuentran los organismos del Sistema Científico Tecnológico Nacional.

El crecimiento experimentado puede leerse en un repaso por la estructura del organismo, sus funciones, su distribución geográfica y la organización de los catorce Centros Científicos Tecnológicos (CCT), los dos Centros de Investigación Multidisciplinarios, las doscientos veinticuatro Unidades Ejecutoras (UE) distribuidas a lo largo del país y los ocho Centros de Investigación y Transferencia (CIT).

El crecimiento en materia de presupuesto del CONICET (de los casi 500 millones de pesos en 2004 a los 3.800 millones de pesos en 2014 y un proyectado para 2015 de 5.260 millones) el constante desarrollo en materia de recursos humanos a través de la incorporación sistemática de alrededor de mil becarios por año y la distribución de los investigadores según 
las grandes áreas de estudio: Ciencias Agrarias, Ingeniería y de Materiales, Ciencias Biológicas y de la Salud, Ciencias Exactas y Naturales, Ciencias Sociales y Humanidades ${ }^{46}$.

Este crecimiento se observa además en el número de tesis defendidas, con un aumento de más de cuatro veces entre 2003 y 2014. De doscientas becas por año a más de mil donde el 80\% de los becarios culmina si doctorado en los 5 años.

Los proyectos de infraestructura que lleva adelante el organismo junto con el Ministerio de Ciencia, Tecnología e Innovación Productiva, integradas en el Plan de Obras para la Ciencia y la Tecnología, le ha permitido al CONICET después de 30 años contar -desde el 2008- con 60 obras de renovación de la infraestructura edilicia. Las mismas se llevan adelante a través de inversión propia del CONICET, del Plan Federal de Infraestructura (PFI) y del Programa de Renovación de Innovación Tecnológica (PIT II). El 65\% de esta nueva infraestructura está destinada a Tucumán, Tierra del Fuego, Mendoza, Santa Fe, Río Negro, Chubut, San Luis, La Rioja, Córdoba, Catamarca; mientras que el 35\% a la Ciudad Autónoma de Buenos Aires y la provincia de Buenos Aires. También se desarrollan Proyectos para Mejoras de Infraestructura que contemplan 100 obras menores donde el 58\% de las refacciones son para institutos y centros del interior del país en un período de 2 años.

Otro aspecto es la ejecución de los Proyectos de Investigación Orientados (PIO) para dar soluciones a problemáticas sociales concretas. No menor es el lugar que ocupa la Argentina en el ranking mundial de producción científica. En 2009, el Consejo Nacional se encontraba en el puesto 151 a nivel mundial, en 2011 en el 121 y este año llegó al lugar 79 de este ranking en producción científica (ver gráfico al final: El CONICET entre las 80 instituciones más importantes del mundo en investigación científica en 2014).

Actualmente, según el reporte SCImago $^{47}$ que publica rankings en áreas de investigación, innovación y visibilidad Web, se encuentra en el puesto 79 entre casi 5 mil instituciones científicas de todo el mundo. A nivel nacional ocupa el primer lugar, mientras que en el

\footnotetext{
${ }^{46}$ Ciencias Agrarias, Ingenierías y de los Materiales: comprende las disciplinas de Ciencias Agrarias; Ingeniería Civil, Eléctrica, Mecánica e Ingenierías relacionadas; Hábitat; Informática; Ingeniería de Procesos Industriales y Biotecnología.

Ciencias Biológicas y de la Salud: conformada por las disciplinas de Ciencias Médicas; Biología; Bioquímica y Veterinaria.

Ciencias Exactas y Naturales: abarca las disciplinas de Ciencias de la Tierra, del Agua y de la Atmósfera; Matemáticas y Computación; Física; Astronomía y Ciencias Químicas.

Ciencias Sociales y Humanidades: comprende las disciplinas de Derecho, Ciencias. Políticas y Relaciones Internacionales; Filología, Lingüística y Literatura; Filosofía, Psicología y Ciencias de la Educación; Historia, Antropología y Geografía; Sociología, Comunicación Social y Demografía; Economía, Ciencias de la Gestión y de la Administración Pública.

Tecnología: se refiere a cualquiera de las disciplinas mencionadas aplicadas al desarrollo tecnológico y social, y proyectos complejos.

${ }^{47}$ Información disponible en: http://www.scimagoir.com/
} 
ámbito regional está segundo luego de la Universidad de San Pablo, Brasil. En Iberoamérica ocupa el tercer lugar luego del Consejo Superior de Investigaciones de España y la mencionada Universidad de San Pablo.

El CONICET se destaca dentro de la categoría de talento científico, donde ocupa el puesto 71, y que está elaborado en base al número total de autores de una institución en el número total de publicaciones. En el ranking innovación el Consejo está en el primer puesto en Argentina y en el 192 a nivel mundial. En 2009 ocupaba el 343. En impacto tecnológico paso del lugar 869 al 364 en el mismo período.

También su crecimiento se experimenta en la promoción de la transferencia tecnológica o los Servicios Tecnológicos de Alto Nivel (STAN) que el organismo brinda.

\section{CONICET entre las 80 instituciones más importantes del mundo en producción científica en 2014}

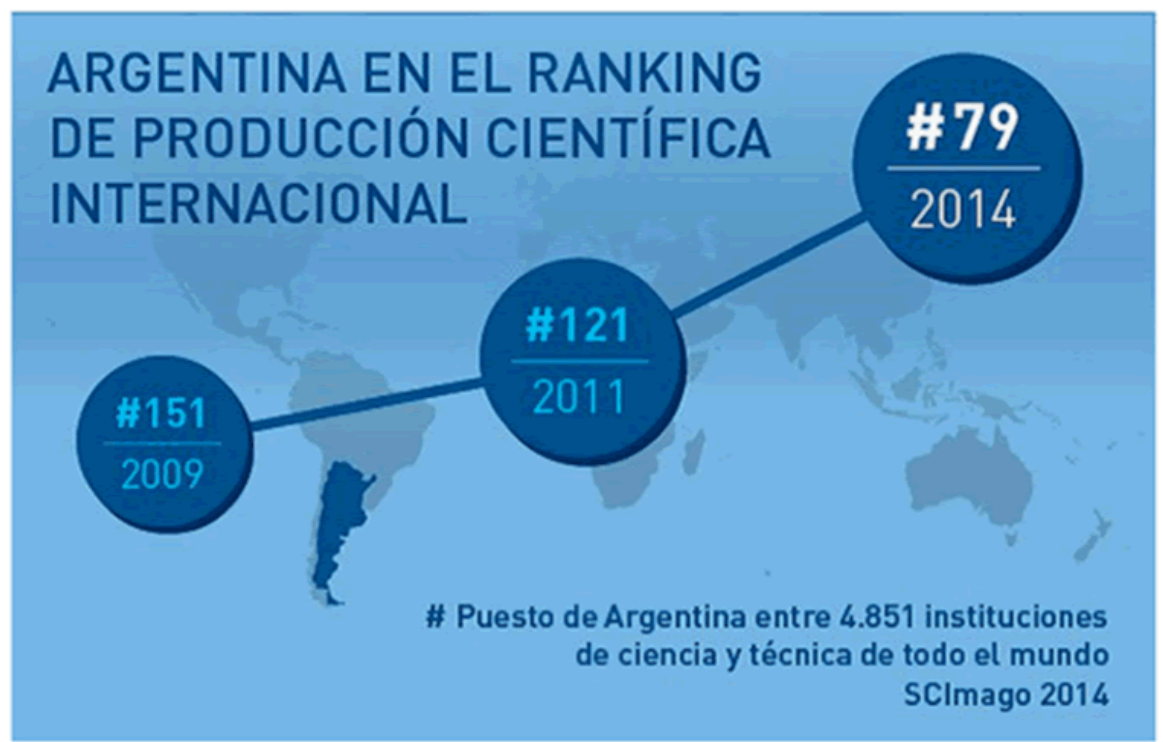




\section{CAPÍTULO III}

\section{Conocer para interpretar}

Antes de avanzar, es necesario conocer e interpretar las particularidades de un CONICET que como organismo autárquico que se encuentra bajo la órbita del Ministerio de Ciencia, Tecnología e Innovación de la Nación, cuenta con una estructura conformada por un órgano de gobierno de 9 miembros. Este Directorio ${ }^{48}$ tiene capacidad en la toma de decisiones centrales.

\section{Misiones y funciones del CONICET y de su Directorio}

Al respecto las funciones de Consejo Nacional de Investigaciones Científicas y Técnicas (CONICET) están definidas en el Decreto 1661/96. El mismo especifica y las define en cuanto al fomento y subvención de la investigación científica y tecnológica, y las actividades de apoyo a las mismas, tanto en el sector público como privado. Esto deberá apuntar al avance científico y tecnológico en el país, al desarrollo de la economía nacional y al mejoramiento de la calidad de vida, respetando los lineamientos establecidos por el Gobierno Nacional.

Otros lineamientos establecen el fomento para el intercambio y la cooperación científicatecnológica dentro del país y con el extranjero. Otorgar subsidios a proyectos de investigación. Del mismo modo a las pasantías y becas para la capacitación y perfeccionamiento de egresados universitarios o para la realización de investigaciones específicas, en el país o en el extranjero. Y en lo que hace a su organización tiene la función

\footnotetext{
${ }^{48}$ El Directorio del Consejo Nacional está integrado con un presidente elegido por el Poder Ejecutivo Nacional, 4 representantes por las Grandes Áreas, 1 del Consejo de Universidades, 1 por las organizaciones de la Industria, 1 por las organizaciones Agro y 1 por los organismos responsables de la ciencia y la tecnología de los Gobiernos Provinciales y el Gobierno Autónomo de la Ciudad de Buenos Aires.
} 
de subvencionar institutos, laboratorios y centros de investigación, los que podrán funcionar en universidades y otras instituciones oficiales o privadas o bajo la dependencia directa del CONICET.

Por su parte reconoce entre sus obligaciones la de administrar las Carreras del Investigador Científico y Tecnológico, y del Personal de Apoyo a la Investigación y Desarrollo ${ }^{49}$; y la función de instituir premios, créditos y otras acciones de apoyo a la investigación científica. También la de brindar asesoramientos a entidades públicas y privadas en el ámbito de su competencia.

El mencionado Decreto considera conveniente que el CONICET goce de autarquía en el cumplimiento de sus responsabilidades dentro del marco de las políticas definidas por el Gobierno Nacional, por lo cual debe contemplarse la realización de auditorías externas periódicas adecuadas.

Por lo cual el objetivo principal radica en la necesidad de fomentar y financiar la investigación científica y tecnológica y las actividades de apoyo que apunten al avance científico y tecnológico en el país, al desarrollo de la economía nacional y al mejoramiento de la calidad de vida, considerando los lineamientos establecidos por el Gobierno Nacional.

\footnotetext{
${ }^{49}$ Es preciso señalar que las definiciones y términos que actualmente emplea el CONICET comprenden a los tres escalafones que son administrados por el CONICET: Investigadores, Personal de Apoyo y Personal Administrativo. Los becarios están considerados dentro del Programa de Becas.

-Investigador: es la persona que trabaja en la concepción o creación de nuevos conocimientos, productos, procesos, métodos y sistemas y en la gestión de los respectivos proyectos. Comprende al personal científico-tecnológico dedicado a la I+D (Investigación y Desarrollo), entendiendo por ésta al trabajo intelectual y experimental llevado a cabo en forma sistemática para incrementar el volumen de conocimientos, incluido el conocimiento del hombre, la cultura y la sociedad y el uso de éstos para derivar nuevas aplicaciones. Comprende a la Investigación Básica, Investigación Aplicada y al Desarrollo Experimental.

Se incluye dentro de esta definición al grupo de investigadores en todas las Categorías que forman parte de la Carrera del Investigador Científico Tecnológico del CONICET. Las categorías de los Investigadores son las siguientes: Asistente, Adjunto, Independiente, Principal y Superior. En esta definición no se han incluido a los Investigadores extranjeros, Investigadores jubilados contratados, rentados o adhonorem, por no tratarse de formas estables de contratación. Tampoco se han incluido a los Investigadores Clínicos, por no contar con dedicación exclusiva a la Investigación.

-Personal de Apoyo: comprende a personas cuyo trabajo requiere conocimiento y experiencia de naturaleza técnica en uno o en varios campos del saber, brindando apoyo técnico calificado a grupos de investigación en la ejecución de los programas de investigación y desarrollo. Ejecutan sus tareas bajo la supervisión de un Investigador del CONICET.

Se incluyeron dentro de este grupo a los agentes de la Carrera del Personal de Apoyo del CONICET, distinguiendo entre las categorías generales de Profesional y Técnico.

-Personal Administrativo: Comprende personas dedicadas a tareas de conducción, coordinación y apoyo administrativo a las actividades Ciencia y Tecnología en todos sus niveles; tales como gerentes, directores y coordinadores, jefes de departamento, profesionales y expertos en temas de gestión, administrativos y de servicios generales.

Se incluyeron dentro de este grupo al Personal Administrativo de planta permanente (que forma parte del Escalafón del Sistema Nacional de Empleo Público), el personal contratado al amparo del Artículo 9 de la Ley de Empleo Público, personal contratado al amparo del Decreto $\mathrm{N}^{\mathrm{0}} 2.345$ y pasantes.

-Programa de Becas: comprende las becas financiadas por el Programa de Becas del CONICET, destinadas a realizar actividades de Investigación y Desarrollo bajo la dirección de un Investigador. La beca consiste en el pago de un estipendio mensual, el otorgamiento de cobertura de una ART y, en los casos que correspondan, la cobertura de obra social o el adicional por cobertura médico asistencial y el adicional por Familia. Las becas son de dos tipos:

Becas Doctorales: están destinadas a realizar un plan de investigación original que forma parte de su tesis de doctorado, con el fin de obtener el título de doctor. El CONICET ofrece becas para iniciar doctorados que duran 5 años.

Becas Posdoctorales: están destinadas a graduados con título de doctor y consisten en desarrollar un plan de investigación original supervisado por Investigadores. Las becas tienen una duración de 2 años.
} 
Por su parte, es de incumbencia del Directorio proyectar el presupuesto anual y cálculo de recursos del organismo. Designar, remover y sancionar al personal científico, técnico y administrativo, conforme a las leyes vigentes. Por otra parte, la disposición lo habilita a contratar científicos y técnicos, nacionales o extranjeros; celebrar y refrendar acuerdos, convenios y contratos referidos a sus objetivos y actividades; y asignar y otorgar recursos para el cumplimiento de sus fines, entre otros aspectos.

En lo que refiere a la fomento y ejecución de las actividades científicas y tecnológicas no es menor el lugar que le toca al orientar el apoyo, realizar y promover los lineamientos que establece actualmente Plan Nacional de Ciencia, Tecnología e Innovación "Argentina Innovadora 2020"50, impulsado por el Ministerio de Ciencia, Tecnología e Innovación Productiva de la Nación (cabe recordar que al ser el Decreto 1661 del año 1996, se ha modificado el organigrama del Estado Nacional, especialmente con la creación del Ministerio de Ciencia y Tecnología en diciembre del año 2007. El Decreto 021/2007 ${ }^{51}$ establece la modificatoria del 357/2002 a fin de reordenar las responsabilidades de distintas áreas del Poder Ejecutivo Nacional. En el mismo se establecen objetivos y responsabilidades de las Secretarías y Subsecretarías que componen el Ministerio de Ciencia, Tecnología e Innovación Productiva). En este orden debe asegurar que las mismas cumplan con los requisitos de calidad, mérito y pertinencia que define el organismo.

Los instrumentos de promoción de la investigación científica y tecnológica impulsados por la institución corresponden a becas, pasantías o apoyos para la ejecución de tareas de investigación y desarrollo que puedan efectuarse en el país o en el exterior. Estos instrumentos involucran a las carreras del Investigador Científico y Tecnológico y del Personal de Apoyo a la Investigación y Desarrollo.

Entre otras fines se encuentra el de brindar el apoyo con subsidios para desarrollar tareas de investigación y desarrollo, edición y/o adquisición de publicaciones, realización de reuniones científicas y adquisición de bienes. Quedando a juicio del Directorio otras tareas que sean convenientes para el cumplimiento de sus objetivos.

\footnotetext{
${ }^{50}$ Disponible en: http://www.argentinainnovadora2020.mincyt.gob.ar/

${ }^{51}$ Disponible en: http://www.mincyt.gob.ar/legislacion
} 


\section{Estructura administrativa}

En lo que refiere a la estructura administrativa ${ }^{52}$ la misma se conforma con 6 gerencias (cada una cuenta con direcciones a su cargo), 2 direcciones y una Auditoría Interna que dependen de la presidencia ${ }^{53}$. Las gerencias y direcciones tienen un rol central con intereses y visiones en lo organizacional dispuestos desde las políticas que impulsa el Directorio (ver gráfico al final: Organigrama del CONICET).

A su vez, las direcciones de los 14 Centros Científicos y Tecnológicos $(\mathrm{CCT})^{54}$ y $\operatorname{los} 2$ centros multidisciplinarios (Centro Nacional Patagónico -CENPAT- y Centro Austral de Investigaciones Científicas - CADIC) ${ }^{55}$ orientan su tarea en la consolidación del entramado institucional generando aportes a la eficacia y legitimidad de los lineamientos de gestión institucional impulsados por el Directorio (ver gráficos a continuación: Organigrama de los CCT; Distribución de Agentes en CONICET y otros organismos).

Los 14 CCT administran actualmente a las 226 Unidades Ejecutoras (UE) ${ }^{56}$ que, en un $90 \%$, son de doble dependencia con Universidades Nacionales tanto públicas como privadas ${ }^{57}$ con las cuales el CONICET tiene convenios.

\footnotetext{
${ }^{52}$ La estructura administrativa está integrada por: la gerencia de Administración y direcciones de Presupuesto, la Unidad de Control y Contabilidad; la gerencia de Asuntos Legales y las direcciones de Asuntos Legales, Control Legal y Técnico, y Sumarios; la gerencia de Desarrollo Científico y Tecnológico, y las direcciones de Desarrollo y Gestión de Unidades Divisionales, y de Convenios y Proyectos; la gerencia de Evaluación y Planificación, y las direcciones de Planificación y Evaluación Institucional, de Coordinación de Órganos Asesores, y una Coordinación General; la gerencia de Recursos Humanos, y las direcciones de Administración y Recursos Humanos, Desarrollo de Recursos Humanos, y una Coordinación de Becas; la gerencia de Organización y Sistemas, y las direcciones de Informática, de Ingeniería de Procesos, de Gestión de Usuarios y Red; y las direcciones de Vinculación Tecnológica y Social, Relaciones Institucionales, y la Unidad de Auditoría Interna, estas tres dependientes directamente de la presidencia del CONICET)

${ }^{53}$ El 29 de marzo del año 2007 se aprobó la estructura organizativa del CONICET, mediante el Decreto 310/2007.

${ }^{54}$ Los Centros Científicos y Tecnológicos (CCT) son: Santa Fe (año de creación 2006), Rosario (2007), Tucumán (2007), Bahía Blanca (2007), Mendoza (2007), Córdoba (2007), La Plata (2007), San Luis (2008), Patagonia Norte (2009), Mar del Plata (2009) Nordeste (2009), Salta (2010), Tandil (2013), y San Juan (2014).

${ }^{55}$ Los Centros de Investigación Multidisciplinarios fueron creados por el CONICET respondiendo a la necesidad de impulsar el desarrollo del conocimiento científico a escala regional, en áreas de vacancia geográfica. Están integrados por grupos de investigación pertenecientes a varias disciplinas.

${ }^{56}$ Las Unidades Ejecutoras (UE) del CONICET están integradas en red. Tal como se las define, su estructura se conforma en base a las asociaciones de investigadores, situados en diferentes lugares de trabajo y vinculados por una temática científica común que llevan adelante mediante soportes informáticos adecuados e interacción directa periódica. Las UE se conforman con el propósito de llevar adelante planes científicos y tecnológicos vinculantes y formar recursos humanos en su especialidad. Cada lugar de trabajo se constituye en un nodo de la UE en red.

La Institución también cuenta con Centros de Servicios, como es el caso del Centro Argentino de Información Científica y Tecnológica (administrado por el CONICET) y el Complejo Astronómico "El Leoncito" compartido con las Universidades Nacionales de La Plata, Cuyo y San Juan. Se trata de son instalaciones equipadas con tecnología acorde a los procesos que desarrollan y recursos humanos capacitados para brindar servicios científico-tecnológicos especializados a usuarios internos y externos al organismo.

${ }^{57}$ Listado de Universidades de gestión estatal con las que se vincula el CONICET (con la mayoría comparte la doble dependencia de UE y Centros de Investigaciones y Transferencias (CIT)): Universidad de Buenos Aires, Universidad Nacional Arturo Jauretche, Universidad
} 
Nacional de Avellaneda, Universidad Nacional de Catamarca, Universidad Nacional de Córdoba, Universidad Nacional de Cuyo, Universidad Nacional de Chilecito, Universidad Nacional de Entre Ríos, Universidad Nacional de Formosa, Universidad Nacional de General San Martín, Universidad Nacional de General Sarmiento, Universidad Nacional de José Clemente Paz, Universidad Nacional de Jujuy, Universidad Nacional de la Matanza, Universidad Nacional de la Pampa, Universidad Nacional de la Patagonia Austral, Universidad Nacional de la Patagonia, Universidad Nacional de la Plata, Universidad Nacional de la Rioja, Universidad Nacional de Lanús, Universidad Nacional de Lomas de Zamora, Universidad Nacional de Luján, Universidad Nacional de Mar del Plata, Universidad Nacional de Misiones, Universidad Nacional de Moreno, Universidad Nacional de Quilmes, Universidad Nacional de Río Cuarto, Universidad Nacional de Río Negro, Universidad Nacional de Rosario, Universidad Nacional de Salta, Universidad Nacional de San Juan, Universidad Nacional de San Luis, Universidad Nacional de Santiago del Estero, Universidad Nacional de Tierra del Fuego, Antártida e Islas del Atlántico Sur, Universidad Nacional de Tres de Febrero, Universidad Nacional de Tucumán, Universidad Nacional de Villa María, Universidad Nacional de Villa Mercedes, Universidad Nacional del Centro de la Provincia de Buenos Aires, Universidad Nacional del Chaco Austral, Universidad Nacional del Comahue, Universidad Nacional del Litoral, Universidad Nacional del Nordeste, Universidad Nacional del Noroeste de la Provincia de Buenos Aires, Universidad Nacional del Oeste, Universidad Nacional del Sur, Universidad Tecnológica Nacional, Facultad Latinoamericana de Ciencias Sociales - Sede Argentina, Universidad de Bologna - Sede Buenos Aires, Universidad Popular de Madres de Plaza de Mayo.

- Listado de Universidades de gestión privada con las que se relaciona el CONICET: Universidad Atlántida Argentina, Universidad Austral, Universidad CAECE, Universidad del CEMA, Universidad Gastón Dachary, Universidad Favaloro, Universidad ISALUD, Universidad Argentina John F. Kennedy, Universidad de Congreso, Universidad Maimónides, Universidad de Palermo, Universidad del Salvador, Universidad Argentina de la Empresa, Universidad Abierta Interamericana, Universidad Adventista del Plata, Universidad de Belgrano, Universidad Blas Pascal, Pontificia Universidad Católica Argentina, Universidad Católica de La Plata, Universidad Católica de Salta, Universidad Católica de Córdoba, Universidad Católica de Cuyo, Universidad del Centro Educativo Latinoamericano, Universidad de Ciencias Empresariales y Sociales, Universidad Champagnat, Universidad del Cine, Universidad de Congreso, Universidad de la Cuenca del Plata, Universidad Católica de Santiago del Estero, Universidad Católica de Santa Fe, Universidad de Concepción del Uruguay, Universidad del Aconcagua, Universidad del Este, Universidad de la Marina Mercante, Universidad Empresarial Siglo 21, Universidad del Norte Santo Tomás de Aquino, Universidad de Flores, Universidad de Mendoza, Universidad Juan Agustín Maza, Universidad del Museo Social Argentino, Universidad de Morón, Universidad Notarial Argentina, Universidad de la Fraternidad de Agrupaciones Santo Tomás de Aquino, Universidad de San Pablo - Tucumán, Universidad Torcuato Di Tella, Universidad de San Andrés. 


\section{Distribución de Agentes en CONICET y otros organismos}

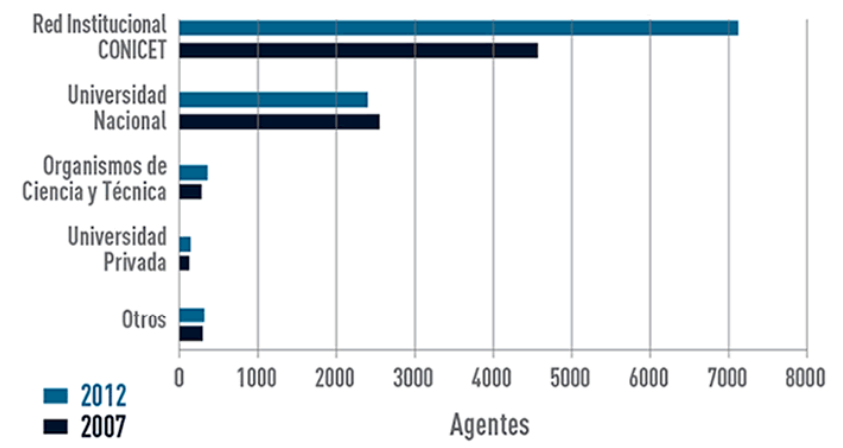

\section{CONICET}

\section{Universidades}

\section{Organismos de Ciencia y Técnica}

El 90\% de los centros del CONICET son de doble dependencia con Universidades Nacionales

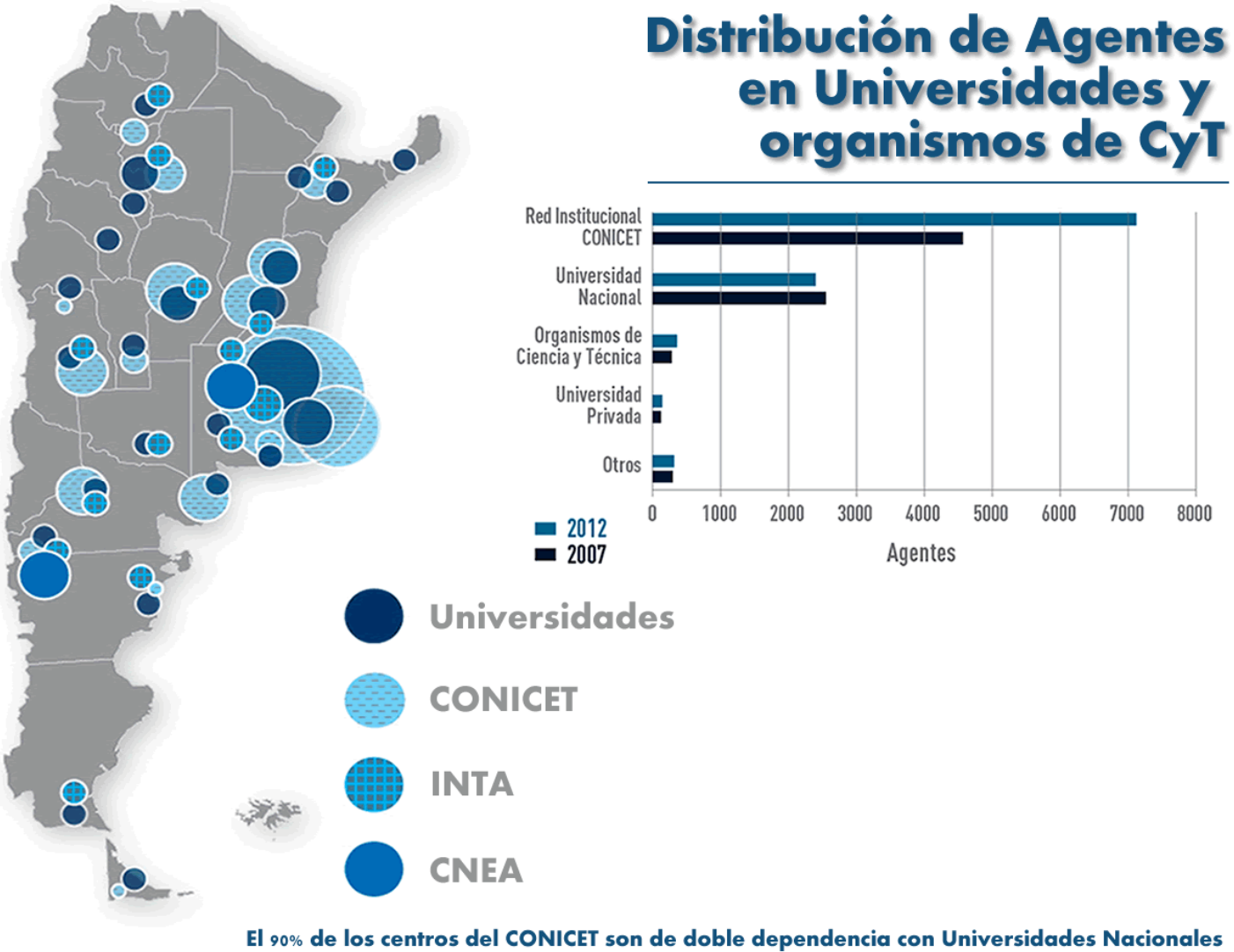


El objetivo primordial de los CCT es asegurar espacios apropiados para la ejecución de investigaciones científicas, tecnológicas y de desarrollo en el espacio físico y de influencia en el marco de sus competencias. Los CCT cumplen la función de contribuir a interrelacionar las UE y a los grupos de investigación en la zona de su inserción; también tienen la misión de brindar servicios de apoyo prioritario a las UE y a los grupos de investigación que están formalmente vinculados así como también a terceros, junto a otros fines como son el de articular y mantener relaciones de cooperación y difusión con la comunidad.

Otros alcances de los CCT se orientan a la posibilidad de promover la constitución de parques tecnológicos o incubadoras de empresas que posibiliten la interacción con el sector productivo de bienes y servicios.

A la conformación de la Red Institucional se suman unidades asociadas y en red y centros de servicios con contrapartes de fundaciones, institutos nacionales e internacionales, gobiernos provinciales y ministerios del Estado Nacional. 

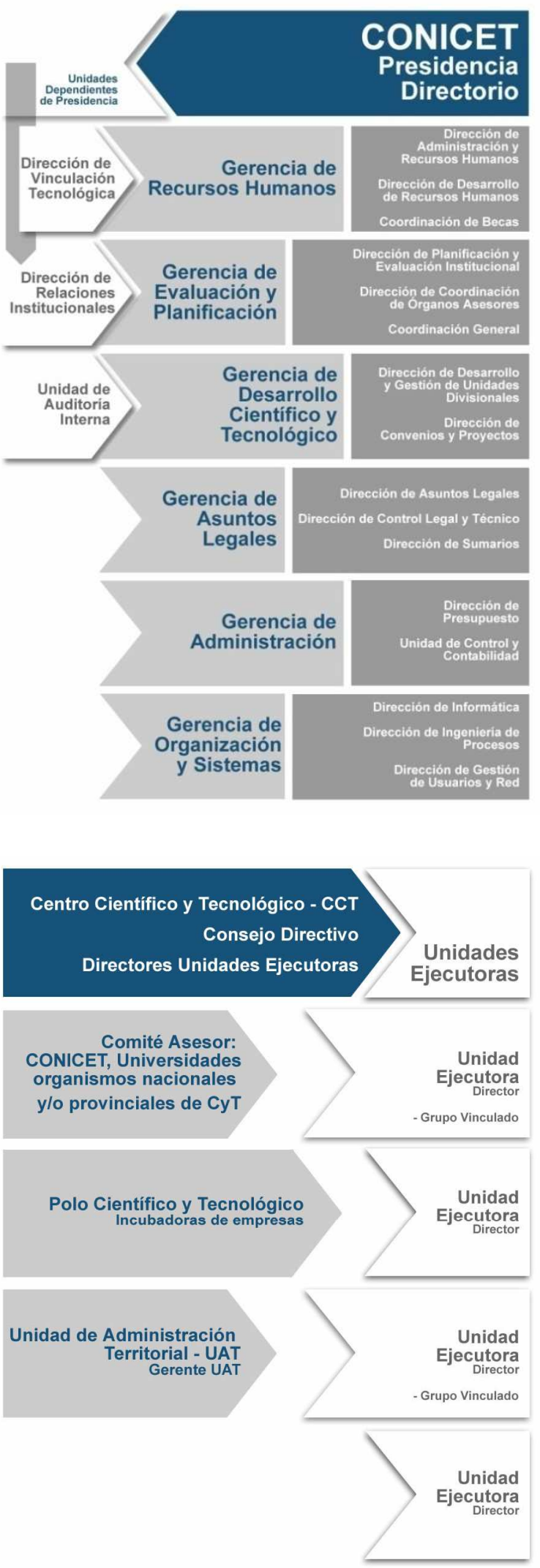


\section{Frente al cambio y la permanencia}

Es oportuno exponer cómo se llega a un conocimiento articulador de prácticas profesionales en función de propiciar nuevas relaciones, despliegue de estrategias y tácticas variadas según la pertinencia y participación en el campo y sus diferentes condicionamientos $\mathrm{y}$ constituciones.

En un primer término asumir que cuando se habla de la comunicación la idea de sustentabilidad no puede estar ausente pues solo desde esa perspectiva adquiere sentido en el largo plazo. Por otro, considerar que las estrategias y los componentes propuestos y desarrollados responden y deben ser válidos a los aspectos centrales de la Institución para atender el nivel de investigación y desarrollo, transferencia, vinculación tecnológica y social.

Es frente a la realidad social como fenómeno complejo, que el comunicador inserto en un sistema de prácticas y saberes, discursos y tradiciones que constituyen su identidad, puede o no constituir su práctica sistemáticamente y de acuerdo a lógicas de intervención y gestión institucional. Inserto en esta complejidad puede acceder a que la institución lo atraviese en el sentido sobre la práctica y su lugar, o pensar en su complejización y ruptura desde una epistemología que ahonde en la crítica y la ruptura en un hecho que implica una vigilancia epistemológica para poder proceder socialmente.

El desafío es pensar en la complejización y reconstrucción de su función y no aceptar lo dado como natural, generando sus prácticas sobre interrogantes que le permitan centrar su lugar en la construcción de la relación: conocimiento articulador y prácticas profesionales. 


\section{Reconocimiento de redes y mecanismos institucionalizados}

Comprender la estructura y la dinámica institucional facilita el aprendizaje organizacional, lo cual supone procesamiento social de la información, de la cultura institucional, de metas, estructuras, estrategias y ambientes. Desde esta perspectiva el reconocimiento de los procesos institucionales, en tanto sociales, identificados a partir de la Red Institucional han jugado un papel central para llevar adelante la aplicación de todas las herramientas e instancias impulsadas desde la DRI.

\section{Red Institucional}

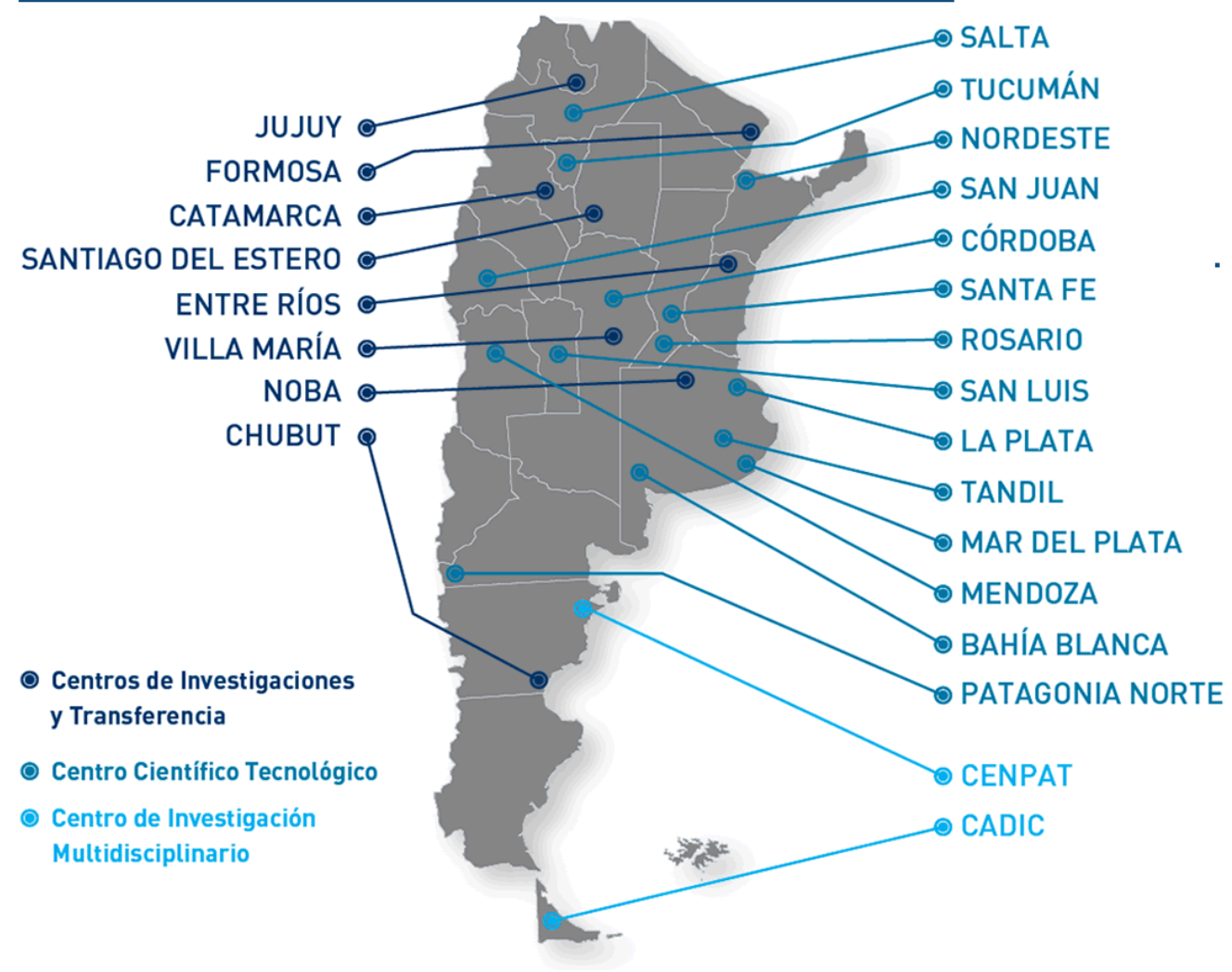


La Red es definida por la Institución como "modelo territorial descentralizador", es decir, ámbitos propicios para la generación de iniciativas regionales y de representación local, descentralización administrativa y más eficiente instrumentación de políticas a nivel nacional. Este último aspecto será considerado cuando se aborden la vinculación de la DRI y los CCT.

\section{Enfoques y estrategias hacia una nueva realidad comunicacional}

Es evidente que para lograr plasmar enfoques y estrategias fue necesario trabajar por un lado en la innovación de procesos (se podrá señalar al final de la lectura de la tesis si se trató de una innovación en el ámbito de la organización con el consiguiente impacto y consolidación que puede tener en la imagen institucional) hasta el momento inexistentes y en el rediseño de los procesos ya existentes, buscando simplificarlos al darles un funcionamiento ágil, eficaz y eficiente en la institución, y asumiendo el concepto de calidad en la confección de productos y materiales periodísticos; por otro, y no menor, en el fortalecimiento de las tecnologías de la información y comunicación que se encontraban en un nivel incipiente de desarrollo ${ }^{58}$.

Asumidos objetivos, modos de actuación y resultados también fue preciso estudiar, proponer e implementar cambios en el cotidiano de las actividades comunicacionales fijadas en la Dirección y los CCT. El desafío estuvo centrado en asumir la complejidad y actuar en consecuencia, desde el lugar de la producción pero también de las evaluaciones y concepciones. Porque no es posible simplificar todas las instancias de manera lineal, ya que es preciso funcionar en el marco de las directrices institucionales pero considerando estudiar, proponer e implementar cambios en el cotidiano de las actividades; cambios que inevitablemente intervienen en lo que ya venía funcionando en las estructuras comunicativas pero que a su vez buscan comprender los sentidos de los procesos que producimos cotidianamente. Hecho en sí que plantea o se pone necesariamente en contradicción con lo que generan otros actores por lo que aquello que construimos afecta necesariamente las relaciones con otros y con el conjunto social.

\footnotetext{
${ }^{58} \mathrm{La}$ introducción a este marco requiere de una primera salvedad en cuanto a la DRI. Previo a lo que se destaca en el estudio como recorte espacio-temporal, se había formalizado un año antes el funcionamiento de la Dirección con la designación de un director. De esta etapa no se han podido recuperar elementos y documentos para el diagnóstico y todo aquello que se integra son las lecturas analizadas de las publicaciones hechas en la página web oficial del organismo.
} 
Se trata de asumir que la práctica comunicacional produce conocimientos y juicios de valor sobre el conjunto de la institución tanto más como sobre los aspectos particulares del comunicador. La articulación entre teoría y práctica realimenta las dimensiones y los vínculos sociales al tiempo que refundan prácticas y saberes.

El tiempo transcurrido, las experiencias, los recorridos, los resultados, los diálogos, las disputas y las nuevas propuestas, configuraron un escenario de maduración del conjunto de los actores para marcar una nueva instancia. En esta se sintetiza el necesario consenso sobre las modificaciones, las reafirmaciones, las continuidades y los nuevos vínculos que se instalaron desde la DRI.

Para consolidar el logro de los objetivos institucionales si bien es necesario considerar estrategias y concentrar esfuerzos poniendo el foco en la producción de impactos significativos en la producción comunicacional, también lo es crear un equipo de trabajo que pueda desarrollar una modalidad de prácticas comunicacionales y periodísticas y que, a la vez, interprete el avance del conocimiento que produce un permanente cambio de fronteras $\mathrm{y}$, por lo tanto, en investigación y desarrollo.

Por tanto, ese equipo de trabajo requiere anticiparse y desarrollar capacidades en áreas del conocimiento científico donde emergen temas de interés tanto para la sociedad como para el interés del periodismo y del periodismo especializado -científico.

En ese orden, necesariamente es oportuno referir a que el desarrollo propuesto a nivel de esta dirección, referido a la participación en la estructura institucional, constituye un promisorio campo para la investigación, la formulación de nuevas preguntas acerca de la realidad comunicacional de ésta y de otras instituciones de ciencia y tecnología como en la provisión de respuestas a viejos y nuevos problemas y a las crecientes necesidades que convergen en este espacio.

Esta tesis no es un punto de llegada sino de partida para aquellos comunicadores que se desempeñan en instituciones y deben priorizar la conformación de una estructura destinada a brindar respuestas a los cambios y las demandas institucionalizadas.

No alcanza con el reconocimiento permanente del contexto y la lectura de las perspectivas fijadas en el plan de acción. Sino que es necesario entender cómo a partir de las herramientas 
y componentes se definen y llevan adelante objetivos para aportar sostenibilidad a la instrumentación de las líneas de acción del organismo, hecho que requiere del profundo involucramiento e intervención institucional desde el lugar de entendimiento y realidad de las prácticas y del investigador en comunicación.

Desde este enfoque, las herramientas que fueron diseñadas son el resultado y emergente de permanentes procesos de evaluación orientados a mejorar la programación de funciones y desempeños, la gestión frente a los cambios de escenarios y la modificación de contextos. Pero para que esto sea posible es el comunicador/productor/investigador quien debe establecer relaciones, integrar conocimientos, generar reflexividades, movimientos y nuevas modalidades, rupturas y desafíos dentro de la institución para generar indagaciones a la vez que responder a las problematizaciones y sus consecuencias.

\section{Problematizar las prácticas en comunicación institucional}

Producto del proceso de enseñanza/aprendizaje y del diálogo propiciado durante el recorrido curricular y los antecedentes evaluados en la Maestría de Planificación y Gestión de los Procesos Comunicacionales (PLANGESCO), se buscó "construir conocimientos y lograr aportes de docentes y maestrandos a la problemática de la planificación y gestión de la comunicación en diversas instituciones y prácticas sociales en el país y América Latina. Para ello se trabaja sobre la base de un modelo pedagógico centrado en el interaprendizaje, la multidisciplina y la transdisciplina" ${ }^{59}$.

Bajo la propuesta de sistematizar los conocimientos en materia de planificación y gestión de la comunicación a través de la investigación operativa, recorrido curricular donde además se facilitó el vínculo con otras disciplinas bajo una mirada enriquecedora para complementar la necesidad de planificar y gestionar prácticas, proyectos y procesos de comunicación en el

\footnotetext{
59 "La Formación de Posgrado de la Facultad de Periodismo y Comunicación Social de La Plata". Boletín № 7 de la Asociación Latinoamericana de Investigación de la Comunicación (ALAIC). Año II, Noviembre de 2002.

Disponible en: http://www.eca.usp.br/associa/alaic/boletin7/poslaplata.htm
} 
marco de la realidad sociocultural latinoamericana, es que se decidió producir esta investigación enmarcada en un estudio de caso.

Se trata pues de un esfuerzo por contribuir al intercambio en función de la producción de procesos comunicacionales $^{60}$. Y como resultante surgen un conjunto de consideraciones y reflexiones donde el mayor reto está en asumir que lo hecho, como práctica y gestión de la comunicación institucional, a partir de implementar estrategias y herramientas de orden comunicacional, presenta un enfoque para ser analizado e interpretado bajo la premisa y la necesidad de conocer dichas prácticas y a los sujetos que las protagonizan. En definitiva se trata de comprenderlas, caracterizarlas, sistematizarlas y poder actuar sobre ellas.

Frente al caso, en el marco de un espacio de reflexión y análisis, se integran nuevos saberes a través de orientaciones profesionales y técnicas destinados a favorecer las prácticas y las articulaciones intrainstitucionales, fortalecer la comunicación externa, promover la generación de proyectos y producciones, siempre desde el reconocimiento de las realidades sociales, territoriales y productivas del CONICET.

Con el fin de pensar e integrar los desarrollos de esta investigación situada en el caso de la Dirección de Relaciones Institucionales del CONICET, se concibe este trabajo en tanto propuesta que gira en torno al entendimiento de la comunicación en la institución, desde un rol activo que facilita la formulación de políticas comunicacionales, nuevas dinámicas y procesos desde una mirada puesta en las experiencias, así como en los modos de vinculación e incidencia de los procesos socioeconómicos, históricos y políticos en los que está inmerso el CONICET.

Sobre esto último es necesario entender que la comunicación es un fenómeno histórico, situacional, complejo que busca construir y deconstruir relaciones y a la vez comprender el sistema de conceptos de la situación comunicacional en cuestión aquí presentado.

Esto permite vincular, desde el campo específico comunicacional, bajo un hilo histórico, articulaciones y desarrollos de etapas posibles que evidencian una aproximación innovadora sobre los desafíos que presentaba el CONICET y que dieron lugar a la intervención concreta.

\footnotetext{
${ }^{60}$ Las experiencias docentes en el Seminario Permanente de Tesis (2002 en adelante), en el grado, y en Periodismo Ambiental (2010 en adelante), de la Especialización en Comunicación y Ambiente, cátedras de la Facultad de Periodismo y Comunicación Social de la UNLP, así como el lugar de investigación desarrollado en diversos proyectos y en el Instituto de Investigaciones en Comunicación (IICOM), conforman los diferentes procesos en cuanto a mi formación docente, las capacitaciones y actualizaciones realizadas pero, especialmente, en torno a los rasgos de mi perfil profesional.
} 
La decisión institucional a partir de 2013 de abrir convocatorias en temas estratégicos identificados en el Plan Nacional de Ciencia, Tecnología e Innovación Productiva 2012-2015 (PNCTI) del Ministerio de Ciencia, Tecnología e Innovación Productiva de la Nación, para el acceso al Programa de Becas y Carrera del Investigador Científico, marca un cambio frente a la libre elección de temas vigente a partir de la pregunta libre que se hacía el investigador como el tesista. Esto tuvo un impacto no solo desde el aspecto social y productivo sino en la comunicación de temas e identificación como involucramiento activo en proyectos de alto impacto para el desarrollo del país.

Las grandes áreas identificadas como de desarrollo prioritario en el PNCTI son: Sector Agroindustria que orienta la investigación en Producción de alimentos, Agricultura Familiar, y Producción y procesamiento de recursos forestales; Sector Energía e Industria: Biorrefinerías, Uso Racional de Energía, Generación y acumulación de energía y sistemas de distribución, Tecnologías para el petróleo y gas, Autopartes y motopartes, Impresión 3D y microelectrónica; Sector Salud: Enfermedades infecciosas, Fitomedicina, Biosimilares y producción pública de medicamentos, Biosimilares y producción pública de medicamentos, Biosimilares y producción pública de medicamentos, Enfermedades crónicas, con componentes multigénicos y asociadas a adultos, Bioingeniería aplicada a la medicina regenerativa; Sector Ambiente y Desarrollo Sustentable: Sistema de información asociados al cambio climático y servicios meteorológicos, Manejo de Recursos Hídricos, Remediación ambiental, Reciclado de distintas corrientes de residuos; Sector Desarrollo y Tecnología Social: Grandes Datos (Big Data) e Informática, Hábitat, Política y gestión de la ciencia, tecnología e innovación, Desarrollo social y productivo.

Otros importantes herramientas -instrumentos de financiamiento- se orientaron en promover una mayor comprensión y atención de problemáticas y desafíos que afronta el país en las distintas dimensiones de su proceso de desarrollo. Los Proyectos de Investigación Orientada (PIO) posibilitaron una activa vinculación con diversos organismos y agentes de gestión pública y privada por impulsar soluciones concretas en áreas de interés común.

Los espacio de evaluación de la actividad de transferencia en el marco de los Proyectos de Desarrollo Tecnológico y Social (PDTS) también acompañan el desarrollo de la ciencia y la tecnología. A partir del acuerdo alcanzado por las instituciones del Sistema Nacional de Ciencia, Tecnología e Innovación, las universidades y el Ministerio de Ciencia, Tecnología e 
Innovación Productiva, se propició un nuevo espacio de evaluación de informes para aquellos investigadores de la Carrera del Investigador Científico (CIC), disponible también para becarios postdoctorales, que realizan actividades de desarrollo y transferencia de conocimientos en el marco del PDTS. Esta nueva modalidad se presentó como una nueva posibilidad accesible para todos los investigadores y becarios del CONICET y del SCN así como un nuevo espacio de evaluación de la actividad de transferencia negada hasta ese momento. 


\section{CAPÍTULO IV}

\section{Políticas públicas y fortalecimiento de la comunicación}

Visto este desarrollo alcanzado en los últimos años producto de las políticas públicas dispuestas por el Estado Nacional para el sector científico y tecnológico, lo ubica al CONICET como la principal institución de ciencia y tecnología del país.

Estas dimensiones y su crecimiento alcanzado sumado a una decisión ministerial de fortalecer la comunicación del organismo que se encuentra bajo su órbita, fueron algunos de los motivos que dieron lugar a intervenir desde la comunicación, en tanto posibilidad de: poner en discusión, observar y caracterizar la concreción y aplicación de herramientas comunicacionales (cuyos causas y consecuencias y modalidades deben leerse, de modo indisociable, en los procesos de orden y de producción científica y tecnológica).

A su vez, el interés que representa poder expresar los modos de inserción y el rol de los comunicadores sociales en el entramado institucional en un organismo como el CONICET, permite reflejar el proceso instalado como la política comunicacional en la organización en el período 2012-2014.

Desde este lugar que hace al entendimiento de lo actuado, sobre lo cual se establece un recorrido con las diferentes instancias que serán presentadas y abordadas a continuación, es que fue posible formular no solo una estructura de gestión de la comunicación sino plasmar un recorrido como un desafío al pensarlo, al ponerlo en marcha y al lograr resultados concretos. A la vez que también permite pensar el papel del comunicador ${ }^{61}$ en el marco de un proceso de aprendizaje conjuntos en situaciones y en acciones concretas desde la práctica profesional, ya sea por lo gestado y por los matices que resultan sobre lo actuado.

\footnotetext{
${ }^{61}$ El sociólogo brasileño Renato Ortiz, en su libro "Taquigrafiando lo social", Siglo Veintiuno Editores (2004), destaca que los elementos ideológicos se insinúan a todo momento y deben ser controlados mediante una vigilancia epistemológica permanente. Destaca que es imposible no reconocer ese aspecto ya que es el que permite el avance de las ciencias sociales. Y agrega que el trabajo del investigador es ambivalente y por lo tanto se nutre del rigor y el control científico y una vinculación visceral con las cosas del mundo. Resta destacar que el concepto de "vigilancia" de Ortiz es análogo al desarrollado por Pierre Bourdieu en el concepto de "vigilancia epistemológica". Respecto a este último, es abordado en BOURDIEU, Pierre, CHAMBOREDON, Jean Claude y PASSERON Jean Claude (1990). "El oficio del sociólogo". México, Siglo Veintiuno.
} 
Desde este punto de vista, es pertinente tomar consciencia sobre este espacio y otros similares y referir a que no se trata solo de procesos, puentes, cauces, espacios, equipos, gerenciamiento, investigadores, profesionales y técnicos de apoyo a la investigación, administrativos y becarios; como de centros, unidades, proyectos y programas, funciones y estructuras, normativas; sino que todo lo anterior es indispensable para planificar estrategias comunicacionales partiendo de imaginar una situación deseada con un conjunto de actores que deciden, concreten y, sobre todo, se permiten imaginar para poder crear.

Esta aproximación acerca a pensar la comunicación que se inicia sobre un recurrente proceso que, por un lado, es base para repensar y elaborar propuestas de comunicación, y por el otro hablar de diagnóstico, planificación, gestión y evaluación y que -centralmente- da impulso para considerar su escritura.

La evolución de la que se da cuenta implica una metodología que por su propia dinámica ha tenido a lo largo de este tiempo una serie de redefiniciones, de problemáticas y acercamientos a las instancias y herramientas propuestas desde la comunicación, las cuales se enuncian conscientemente sobre las problemáticas y acercamientos pendientes, y virajes necesarios para llevar adelante la gestión de la dirección.

Para comprender este desarrollo es preciso interpretar que este trabajo se delineó y se planteó en una institución científica que parte de una serie de definiciones y delimitaciones iniciales para la DRI, con objetivos de comunicación para la jerarquización de un área cuyos límites entre un interior y un exterior habían sido definidos anteriormente pero no llevados a la práctica.

Este primer desafío marcó una frontera para las actividades, los roles y la fijezas, pero necesariamente planteó desde la disciplina una función reflexiva y esencial sobre el saber, sobre las experiencias y sobre la necesidad de intervención y cambio que el contexto interno y externo requería.

En este propósito anidaba la necesidad de potenciar la capacidad comunicacional de la institución en todo el país, dada su extensa Red Institucional ${ }^{62}$. Su antecedente más cercano

\footnotetext{
${ }^{62}$ La Red Institucional del CONICET está integrada por 14 Centros Científicos y Tecnológicos (CCT), 2 Centros de Investigación Multidisciplinarios (CADIC y CENPAT), 8 Centros de Investigaciones y Transferencia (CIT), y 226 institutos y centros de investigación.
} 
refería a la creación de la dirección ${ }^{63}$ y a primeros pasos que se habían dado en ese sentido a mediados de 2010. Además, contemplaba un punto de partida centrado en la articulación entre los actores de la organización sobre diversos roles orientados y definidos, hecho que sirvió como puntal para dar cuenta de la posición desde la cual enunciar y pensar la organización de la dirección.

A partir de estas y otras definiciones alcanzadas, se establecieron 5 herramientas o componentes centrales: Comunicación Pública; Comunicación Científica y Tecnológica; Eventos, Ceremonial y Protocolo; Relaciones con la Comunidad; y Comunicación Audiovisual.

Estos componentes son considerados herramientas dirigidas a promover y difundir las acciones producto de las instancias de gestión de las políticas institucionales, la investigación, los desarrollos y la transferencia e innovación en tecnología; pero también las que tienden a aportar conocimiento a escala local, regional, nacional e internacional dado el alcance de la institución. Frente a este desafío, estas 5 herramientas son consideras claves para plantear oportunidades orientadas al desarrollo y al cambio de la gestión de la comunicación institucional del CONICET.

\section{La comunicación institucional}

En lo referente a la comunicación institucional y al período señalado en el CONICET, la intención es interpretar el modo en que se diseñó y plasmó un esquema de trabajo que apeló a repensar las relaciones institucionales enfocadas en la comunicación y en la resolución de las

\footnotetext{
${ }^{63}$ El Decreto 310/2007 del Consejo Nacional de Investigaciones Científicas y Técnicas (CONICET), establece hasta la fecha la estructura organizativa para el citado organismo descentralizado dependiente de la Secretaría de Ciencia, Tecnología e Innovación Productiva del Ministerio de Educación, Ciencia y Tecnología. Actualmente, y debido a la creación del Ministerio de Ciencia, Tecnología e Innovación Productiva en diciembre de 2007, el CONICET queda enmarcado bajo su órbita.

Disponible en: http://web.conicet.gov.ar/documents/11716/0/Decreto+310+de+2007.pdf

Es preciso destacar que el Decreto $\mathrm{N}^{\mathrm{o}} 1661$, del 27 de diciembre de 1996, establece las misiones y funciones, conducción, gestión y control, fomento y ejecución de las actividades científicas y tecnológicas del CONICET.

Disponible en: http://web.conicet.gov.ar/documents/11716/0/Decreto+1661+de+1996.pdf
} 
necesidades existentes en este organismo que integra el Sistema Nacional de Ciencia, Tecnología e Innovación (SNCTI) ${ }^{64}$.

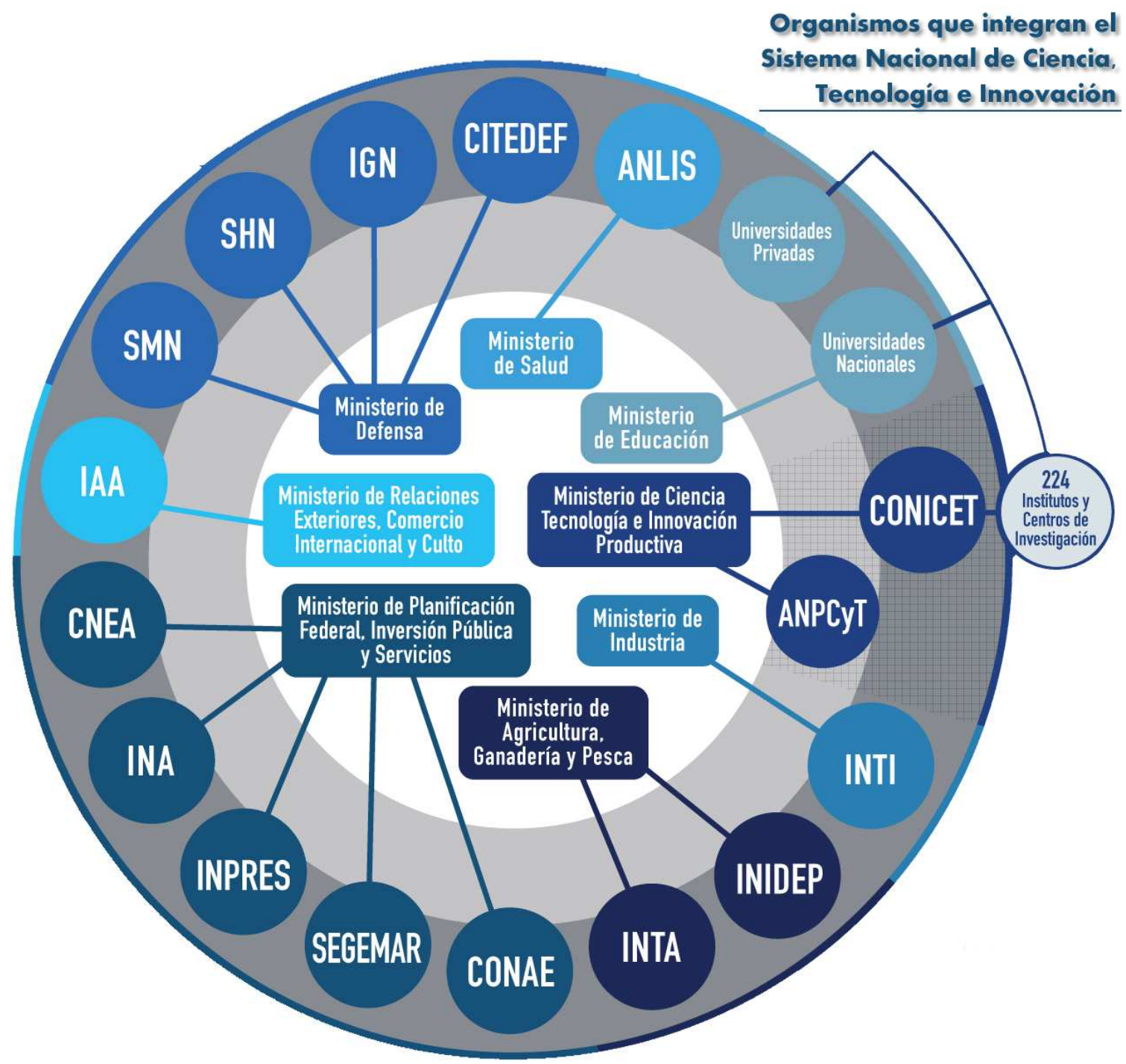

Esta experiencia generada parte de un primer supuesto donde se interpreta que la comunicación dejó de ser una cuestión de técnica, de medios como instrumentos, para transformarse en dimensión constitutiva de las prácticas sociales. En segundo lugar, al hablar

\footnotetext{
${ }^{64}$ Los organismos que integran el Sistema Nacional de Ciencia, Tecnología e Innovación son: Consejo Nacional de Investigaciones Científicas y Técnicas (CONICET), el Consejo Interuniversitario Nacional (CIN), la Comisión Nacional de Evaluación y Acreditación Universitaria (CONEAU) y el Consejo de Rectores de Universidades Privadas (CRUP). También lo hicieron organismos del sistema científico nacional como el Instituto Nacional de Tecnología Industrial (INTI), el Instituto Nacional de Tecnología Agropecuaria (INTA), la Comisión Nacional de Energía Atómica (CNEA), la Comisión Nacional de Actividades Espaciales (CONAE), el Instituto Nacional del Agua (INA), el Instituto de Investigaciones Científicas para la Defensa (CITEDEF), la Administración Nacional de Laboratorios e Institutos de Salud (ANLIS), el Instituto Nacional de Investigación y Desarrollo Pesquero (INIDEP), el Servicio Geológico Minero Argentino (SEGEMAR), el Instituto Antártico Argentino (IAA), la Secretaría de Políticas Universitarias (SPU) del Ministerio de Educación y la Comisión de Investigaciones Científicas (CIC) de la provincia de Buenos Aires.
} 
de comunicación es insoslayable la pregunta acerca de alcanzar la reflexividad ${ }^{65}$ de nuestras propias prácticas.

Nos adentramos en describir y dar cuenta de una noción de caso donde se abrieron caminos de planificación, intervención, gestión y desarrollo ${ }^{66}$ de la comunicación para no solo comenzar a situar respuestas, sino las condiciones culturales históricas, sociales y como la dimensión simbólica presente en las prácticas que crean la posibilidad de análisis, desde una mirada donde aparecen nuevas referencias sobre la apropiación de herramientas planteadas, las ausencias y los desvíos generados durante el proceso planteado.

Surge aquí una primera aseveración al hablar del caso que se presenta y de la experiencia realizada: existió un proceso de comunicación trascendente que favoreció los cambios y sobre el cual es posible describir herramientas y recursos empleados que le asignan sentido. Partiendo de esta aseveración, al abordar esta complejidad hemos tenido que tomar en cuenta que nuestra noción de comunicación atiende y da por comprendido que hablamos de una estructura de relaciones donde acontece la producción social de sentido.

Resta afirmar, en virtud de señalar lo comprendido durante el desarrollo de la Maestría PLANGESCO, que la comunicación puede ser vista como un acto social fundamental, fruto de la experiencia compartida, del diálogo y del intercambio entre las personas, entendido como un proceso de significación y de producción de sentido.

En cuanto a la importancia el caso analizado, hasta el año 2012, lo actuado se fundamentaba más en la recurrente mirada comunicacional que limitó la comunicación a los medios e hizo perder de vista gran parte de la experiencia comunicacional que trasciende los medios y las técnicas y que nos habla de los modos de relacionamiento entre las personas y entre los actores sociales. Pero sobre todo nos ha impedido un reconocimiento más claro y directo de lo comunicacional que se constituye en el espacio de las prácticas sociales y de las

\footnotetext{
${ }^{65}$ Aquí el concepto de reflexividad, tal como lo presenta Rosana Guber en "La etnografía, método, campo y reflexividad", nos permite entender que se trata de una propiedad de toda descripción de la realidad, por lo que no es privativa de los investigadores, de algunas líneas teóricas, y de los científicos sociales como lo expresa. En tal sentido, admitir la reflexividad del mundo social tiene sus efectos en la investigación social, esencialmente en los relatos del investigador que son comunicaciones intencionales que describen rasgos de una situación, pero estas comunicaciones no son "meras" descripciones sino que producen las situaciones mismas que describen.

${ }^{66}$ Desde esta perspectiva pensamos en la dimensión institucional, que se define en el proceso de elaboración de la tesis, donde es imposible escindir el proceso de investigación de esas condiciones y de las definiciones asumidas para relacionar y articular las dimensiones de lo institucional y de lo individual. Y desde esta posición y abordaje realizar una primera distinción acerca de la planificación como un camino, que sintetiza saberes de distintas disciplinas en la producción de instrumentos para la transformación de la realidad. En consecuencia, la aplicación de estos instrumentos transforma a la planificación en una tecnología imprescindible para el desarrollo. Esta tecnología implica la puesta en marcha de diferentes técnicas, involucra diagnósticos comunicacionales, formulación de proyectos de índole institucional, social o productivo, así como la producción de estrategias para el desarrollo.
} 
organizaciones. Esto se traduce en que lo comunicacional así entendido se perdió o no se tuvo en cuenta como objeto de estudio en relación a las mismas prácticas, hasta este abordaje.

Esta ha sido y es una razón suficiente donde se sustenta la idea de poner a discusión estos tres años de trayectoria profesional en comunicaciones en el ámbito de una organización como el CONICET, recuperando el concepto de comunicación e interpelando lo comunicacional en sentido amplio que acontece en las organizaciones.

\section{Marco normativo para el desarrollo de la gestión}

La situación planteada nos conduce a preguntarnos acerca de lo que la Institución requiere hacer visible de la comunicación pero fundamentalmente cuáles han sido los registros posibles para poder aportar conocimiento y habilitar la intervención en la organización.

Por tanto compartimos aquello que señala María Cristina Mata ${ }^{67}$ en cuanto a su consideración sobre las prácticas comunicativas, las que considera espacios de interacción entre sujetos en los que se comprueban procesos de producción de sentido, concepción que como tal asume la no linealidad de la circulación del sentido.

Es preciso sostener que el CONICET es una organización atravesada por procesos de cambio permanente, en plena expansión y que puede ser comprendida como un caso paradigmático, si se toma como dato central su crecimiento experimentado en los últimos 12 años entre los organismos de ciencia y tecnología del país.

En todo el territorio supera los 21.000 integrantes, cifra que crece anualmente con la incorporación de investigadores (actualmente 8.400), profesionales y técnicos de apoyo a la investigación (2.500), becarios pertenecientes al Programa de Becas (7.100 becarios de doctorado y 2.000 becarios postdoctorales) junto al refuerzo del plantel de administrativos.

${ }^{67}$ MATA, María Cristina. (1990)."Nociones para pensar la comunicación y la cultura masiva". La Crujía, Buenos Aires. Argentina. 
De tal manera y a modo de primera definición podemos decir que el aporte central generado en función de los requerimientos de la comunicación institucional ha sido el de apoyar las necesidades de su Red Institucional y superar el enfoque de comunicación como sinónimo de difusión, a partir del análisis de su estructura de relaciones.

Este es un punto válido para considerar debido a la necesidad que existía en 2012 de cubrir la vacancia entre la comunicación institucional y la necesidad de integrar a la tarea institucional a la comunicación como elemento conductor del proceso de gestión.

Para comprender este aspecto, de acuerdo al Decreto 310/2007, la Dirección de Relaciones Institucionales tiene como "responsabilidad primaria": Impulsar y atender las relaciones institucionales con las organizaciones regionales e internacionales oficiales y privadas, y con los organismos públicos nacionales y provinciales, promoviendo, la celebración de convenios bilaterales y multilaterales.

En esta línea, las acciones encomendadas son las siguientes:

1. Contribuir a la articulación e integración de la institución con su contexto mediante la administración de las relaciones públicas e institucionales del Consejo Nacional de Investigaciones Cientificas y Técnicas con organismos públicos y privados nacionales e internacionales en el marco de las políticas institucionales, el aporte a la promoción, desarrollo y gestión de la Red Institucional de ciencia y tecnología y la colaboración en el desarrollo de fuentes de recursos financieros para el soporte de la actividad Científica y Técnica.

2. Desarrollar, fortalecer y consolidar la imagen y posicionamiento institucional del Consejo Nacional de Investigaciones Cientificas y Técnicas a través del desarrollo de contenidos comunicacionales y la administración de su difusión a través de los medios y canales de comunicación.

3. Administrar la gestión y adjudicación de premios institucionales a la innovación tecnológica en el marco de la gestión y consolidación de las relaciones institucionales. 
Cabe agregar entonces que para trabajar en este marco, se requirió pensar en lo comunicacional como la trama presente en la multiplicidad de procesos en juego en la vida de la Institución y en todo proceso de desarrollo vigente hasta ese momento.

Este estudio -además- recupera esencialmente el valor de una experiencia, que hasta el presente no había tenido un registro escrito de su evolución, pretendiendo asimismo dar cuenta de reflexiones, estrategias y herramientas implementadas donde hubo que valerse en ciertas circunstancias de la creatividad en la búsqueda y adopción de modelos organizacionales, metodológicos y operativos frente a cada situación.

De este manera al impulsar y atender las relaciones institucionales en el período se trabajó en un diagnóstico que permitió considerar emergentes y que desde el análisis buscó no limitar su alcance sino establecer una contribución desde la comunicación (que no solo contemplara el qué debía hacer desde la DRI, cómo hacerlo y con qué herramientas) y que involucrara a todo CONICET. Esto puede traducirse en un modelo de trabajo que permitió abarcar la comunicación interna, la interinstitucional y la externa y que aspiró a desenvolverse en un contexto de complejidad y permanente cambio en el que se encuentra involucrada.

Frente a ello fue preciso y fundamental adoptar una concepción de comunicación que acompañara el dinamismo y promoviera el desarrollo de las Red Institucional. Esta intervención, fijada en procesos de desarrollo que son caracterizados a lo largo de la tesis, requirió un enfoque de comunicación que se fue consolidando en las prácticas, reconociendo e integrando a los actores a partir de sus intereses y necesidades, saberes y percepciones, pero esencialmente apuntó al reconocimiento y la creación de espacios y dispositivos de articulación que permitieron recuperar la diversidad de posiciones generadas, los conflictos y las tensiones como elementos generadores del cambio en la gestión de la comunicación.

Es la intención entonces explicar lo que debe ser explicado como condición de la metadiscursividad de la práctica profesional, si consideramos que este caso es iniciático en cuanto a modos de intervención que nunca antes se habían generado, al menos en esta Institución inscripta en un proceso permanente de crecimiento desde el 2003 a la fecha. 
El tratamiento de la comunicación en el CONICET ofrece una nueva perspectiva sobre las formas tradicionales de pensamiento y acción comunicacional ${ }^{68}$ ya que no solo se capitaliza la experiencia, a partir de la aplicación de estrategias y herramientas para la gestión, sino que se busca poner en discusión el proceso de reflexividad de investigador en comunicación.

\section{Aproximaciones a la comunicación institucional}

En virtud de generar aclaraciones necesarias es preciso establecer que más allá de las definiciones a priori con las cuales un comunicador se encuentra en virtud de las acciones o las condiciones operativas a cumplir o emprender en una institución como "responsabilidades", debe exigirse ya sea partiendo de sus propias y válidas manifestaciones la posibilidad de conceptualizar el lugar desde donde aborda al objeto de interés profesional y el desarrollo de la comunicación institucional.

Aquí es donde su interés se ve alentado en compartir decisiones sobre el futuro a partir de la importancia que las instituciones otorgan a la comunicación con sus diferentes públicos pero con una condición más, la de interpretar la estructura institucional como flujo permanente de comunicación. El desafío está en la necesidad de volver al problema del sujeto en la producción de conocimiento y no de los métodos o los objetos ${ }^{69}$ lo cual implica rescatar los enfoques cualitativos que ciertamente están vinculados con la producción de sentido.

Si hay conciencia, el comunicador puede entender su lugar en la producción y recreación social del sentido. En esta misma línea de interpretación y coincidiendo con Florencia Saintout $^{70}$, confirmar desde su conocimiento y práctica que la comunicación dejó de ser una cuestión de técnica, de medios como instrumentos, para transformarse en dimensión constitutiva de las prácticas sociales.

\footnotetext{
${ }^{68}$ En esta aspecto se considera lo que señala Sandra Massoni en el artículo "Modelo de Comunicación Estratégica", que se encuentra contenido en la versión de "Tres movimientos y siete pasos para comunicar estratégicamente" publicado en el libro de esta autora: "Estrategias. Los desafios de la comunicación en un mundo fluido". Homo Sapiens Ediciones. Rosario, Argentina, 2007.

${ }^{69}$ SAINTOUT, Florencia (2004). "Abrir la comunicación, Tradición y movimiento en el campo académico". Ediciones de Periodismo y Comunicación. Facultad de Periodismo y Comunicación Social, Universidad Nacional de La Plata. La Plata.

${ }^{70}$ SAINTOUT, Florencia (2008). "Los estudios socioculturales y la comunicación: un mapa desplazado". Revista Latinoamericana de Ciencias de la Comunicación.
} 
Desde este lugar de reconocimiento ubicar e interpretar el sentido que le otorga a las prácticas comunicacionales que en la institución se gestan, analizando y reflexionando sobre su dinámica, componentes, características y modalidades, a los fines de contribuir al trabajo interdisciplinario desde la comunicación. Otros enfoques llevan a asumir tareas de indagación, planificación y producción bajo criterios analíticas y de reflexividad, para brindar contenidos centrado en el conocimiento y manejo de la práctica.

\section{En el diseño de instancias comunicacionales}

Como ya hemos destacado, toda intervención institucional responde y debe identificarse con el modelo de matriz basado en el desarrollo de una estructura programática de carácter político o que responde a esa condición, necesaria y excluyente para alcanzar metas. Pero al mismo tiempo instala para alcanzar metas la necesidad de describir los momentos clave respecto de las acciones tendientes a promover el reconocimiento, intercambio y discusión desde la elaboración y el diseño de instancias comunicacionales.

Asimismo, consideramos que la organización debe deliberar sobre cuáles son los caminos más convenientes y al alcance de sus posibilidades para lo cual se requieren estrategias de acuerdo a los cambios que se producen en la propia organización o en la realidad inmediata que la rodea. Es en este espacio donde llegamos a conceptualizar producción comunicacional (en nuestro caso: nuevas prácticas para la producción de información institucional), y a promover nuevas instancias dirigidas a establecer: dinámicas de planificación comunicacional.

Es decir, proponer nuevas herramientas desde la intervención, entendidas desde la metodología como un recurso conceptual que permite definir los principales objetivos de mediano y largo plazo, y diseñar las mejores estrategias generales posibles para el logro de los objetivos. 
Página 78 de 205 


\section{CAPÍTULO V}

\section{El eje investigación/producción/gestión de nuevos lineamientos comunicacionales}

La construcción de este proceso de investigación, desde el estudio de caso posibilita analizar la articulación existente en el eje investigación/producción/gestión de nuevos lineamientos comunicacionales en esta Institución, como forma de generar, reconocer y delinear instrumentos bajo los criterios de integración ciencia/tecnología/sociedad (al basarse en problemas concretos de la comunidad y en los espacios donde actúan).

Debemos indicar que la primera aproximación metodológica responde a la necesidad de situar el campo, las problemáticas operantes, las prácticas y los saberes institucionalizados. Y en una segunda etapa trabajar el estudio de caso, que permite producir información sobre singularidades, particularidades, acciones y situaciones que son de interés poner en circulación.

Esta segunda etapa de la investigación, definida en la selección y análisis de caso, implicó centrar el eje sobre las acciones que realiza la DRI. A partir de aquí se pudieron determinar coordenadas espaciales/temporales con los Centros Científicos Tecnológicos (CCT), acerca de la primacía de la acción e institucionalizar enfoques comunicacionales que de otro modo hubiesen quedado en una instancia reduccionista y difíciles de comprensión debido a la variante de cada escenario.

Dicho así, centrar el eje en la DRI del CONICET permitió trazar un horizonte pensando en las posibilidades concretas de acción de la Red Institucional que integran los CCT. 


\section{El marco inicial o punto de partida. Consideraciones iniciales en el diagnóstico}

Trabajar al interior de la Institución y más puntualmente sobre tres instancias de intervención reconocibles, para acudir al dato, a la información y al conocimiento para poder reflexionar, fue necesario con el fin poder establecerlos como escenarios y definirlos. Hablamos del CONICET, y su anclaje en los procesos históricos; la DRI, y los modos de planificar y gestionar la comunicación para contribuir a valorizar y aportar sustentabilidad cuando se habla hoy de ciencia y tecnología (definición que no puede estar ausente de la actividad científica y tecnológica de la Institución); y la Red Institucional, al descubrir qué, cómo y quiénes comunican los procesos, productos y relaciones entabladas entre los sujetos en las prácticas investigativas, hecho que resulta una cuestión transversal a las restantes cuestiones que hacen a la vida institucional, sobre todo al momento de planificar y gestionar una política científica dispuesta por el Ministerio de Ciencia, Tecnología e Innovación Productiva de la Nación.

A partir de la cuestiones halladas en el diagnóstico institucional, fue posible evaluar y de hecho dio lugar a reconocer un primer entramado de las jerarquías, en cuanto acciones de comunicación y discursos que legitiman el propio ejercicio de poder.

Esto nos llevó a interpretar el modo en que las tramas de la comunicación son, invariablemente, como lo expone Michel De Certeau ${ }^{71}$, relaciones de poder. Visto así, surgió ante este planteo la necesidad construir nuevos escenarios desde una instancia integradora con las gerencias, las direcciones y la Red Institucional en cabeza de los CCT, pero de modo de no obstaculizar la comunicación y no generar procesos de resistencia que hicieran peligrar (como deseo) la aplicación de las herramientas y garantizar las nuevas prácticas de producción de información institucional.

${ }^{71}$ DE CERTEAU, Michel. (1996). "La invención de lo cotidiano I". Artes de hacer. Universidad Iberoamericana. México D.F. 


\section{EI diagnóstico como posibilidad de comprender la realidad}

Partimos en primer lugar de considerar al diagnóstico en tanto posibilidad de diferenciación de elementos de una determinada situación en el que se juega efectivamente la posibilidad de responder a las condiciones del contexto, tal cual las consideraciones compartidas con Daniel Prieto Castillo ${ }^{72}$. Se trata de comprender, a partir de una lectura de la situación social, lo que sucede donde el diagnóstico es una lectura esencial para describirla desde una perspectiva histórica.

Al tomar como punto de partida que la acción en la Institución es considerada una intervención y que como tal genera un conjunto de nuevas y complejas interacciones, es preciso para poder orientar y organizar el conjunto de estrategias y herramientas alcanzar un conocimiento de los temas y de los problemas allí suscitados. Esto requiere adquirir un conocimiento adecuado de la situación o sobre el problema que se trata de incidir.

En consecuencia consideramos que la comunicación es esencial para el desarrollo de una organización y, aún más fundamental, es que esta sea compartida por quienes la integran. Aquí yace un primer aspecto clave y hablará de la coherencia de las propuestas a ser implementadas. Otro refiere al diagnóstico. Desde ya que si bien no lo soluciona todo, permite saber sobre qué se está actuando y, al menos, prever si se toma un camino u otro. El valor que el mismo expresa está en línea con la apropiación de experiencias y conocimientos, al facilitar el análisis de la propia realidad y de coordinar lineamientos para el beneficio de quienes integran la institución.

Claramente un diagnóstico se contrapone al ejercicio y a una simplificación de adquirir información. Lo reconocemos como una instancia de aprendizaje de la situación propiciada a partir de nuestra intervención profesional, en la que tomamos conocimiento de las causas fundamentales acerca de los problemas para poder proceder a la gestión de acciones a partir de un análisis en profundidad, con lo cual nos lleva a componer una interpretación del poder de decisión vigente, de las relaciones constituidas y las que se fundan.

${ }^{72}$ PRIETO CASTILLO, Daniel (1985). "Diagnóstico de Comunicación". Editorial: Manuales Didácticos. CIESPAL. Ecuador. 
Surge en todo intento de reconocer, evaluar y programar lo comunicacional un conjunto de acciones destinadas a fortalecer el espacio y en enriquecer con elementos lo que existía, siempre sosteniendo el interés por la cuestiones comunicacionales en las distintas situaciones para reforzar la comunicación institucional.

\section{Abordaje metodológico e insumos}

En la necesidad de lograr promover herramientas, productos y acciones comunicacionales para la Institución, en el marco de una nueva realidad comunicacional, se proyectaron iniciativas destinadas a alcanzar un mayor conocimiento de ésta en la sociedad. Al mismo tiempo, esto se genera en cuanto que estas instituciones son caracterizadas por el escenario de intervención y orientadas a la gestión como es la promoción de actividades y de bienes sociales.

El desarrollo de la planificación ${ }^{73}$ supone instalar en la comunidad productos comunicacionales desarrollados como una de las múltiples instancias que busca promover y, a su vez, originar la interpretación y apropiación de los conocimientos alcanzados por parte de los sujetos que integran las instituciones/organizaciones de la comunidad, promoviendo bases para la adopción de las distintas instancias participativas.

Desde esta perspectiva la investigación avanzó en una instancia descriptiva para la construcción de escenarios comunicacionales, apoyada en una instancia exploratoria que apuntó a construir una visión diagnóstica general y que permitió identificar los principales ejes temáticos de la discusión: insumos básicos para el desarrollo de las herramientas comunicacionales. Así también para la organización y promoción de todas las actividades pertinentes para el inicio y desarrollo integral del proceso.

\footnotetext{
${ }^{73}$ Planificar es preparar-prepararnos, organizar-organizarnos para el cambio. Es una forma de cálculo que precede y preside a la acción. Y se puede agregar que "la planificación es, así, una herramienta de las luchas permanentes que tiene el hombre desde los albores de la humanidad para conquistar grados crecientes de libertad", según la define Carlos Matus en "Planificación, libertad y conflicto". Ponencia presentada ante el Ministerio de Sanidad y Asistencia Social de Venezuela. Caracas, 1984.
} 
En otro plano, se pensó en la dimensión de la participación y concertación con agentes y sectores sociales involucrados para poder confrontar, contrastar y refrendar las principales herramientas comunicacionales construidas. Para ello se contempló la construcción de un mapa de actores, pensado desde la Red Institucional que los soporta y colabora en la construcción. Un mapa de actores que señala y permite reconocer el papel que le corresponde a cada uno en la estructura de las decisiones y por lo tanto, registrar aquellos que resultan imprescindibles para el trabajo dentro de la promoción y establecimiento de estrategias. El mismo se orientó a determinar posiciones clave que debieron incorporarse al proceso, referentes e instancias desarrolladas a informar durante el desempeño en el mismo.

Uno de los aspectos a destacar en que si bien la planificación alcanza relevancia para las Institución, al permitir adelantarse a los cambios inexorables, preverlos y concertar una respuesta colectiva, quienes participan activamente en el proceso de construcción representaron en la organización entre el 1 y 3\% del total que la integran.

Esto lleva a presuponer que si bien cuando nos referimos a planificación describimos un proceso plural, pocas veces se conocen sus alcances. La necesidad de re-conocimiento de los actores como promotores de un proceso cuya base de sustentación reside en la aplicación de mecanismos de "empoderamiento social por la vía de la participación en sentido amplio (lo público / lo privado / la sociedad civil), componiendo un complejo escenario 'involucrante', centrado en el debate y la construcción de consensos no solo con las organizaciones de la sociedad civil, del sector público y del privado, sino con la comunidad 'no organizada' y aún la 'no participativa directa"' ${ }^{74}$.

La planificación es considerada un proceso que, al tiempo que determina, comprende la generación de información, la adopción de metodologías participativas de definición de agenda pública, la formulación de lineamientos estratégicos de desarrollo, la aplicación de tecnologías de gestión y la redefinición de la administración institucional para hacer frente a los desafíos planteados.

De este modo el paso hacia la planificación se ve transversalizado por la participación como condición esencial al proceso, donde se reconoce a los actores a partir de sus intensidades,

\footnotetext{
74 TAUBER, Fernando, DELUCCHI, Diego, MARTINO, Horacio y PINTOS, Patricia (2006). "La Planificación Estratégica Participativa. Para el desarrollo urbano y regional". Editorial de la Universidad Nacional de La Plata. La Plata, provincia de Buenos Aires.
} 
perfiles e intereses que los mueven a participar, comprometerse y vincularse con el proceso específico.

Por lo tanto, en la generación de mapas acerca de los espacios de participación reconocidos en la Institución se trazan las líneas argumentales de articulación entre actores -sentido de capilaridad-, al disponerse desde sus particularidades un lugar para el entendimiento: rescatando la diversidad de visiones, posturas e intereses. Trayecto que encausa una metodología de la participación y concertación hacia el interior de cada institución/organización y la adopción de mecanismos para la identificación de necesidades y problemáticas, en la selección de prioridades, así como en la formulación de proyectos y procesos de ejecución y gestión de la puesta en marcha.

El orden a lo expuesto, se rastreó y revisó cuál es el tipo de relación que los actores tienen con el contexto en que se desenvuelven. A partir de donde se pudo comenzar a transferir conocimiento para generar, en el ámbito en el que la organización desarrolla sus acciones, propuestas en una determinada realidad local, regional o nacional: en esa realidad se dan interrelaciones permanentes entre los actores institucionales que favorecen los procesos en que intervienen desde su posición institucional.

Se considera que en el proceso de planificación es necesario tener la capacidad de prever lo que puede hacer el otro y otros que también están actuando en el mismo escenario. Por consiguiente, es fundamental analizar y precisar las características de ese escenario y cómo influye sobre los actores que en él se desenvuelven. Es necesario hacer un esfuerzo por describir y analizar cómo es el contexto en que se desenvuelve la organización.

Así como es importante reflexionar sobre la concepción y caracterización de actor, contexto y proyecto institucional, antes de aportar elementos para una planificación, es requisito acordar sobre lo que se entiende por panificación. Planificar es prever "las acciones a realizar en función de los recursos y los objetivos que se quieren lograr para generar transformaciones", tal cual la define Ezequiel Ander $\operatorname{Egg}^{75}$.

A esa definición primera le agregamos que la realidad de las organizaciones tiene, en la actualidad, un creciente e importante papel en los procesos de desarrollo socio-económico y cultural como así también en el fortalecimiento de la participación popular y del sistema

${ }^{75}$ ANDER-EGG, Ezequiel (1995). "Introducción a la Planificación". Editorial Lumen. Buenos Aires. Argentina. 
democrático en Argentina y en Latinoamérica. De ahí que la herramienta técnica-política, la planificación, resulta un recurso conceptual metodológico que permite definir los principales objetivos de mediano y largo plazo y, en consecuencia, diseñar las mejores estrategias generales posibles para lograrlos.

\section{La planificación como modo de orientar las acciones en la Institución}

Partimos de afirmar que la planificación es un modo de orientar las acciones de una organización, que tiene en cuenta el modelo político vigente (aquí hablamos en términos de la Institución involucrada en los planes y políticas del Gobierno Nacional. La intervención del Estado es fundamental para crear las condiciones necesarias que hagan posible la instalación de un ambiente propicio, como: procesos generalizados de transferencia de tecnología -al sector gubernamental, productivo y social-, la innovación y la inserción competitiva del país dentro de los escenarios internacionales) y el comportamiento de los diferentes actores sociales que intervienen en él.

Comprende una situación inicial a partir del resultado del diagnóstico realizado y desde ese punto se establece una trayectoria reconocida como arco direccional, hacia la nueva situación "objetivo" deseada. A esta situación deseada se requiere llegar mediante el consenso entre diferentes actores sociales.

Es preciso reconocer, en la construcción del objeto de estudio, según nuestro enfoque particular, que: la planificación puede sostener criterios válidos y consistentes para planificar y crear nuevos escenarios comunicacionales, a partir de las prácticas de comunicación que son propias de la gestión en instituciones/organizaciones.

Se trata de un planteo que impone recuperar para el análisis decisiones estratégicas, partiendo de interpretar cómo las prácticas de comunicación que se deben gestionar, pueden servir para planificar y evaluar prácticas comunicativas, bajo el dominio/influencia de variables no comunicativas sociopolíticas y culturales. 
La transferencia de conocimiento, el análisis y el examen epistemológico sobre planificación, acerca de las teorías propuestas para explicar este fenómeno de la comunicación y al usar la metodología más adecuada conforme a los escenarios estudiados, deberá dar lugar a productos comunicacionales que expongan, describan y planteen aplicaciones que la comunicación/planificación puede brindar en la gestión estratégica de comunicación en instituciones como el CONICET.

Cuando sujetos ${ }^{76}$ comparten un proyecto común y pueden crear un aporte significativo para alcanzarlo y enriquecerlo con el aporte de los demás participantes en un clima de reciprocidad, ocurre, un aprendizaje. Aprender no se reduce a alcanzar un conocimiento que alguien poseía, sino el modo de socializar la información disponible. Es apropiarse de nuevos sentidos y posibilidades de actuar, de accionar y de sentir. En un llamado en donde se trata de re-crearse y a recrear el sentido del convivir, el orden social, según una lógica nueva. Es alcanzar un lenguaje inclusivo y aprender a reconocer cada novedad descubierta como un acontecimiento que surge del "entre nosotros" y "nos atraviesa".

Para ello es necesario crear, en primer lugar, el inter-objeto, es decir, el objeto de deseo compartido que surge al priorizar necesidades, focalizar un asunto; y en una instancia posterior, convertirla en objeto compartido para resolver juntos un problema, lograr un objetivo común con todos, es decir, sumar el propio aporte al logro ${ }^{77}$.

\footnotetext{
${ }^{76}$ Consideramos "sujetos" en cuanto a "la aparición de ciudadanos comunes" posibles de ser reconocidos porque carecen de alguna pertinencia partidaria en la lista de los posibles sujetos sociales en tanto hecho reciente. Además, aquello con los que "sentimos la constante tentación de asignarle un rol a los grupos que se movilizan o, en nuestro caso, a los movimientos sociales. Quizás haya llegado el momento de imaginar a todos esos sujetos como internecesarios y a ninguno de ellos, sin los otros, como suficientes", según las reflexiones de Alberto Irven, en su libro "Hacerlo posible: autoorganización y procesos de cambio social". 1era. ed. Editorial SB. Buenos Aires. 2007.

${ }^{77}$ Esta idea es compartida con quienes proponen una "pedagogía de la reciprocidad". Sostienen que los aportes de cada uno son concebidos como complemento necesarios, como diferencias co-imprescindibles que formulan en un recíproco enriquecerse suscitando un valor agregado imprevisto. IRVEN, Alberto. (2005). "Hacia una pedagogía de la reciprocidad". Ciudad Nueva. Buenos Aires. Argentina.
} 


\section{Campo de posibilidades y planificación}

Establecer y poner de relieve nuestra mirada sobre el campo de posibilidades de lo comunicacional requiere interpretar las relaciones como sujetos activos en la resignificación y creación de sentidos propios, hecho que nos habla del potencial en cuanto a la creación que encierran los procesos comunicacionales. De esta manera es posible considerar a todos los actores en diversos procesos sociales como sujetos de conocimiento.

$\mathrm{Y}$ en realidad la mirada sobre la planificación que impulsamos también involucra y se relaciona con la preocupación por instalar una nueva mirada del sujeto. En línea con esa reflexión podemos decir que los actores sociales actúan como sujetos de conocimiento. Y sumar que aquellos que participan de procesos de planificación son sujetos que planifican con la intención de "conocer el mundo para transformarlo en sentidos propios y deseados. Los sentidos son una construcción social, que están insertos en nuestras prácticas micro y macro sociales, e individuales. Los sujetos de la construcción de conocimiento en los procesos de planificación son también sujetos de transformación; delimitan escenarios, construyen problemas, inventan herramientas y también relacionan estratégicamente teorías, nociones y conceptos" $^{78}$.

\section{Una aproximación desde la prospectiva}

En la permanente búsqueda por interpretar los requerimientos de atención científico y tecnológico ha sido necesario desplegar desde la comunicación, para no dejar vacios en los problemas relevantes tratados y por tratar, el conocimiento y del modo en que se expresa para visualizar que la institución accede al conocimiento para su desarrollo y cómo se transforma

\footnotetext{
${ }^{78}$ CERASO, Cecilia y ARRÚA, Vanesa (2006). "Aportes de la comunicación a la planificación de procesos de desarrollo". Ponencia X Jornadas Nacionales de Investigadores en Comunicación. Una Década de encuentros para (re)pensar los intercambios y consolidar la red. Red Nacional de Investigadores en Comunicación. San Juan.
} 
el contexto y las relaciones en la institución. Lo que puede ser leído como un hecho singular debe ser considerado por y para los agentes que producen, procesan y difunden el conocimiento.

La calidad institucional, la creatividad y pertinencia del sistema de ciencia y tecnología son factores que interactúan al igual que están presentes los intangibles como la identidad, los hábitos solidarios, el lenguaje, la confianza, el aprendizaje, las categorías cognitivas, las relaciones entre agentes e institución, la tradición y los valores.

En el diagnóstico de lo existente y las problemáticas, en la detección de necesidades y en la necesidad de avanzar en la construcción de información consolidada, la sistematización de esquemas de análisis, la adopción de una mirada compleja para la crítica, y el trabajo sobre los escenarios deseables, los necesarios, los posibles, los actuales y los indeseables, se constituyen las acciones sustantivas pensando en la viabilidad operativa de las herramientas comunicacionales.

Desde esta perspectiva, el trabajo desde la DRI en la aplicación de las herramientas se constituyó en una acción comunicativa compleja que se caracterizó por propuestas prospectivas integrales desde lo conceptual (este fue un ejercicio permanente para el desarrollo de la gestión) y lo operativo (independientemente de la validez o de las limitaciones de dichas acciones, lo que estamos remarcando o poniendo en evidencia es no omitir el desempeño social de los actores institucionales -investigadores, personal de apoyo, becarios, administrativos, responsables de la gestión-. Lo que hace que al considerarlos se deba pensar en los valores, el conocimiento, las iniciativas, y el comportamiento de dichos sujetos. Pero también y en otros términos valorizar la capacidad, la creatividad y las iniciativas de los actores sociales de la región con los que se vincula la Institución). Esto requirió adecuarse a las especificidades históricas, culturales, políticas, sociales y económicas que definen al CONICET.

En el contexto de transformaciones recientes que ya llevan más de una década, aparecen nuevos desafíos y nuevas dimensiones institucionales donde la ciencia y la tecnología articula con las inquietudes sociales, posible debido a la sostenida consolidación de los sectores sociales y del trabajo ligado al desarrollo del conocimiento. 
El énfasis puesto por el Estado nacional en la ciencia y la tecnología, a la vez que trasciende a la organización y el papel que ésta representa en la relaciones de producción de conocimiento, en una economía fundada en el conocimiento ${ }^{79}$ como una de sus posibles lecturas, permite pensar en el futuro. Pero es necesario cuestionar y aclarar esta orientación acerca del conocimiento. Cuestionarlo en cuanto a que hasta ya entrado el 2002 la Argentina del neoliberalismo lo había potenciado como mercancía y recurso estratégico del sistema de mundialización y, si bien es posible señalar que esta concepción en determinados ámbitos continúa vigente, también lo es el nuevo lugar o rol central del conocimiento y del aprendizaje en instituciones del Sistema Científico y Tecnológico Nacional a partir del 2003.

Considerándose la última década, se puede decir que el énfasis fue puesto por el Estado en el ámbito local como un ámbito privilegiado de generación de conocimiento y de procesos de innovación ${ }^{80}$ para que el país pudiera insertarse de manera virtuosa en la economía del conocimiento. Se trató entonces de una fase que aún continúa en pleno desarrollo del sistema económico argentino donde el sistema científico está ya generando sus aportes en la que la generación y difusión de conocimientos (la explotación hidrocarburífera de Vaca Muerta, el satélite SAC-D Aquarius, el Arsat-1, el Tronador II, la instrumentación de la Televisión Digital Abierta (TDA), la puesta en marcha de Atucha II, entre los más recientes como la importancia del Programa Conectar Igualdad, el Programa Raíces, por citar solo algunos), y su incorporación al proceso económico a través de la innovación hecho que está alcanzando un papel central en la competitividad de las economías nacionales, regionales y locales y de las empresas (especialmente la PyMES) de las que hay que empezar a dar cuenta.

\footnotetext{
79 En los dos últimos años, por citar un caso como puede ser el desarrollo de la nanotecnología, se ha avanzado en el programa de Desarrollo de Tecnologías de Litio que viene liderando Y-TEC (empresa conformada por YPF, 51\%, y el CONICET, 49\%), donde la importancia está centrada en el desarrollo de toda la cadena de valor del litio, desde la materia prima hasta la batería terminada. Desde esta perspectiva, el potencial del país para el desarrollo de esta industria lo ubica en 4to. lugar en reservas mundiales de yacimientos de litio. En respuesta a la demanda creciente de energía en el país y la necesidad de ir reconvirtiendo la matriz energética nacional hacia mayor uso de energías renovables, una de los principales objetivos fue crear un Centro de investigaciones sobre Litio en la provincia de Jujuy desde donde se impulsará la fabricación de baterías ion-litio. La misma incluirá todas las etapas productivas, desde la extracción y obtención de la materia prima estratégica a través de una planta piloto de extracción y purificación de salmueras de litio, una planta piloto de materiales activos para baterías de ion-litio y una planta piloto de electrodos y celdas para baterías de litio.

De esta manera el desafío del sistema científico y tecnológico nacional será trabajar para que el país no sea solo un productor de materias primas, sino desarrollar un país que genere productos con valor agregado. En este marco se plantea la importancia de la interacción entre el mundo académico y el productivo para dar respuestas concretas a la sociedad en conocimiento científico y tecnológico.

La comunicación adquiere un rol central en el aporte de un enfoque situacional, especialmente desde la comunicación estratégica como comunicación para la innovación. Esto permite un mayor acercamiento, abordaje y comprensión de la gestión del conocimiento organizacional lo cual posibilita pensar en la gestión del conocimiento en un organismo como el CONICET. Este conocimiento facilita el abordaje de la generación de nuevos modelos de trabajo desde el organismo con empresas como es el caso de Y-TEC, donde el CONICET participa en forma directa, fomentando la creación de empresas de base tecnológica con la participación de investigadores y realizando acuerdos con distintas empresas para la realización de investigaciones conjuntas.

80 "...mejorar la competitividad, que no pasa ni por el club de los devaluadores ni por el club de los endeudadores, que pasa por el club de los que queremos generar mayor valor agregado, mayor innovación, mayor ciencia y tecnología. Por eso también, nuestro ministerio de Ciencia y Tecnología y todas nuestras áreas técnicas desempeñan un rol tan importante y lo van a seguir haciendo. Es clave la innovación y la ciencia y la tecnología en la competitividad en esta etapa". Discurso de la presidenta de la Nación, Cristina Fernández de Kirchner, durante el acto de asunción del mando en el Congreso de la Nación ante la Asamblea Legislativa. 10 de diciembre de 2011. Disponible en: Presidencia de la Nación www.casarosada.gov.ar
} 
Esto fue posible por un clara decisión del gobierno nacional de incrementar la inversión en educación (se pasó de una Argentina que en el año 2002 destinaba el 5\% de su producto bruto interno al pago de la deuda externa y apenas el $2 \%$ a la educación, para revertir esa ecuación con un $6.3 \%$ a la educación ${ }^{81}$ y un $2 \%$ al pago de la deuda), en tecnologías de la información y las comunicaciones, en investigación y desarrollo (donde la inversión pasó de un 0.44 del PBI, en 2004, para alcanzar el 0.65 en la actualidad ${ }^{82}$ ). Política que fue acompañado por la promoción y por un crecimiento de la participación del sector privado en el financiamiento de la investigación y desarrollo recomponiendo el vínculo entre la investigación científica y la industria y entre los distintos agentes del sistema de innovación.

Desde la disciplina pensar en el futuro es un acto de intervención. Esta posición, la mirada y la construcción del futuro ya implican un modo de encarar el presente. Por esta misma razón encuadramos esta instancia de tesis en tanto que intervención ${ }^{83}$ comunicacional.

De aquí en adelante, en reconocimiento del lugar de la comunicación y del comunicador es posible compartir y cuestionar desde las experiencias subjetivas los sentidos que le damos a las prácticas sociales. Así también incorporarnos a los debates -necesarios- sobre el conocimiento acerca de la generación de bienes y servicios, así como la posibilidad de enfrentar de forma innovadora los nuevos desafíos productivos de manera sustentable, los cuales representan procesos de cambio estructural en la ciencia y factores novedosos tanto en el esquema productivo del país como en la calidad de vida de sus habitantes.

Definir de un modo particular lo que como intervención se presenta y comprender el papel apelativo, imperativo o propositivo desde la comunicación, es un modo de asumir hacer prospectiva. En la prospectiva el cambio es inherente, porque se proyecta un futuro distinto. La prospectiva de comunicación lleva implícita una idea de cambio en su misma definición, y es el punto de partida para la toma de decisiones comunicacionales pero esencialmente de orden político.

\footnotetext{
${ }^{81} \mathrm{Al}$ respecto, la presidenta señaló que "la OCDE que es la organización que nuclea a los países más desarrollados, en diciembre de 2014, en su capítulo de tendencias recientes en educación, reconoce a la Argentina por ser el mayor inversor - escuchen, OCDE- en educación América Latina en términos de recursos sobre el PBI. Señala que destina 6,3\% del PBI, más que el promedio regional y más que el promedio también de la propia OCDE que agrupa a los países desarrollados". Discurso de la presidenta de la Nación, Cristina Fernández de Kirchner, en la inauguración del $133^{\circ}$ período de Sesiones Ordinarias del Congreso Nacional. 3 de marzo de 2015. Disponible en: Presidencia de la Nación www.casarosada.gov.ar

${ }^{82}$ Fuente Ministerio de Ciencia, Tecnología e Innovación Productiva de la Nación.

${ }^{83}$ Vale aclarar qué decimos cuando hablamos de intervención. La misma nos permite dar cuenta de la conceptualización y la práctica de la comunicación social; es decir, que en tanto tal hace a descifrar y analizar los paradigmas, matrices y enfoques que operan y atraviesan las prácticas, decisiones y discursos en la Institución de la que somos parte. Se trata entonces de un hecho que se transforma y configura como central para lograr cualquier intervención e investigación social. Y es apostar a la construcción de un conocimiento ampliado, relacional y estratégico para la toma de decisiones y la planificación de procesos comunicacionales.
} 
Planificar en función de la sustentabilidad comunicacional se relaciona con la prospectiva como parte de la estrategia asumida desde la comunicación.

La prospectiva no busca adivinar el futuro, sino que pretende construirlo plantean Miklos y Tello $^{84}$. La acción se centra en la configuración de un futuro deseable e imaginado, para luego reflexionar sobre el presente y accionar para incidir hacia el futuro objetivado.

La prospectiva se presenta como un enfoque que incluye el análisis de los procesos y la construcción con los otros, pero también la construcción del futuro como un espacio de innovación. En tal sentido, hablar de prospectiva y de su fundamento es hablar de la posibilidad de creación, transformación y cambio ${ }^{85}$. Pero para que esos cambios sean los deseados se deben construir prácticas, políticas, acciones, programas que lleven al desarrollo de esos escenarios. En una breve síntesis la prospectiva plantea una la visión holística, las consideración de variable cualitativas, las relaciones dinámicas, la creatividad y la participación, tal cual lo destaca Agustín Merello ${ }^{86}$.

Los conceptos de prospectiva, estrategia, planificación están en la práctica íntimamente ligados, cada uno de ellos conlleva el otro y se entremezcla destaca Michel Godet ${ }^{87}$. Al respecto, señala que hablamos de planificación estratégica, de gestión y de prospectiva estratégica. Y si bien cada uno de estos conceptos representa un referente de definiciones, de problemas y métodos donde la especificidad de cada uno de ellos es tan evidente, dónde se generan los encuentros. El interrogante lleva a pensar en la existencia de una caja de herramientas y los gestores bien informados hacen buen uso de la misma para así crear un lenguaje común y multiplicar la fuerza del pensamiento colectivo, reduciendo en lo posible los inevitables conflictos, da cuenta Godet.

En ese orden, el lugar de síntesis conceptual que se alcanza entre la prospectiva y la estrategia debe estar encarnado dentro de la realidad cotidiana y dar lugar a una verdadera movilización de la inteligencia colectiva a través de la apropiación. Este comportamiento involucra a todos

\footnotetext{
${ }^{84}$ TELLO, María Elena y MIKLOS, Tomas (2004). "Planeación prospectiva. Una estrategia para el diseño del futuro". Editorial Limusa. México.

${ }^{85}$ GODET, Michel (2000). "La caja de herramientas de la prospectiva estratégica". Laboratoire d'Investigation Prospective et Stratégique. ${ }^{86}$ MERELLO, Agustín (1973). "Prospectiva, teoría y práctica". Editorial Guadalupe. Buenos Aires.

En la década del '70 este autor trabajó con esta noción haciendo la diferenciación con otras vías de aproximación, donde el porvenir es a partir del futuro y no del presente. Desde esta posición se diferencia de la proferencia, es decir, donde se revisan las regularidades del pasado desde el presente y se proyecta lo que será el futuro, con una clara limitante en lo que fue de ese pasado. Otro aspecto a destacar es que la prospectiva plantea un importante cambio frente a la previsión o el pronóstico clásico es reduccionista, determinista y cuantitativista.

87 GODET, Michel y DURANCE, Philippe (2007). "Prospectiva Estratégica: problemas y métodos". Laboratoire d'Investigation Prospective et Stratégique. París.
} 
los actores concernientes, situados desde arriba hasta abajo de las jerarquías consideradas en la institución. Precisamente a partir de esta visión de futuro, con razón o sin ella, es como estos actores van a orientar sus propias acciones.

Una razón no menor al pensar en la prospectiva: es una etapa previa a la planificación porque a partir de la construcción de escenarios ${ }^{88}$ se apunta al desarrollo de herramientas que pretendan llegar a esos escenarios.

Por su parte, no existe una sola manera y solo una de llevar adelante un trabajo de diagnóstico dinámico y planificación prospectiva estratégico desde la comunicación ${ }^{89}$; en tanto que es una propuesta para llevar adelante adaptándola a las características de cada situación o ámbito de trabajo. Por consiguiente, de lo contrario sería imponerle al desarrollo metodológico un rigor que carece de sentido y contradice la premisa básica de responder a los requerimientos, por cierto distintos, de cada realidad.

La prospectiva nos enseña, según Francisco Mojica ${ }^{90}$ que no es necesario sufrir o padecer el futuro, sino que podemos construirlo. Pero también del análisis se pueden adquirir ventajas competitivas, sencillamente porque permite adelantarse a tomar decisiones que otros todavía no han pensado.

La prospectiva de ninguna manera se puede aceptar como un ejercicio de pura imaginación que busca inventar un mundo mejor o distinto sin ninguna relación con el actual. Claramente su finalidad es contribuir a una mejor comprensión del mundo contemporáneo, explorando lo que puede suceder y lo que se puede hacer en cuanto a políticas y estrategias, por medio de un proceso pluridisciplinario que tiene en cuenta la dimensión -especialmente- del largo plazo.

Hay razones que también se deben considerar al hablar acerca de las posibilidades, el arco de las mismas en una institución es muy amplio, pero también se restringe en lo probable, y se restringe aún más en lo que refiere a los términos de apuesta política institucional en el sentido de construcción colectiva de la voluntad en términos de lo deseable.

\footnotetext{
${ }^{88}$ Los estudios prospectivos lo que pretenden es construir escenarios y en esta tarea prever diferentes tipos de escenarios. Así, introducir la prospectiva es una forma flexible, plural y no determinista de construir escenarios deseables, posibles y probables. Para ello se tienen que tomar en cuenta variables cualitativas y se otorga importancia a la voluntad, la conciencia y la creatividad de las actores institucionales y los equipos de trabajo en la construcción del futuro.

${ }^{89}$ URANGA, Washington (2008). "Prospectiva estratégica desde la comunicación. Una propuesta de proceso metodológico de diagnóstico dinámico y planificación". Buenos Aires.

${ }^{90}$ MOJICA, Francisco José (2005). "La construcción del futuro. Concepto y modelo de prospectiva, estratégica, territorial y tecnológica". Convenio Andrés Bello - Universidad Externado de Colombia. Buenos Aires.
} 
Se puede hacer coincidir moderadamente, críticamente, escenarios probables, posibles y deseables, o en todo caso que no sean tan deseables como se quisiera en términos de políticas públicas o desde la implementación de las mismas, pero sí por lo menos reorientar esos escenarios hacia apuestas de voluntades socialmente construidas y productivas, con alta probabilidad de recurrencia ${ }^{91}$.

En términos más conceptuales se puede señalar que la prospectiva es un proceso para poner en evidencia muchas veces algo que en otros ámbitos, sobre todo de la táctica cotidiana o de la práctica cotidiana está bastante escondido y que son las orientaciones de las percepciones del mundo, o en algunas tradiciones más conocidas, la ideología.

Por lo tanto, es posible advertir que la decisión como la acción exceden a la prospectiva e involucra directamente a la planificación. Estas instancias tienen que ver con la toma de decisiones que están basadas en opciones posibles permitidas por la construcción de escenarios prospectivos; es decir, se requiere acudir al dato, a la información y al conocimiento para poder reflexionar, para poder establecer escenarios prospectivos y tener opciones. La planificación prospectiva implica poner en diálogo una conceptualización del tiempo, más precisamente una aproximación a la relación que se establece entre el pasado, el presente y el futuro.

\section{Las conceptualizaciones sobre la organización}

Después de remarcar aspectos sociales e históricos que dieron lugar a poder comprender el lugar de la Institución y sus estrategias de desarrollo institucional a lo largo de este tiempo, es posible pensar las líneas que la contienen y las diferentes perspectivas de abordaje del concepto de organización.

Al conformarse los 5 componentes de comunicación se entró en tensión acerca de lo instituido y lo que puede emerger, los alcances de las estrategias de comunicación y su

\footnotetext{
${ }^{91}$ GIORDANO, Carlos José (2009). "23 tesis sobre la tesis. La comunicación para la transformación de la gestión educativa". Tesis doctoral. Facultad de Periodismo y Comunicación Social. Universidad Nacional de La Plata. La Plata. Argentina.
} 
desarrollo con los actores en el territorio, donde emergen desde estas miradas críticas que deben ser recuperadas. Un acercamiento, para repensar la posibilidad de un espacio de trabajo en comunicación, dentro de las unidades, requiere repensar el involucramiento de los actores y reconocer las diferentes perspectivas de abordaje del fenómeno organizacional.

La idea es replantear principalmente el concepto de organización para ingresar a la mirada comunicacional en el territorio y hacer emerger procesos de articulación institucional con la política pública en ciencia y tecnología.

Al respecto, se puede señalar que la comunicación no se constituye únicamente porque desde la organización se la piense, sino que se tiene la necesidad de constituirse en una función sustantiva para contribuir al logro de los objetivos planteados, al ser la comunicación parte constitutiva de la organización ${ }^{92}$.

Para avanzar en su definición es necesario reconocer que desde distintas disciplinas, enfoques y autores se han generado acercamientos a este concepto. Se puede mencionar que la sociología, la psicología organizacional, la administración, la psicología social, el análisis organizacional y la ciencia política entre otras, mantienen conceptualizaciones desde el punto de vista organizacional que han permitido integrar más conocimientos, lo cual lleva a definir el concepto desde la transdisciplina.

La propuesta de comunicación institucional -en este marco- incluye una variedad de supuestos y el reconocimiento de la identidad que es dinámica, donde las partes de un todo complejo y sus propiedades adquieren sentido en la interacción y en su relación con la organización.

Desde universo de estas concepciones se dirá que las organizaciones se analizan en forma continua desde una diversidad de perspectivas. La sociología entiende a las organizaciones como un elemento constituyente de la sociedad. La organización es una colectividad con una frontera identificable, según Richard Halls ${ }^{93}$. En tanto, Max Weber ${ }^{94}$ destaca el grupo corporativo de otras formas de organización social. Para Edgar Schein ${ }^{95}$ la organización desde la psicología social es la coordinación planificada de las actividades de un grupo de

\footnotetext{
${ }^{92}$ BRONSTEIN, Víctor y GAILLARD, Juan Carlos (1995). "La comunicación en las organizaciones". Instituto Nacional de Administración Pública - INAP . Jefatura de Gabinete de Ministros. Buenos Aires.

${ }^{93}$ HALL, Richard (1996). "Organizaciones. Estructuras, procesos y resultados". 6ta. Ed. Prentice Hall. México.

${ }^{94}$ WEBER, Max (2002). "Economía y sociedad". 2da. reimpresión. Fondo de Cultura Económica. España.

${ }^{95}$ SCHEIN, Edgar (1982). "Psicología de la organización". Prentice-Hall Hispanoamericana S. A. México.
} 
personas para procurar el logro de un objetivo explícito y común. Por su parte, Leonardo Schvarstein ${ }^{96}$ destaca el carácter de construcción social que presentan las organizaciones. Otros aportes como el de Gareth Morgan ${ }^{97}$ formulan que la organización es una serie de metáforas a través de las cuales es posible estudiarla; en tanto, Michel Crozier y Erhard Friedberg ${ }^{98}$ plantean que puede analizarse como relaciones de poder, influencia, de regateo y cálculo; donde las organizaciones constituyen el espectro central de las sociedades contemporáneas. Por su parte, Jorge Etkin $^{99}$ explica desde la complejidad que el funcionamiento de las organizaciones debe considerar la coexistencia de fuerzas y lógicas tanto complementarias como antagónicas.

Las teorías constructivistas y los nuevos paradigmas señalan que el conocimiento no es externo a quien lo produce. Esta noción también es empleada para analizar el funcionamiento de las organizaciones desde una mirada sistémica según Jorge Etkin y Leonardo Schvarstein ${ }^{100}$.

Por su parte Gareth Morgan ${ }^{101}$ centra su aportes en las metáforas, en cuanto posibilidad para entender las organizaciones y refiere a que se tratan de posibles ingresos a las mismas donde necesariamente conviven modelos diferentes en cada uno. Refiere a un proceso donde las imágenes de la organización permiten la posibilidad de crear comprensión común a través de imágenes e ideas con la finalidad de hacer cosas nuevas.

En cuanto a la integración de las teorías organizacionales, son Lee Bolman y Terrence Deal ${ }^{102}$ quienes proponen aportes desde perspectivas de estudio para el análisis estructural, de los recursos humanos, de la política ya que junto al poder no pueden no ser considerados, y desde una realidad simbólica. Asimismo, al hablar de las estructuras organizacionales Henry Mintzberg $^{103}$ configura el resultado de la articulación de cinco tipos de estructura: la estructura simple, la burocracia mecánica, la burocracia profesional, la formación divisional, y la adhocracia. Posteriormente Mintzberg pone de manifiesto la influencia del contexto

\footnotetext{
${ }^{96}$ SCHVARSTEIN, Leonardo (1997). "Psicología Social de las organizaciones". Nuevos Aportes. Paidós. Buenos Aires.

${ }^{97}$ MORGAN, Gareth (1991). "Imágenes de la organización". Editorial Alfaomega S.A. de C.V, México.

${ }^{98}$ CROZIER, Michel y FRIEDBERG, Erhard (1990). "El Actor y el sistema: Las restricciones de la acción colectiva". Alianza Editorial. México.

99 ETKIN, Jorge (1989). "Administración hoy". Publicación de la Asociación de Docentes Nacionales de Administración General (ADENAG). XV Asamblea Nacional de Graduados en Ciencias Económicas. Tesis. Buenos Aires.

${ }^{100}$ ETKIN, Jorge y SCHVARSTEIN, Leonardo (1994). "Identidad de las organizaciones. Invariancia y cambio". Paidós. Buenos Aires.

${ }^{101}$ MORGAN, Gareth. (1990). "Imágenes de la organización". Ra-ma Editorial. Madrid.

102 BOLMAN, Lee y DEAL, Terrence (1995). "Organización y liderazgo". Addison-Wesley Íbero América S.A Wilmington, Delawere, Estados Unidos. Traducción Centro para el Desarrollo de Recursos Humanos. Instituto de Estudios Superiores de Administración (IESA) Caracas, Venezuela.

${ }^{103}$ MINTZBERG, Henry (1984). "La estructuración de la organizaciones". Editorial Ariel. Barcelona.
} 
sobre la estructura organizacional y genera aportes donde aparece la importancia de la innovación frente a la complejidad del entorno.

Este recorrido por las distintas perspectivas y modelos organizacionales ${ }^{104}$ contribuyó a situar la importancia del entramado relacional, donde el contexto no es inerte sino que forma parte porque es el lugar del intercambio. Desde el plano de la diversidad presenta a la organización en la acción, abierta, inestable, discontinua, sintética, y en reconocimiento de la diferencia del otro, integrada por sujetos activos, en diálogo, para dar cuenta de la red de interacciones que configuran el entramado relacional institucional, tal como es percibido en esta tesis desde la comprensión de la complejidad organizacional.

Desde el nuevo paradigma y modos de transitar la complejidad, Edgar Morin ${ }^{105}$ propone tomar la comunicación como un modo de comprensión y acción en la incertidumbre. Aquí es justamente el conocimiento el que pone al hombre frente a la tragedia de la subjetividad y, por tanto, lleva en sí mismo la contradicción, integra nociones antagónicas en lo que define como pensamiento complejo. Desde una nueva propuesta de ciencia, Morin convoca a la unidad destacando que en todo sentido no se trata de lograr la sustitución de una ciencia única en lugar de otra, sino de alcanzar una propuesta inclusiva que es capaz de aprehender, al mismo tiempo, unidad y diversidad, continuidad y rupturas. En esta visión de la ciencia y en la revisión de sus constituciones, esta ciencia nueva debe adaptarse a los objetos y estos por no ser adecuados ser excluyentes de ella. Y en todo su recorrido convoca a considerar la complejidad en tanto concepción del mundo como epistemología abierta, que se constituye por oposición a la noción de conocimiento controlado y cerrado; y establece la duda como posibilidad en sí misma.

Ante escenarios institucionales cambiantes se requieren estrategias para profundizar algunos aspectos en la intervención, fundamentalmente en lo que respecta a la articulación entre sectores de la organización. De esta forma, se trata de aprovechar lo ya consolidado hacia adentro en la organización, para intervenir en el medio.

\footnotetext{
${ }^{104}$ Otros aportes: PETIT, Francois (1984). "Psicosociología de las organizaciones". Editorial Herder. Barcelona. FERNÁNDEZ COLLADO, Carlos (1991). "La Comunicación en las Organizaciones". Editorial Trillas. México D.F. KREPS, Gary (1995). "La comunicación en las organizaciones". Addison-Wesley Iberoamericana. Estados Unidos. ${ }^{105}$ MORIN, Edgar (2011). "Introducción al pensamiento complejo". Gedisa, Barcelona.

- (2002). "El método. El conocimiento del conocimiento". 4ta. ed. Cátedra. Madrid.

Buenos Aires.
} 
En este contexto, desde la comunicación se avanza en la tarea de resignificar el concepto de sustentabilidad, vinculándolo con los procesos de organización social y de construcción cultural y con la capacidad de aprendizaje colectivo de los actores de la Red Institucional (en el territorio) desde una perspectiva multidimensional, que considera en forma integrada las relaciones mutuas entre sociedad y cultura, economía y producción, gestión y participación.

Desde esta óptica, revisar los sentidos construidos en torno a las organizaciones se transforma en un desafío de la comunicación frente a escenarios de cambios incesantes y permanentes. 


\section{CAPÍTULO VI}

\section{Seis puntos hacia una redefinición de la Dirección de Relaciones Institucionales}

\section{Punto 1: Competencias comunicacionales}

Cuando se trabajó el diagnóstico de la Dirección de Relaciones Institucionales del CONICET, surgieron elementos contundentes que debieron ser considerados en el marco en el cual se definían las políticas institucionales. Cabe destacar que más allá de las responsabilidades y acciones enunciadas en el Decreto 310/96, la DRI al mes de marzo del año 2012 no contaba con una estructura que articulara y ordenara las acciones en comunicación.

La conformación del equipo de trabajo hasta ese momento, en un $60 \%$, no respondía al perfil de profesionales de la comunicación así como tampoco contaban con capacidades o habilidades para el desarrollo de grupos de trabajo interdisciplinarios. Si bien, el otro $40 \%$ estaba formado en disciplinas conexas o dotados con capacidades en publicidad y marketing, habiendo solo un técnico en periodismo deportivo, es evidente que para impulsar las herramientas comunicacionales era preciso aumentar la integración de profesionales con conocimientos en la materia y acordes a los nuevos perfiles de trabajo que surgían del diagnóstico.

Esto llevó a plantear una primera necesidad. Establecer qué roles se deberían cubrir en función de las nuevas herramientas diseñadas y qué competencias debían tener estos profesionales, en función de poder desempeñarse de la mejor manera de acuerdo a los temas a trabajar y a las circunstancias en las cuales se inscriben los mismos. Resultó una prioridad para integrar al equipo de la DRI a profesionales como coordinadores ${ }^{106}$ de las herramientas dispuestas. Los mismos debían tener conocimientos del campo laboral en el que se inscribían las acciones del CONICET y, especialmente, las que impulsaría la DRI en el ámbito de la

\footnotetext{
${ }^{106}$ Es necesario destacar que las incorporación a la DRI de profesionales se dio en el marco de las capacidades que permite el Sistema Nacional de Empleo Público, en el caso de los organismos de la Administración Pública Nacional. Claramente en lo que hace a las remuneraciones esta es una limitante para la incorporación de los mismos, así como la modalidad de contratación a través de lo que se conoce como Art. 9 en el marco de la Ley $\mathrm{N}^{\circ} 25.164$.
} 
ciencia y la tecnología. Debían poder articular, dirigir y generar actividades destinadas a promover conocimiento de planes, proyectos y programas; pero, especialmente, ser capaces de poder impulsar y llevar adelante las herramientas, contar con la capacidad de desarrollar vínculos y relacionarse con los equipos de trabajo -desde la DRI- con las 6 gerencias y la Dirección de Vinculación Tecnológica y Social. Este aspecto resultó ser el eje central para la elección y asignación de coordinadores frente al nuevo proceso de comunicación que acompañaría los cambios organizacionales que se impulsaron.

Para pensar la gestión comunicacional y conforme al modo de trabajo y las decisiones metodológicas indicados más arriba, es que fue necesario contar con el rol de 5 coordinadores asignados a las herramientas comunicacionales: Comunicación Pública; Comunicación Científica y Tecnológica; Eventos, Ceremonial y Protocolo; Relaciones con la Comunidad; y Comunicación Audiovisual.

Además, se pensó especialmente que estos coordinadores también generarían un aporte al conocimiento del estado y proceso en que se desenvuelve la comunicación en el CONICET; es decir, debían ser capaces de generar insumos para pensar modos de planificar y gestionar políticas que contribuyeran a la comunicación de la actividad científica de la institución.

De acuerdo con la concepción en que fueron pensadas las herramientas, también fueron necesarios los coordinadores para describir y descubrir qué, cómo y quiénes comunican los procesos, los productos y las relaciones entabladas entre los sujetos en las prácticas investigativas que se promueven. Esto último resulta una cuestión transversal a las restantes cuestiones que hacen a la vida institucional, sobre todo al momento de gestionar una política científica.

\section{Punto 2: Del diagnóstico}

Las cuestiones halladas en el diagnóstico, representaron un insumo para la definición de políticas de comunicación y su gestión, esencialmente frente a la pregunta acerca de: ¿Cómo comunicar la investigación dentro del CONICET?. Y, en tal caso ¿qué cuestiones a resolver emergen de estas prácticas?. 
El trabajo pensado desde la DRI para acercar más (lo cual no es sinónimo de mejor) al CONICET a la sociedad fue una pretensión anunciada por el Directorio del organismo y por el Ministerio de Ciencia, Tecnología e Innovación Productiva de la Nación, a través de su Ministro y de la vocera de ese organismo. Una mayor integración desde la comunicación institucional y un reforzamiento en el vínculo entre el CONICET y el Ministerio de Ciencia y Tecnología se destacaba y apreciaba como la instancia a resolver, dadas las distintas líneas de trabajo compartidas $\mathrm{y}$, especialmente, debido a que el CONICET se presentaba como herramienta de aplicación de las políticas públicas impulsadas por la Cartera Nacional.

De aquí en adelante es posible detallar los temas como problemas que se abordaron de manera conjunta con prensa del Ministerio que estuvieron referidos a: la construcción de nueva infraestructura, donde el CONICET fue el principal destinatario del Plan de Obras para la Ciencia y la Tecnología; el desarrollo del Programa RAICES (Red de Argentinos Investigadores y Científicos en el Exterior, fue declarado como Política de Estado, Ley 26.421 del 22 de octubre de 2008) donde se superaron los más de 1.100 científicos repatriados con el propósito es fortalecer las capacidades científicas y tecnológicas del país mediante la implementación de políticas de retención, de promoción del retorno y de vinculación. En este sentido, el CONICET es el principal lugar de destino laboral de las presentaciones y tramitaciones de las solicitudes de ingreso a la Carrera del Investigador Científico y Tecnológico desde el exterior. Y la importancia del Plan Nacional de Ciencia, Tecnología e Innovación Productiva “Argentina Innovadora 2020”, en la definición de temas estratégicos y el lugar que ocupa el CONICET.

Estos temas y otras líneas de desarrollo requerían impulsar una mayor vinculación en las comunicación entre los organismos, definiéndose espacios de articulación en el nivel de la gestión desde las herramientas con las nuevas necesidades y trabajo conjunto entre ambos instituciones (en Tecnópolis, Semana Nacional de la Ciencia y la Tecnología, promoción de vocaciones científicas, divulgación científica y noticias institucionales, Pampa Azul, entre otros).

Esta articulación formó parte de una decisión política que a partir de 2012 constituyó un acercamiento en el proceder comunicacional de la vocería del Ministerio y la DRI, sobre todo a partir del crecimiento en incorporación de investigadores y becarios como en los logros en investigación y desarrollo; buscando de este modo paliar la desarticulación y superposición 
de anuncios, así como la conformación de una agenda de temas ministeriales que recuperara lo desarrollado por el CONICET en lo referente a los artículos de divulgación científica. Para esto se generaron espacios de articulación con la vocería del ministerio por herramienta, en lo referente a: la difusión, estrategias de divulgación masivas y análisis de las repercusiones alcanzadas.

Se trató entonces, a partir de 2012 como ya mencionamos, de construir una mirada compartida en y hacia los medios masivos donde se incluyeron las particularidades de lo que la institución definía como federalización, así como la incorporación y el entendimiento de la regionalización desde las temáticas y las problemáticas y el establecimiento de lazos comunicativos en cuanto a los procesos de comunicación de la ciencia, la tecnología y la innovación; al identificar cómo se estaba dando la existencia de hechos y experiencias en cada CCT y UE.

\section{Punto 3: Desarrollos}

Desde la DRI en relación con el entorno, al desarrollar las herramientas en Comunicación Pública y Comunicación Científica y Tecnológica, se priorizaron las instancias de difusión de la investigación, innovación y transferencia en los CCT y las UE que administran. Este aspecto surgía como necesario desde el diagnóstico y estas herramientas tuvieron el objetivo de acompañar la política de apertura y vinculación con la sociedad que se venía profundizando desde el año 2003, poniendo a disposición de los sectores socioeconómicos su experiencia en investigación y desarrollo.

La comunicación se vio favorecida a partir del trabajo que venía ya desarrollando la Dirección de Vinculación Tecnológica y Social, actuando como unidad de enlace entre las demandas de los distintos sectores de la sociedad y los equipos de investigadores y profesionales y centros de investigación capaces de responder a esos requerimientos.

Su importancia y entendimiento desde la DRI estuvo centrada en las oficinas de Vinculación Tecnológica que jerarquizaron de la actividad, el diseño y la ejecución de políticas integrales de promoción de la vinculación y la transferencia tecnológica, con procedimientos de: 
propiedad intelectual, destinados a proteger los resultados de la investigación científica y tecnológica; convenios, para formalizar la vinculación entre el CONICET y las empresas u otras entidades que requieran conocimiento de personal científico tecnológico del Consejo; en la conformación de empresas de base tecnológicas, a partir de políticas de incentivo y apoyo al emprendedurismo tecnológico, desde el interés del CONICET avanzar activamente en este campo y adoptar un rol protagónico en el nacimiento y desarrollo de Empresas de Base Tecnológicas (EBT) desde el conocimiento y desarrollo generado por sus científicos; y al promover los Proyectos de Desarrollo Tecnológico y Social (PDTS), generando espacios de evaluación de informes para aquellos investigadores de la Carrera del Investigador Científico que realizan actividades de desarrollo y transferencia de conocimientos

Por solo situar las cuestiones halladas en el diagnóstico, en las distintas gestiones e instancias que se impulsan, permitió conocer todas las etapas para apuntar a la disposición desde la DRI para la producción y difusión del conocimiento que se produce en investigación, desarrollo, innovación, transferencia y gestión de políticas institucionales.

El desafío estuvo entonces en construir en un breve lapso de tiempo los equipos de trabajo que pudieran transmitir el saber que se genera en la institución al público en general. Hasta este momento, quienes tenían la responsabilidad de la organización de estos procesos no eran especialistas en el campo de la comunicación.

En la viabilidad de la incorporación de las herramientas es posible ver reflejada la importancia que se les asignó oportunamente en la Institución, con profesionales del campo del periodismo y la comunicación social, sin excluir los equipos transdisciplinarios (provenientes de la Carrera del Investigador Científico que funcionaron como asesores), los que se pensaron también para la articulación en el nivel de gestión de la institución con el resto de la sociedad. Quizás el proyecto más destacado en este aspecto haya sido País Ciencia -desarrollado más adelante-.

Es importante particularizar que este trabajo reúne elementos que surgieron del análisis de la comunicación interna y de las dimensiones que hasta ese momento componía no solo la tecnología sino la información intrainstitucional. Otros aspectos revisados hicieron a los destinatarios, formatos y lenguajes desarrollados por la DRI, los medios de comunicación con 
los que se relacionaba y las modalidades de intercambio de información que aparecían consolidadas entre las distintas gerencias, direcciones, CCT y UE.

El aspecto no menor ha sido evaluar y encontrar la ausencia de estrategias y/o políticas de comunicación hasta ese momento en la DRI.

En lo referente a la comunicación con la sociedad, acontecía la necesidad de revisar el escenario y las competencias generadas en divulgación y transferencia de conocimientos. Estableciendo en tal caso la necesidad de nuevas competencias, lo cual permitió resignificar el qué, cómo y para qué de la divulgación científica en cuanto a los intereses que debía perseguir, prestando especial interés en las demandas o carencias detectadas de comunicación a partir de la aplicación de la herramienta.

La definición antes ensayada destaca algunos rasgos como centrales, considerando que el concepto de divulgación desde la comunicación, se inscribe en: una estrecha relación del saber con el hacer y el actuar, establece una evidente relación con lo contextual y requiere con lo nuevo la respuesta ante lo complejo; relacionada con el complejo ámbito problemático la relación ciencia y sociedad.

Con respecto a esta tendencia de desarrollo actualmente se puede señalar que en la búsqueda del modelo apropiado la comunicación pública de la ciencia, en su más amplia conceptualización, resulta un elemento importante en las políticas de ciencia y tecnología y, por lo tanto, es responsabilidad de los organismos dinamizar recursos y herramientas a tal fin. Es importante resaltar que el concepto de fomento de la cultura científica resulta más abarcativo que la divulgación científica ya que supone ampliar el horizonte de llegada.

El conocimiento científico debe ser parte esencial del saber de las personas, de manera que permita interpretar la realidad con racionalidad y libertad, ayude a construir opiniones libres y a dotar de argumentos para tomar decisiones.

Un elemento que detalla una tensión existente y que contrasta en la realidad esta afirmación, teniendo en cuenta los resultados de la Tercera Encuesta sobre "La percepción de los 
argentinos sobre la investigación científica en el país" ${ }^{107}$, es cuando se analizan los "Hábitos informativos y culturales en relación a ciencia y tecnología".

Este es un indicador que muestra claramente que la amplia mayoría de los argentinos no se informa a través de la noticias científicas publicadas por los diarios. Solo un $15 \%$ de la población encuestada utiliza esta fuente de información de manera activa. Del orden de la mitad de la población señala que nunca se informa sobre ciencia y tecnología leyendo un diario. Un tercio de los encuestados indica que con cierta frecuencia mira programas o documentales televisivos sobre ciencia, tecnología y naturaleza. Este es un elemento a considerar que destaca el crecimiento particularmente en el conocimiento de las señales de televisión públicas: Canal Encuentro, Paka-Paka y TEC TV (Tecnópolis TV).

La búsqueda de información científica en Internet está en el mismo nivel que la lectura de diarios y, en el caso de la radio, el consumo se hace aún menos frecuente.

Los más jóvenes están comparativamente algo menos informados a través de estos medios pero sin que las diferencias con otros grupos de edad sean pronunciadas. Tampoco la región geográfica indica discrepancias y más allá de esto, tanto el consumo de noticias científicas como la ausencia de estas parecen distribuidos de manera sustancialmente equivalente en el territorio nacional.

Vinculando centralmente a que el gobierno sí es percibido como el principal agente de promoción de la ciencia y la innovación, recae entonces en las instituciones de educación y de ciencia y tecnología las demandas sociales que conllevan a un proceso que moviliza a muchos actores de la vida social en la promoción de acciones coordinadas de puesta en conocimiento de la ciencia y la tecnología; instituciones que desde la territorialidad deben concretan dichas políticas y materializar la innovación y desarrollo sociales en un proyecto de vida comunitario e inclusivo. Por ejemplo, sobre nuevas situaciones a nivel nacional que afectan al desarrollo de las políticas públicas se encuentran la creación del Ministerio de Ciencia y Tecnología, El Paseo del Bicentenario en 2010, la creación de Tecnópolis en 2011 (Parque del Bicentenario, Ciencia, Tecnología y Arte, considerada la feria de ciencia y

\footnotetext{
${ }^{107}$ MINCyT (2014). "La percepción de los argentinos sobre la investigación científica en el pais". Tercera Encuesta Nacional (2012), Ciudad Autónoma de Buenos Aires, MINCyT.

Disponible en: http://www.mincyt.gob.ar/_post/descargar.php?idAdjuntoArchivo=35806
} 
tecnología más grande de América Latina) así como las condiciones estructurales en las actualmente los científicos y tecnólogos hacen ciencia e innovación en el país.

En este reconocimiento se observa la importancia y trascendencia que implica contar con instituciones de producción integrales de políticas públicas, en torno a la creación y divulgación de las ideas, las experiencias, los debates, los análisis y las recomendaciones, tanto de la gestión como de los agentes que manifiesten su voluntad de vinculación e involucramiento bajo estas líneas de pensamiento y acción.

\section{Punto 4: Configuración}

El entendimiento más frecuente respecto a los medios resulta de la configuración que los decisores de la Institución realizan y donde aparece como un par indisociable, acerca de sus usos, el lugar de los medios como: transmisores y/o reproductores de contenidos, en función de los usos prácticos o las situaciones que así lo requieren. Desde las acciones de planificación comunicacional, pasando por el diseño de imagen y los intereses y funciones sociales implicados, se complejiza la lectura acerca de los medios en los espacios institucionales.

En relación con los usos como transmisores, el diagnóstico permitió observar la existencia de un imaginario acerca de qué esperan las autoridades acerca de los medios; en tanto que por sus usos, los medios ayudan resolver situaciones problemáticas y facilitan el desarrollo de la información vinculada a proyectos y programas, pero desde su dimensión técnica.

Esta determinación, si bien se observa o se puede leer que se expresa desde el conjunto de los decisores (con rango gerencial y de dirección), no se presenta en todos los casos de manera homogeneizante en cuanto a los sentidos que adquieren los medios masivos de comunicación y en cómo estos intervienen en la configuración de la percepción acerca de las posibilidades técnicas de llevar adelante prácticas vinculadas con la producción y puesta de conocimiento en ciencia y tecnología. 
En la medida que el tema fue abordado de manera individual con cada decisor, nos encontramos principalmente con definiciones donde los medios masivos de comunicación aparecían configurados y configuradores de la cultura. Esto nos obligó a pensar los debates y la comprensión de las significaciones culturales en torno de los medios masivos, hecho constituyente para el diagnóstico que permitió dar cuenta del estado de situación del que partíamos y el marco para planificar líneas de acción a ser implementadas desde la DRI en el tema. Esto visto frente al lugar que le asignamos en la gestión y desde una articulación razonable- entre la información sobre gestión, el conocimiento sobre transferencia e innovación, y el fortalecimiento y crecimiento de la Institución en entornos sociales y productivos.

Esencialmente aquí recuperamos aquello que sobre la gestión de la comunicación en una organización se traduce necesariamente en un juego de consensos y disensos, también de transformaciones, en el interior de la organización misma y en la multiplicidad de relaciones que ésta opera con su entorno.

Definitivamente durante este proceso en la DRI han emergido cuestionamientos explícitos sobre el lugar que se le asigna y desde donde se caracterizan a los medios tradicionales. Este no es un síntoma menor, ya que la incorporación de la Comunicación Institucional en este ámbito es reciente, pero la aplicación de una visión restringida en la institución fundamentalmente mediática estaba polarizada en los medios y desde una perspectiva tradicional.

Dicho así cuando se describe lo que es el espacio público, tal como se lo refería desde una mirada simplificadora, respondiendo acerca del lugar donde se instala la opinión pública, era presentado como la única realidad por los medios como la televisión, diarios, radios, revistas y cuanto medio esté disponible.

Estos posicionamientos de orden político-ideológicos nos han llevado a una productiva discusión político-comunicacional con los decisores y los integrantes del Directorio. En más de una oportunidad hemos coincidido y encontrado que el uso de una tecnología obedece, antes que a un supuesto determinismo de índole técnica, a verdaderas decisiones de los actores; es decir, desde el lugar desde dónde y acerca del cual se hacen las elecciones sobre los medios y el uso de las potencialidades propias de las tecnologías de las comunicaciones 
como opción en la gestión. El uso social de las medios y las tecnologías aquí es un espacio de tensión política y socio-comunicacional entre el momento institucionalista y el momento creativo, productivo y de las condiciones de oportunidad, posibilidad y circulación de información.

\section{Punto 5: Preguntas críticas}

El trabajo de diagnóstico realizado en la institución permitió, con antelación a cualquier decisión, efectuar una adecuada evaluación de la misma. Tomar conciencia de su modelo comunicacional actual dominante, dar cuenta del movimiento hacia nuevos modelos, buscar las necesidades auténticas, identificar prioridades, analizar cuidadosamente el contexto, consultar a todos los involucrados, comprobar las condiciones económicas, técnicas y de gestión.

Lo dicho puso sobre relieve la formulación de preguntas críticas que debería hacerse toda institución dispuesta a modificarse asumiendo, de alguna manera, que preguntarse por la comunicación es preguntarse por las prácticas y los sentidos que han ido configurando determinada forma de decir de la comunicación.

El primero de estos interrogantes se dirige a saber si la institución desea un gran cambio en su enfoque comunicacional. Lo segundo, interpretar a la institución como unidad de comunicación.

La referencia de la Institución como unidad de comunicación presupone en primera instancia el concepto de corresponsabilidad comunicacional. El primer término remite a estar inmersos en una unidad de comunicación, con pluralismo pero a la vez empujando en una dirección dada por ideales acordados. En tanto que la corresponsabilidad comunicacional toca a todos los integrantes de una institución.

Se apoya en la voluntad de comunicación que supone la existencia de una voluntad explícita de comunicar, en hacer el esfuerzo de llegar al otro. De buscar el intercambio y de establecer relaciones de interlocución (de voces que se intercambian, que no es lo mismo que hablar de 
destinatario o receptor) que supone alguien con ideas, historia, vida, afectos; y que no refiere a un problema de eficacia, sino que es humano de seres que se comunican con ideas, historia, vida y afectos.

Consideramos por tanto necesario indagar los procesos comunicacionales que se suceden a partir de la incorporación de diversas herramientas que se constituyen como objetivos de la DRI.

En ese sentido, los aportes que surgen del estudio de caso están centrados en contribuciones para el empleo, la mirada y perspectiva de mapas conceptuales propios de la planificación y gestión de procesos comunicacionales.

Un escenario deseable es la configuración del contexto que queremos para el desarrollo de un proceso, tal como lo platean Tomas Miklos y María Elena Tello ${ }^{108}$. Éste debe responder a preguntas: ¿cómo queremos que sea el escenario?, ¿cuáles habrán de ser sus características básicas?, ¿qué tareas iniciales requerimos para su diseño y proyección al futuro?, ¿cómo es el presente de la situación actual?, ¿cuáles son los problemas que obstaculizan actualmente el camino hacia el futuro deseable?, ¿qué distancia cualitativa hay entre el escenario actual y el futuro deseable?.

Asumimos al respecto -desde la planificación- la definición de Michel Godet ${ }^{109}$ quien señala que "un escenario es un conjunto formado por la descripción de una situación futura y la progresión de los acontecimientos que permiten pasar de la situación de origen a la situación de futuro".

Gestionar, es ir más allá de los aspectos técnicos o instrumentales, y esto está en estrecha relación con encontrar los modos de actuación que permitan arribar a escenarios futuros; para que estos se concreten se parte de entender a la planificación como una fase de la gestión.

\footnotetext{
${ }^{108}$ MIKLOS, Tomás y TELLO, María Elena: (1991). "Planeación Prospectiva. Centro de Estudios Prospectivos". Fundación Javier Barros Sierra, A.C. Edit. LIMUSA y Grupo Noriega Editores. México

${ }^{109}$ GODET, Michel. (1979). "The Crisis in Forecasting and the Emergence of the Prospective Approach. Pergamon Press". USA. (1985). Prospectivas y Planificación. CPE. Economía. París.
} 


\section{Punto 6: Agendas de gestión}

La acción llevada adelante desde la DRI se asentó sobre un largo camino que se pensó que debía preceder a nuestra gestión. La tarea concentró toda la actividad de las distintas áreas y consideró este espacio en movimiento para pensar en redes, en procesos, puentes, cauces, espacios, equipos, mediadores, a fin de construir una mejor comunicación. Una comunicación pensada de manera dinámica desde una posición que valoriza la capacidad dialéctica tanto de emisores como receptores, para transformar la realidad y tender hacia el desarrollo integral de las instituciones.

En línea con entendimientos generados de lo que aquí unos y otros constituyen en este organismo autónomo bajo la órbita del Ministerio de Ciencia y Tecnología, y como uno de los elementos centrales, se valorizó el lugar de los actores estatales (investigadores, profesionales y técnicos de apoyo, becarios, administrativos) a la hora de diseñar estrategias de posicionamiento en la agenda pública.

Por otro, se interpretó la mediación y no solo la mediatización. Esto requirió abrir los debates necesarios para la comunicación institucional. Se centraron en la necesidad de fortalecer lo institucional como el ámbito que establece los posicionamientos estratégicos de la mediación de intereses bajo la responsabilidad de enfocar hacia el espacio público, como aquel en el que además de la lucha por los intereses comunicacionales se crean y sostienen los colectivos identitarios orientados a reglas y valores.

En la misma complejidad del proceso de análisis y construcción institucional la comunicación no puede quedar reducida al diseño publicitario o al marketing, en las que la formación en comunicación es subsidiaria de estas áreas, o sustentada solo en estrategias orientadas a los medios masivos de orden nacional.

A partir de observar las características salientes de la organización, las prácticas hegemónicas, las prácticas tradicionales, los ejes normativos, su estructura orgánica, su estructura administrativa y física, las redes y flujos informativos y comunicativos, los sujetos institucionales y vinculaciones multiculturales; precisamente la comunicación no se reduce y 
circunscribe al lugar de los medios y se relaciona con el marco cultural y las condiciones sociales e históricas de producción.

En la interpretación de carácter de la articulación de intereses se logró replantear el lugar de los medios de comunicación para intervenir en el espacio público, a través de la argumentación desde el lugar que ocupa en el CONICET la ejecución de las políticas públicas. A la luz de estas reflexiones, se consideraron y analizaron las características del espacio público ${ }^{110}$ y los territorios de la comunicación en la que los actores pujan por incluir sus demandas en la agenda pública.

El desafío estuvo en interpretar sus formas de promover el nuevo conocimiento, su significación de la acción sobre la realidad dentro de la diversidad de instituciones de ciencia y tecnología de la Argentina.

Aclarado un primer debate con los decisores institucionales (integrantes del Directorio, gerentes y directores de direcciones y de los CCT) acerca del rol del comunicador social y su actividad, entendido desde su actividad como generador de acciones en la construcción de los campos laborales delimitados como incumbencias de los comunicadores, esto propició la posibilidad de diagnosticar e intervenir en las actividades de los sujetos por intermedio de acciones comunicativas que alentaron a la participación en la organización.

Por esta razón para explicar pero, principalmente, para comprender las situaciones comunicacionales concretas, el diagnóstico fue el instrumento central para el reconocimiento de los antecedentes, la recuperación de otras experiencias, la evaluación y las perspectivas futuras.

En tanto, al revisar desde enfoque basado en las representaciones sociales nos permite considerar que lo que una organización es y hace, es una construcción colectiva de significados, y estos son retraducidos, y se hacen presentes en los discursos, las prácticas, los

\footnotetext{
110 SOUZA, María Silvina (2005). "El espacio público como objeto transdisciplinarios. Cruces y transversalidades". Anuario de investigaciones 2004. Editado por la Secretaría de Investigaciones Científicas y Posgrado de la Facultad de Periodismo y Comunicación Social. Universidad Nacional de La Plata.

En este artículo, Souza menciona y destaca al espacio público o, de una manera más amplia y articulada, el espacio colectivo, que reconocemos desde lo institucional a partir del vínculo que ejerce la Red Institucional en las distintas ciudades del país, es o debe ser el espacio más importante en la ciudad, puesto que allí se realiza la actividad fundamental para la colectividad que la habita. De otra manera, podríamos decir que es el espacio público el que hace a la ciudad y la diferencia de una simple agrupación de casas y edificios. Suma además la definición de Fernando Viviescas (1997) en "Espacio Público. Imaginación y planeación urbana" quien, bajo conceptos de las ciencias sociales, se refiere al espacio público como sustento jurídico-político de la expresión autónoma y de la creatividad individual, para la socialización, la crítica, la decantación y depuración colectiva de los planteamientos, de los criterios, de los imaginarios y, también, como entidad física, como continente y determinante de la calidad de lo que se dice, de lo que se piensa, de lo que se juega y de lo que se diverge. Espacio público, entonces, como cualificador de la existencia individual y colectiva, y del ejercicio, uso y disfrute de la ciudadanía.
} 
modos de relacionamiento interno y externo y en un conjunto de evidencias que la organización construye a través del tiempo. A pesar de que parecieran aparecer naturalizados y espontáneos, los discursos son definidos y actúan desde su historicidad, su impacto momentáneo y el sentido de futuro al que apuntan.

La mediatización de los mensajes que circulan acerca del sistema científico y tecnológico se da en los medios de comunicación y en revistas especializadas ${ }^{111}$ (las publicaciones especializadas configuran uno de los medios más importantes para asegurar la más amplia difusión de los resultados y conclusiones de sus investigadores tanto para el respaldo, refutación o uso del conocimiento generado).

Aunque evidente, esta ha sido la primera distinción que no es caprichosa e involucra una historicidad acerca de la acción en comunicación en la Institución, la cual delimita los terrenos en los que se incidía.

Por una lado, pasar del momento institucionalista y reproductivo a un momento instituyente y creativo debe buscarse en nuevas propuestas y reconocer la problemática de la apropiación y uso. En la adopción de esta concepción es importante revisar la reflexión de Daniel Prieto Castillo acerca de que la "planificación de la comunicación institucional es una necesidad de las organizaciones públicas y privadas, aunque muchas no hayan tomado conciencia de ello" ${ }^{112}$, y su ausencia -destaca- provoca "problemas tanto en las relaciones internas como externas".

A partir del relevamiento de acciones en la DRI se pudieron determinar las formas comunicativas e iniciativas de prensa que se llevaban adelante, las actividades y medios disponibles, lo que da lugar a poder afirmar que se carecía de mínimas pautas para el trabajo sobre lo cual fue necesario desarrollar conocimiento y acciones tendientes a mejorar las condiciones. En lo que se venía generando los medios de comunicación en general tenían una activo y decisivo lugar en la generalización de la acción de comunicar. Tras considerar que la

\footnotetext{
${ }^{111}$ Las investigaciones realizas por equipos científicos argentinos han alcanzado impacto internacional y han llegado a ser publicación de tapa en revistas de prestigio científico internacional, como es el caso de: Cells (2014, Glycosylation-Dependent Lectin-Receptor Interactions Preserve Angiogenesis in Anti-VEGF Refractory Tumors); Nature Medicine (2010, A sweet path toward tolerance in the gut); Nature Protocols (2009, Transient transformation of sunflower leaf discs via an Agrobacterium-mediated method: applications for gene expression and silencing studies); Science (2007, Blue-light-activated histidine kinases: two-component sensors in bacteria); Nature (2004, Coupling of agonist binding to channel gating in an ACh-binding); PNAS (2004, Analysis of Rhizobium etli and of its symbiosis with wild Phaseolus vulgaris supports coevolution in centers of host diversification), entre otros publicaciones y en cuanto solo a destacar las más importantes en investigación básica nacional.

112 PRIETO CASTILLO, Daniel (1993). "Planificación de la comunicación institucional". San Salvador: Universidad Centroamericana José Simeón Cañas. Mimeo.
} 
comunicación se podía resumir desde la DRI desde esa perspectiva, entendida en términos consensuados por los decisores del CONICET, es que se trabajó en integrar la idea de procesos comunicacionales, entendidos como complejidad de factores que se entrecruzan en el quehacer de los individuos y de los actores sociales. Dicho así y sin desestimar el lugar de los medios, sí es necesario producir sentido en el ámbito de la vida cotidiana y desde la tarea institucional encomendada, para lo cual se requiere planificar estrategias de comunicación desde una perspectiva que supera el mero hecho de diseñar modos de acceder a los medios o de generar informaciones desde las áreas de prensa. Las acciones destinadas a generar diálogos e intercambios públicos también necesitan incorporar a las nuevas tecnologías de información y comunicación, por ejemplo, hecho que se convierte en un camino ineludible. Al promover sentidos políticos y culturales, y al apoyar a los productores de información desde aspectos de comunicación específicos del ámbito científico y tecnológico, también se da sustento a las políticas públicas.

El análisis de dichas articulaciones permitió visualizar y poder alcanzar un síntesis de múltiples relaciones, al fin de señalar que estas actividades se generaban bajo el predominio de una mirada instrumentalista que se limitó a un supuesto rol difusor de la comunicación y el lugar que ocupan los medios.

El diagnóstico demostró la falta de coordinación en la información generada y los superposición de pedidos a una misma área. Los responsables de brindar información a la prensa o responder a las solicitudes no contaban con lineamientos claros ni con información consolidada, carecían de voceros y les era recurrente la imposibilidad de interrelacionar los datos. El lugar de los medios se concebía desde formas de relacionamiento, de vinculación y de negociación posible de graficarlo como un "delivery" ante los pedidos de periodistas.

En este sentido, se contaba con información segmentada o parcializada que impedía realizar análisis más complejos, multidimensionales y oportunos en el tiempo para la toma de decisiones comunicacionales o para elevarlos a los decisores y poder proceder.

Aquí se debe reconocer que la intervención e injerencia en la definición de políticas comunicacionales estuvo definida por los decisores institucionales, presidente y directores del Directorio. 
Su injerencia va desde validación en la conformación técnico operativa del área, en la disposición de las actividades de comunicación al mismo tiempo que del uso de los instrumentos informativos. Centrado en las decisiones del presidente y los vicepresidentes, estas disposiciones eran determinantes en las funciones específicas de la labor previas a la creación de la DRI y hasta nuestra llegada. Esto en cuanto al conjunto de los destinos de la política institucional centralmente y en la producción y generación de condiciones para que los conocimientos, las producciones y los contenidos pudieran se comunicados o transmitidos por las tecnologías disponibles.

Con el arribo a la dirección se determinó que la nueva instancia de ordenamiento para la gestión comunicación tendría como lugar de exposición y debate a las reuniones de gerentes y directores y, centralmente, a las plenarias de Directorio con una frecuencia quincenal. Este fue el lugar de las respuestas y solicitudes de encuadres frente a los acontecimientos del devenir político institucional y de temas de gestión.

Más allá del uso o del manejo de los medios de comunicación, debate recurrente en este espacio, supuso desde un primer momento precisar y hablar de determinados temas desde posición de la comunicación en su integralidad y en su complejidad.

Desde el conjunto de prácticas que se realizaron a partir de la coordinación y articulación de las distintas experiencias, desde cada una de las 5 herramientas planificadas e impulsadas, consistentes en el trabajo de acompañamiento en las comunicaciones de los investigadores, el seguimiento del desarrollo de temas prioritarios en investigación pasando por los debates y las condiciones de oportunidad, posibilidad, producción y circulación de información, siempre se buscó poner en superficie las complejidades originadas entre las dificultades y los desafíos.

Por otro lado, surgió la necesidad de concentrar la mirada en las tecnologías de información y comunicaciones (TICs) como espacios tanto de implementación de los proyectos, es decir, considerarlos como ámbitos de renovación de imagen institucional en apelación válida a una mejor democracia institucional, pero también como sedes de luchas por el sentido, el uso y la apropiación.

En relación a su uso institucional se hicieron manifiestas posiciones que sostienen o ponen el acento en las mismas como herramientas de eficientización de la administración pública y 
quienes, en el mismo marco institucional, buscan que su uso apuntale el desarrollo de opciones democráticas más extendidas y de esencia deliberativa y continua.

En el espacio de la comunicación y las instituciones las tecnologías de información y comunicaciones, presentan retos que afectan desde la necesidad de enfrentar el cambio de paradigma que significa la digitalización de la comunicación.

La apelación a las potencialidades de las TICs para favorecer la construcción de redes sociales, la participación democrática y el acercamiento a la ciudadanía, ha sido analizado en la búsqueda de preservar como premisa esta relación. Se ha observado que frente a este terreno los requerimientos giraban más en alcanzar parámetros de eficiencia que en generar un conocimiento más profundo de la propia acción institucional generada, instancias que eran observadas en cuanto a modelos de replicabilidad de experiencias exitosas del sector privado con analogías que situaban a los ciudadanos al rol de clientes a quienes proveer servicios.

Encontramos enfoques que permiten sostener que las innovaciones tecnológicas en los procesos comunicativos, donde cada tecnología (como cada medio) si bien tiene posibilidades distintas y específicas no posee, sin embargo, una direccionalidad comunicacional intrínseca, sino que sus usos dependen de las concepciones o propuestas que permitan enmarcarlas y otorgarles sentido.

Utilizar Facebook y/o Twitter (Conicet Dialoga ${ }^{113}$ ) como otras al alcance de un organismo del Estado, requiere no solo disponer información sino focalizar en que esa producción debe responder y estar acorde a los propios intereses y dinámicas que se da para sí la Institución. Porque si bien las páginas de Facebook y el espacio del Twitter tienen lógicas preestablecidas en el momento del diseño, no deben tomarse como meros instrumentos, sino que deben integrar y ser parte de los diagnósticos y seguimientos con la finalidad de evaluar cuáles deberán ser sus aportes y éstos, desde la planificación comunicacional y la gestión de procesos comunicacionales, como contribuyen a componer a la organización.

A la luz de las nuevas realidades, se sitúa en la necesidad de obtener respuestas sobre las potencialidades tecnológicas para generar propuestas de comunicación partiendo del sitio Web institucional como respuesta.

${ }^{113}$ Las direcciones son: https://es-es.facebook.com/ConicetDialoga y https://twitter.com/conicetdialoga 
De acuerdo con nuestra perspectiva, la posibilidad de pensar formas nuevas de comunicación no está nunca disociado de su composición: la interacción de espacios reticulares, individuales y grupales; de campos cooperativos de producción de sentido y de interpretación y reconocimiento, es decir, de conocimiento y fundamentados en la socialización.

En este proceso se propuso desde el primer momento utilizar los canales comunicacionales formales del Estado argentino (dependientes de la Secretaría de Comunicación Pública de la Jefatura de Gabinete de Ministros), y buscar garantizar la articulación entre las diversas instituciones comprendidas bajo el esquema de federalización dispuesto por el CONICET con estrategias para la articulación regional y de estas con la comunidad. Este desarrollo incluyó la difusión de políticas institucionales tendientes a fomentar actividades de investigación, desarrollo tecnológico y vinculación con las universidades y los sectores público y privado. Promover mecanismos conjuntos de cooperación con el sistema universitario argentino. Coordinar procesos de comunicación interinstitucional y participar en los procesos de integración e intercambio a nivel nacional e internacional en las líneas de interés y desarrollo del organismo, y conducir acciones para instalar su liderazgo en el ámbito de su competencia.

En este contexto, se evaluó la implementación de la ley de Servicios de Comunicación Audiovisual 26.522 que propugna ampliar las voces y las miradas. En debates con comunicadores, especialmente del Ministerio de Ciencia y Tecnología, el INTA, el SENASA y la $\mathrm{CNEA}^{114}$, coincidimos en la necesidad de otorgarle visibilidad, legitimidad a las acciones institucionales en el marco de lo que plantea la Ley.

\footnotetext{
${ }^{114}$ En el caso del Ministerio, desde el Área de Comunicación y Prensa se nutre de contenidos a TEC TV. El INTA produce el noticiero Pampero TV junto al Canal 12 de Trenque Lauquen, de la provincia de Buenos Aires, a partir de un convenio entre el organismo y Radio Televisión Argentina (RTA), con colaboración del SENASA. La CNEA ha desarrollado producciones para Construir TV. En cuanto al CONICET, a través de su productora CONICET Documental desarrolla contenidos que se difunden por Paka-Paka, Encuentro, TEC TV y la Televisión Pública.

Estas y otras propuestas integran la programación de los canales disponibles a través de la Televisión Digital Abierta (TDA). La TDA es el resultado de política de integración digital impulsada por el Ministerio de Planificación Federal Inversión Pública y Servicios que, con la más moderna tecnología digital, transmite en alta calidad de imagen y sonido de manera gratuita, permitiendo integrar y ofrecer adicionalmente otros servicios interactivos.

Pero quizás su lugar más destacado esté en la historia política como hecho central. En la decisión de Cristina Fernández de Kirchner de promover el ingreso de nuevos actores sociales y de los radiodifusores existentes a un nuevo sistema televisivo como el propuesto por la TDA. Un hecho plasmada en la Ley de Servicios de Comunicación Audiovisual sancionada en 2009, donde se reconoce el lugar de las organizaciones sociales, los pueblos originarios y las universidades, entre otros, y que tienen la oportunidad de acceder a licencias o permisos de radiodifusión abriendo el juego al ingreso de nuevas voces.

La Ley de Servicios de Comunicación Audiovisual apunta centralmente a revertir la conformación oligopólica y monopólica que presenta el sistema de medios en Argentina. Los aspectos que destaca están en multiplicar las voces a partir del reconocimiento del sector público, el sector privado comercial, y el universo de las organizaciones libres del pueblo. Esta normativa democrática, antimonopólica y moderna en términos tecnológicos impacta cualitativamente en las relaciones sociales y políticas del país generando una acceso más democrático para que todos podamos disfrutar de las tecnologías de la comunicación y la información y de los bienes culturales. Su importancia está dada en la medida que logra transformarse en una herramienta vital de las comunidades en la permanente lucha por mejorar sus condiciones de vida y en la tarea constante por alcanzar la justicia social.
} 
Esto permitió alcanzar una mayor certeza y abonar a una realidad sobre la existencia de voces que permite la misma y correr -críticamente- el debate del lugar en el que lo han instalado las grandes corporaciones de medios; y, por otra, impulsar y sumar a las organizaciones sociales para afirmar que como organismos del Sistema Nacional de Ciencia, Tecnología e Innovación se debe dar un proceso de definición en torno a las mismas (centralmente sobre la Ley, el lugar de las organizaciones y los medios audiovisuales) para completar un debate aún inconcluso o poco abordado por las áreas de comunicación del Estado y los decisores políticos, acerca de las particulares condiciones de confrontación con los medios masivos de comunicación, de la movilización y discusión social y política en torno a lo que esta genera.

El derecho a la comunicación es condición necesaria para la reivindicación de los derechos de otros ámbitos de lo social porque sin posibilidades de aparición y presentación en la esfera pública, de articulación y expresión de demandas, etc., no es posible el reclamo por la vigencia o ampliación de cualquier otro derecho. Sin lugar a dudas la continuidad del reclamo por su aplicación debería ser uno de los principales temas de los funcionarios estatales en todos los niveles, así como pensar en disponer medios y recursos para diversificar los contenidos, superar la visión instrumental de la relación entre comunicación y medios y considerar a la comunicación como una condición necesaria para la vida en democracia. 


\section{CAPÍTULO VII}

\section{Diagnóstico de la comunicación en la Red Institucional}

Durante el desarrollo de esta tesis se definió la importancia que tenía para el trabajo comunicacional la Red Institucional integrada por los Centros Científicos y Tecnológicos $(\mathrm{CCT})^{115}$ y los dos Centros de Investigaciones Multidisciplinarios (CENPAT y CADIC). Y por tanto, no menor en estas unidades la labor de los comunicadores institucionales desde donde cobra importancia la comunicación y la implementación de las herramientas comunicacionales impulsadas de la Dirección de Relaciones Institucionales.

El proceso iniciado en 2012 desde la DRI coincide con el avance en la aplicación -en 2010 y 2011- del Programa de Evaluación Institucional (PEI), a partir del convenio entre el Ministerio de Ciencia, Tecnología e Innovación Productiva y el CONICET ${ }^{116}$. Cuando se impulsaron las herramientas de comunicación previamente se tomó conocimiento de los distintos estados de avance de los PEI en los CCT y Centros Multidisciplinarios a los fines de conocer las demandas en comunicación.

El Programa fue gestionado desde la Subsecretaría de Evaluación Institucional, perteneciente a la Secretaría de Articulación Científico Tecnológica del Ministerio de Ciencia, Tecnología e Innovación Productiva (MINCyT) en coordinación con la Gerencia de Evaluación y Planificación del CONICET, y en cada caso la autoevaluación es abordada a través de la descripción y revisión de las acciones de los CCT desde una mirada holística, sistemática e histórica de toda la Institución.

El PEI promueve la evaluación permanente y el mejoramiento continuo de las instituciones pertenecientes al Sistema Nacional de Ciencia, Tecnología e Innovación, para lo cual se les ha brindado a las instituciones intervinientes el apoyo técnico y económico. Una cuestión a

\footnotetext{
${ }^{115}$ De acuerdo a la definición que maneja el CONICET para la aplicación del PEI, los Centros Científicos Tecnológicos (CCT) constituyen un conjunto heterogéneo por el contexto institucional en que están insertos, el número, trayectoria y personal de las unidades ejecutoras, la variedad de sus relaciones de dependencia con otras instituciones y las disciplinas comprendidas. La heterogeneidad en las dimensiones anteriores explica diferencias observadas en su proceso de consolidación y modo de funcionamiento, así como en la recepción y apreciación de sus servicios por parte de quienes componen las unidades ejecutoras (UE), investigadores y becarios. Esta heterogeneidad también explica algunas de las características de funcionamiento de los CCT y de sus contribuciones.

${ }^{116}$ Aclaración: todos los documentos institucionales con los que se trabajó, que corresponden a la autoevaluación como a la evaluación externa, están listados en el apartado correspondiente a la bibliografía.
} 
destacar es que la evaluación constituye una obligación permanente del Estado y las instituciones pertenecientes al sistema, tal como lo establecen los artículos 23 y 24 de la Ley Marco 25.467 de Ciencia, Tecnología e Innovación.

Los objetivos del programa reflejan la necesidad de acompañar el proceso de autoevaluación, brindando asistencia técnica y apoyo financiero para su realización; gestionar el proceso de evaluación externa; organizar y acompañar la evaluación externa; brindar asistencia técnica para la elaboración de los planes de mejoramiento y monitorear la implementación de los planes de mejoramiento.

Desde su inicios la implementación del Programa en CONICET planteó dos etapas, una de autoevaluación y otra de evaluación externa, para posteriormente dar respuesta a través de los planes de mejoramiento a las necesidades vigentes.

Hasta el mes de octubre de 2014 eran 11 CCT y 2 Centros Multidisciplinarios los que habían completado las dos etapas y estaban en distintos momentos en el proceso de desarrollo de los planes de mejoramiento. Estos son: Bahía Blanca, La Plata, Córdoba, San Luis, Santa Fe, Rosario, Tucumán, Patagonia Norte, Mendoza, Nordeste, Mar del Plata, CADIC y CENPAT. El CCT Salta es el único que no había iniciado ninguna de las etapas.

Esta autoevaluación que abarcó tanto la misión y objetivos como los procesos de gestión organizacional, la actividad científico tecnológica, sus productos y resultados brindó información suficiente que permitió evaluar y analizar el funcionamiento de cada uno de los CCT mencionados en lo que refiere a la comunicación institucional.

Al respecto, el CONICET adoptó como parte de sus políticas de modernización de la gestión la implementación del PEI y, desde este punto de vista, facilitó y puso a disponibilidad información valiosa acerca de poder conocer los mecanismos internos que dan cuenta de la complejidad institucional en cada unidad, desde la estructura vigente y aquella no formalizada, los mecanismos de negociación y aspectos técnicos -considerados desde la gestión-; como así también flujos de información y comunicación, entre otros, del que participan distintos actores en la generación de acuerdos para la toma de decisiones.

Además, y más allá de los casos particulares, se evaluaron los desafíos comunicacionales a partir de procesos reconocidos y en base a la comprensión de la complejidad organizacional. 
Es decir, en el contexto en el que actúan, en su evolución, en los cambios que van produciendo en el entorno y en la incidencia que estos organismos de la Red Institucional tienen en la generación de la agenda pública donde se encuentran.

Estos elementos desde una perspectiva analítica permitieron observar el funcionamiento a lo largo de distintas fases, los estadios en las dinámicas y el accionar, actividades, dimensiones, alcances y dispositivos socio-institucionales en los cuales era necesario pensar; para alcanzar una combinación de insumos y la interacción de los agentes institucionales que podían fortalecer tanto la formulación ajustada a cada CCT y la implementación de las herramientas comunicacionales (ver Capítulo VIII). Adoptar esta perspectiva suponía ventajas sustanciales que caracterizarían la aplicación de herramientas comunicacionales como el impulso de procesos en unidades donde hasta ese momento carecían de un comunicador y de la institucionalización de un Área de Comunicación Institucional.

A diferencia de otros abordajes, trabajar sobre la consolidación de herramientas comunicacionales en la Red Institucional aparecía como posibilidad para la agregación de capacidades de las áreas de comunicación. Y su importancia no estaba en la característica individual de cada componente, sino en las relaciones y el grado de integración entre las áreas vigentes (y aquellas por conformar) con la DRI y viceversa. Articular permitiría considerar el monitoreo, la evaluación y los resultados de las herramientas aplicadas a los procesos.

El desarrollo de las mismas a través de los comunicadores integrantes de la Red aportaría: conocimientos, prácticas y técnicas, hábitos, formas de obtención de la información, criterios comunicacionales y estéticos, conocimientos científicos y saberes consuetudinarios, visiones y configuraciones de orden de prioridades, subordinación de acciones, formas de poder y regímenes de la relación con el entorno social.

A la vez que se aplicarían condicionando formas de uso, pertinencia y necesidad de conocimientos, y en función de niveles de generación de beneficios, de organización de la producción, de procesos de reconocimiento de la territorialización y visiones acerca de lo que es posible e imposible en y desde la gestión institucional.

Los documentos generados a partir del PEI fueron insumos para comprender las diferentes perspectivas de abordaje del fenómeno institucional y de conocimiento como nueva formas de pensar lo organizacional. 
El PEI tampoco resultó ser un insumo conclusivo, ya que aportaba el qué pero no el cómo donde la comunicación era uno de los aspectos a focalizar a partir -esencialmente- de que se había utilizado la matriz FODA (Fortalezas, Oportunidades, Debilidades y Amenazas), como herramienta de análisis para profundizar sobre las distintas realidades de las unidades de la Red Institucional.

En cada uno de los CCT, sobre los aportes de estos documentos, se realizaron ajustes metodológicos y consideraciones para el diagnóstico, resultando una primera radiografía de la potencialidad, las fortalezas y las debilidades del entramado científico regional y su vinculación con los organismos de la región, especialmente con las facultades y las universidades.

De modo tal que el PEI se constituyó para la DRI en la base documental primaria entender y poder elaborar a posteriori una serie de estrategias a los fines de fortalecer el funcionamiento de la comunicación en los CCT y Centros Multidisciplinarios.

En el desafío de la gestión que se iniciaba desde a DRI, en un campo caracterizado por la complejidad y la rapidez de los cambios, el dinamismo del ambiente científico, su creciente interdependencia con las universidades en investigación y desarrollo pero también en la faceta económica, y en las modalidades de gestión compartida de los centros y laboratorios de doble dependencia ${ }^{117}$, se recorrieron durante 2012 todos los CCT y Centros Multidisciplinarios.

A los fines de coordinar la organización y gestión del trabajo y la comunicación institucional en los CCT donde se contaba con un comunicador o encargado de las instancias comunicacionales, se dialogó con el Director. En aquellas unidades donde no existía la figura del comunicador se destacó frente al Consejo Directivo (CD), que dirige al CCT y que está integrado por todos los directores de las UE vinculadas al mismo, la relevancia que adquiría su figura a fin de mantener, ampliar o crear alternativas dentro de la institución.

Estos diálogos implicaron situar el lugar de los profesionales de la comunicación en sus prácticas y elaborar estrategias de acción para colaborar con la gestión institucional, por lo

\footnotetext{
${ }^{117}$ En la versión de agosto de 2012 del "Informe de Autoevaluación del Centro Científico y Tecnológico CONICET La Plata" se destaca que cuenta con 2.200 agentes, de los cuales unos 800 son investigadores y un $28 \%$ se encuentra fuera de las 23 Unidades Ejecutoras (UE). La magnitud de este CCT por si solo explica que las actividades científicas y tecnológicas que allí se desarrollan abarcan todas las áreas del conocimiento. El CCT cuenta con 18 UE de doble dependencia entre la Universidad Nacional de La Plata (UNLP) y el CONICET, cuatro con la Comisión de Investigaciones Científicas de la Provincia de Buenos Aires (CICPBA), y una de dependencia exclusiva del CONICET.
} 
cual se planteó y fundamentó la necesidad de cada recurso también ante la Gerencia de Recursos Humanos y el Directorio del CONICET.

Fue así que entre la articulación de saberes y premisas de trabajo los comunicadores debían, al configurar un nuevo espacio comunicacional, integrar conocimientos para la producción de materiales y productos, articular y contribuir en la difusión y desarrollo de noticias y artículos de divulgación y, desde la aplicación de las herramientas comunicacionales, aportar a la configuración de la relación entre las circunstancias contingentes y los desafíos institucionales.

Aportes que con la colaboración de la DRI circunscribieron las funciones pero que además requirieron la comprensión del contexto en el que se desarrolla la ciencia nacional y los aspectos que como tales condicionan, enmarcan y determinan las posibilidades de la práctica comunicacional en la institución.

\section{La comunicación en la Red Institucional}

La conformación desde un inicio de herramientas comunicacionales para la gestión de la comunicación institucional tuvo su adecuación junto a los miembros del equipo de trabajo de la DRI hacia la sustentabilidad de las mismas y su institucionalización en la Red.

Para cumplir con lo señalado se recuperaron las vacancias informadas en los documentos del PEI y los aportes resultantes de los encuentros promovidos y apoyados por distintos actores institucionales, sobre aspectos a incluir y poner de manifiesto hacia la configuración de la gestión inclusiva del trabajo en Red. Esto con relación al trabajo en temas críticos, a la construcción y a la viabilidad para la implementación de programas e intervenciones sociales, sobre diferentes tratamientos de contenidos y modalidades según las condiciones en las que se desenvuelve la gestión de cada unidad, la programación de actividades y los procesos subsidiados, coproducidos, o con apoyo directo e indirecto de la DRI. 
Al respecto, se considera necesario recuperar esas nociones para abordar aspectos relativos en torno a la evaluación de la comunicación en los CCT y Centros Multidisciplinarios.

La importancia de estas cuestiones comunicacionales implicó asignarle a la institucionalización y al afianzamiento de las actividades y procesos de la comunicación un lugar relevante y prioritario, lo que permitió hablar de herramientas y facilitar y conducir los procesos de programas y proyectos a nivel país desde la DRI.

La combinación de momentos internos y externos de evaluación resultó un ejercicio de traslación del esquema de funcionamiento de las unidades en cuanto a las particularidades de los proyectos, intenciones y objetivos y sus contextos.

Para ahondar en lo ya detallado se citan las principales dimensiones que caracterizaban lo comunicacional, de acuerdo a los documentos del PEI, en los CCT y Centros Multidisciplinarios.

\section{-Aspectos observados sobre la comunicación:}

Los relatos orales y escritos de los actores institucionales (directores e integrantes de los Consejos Directivos) consideran el reconocimiento y la legitimidad de la comunicación en materia de difusión de las actividades (materiales científicos, libros, acontecimientos institucionales) y su valoración para la creación de una plataforma institucional que sirva de base para la comunicación de la comunidad científica del CONICET con la región.

Sobre los criterios expuestos acerca del funcionamiento de las áreas de comunicación en los CCT y Centros Multidisciplinarios, se partía del conocimiento de la existencia de líneas de base confeccionadas y ejecutadas sobre lineamientos estratégicos de comunicación y relaciones públicas consensuados con los Consejos Directivos. Estos lineamientos habían sido pensados y orientados en la promoción de actividades propias y asociando a los centros de investigación y laboratorios administrados por el CCT, pero carecían de articulación en la valoración de las posibilidades para hacer trascender temas de investigación, transferencia e información de la gestión más allá del área de influencia. Dado el interés que determinados desarrollos o temas generan en la comunidad y en la opinión pública. 
Se evidenciaba en el personal del CONICET de las áreas de comunicación la necesidad de fortalecer los vínculos con las facultades y las universidades, a partir del vínculo de la doble dependencia de centros de investigación y laboratorios.

\section{-Estrategias de difusión:}

En políticas y estrategias de difusión y extensión de las actividades científicas y tecnológicas unos pocos CCT contaban con un Área de Relaciones Institucionales reconocidas como tal, cuya función consistía según la visión aportada en la evaluación en posicionar al organismo en la vida pública de la región, generando una estrategia de acercamiento a la comunidad.

De acuerdo a dicho enfoque al cumplir esta función, la estrategia de comunicación contiene un enfoque integrador de diferentes canales y herramientas para distintos públicos y mensajes.

Al respecto, se señalaba una correspondencia en la ejecución de estas estrategias en sintonía con la política de comunicación estructural y común para todo el país fijada en los distintos encuentros de comunicadores del CONICET de todos los CCT anterior al 2012, pero atendiendo a las adaptaciones necesarias para cada región.

En las funciones del Área de Comunicación se incluían como acciones específicas las relaciones con la prensa, la comunicación en situaciones complejas (crisis, rumores, controversias públicas), las actividades de comunicación interna, y el asesoramiento en el diseño de materiales de comunicación.

Eran además sugeridas las adecuaciones de las relaciones con representantes de gobiernos nacionales, provinciales y municipales, la colaboración con la organización de actividades de divulgación científica, como jornadas científicas, ferias de ciencia, premios, entre otros; la gestión y ordenamiento de la información científica del CCT; la gestión del sitio WEB y la comunicación audiovisual.

Dadas las evaluaciones se pudo contar con la información acerca de que las actividades de un Área de Relaciones Institucionales se centraba -básicamente- en dos funciones reconocidas 
por las autoridades de los CCT: relaciones con la prensa y comunicación en situaciones complejas.

Dados los diagnósticos que imponían enfoques conceptuales y opiniones o los puntos de vista de los decisores institucionales, se asumía y reconocía en las evaluaciones que desde la situación inicial planteada se requería tiempo para impulsar las acciones siendo esto más visible en los CCT con mayor número de Unidades Ejecutoras (UE) a cargo. También resultaba ser un inconveniente la presencia de un solo comunicador en muchos de los CCT.

Las evaluaciones dieron cuenta de que el comunicador fue un articulador de las políticas internas en cada caso para la integración de las necesidades comunicacionales planteadas y para dar sustento al relacionamiento con los medios, viéndose incrementado año a año según la cuantificación de notas periodísticas publicadas en diversos medios periodísticos.

Otros aspectos donde tuvieron una destacada intervención los comunicadores surgía de las actividades de difusión que realizaban las UE, donde pudieron distinguir las comunicaciones oficiales orientadas a la comunidad científica, como la participación en los congresos, los encuentros y las publicaciones y las que estaban dirigidas a un público más amplio, integrado por usuarios de los conocimientos científicos y tecnológicos, como el personal del sector industrial o de diferentes áreas estatales.

Entre las actividades en las que intervinieron los comunicadores se contaba la participación en ferias, exposiciones y jornadas, tanto en la organización, logística como en la confección de notas para enviar a medios de comunicación y destinadas a las web de los CCT.

En la lista de acciones también se consideran aquellas realizadas con colegios secundarios de la región y visitas guiadas para estudiantes. Asimismo, en proyectos de difusión propios de las UE para escuelas primarias consistentes en capacitaciones a docentes y profesores.

La complementación de acciones integrales o esporádicas se orientó en la confección de folletos, posters, artículos y publicaciones de divulgación en diferentes tipos de medios de comunicación y la difusión a través de las páginas web institucionales.

Las actividades de extensión y difusión también se realizaban por iniciativas que dependían en mayor o menor medida de los grupos de investigación e investigadores y de las propias 
UE. Según los informes, el tipo de investigación que desarrolla cada UE condiciona sus posibilidades de realizar estas actividades.

En otras líneas, se generó la participación de los comunicadores en la edición de revistas y en charlas abiertas a las escuelas y a la comunidad y en el desarrollo de presentaciones con atractivos para los visitantes a los CCT y UE.

\section{-Tecnologías disponibles:}

En todas las evaluaciones, con respecto a los medios tecnológicos que se empleaban para la comunicación institucional, se destacó el hecho de que pocas UE contaban con página Web activa y menor era el número de las que poseían otro tipo de recursos de publicidad y comunicación. En la mayoría de los casos, los recursos que se disponían para esta finalidad se limitaban al envío de correos electrónicos y de folletos de las UE.

Otros componentes analizados referían sobre la necesidad de elaborar o la manera de incluir al personal del CONICET no incluido en una UE, para que tuvieran una mayor participación y un canal de comunicación con el CCT. A su vez, los responsables de la gestión debían de buscar el modo en que sus decisiones y actividades fueran conocidas por todo el personal del CCT.

Solamente en uno de los CCT evaluados fue identificado como antecedente en materia comunicacional la formación de la Comisión de Prensa y Difusión, en la cual participan directivos, personal de apoyo a la investigación y el responsable de Comunicación Institucional, desde donde se elabora un boletín electrónico de la unidad.

Por su parte, con referencia a las valoraciones y aportes acerca de las áreas específicas de comunicación en los CCT, se indicaba que si bien hubo un crecimiento de la presencia en los medios de las actividades científicas y tecnológicas que se desarrollaban en el ámbito del CCT y que mejoraron la comunicación interna, resultaba necesario definir una política de prensa y difusión que comprendiese estrategias para fortalecer esa presencia. Las mismas debían apoyar las tareas de divulgación que realizan las UE y los investigadores y, entre otros aspectos, mejorar en cada caso la página web de los CCT, entre otras medidas recomendadas. 


\section{-Perspectivas:}

En cuanto a la adecuación de personal o Áreas de Comunicación en los CCT evaluados donde no existía el rol ni la figura institucionalizada en el organigrama, se consideraba innegable la necesidad de conformar un plan para la comunicación institucional y el desarrollo de nexos con la comunidad. Así como prever la contratación de un profesional para el área para fortalecer la comunicación institucional.

Adicionalmente los distintas planteos en las evaluaciones externas, respecto de los CCT, giraban en torno a una misma recomendación: con determinación era posible subsanar los déficits que existían en materia de información y comunicación interna. Estos déficits tenían consecuencias negativas con respecto al propósito institucional de avanzar hacia una mayor integración de las UE y los investigadores, notándose la ausencia o debilidad de una cultura de intercambio de información que permitiera construir identidad a los CCT y asintiera el desarrollo de actividades colaborativas.

En todo orden se planteaba la necesidad de crear mecanismos de comunicación para el conjunto.

\section{Red Institucional de comunicadores}

La constitución de la Red de Comunicadores resultó ser sino la principal una de las más importantes estrategias a la hora de definir lineamientos de acción en diferentes áreas de 
interés y coordinar la labor científica y tecnológica en los CCT y Centros Multidisciplinarios, en relación con las localidades donde se encuentran, la región y la provincia.

En el transcurso del $2012^{118}$ se reconocieron los rasgos más importantes en torno a la tarea de cada CCT y Centros Multidisciplinarios para llevar adelante la experiencia de gestión de comunicación.

En diálogo con los comunicadores que ya desempeñaban funciones en estas unidades, unos 8 al inicio de la gestión en la DRI, se pudo ver rápidamente las consecuencias relevantes de que una política de cooperación y de fortalecimiento de recursos humanos como tecnológicos traería cambios en la situación dada; ligada expresamente a las nuevas condiciones de posibilidad que emergían frente a la consolidación de las políticas públicas y la necesidad de dar a conocer este proceso.

A pesar de las adversidades suscitadas en algunas unidades donde se había desdibujado la figura del comunicador, donde los comunicadores asumieron tareas que no eran propias para el rol para el cual habían sido convocados, y bajo condiciones estructurales que dificultaban el trabajo y la producción, desde la DRI se mantuvo la convicción de que la Red Institucional de comunicadores podía funcionar de manera organizada; experimentando buenos resultados a la hora de intervenir en el desarrollo de temas destinados a la opinión pública.

En todos los casos donde se pudo llevar adelante la gestión asociada en el desarrollo de la comunicación institucional entre los CCT y la DRI, que implicaron la conformación de escenarios de gestión interdisciplinarios junto a investigadores, profesionales y técnicos de apoyo, y becarios, se trató de modos de trabajo articulados y basados en discusiones; acuerdos que orientaron tanto a una mayor racionalidad del uso de recursos como a la democratización de los vínculos con las distintas unidades en la búsqueda de la sustentabilidad comunicacional. Claramente se observa negociado este término y la posibilidad de encontrar en los proyectos una continuidad en el Programa de Promoción de Vocaciones Científicas (VocAr) y la Plataforma País Ciencia ${ }^{119}$, donde se alcanzaron las convenientes articulaciones institucionales para afianzarlos en algunas regiones del país y, a

\footnotetext{
${ }^{118}$ En ese año contaban con comunicador: CCT Tucumán (1 comunicador), Córdoba (1), Santa Fe (2), Rosario (1), La Plata (1), Bahía Blanca (1), Patagonia Norte (1), y CADIC (1).

${ }^{119}$ Este aspecto se observa en el desarrollo de la Herramienta Comunicacional Relaciones con la Comunidad.
} 
su vez, impulsar a partir de estos la consolidación de otras formas organizativas al interior de cada unidad.

En el enfoque de la gestión de la comunicación otros aspectos hacen al trabajo compartido desde la DRI con la Red. A medida que se fue consolidando la comunicación pública de la gestión, estuvo la consulta y la organización de instancias de capacitación y la incorporación de nuevas modalidades para la generación de artículos científicos, de acciones comunicativas en función de las redes sociales y el reconocimiento y seguimiento de temáticas de la agenda política o pública en el espacio local y regional.

El conocimiento sobre la experiencia previa se abonó en una posición optimista, ya que se pasó de 9 a 19 comunicadores ${ }^{120}$ distribuidos en 11 CCT y 2 Centros Multidisciplinarios en el período 2012-2014, triplicando y hasta quintuplicando en algunas regiones -en consecuenciala aparición de noticias en medios locales, regionales y nacionales (como una de las maneras de medir visibilidad pública, más allá que no haya sido la única estrategia ni se adhiera a esto como el fin único de la comunicación institucional, posición que en la tesis queda por demás aclarado). Lo cual podría pensarse como beneficio de un crecimiento programado producto de los diagnósticos, los pasos necesarios, las acciones desplegadas y las decisiones de orden institucional consensuadas que permitieron el fortalecimiento de la Red Institucional de comunicadores.

\footnotetext{
${ }^{120}$ Desde el año 2012 al 2014 se incorporaron comunicadores en los siguientes CCT: Nordeste (1 comunicador), San Luis (1), Mar del Plata (1), Mendoza (1), Patagonia Norte (1), y CENPAT (2). Y se reforzaron los siguientes CCT integrando un comunicador al Área: Córdoba (1), Rosario (1), y La Plata (1). Quedaron en proceso de incorporación aquellos CCT de reciente creación: San Juan (2014), Tandil (2013) y Salta (2010).
} 


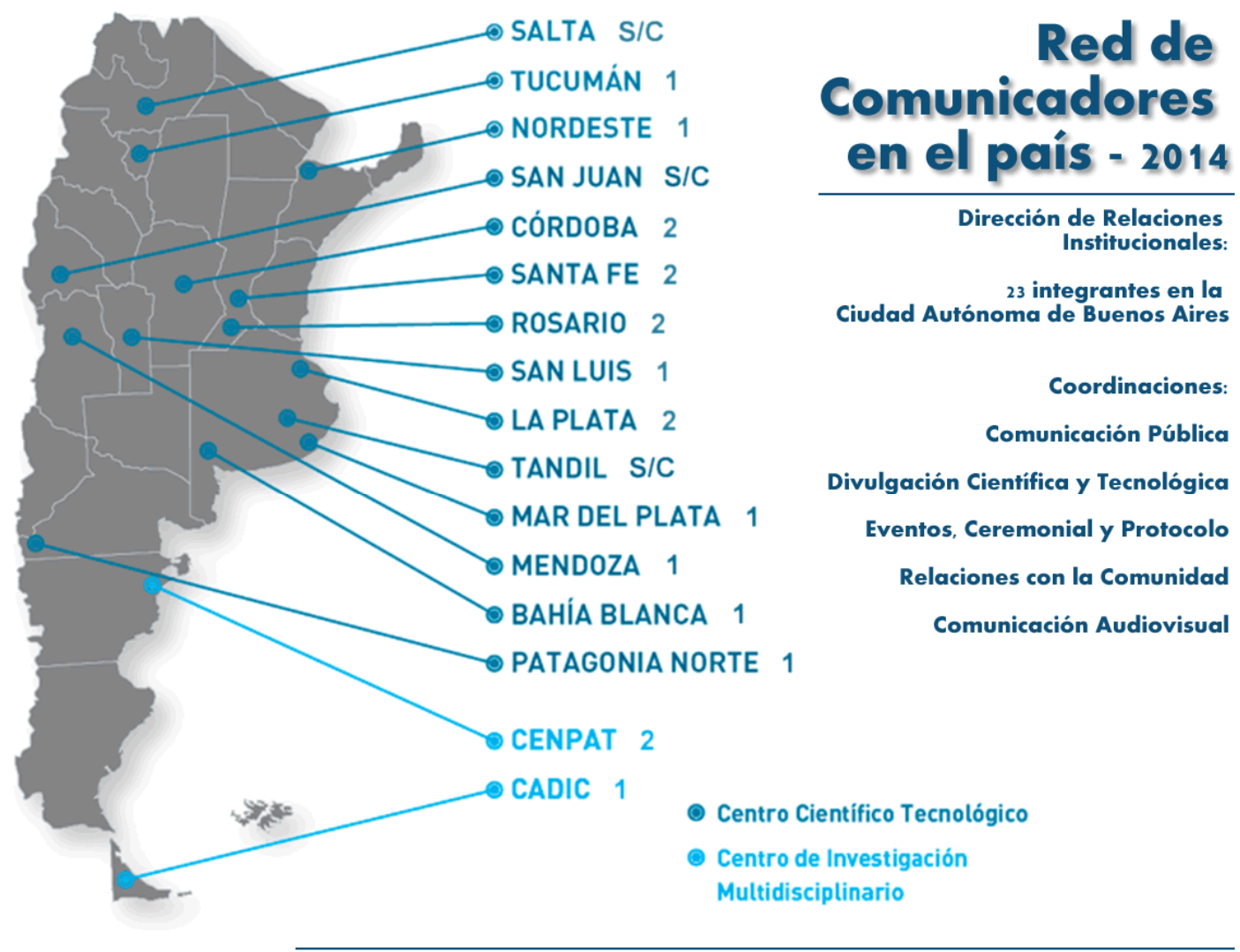

En el período 2012 al 2014 se pasó de 9 a 19 comunicadares en la Red Institucional 


\section{CAPÍTULO VIII}

\section{Las 5 herramientas para la gestión de la comunicación}

El principal desafío que tenía el desarrollo de herramientas de comunicación para la gestión comunicacional, además de que debían impulsar y jugar un rol central en la construcción y fortalecimiento de redes de relaciones en el nivel intrainstitucional, era el de facilitar el diálogo, la articulación de acciones y proyectos y la generación de consensos en las instancias propuestas en la comunicación. La articulación, el lugar y aprendizaje desde nuevos roles y la experiencia de otros sujetos en función de los aportes hacia promover la comunicación en una dimensión inter y transdisciplinaria, debía permitir no solo nuevas dinámicas comunicacionales sino la transformación de las propias prácticas y saberes.

En el desarrollo y el desempeño de la herramientas para la gestión se impulsó una mirada autocrítica y una indagación permanente de los lugares alcanzados, las referencias políticas e institucionales para instalar y hacer posible la institucionalidad en contextos de la comunicación. Así se buscó fortalecer la comunicación entre diferentes organizaciones ("El CONICET y el INTA firmaron un acuerdo por la memoria"121, "El Senasa y el CONICET acordaron fortalecer temas de investigación científica" ${ }^{122}$ ) con acciones, dimensiones, categorías, instrumentos y nociones que permitieron a los sujetos institucionales ser protagonistas en estas prácticas sociales.

Los recursos de la comunicación que se propusieron abarcaron a las tecnologías que permitieron profundizar la producción de mensajes propios, desde el uso de diferentes lenguajes y que aportaron nuevas posibilidades de expresión a los actores involucrados

\footnotetext{
${ }^{121}$ El Consejo Nacional de Investigaciones Científicas y Técnicas (CONICET) y el Instituto Nacional de Tecnología Agropecuaria (INTA), firmaron un acuerdo que compromete a ambos organismos para reparar la memoria institucional sobre lo ocurrido durante el gobierno de facto entre 1976 y 1983. En 2014 y después del trabajo de integración y reconocimiento sobre las posibilidades de aporte a la temática, se formalizó el convenio sobre el proyecto de investigación realizado por la becaria doctoral e historiadora Cecilia Gárgano (CONICET, UNSAM), en el marco del compromiso de las instituciones con la lucha por la memoria y contra la impunidad por las violaciones de los derechos humanos. La investigación reconstruyó tanto la historia del terrorismo de Estado dentro del INTA como los cambios en las agendas científicas de investigación que produjo la dictadura cívico-militar en el organismo.

Más información disponible en: http://www.conicet.gov.ar/el-conicet-y-el-inta-firmaron-un-acuerdo-por-la-memoria/ http://www.conicet.gov.ar/el-senasa-y-el-conicet-acordaron-fortalecer-temas-de-investigacion-cientifica/

${ }^{122}$ Más información disponible en: http://www.conicet.gov.ar/el-senasa-y-el-conicet-acordaron-fortalecer-temas-de-investigacion-cientifica/
} 
("Colegios secundarios visitaron el Buque Oceanográfico Puerto Deseado"123. La embarcación del CONICET abrió sus puertas para despertar vocaciones científicas en los jóvenes).

Las herramientas se constituyeron en espacios para la producción gráfica, audiovisual, facilitaron la creación de estrategias propias de comunicación, donde la posibilidad de que los actores sociales sean parte de sus propios mensajes o se vean reflejados se tradujo en unos de los modos de decir y hacer.

Las herramientas han sido desarrollos fundamentales para la construcción y fortalecimiento de redes de relaciones que en el nivel de la Institución gestionan el desarrollo. Facilitaron elementos hacia un mayor diálogo social, una mayor articulación de acciones y proyectos y la generación de consensos.

Las herramientas comunicacionales aportaron a una mayor vinculación entre los espacios institucionalizados, constituyendo una línea de discusión, intervención e indagación novedosa en el campo de la comunicación institucional del CONICET.

${ }^{123}$ Más información disponible en: http://www.conicet.gov.ar/colegios-secundarios-visitaron-el-buque-oceanografico-puerto-deseado/ 


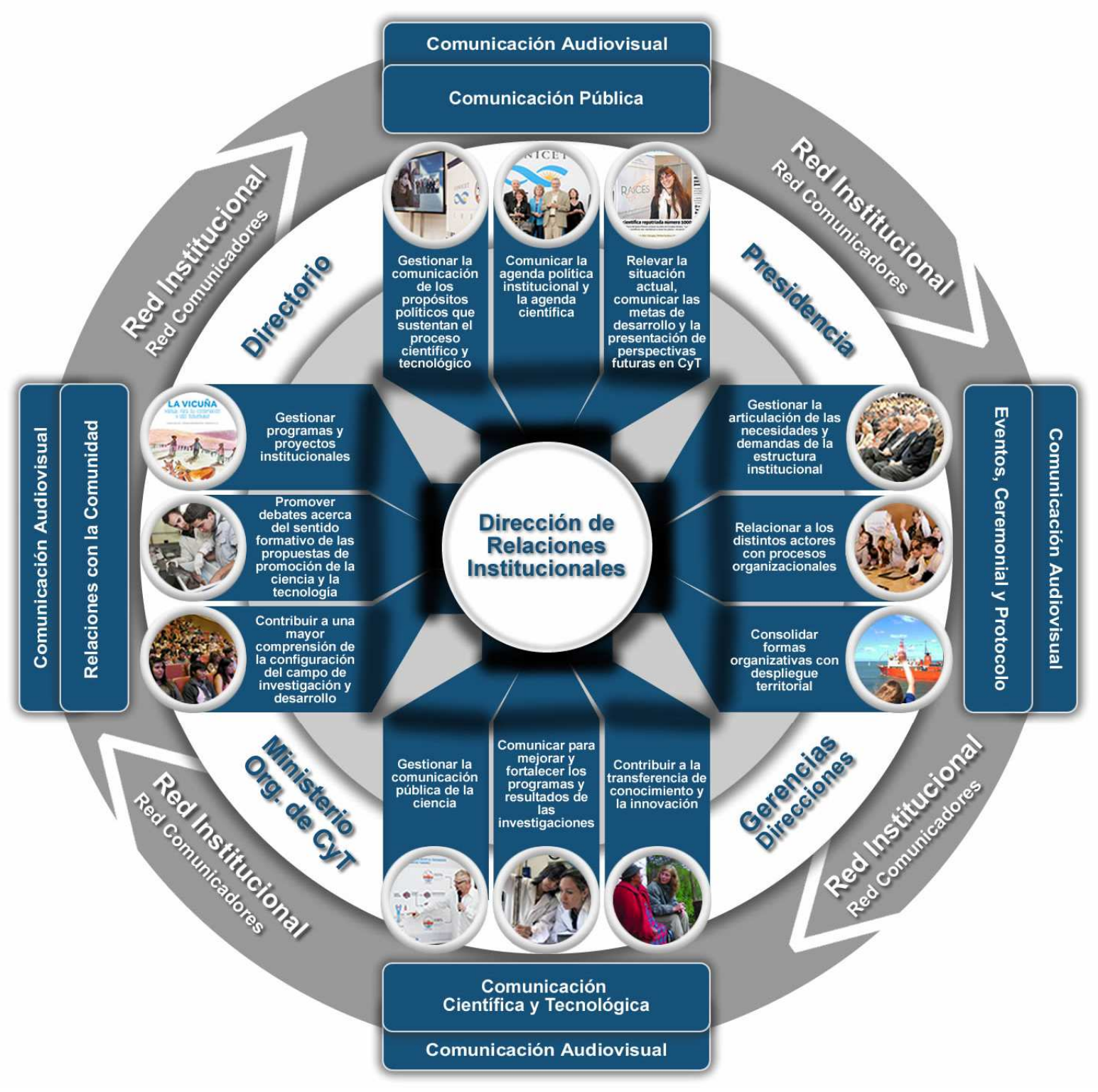

Página 132 de 205 


\section{Herramientas comunicacionales para la gestión}

\section{Comunicación Pública}

Aportar a la construcción de herramientas comunicacionales para integrarlas a las estructuras institucionales de gestión de la comunicación hubiese sido imposible sin una o varias preguntas que fundaran su sentido. La misma está en referencia a la concepción del rol de la ciencia y de los científicos que integran el CONICET, para entender la organización y su funcionamiento y delinear aspectos detallados acerca de su fortalezas y debilidades, pero también en lo que puede decir en cuanto a las oportunidades y a las amenazas (ver Capítulo VII).

Para ello ha sido oportuno hacer explícito no solo desde lo cuantitativo el crecimiento alcanzado sino también desde lo cualitativo la conformación de un explicita relación entre ciencia y política y, en especial, en directa referencia a la medida en que los encargados en la toma de decisiones contribuyen a determinar la política pública para que la sociedad conozca y entienda la función de la ciencia y la tecnología en los asuntos del Estado argentino.

Para avanzar en esta contribución surgió la necesidad de reforzar los planteamientos comunicacionales existentes y preparar, con el acuerdo y entendimiento de los encargados de adoptar decisiones y la comunidad científica de la Institución iniciativas y prácticas y en base a conocimientos bajo el concepto de sustentabilidad de la comunicación. Como ya fue expresado, desde esa perspectiva la comunicación adquiere sentido en el largo plazo.

\section{De la perspectiva a impulsar el pasaje}

Desde una mirada o perspectiva que permitió conocer sobre cómo se entendía a la comunicación en el CONICET, era necesario y oportuno reconocer las instancias 
estructurales y programáticas de la DRI como central de las comunicaciones nacionales. Así la propuesta de fortalecer la comunicación institucional, considerada como una estrategia de articulación de la Institución con las comunidades con las que desarrolla una gran diversidad de propuestas y experiencias, fueron los ejes de reflexión desde los cuales se inició el camino de conocimiento para la aplicación de las herramientas comunicacionales $y$, consecuentemente, la creación de nuevas realidades.

Las nuevas realidades requerían organizar la mirada sobre las experiencias, los oficios y los perfiles de los profesionales que hasta ese momento diseñaban e implementaban la política comunicacional. Era necesario transformar una realidad en la que se reconocía a la comunicación vinculada casi exclusivamente en aportes para el periodismo.

Para ello fue necesario contemplar los vínculos construidos entre los sujetos con sus contextos cercanos que estructuraban los procesos y también comprender que estas postulaciones que estaban vigentes, desde un enfoque instrumental de la comunicación era necesario pensarlas, no bastaba solo con modificar la estructura operativa sino pensarlas en un abordaje y puesta en juego de las herramientas de comunicación para la gestión de procesos de comunicación.

Cuando se señala el enfoque instrumental se hace referencia sobre los modos más institucionalizados y hegemónicos que pudieron reconocerse al interpelar por primera vez esa realidad y que luego fueron reconocidos en un diagnóstico (ver Capítulo VII) más profundo sobre estas situaciones; aunque también debe decirse que se distinguieron otros intentos y proyectos que se posicionaron o, al menos, lo intentaban desde otro paradigma. Esto pudo registrarse en el diálogo con ciertos gerentes y directores de los CCT como con algunos de los miembros del Directorio.

Describir la conformación y las actividades desarrolladas por el equipo de comunicación en cada una de las experiencias, permitió abordar los casos y experiencias concretadas para no volver a la idea y propuesta de que extender, transferir, divulgar en un organismo es presentarse como un único actor emisor, sino que requiere aportar significativamente a la puesta en marcha de políticas institucionales. Aquí comenzaba la tarea de alcanzar una mayor articulación desde las herramientas a los efectos con el objetivo de construir sentidos 
colectivos dentro de la Institución y como dispositivos importantes para la toma de decisiones para la planificación y gestión de las políticas científicas.

Esta experiencia ha tenido y tiene como contexto específico a la gestión institucional, a la investigación y desarrollo, y se presenta desde un marco disciplinar concreto que es la comunicación.

\section{Ruptura y continuidad}

La Herramienta Comunicación Pública ${ }^{124}$ fue concebida como apoyo a los cambios operados en el CONICET respecto de: dar a conocer las transformaciones en una dialéctica que puede ser leída como de ruptura y continuidad, en cuanto a la información que se gestaba desde la conducción de la organización acerca del reconocimiento por parte de la sociedad de las contribuciones a la ciencia y la tecnología, teniéndose en cuenta la evolución constante de las políticas ${ }^{125}$ para el sector.

Desde esta primera definición y encuadre, que a su vez especifica el lugar de la comunicación, se da cuenta de la primera necesidad: abrir los debates y definir las

\footnotetext{
${ }^{124}$ Las actividades de rutina asignadas a la coordinación de Comunicación Pública se pueden reconocer en las siguientes tareas: coberturas, armado, edición y envío de notas institucionales, que posteriormente se envían a los medios. Envío de materiales a medios y periodistas. Atención telefónica de consultas y derivación de pedidos de información a las Áreas correspondientes. Redacción de notas institucionales para el público interno que se envían por mailing list. Gestión de notas de prensa y solicitudes de entrevista de medios gráficos y audiovisuales para presidencia y Directorio del CONICET . Generación de reportes diarios sobre seguimiento de notas. Generación de reportes diarios de Google Analytics referidos al tráfico y circulación en la Web institucional y las Webs de los CCT. Reporte de Redes sociales, como Twitter y Facebook. Publicación y replicación de notas en estos sistemas. Derivación de consultas surgidas de las mismas. Desarrollo integral de la Web Institucional. Carga y mantenimiento, elaboración de la arquitectura del rediseño activo y formulación gráfica del look and file de nuevas versiones de la Web. Generación, recepción y envío de la Agenda Semanal a todos los usuarios del CONICET. Desarrollo integral de procesos dinámicos de Intranet. Desarrollo de imagen e identidad visual de CONICET Digital. Diseño integral de publicaciones gráficas y digitales destinadas al Programa de Promoción de Vocaciones Científicas (VocAr). Diseño e impresión de material institucional para enviar a los CCTs, UE y entregar en eventos institucionales. Recepción y armado de noticias para novedades en la Web. Carga integral y mantenimiento de la Web Institucional en Inglés. Seguimiento de los envíos de Comunicación Institucional. Desarrollo integral de notas, infografías y coberturas fotográficas sobre solicitadas por medios de comunicación como por prensa del Ministerio de Ciencia, Tecnología e Innovación Productiva. Gestión de Proyectos y Programas (Cooperación con el Ministerio de Turismo de la Nación. Con el Ministerio de Ciencia y Tecnología por Pampa Azul) y de Divulgación Científica y Tecnológica. Trabajo conjunto en la organización, cobertura y difusión de VocAr y País Ciencia en todo el territorio nacional.

${ }_{125}^{125}$ Es necesario hacer una aclaración desde el lugar desde donde comprendemos el lugar real de la política. Todo proceso y práctica de comunicación constituyen una dimensión en la cual se producen y sintetizan, así como ponen a circular, decisiones políticas, opiniones, modalidades de articulación entre el Estado y la sociedad civil. Y es en el hecho que se consuma con el ejercicio de la comunicación donde no es posible desvincular la política de la comunicación. A través de esta última se expresan conflictos y se producen momentos de legitimación.
} 
trayectorias para identificar las políticas para luego, desde la disciplina, formular una estrategia nacional de comunicación.

Al garantizarse esta primera premisa se anticipaba la tendencia para lo cual era propuesta la herramienta: la definición y elaboración de la agenda de gestión, la definición con antelación de los contenidos y la información a comunicar por los decisores y sus usos públicos. Y para hacer especial hincapié en la necesidad de articular y apoyar las metas de desarrollo, la situación actual y las perspectivas futuras en ciencia y tecnología.

Desde este lugar de sustento fue posible involucrarse en el diseño, preparación y difusión de una política científica y tecnológica impulsada desde el Ministerio de Ciencia, Tecnología e Innovación Productiva, en colaboración de la vocería ministerial y en una esquemática de un proceso donde se buscaba destacar dos aspectos centrales. El primero, en el lugar del conocimiento el crecimiento científico expresado desde el 2003 en adelante y los intereses políticos allí presentes; y en segundo término, el abordaje de los temas y los problemas derivados de la información circulante y de la interacción entre encargados de la gestión, científicos, políticos, periodistas, comunicadores, y usuarios en general.

Desde el 2012 se pudo hablar desde la comunicación del CONICET a partir de los tomadores de decisiones de una nueva agenda política y nuevas agendas científicas. Como sustento a las definiciones políticas que surgieron puede leerse el discurso del presidente del CONICET $^{126}$ durante la celebración de los 55 Años del organismo en Tecnópolis.

Para caracterizar las actividades que involucraron el delineamiento de la herramienta es necesario, además de comprender a múltiples actores, revisar y sintetizar las condiciones y posibilidades de comunicación, factores, impactos y futuros posibles, conocer en particular los propósitos que sustentan el proceso científico y tecnológico.

El conjunto de organismos que aplican en la ciencia básica hasta la transferencia de tecnología (entendida como una instancia superior de investigación, desarrollo e innovación bajo la fórmula $\mathrm{I}+\mathrm{D}+\mathrm{i}$ ), pasando por una visión extensionista con una fuerte presencia en el territorio, sumado a la intervención y articulación en las cadenas agro productivas, permite

\footnotetext{
${ }^{126}$ El 10 de septiembre de 2013, en Tecnópolis, el CONICET conmemoró sus 55 años de creación, un 5 de febrero, Decreto Ley 1.291/58. En esa oportunidad el presidente del organismo destacó: "La reconstrucción del sistema científico fue una tarea que emprendió el gobierno nacional en el año 2003 retomando un objetivo claro: la ciencia y la tecnología como un insumo básico para el desarrollo del país. Un sistema que conduzca a una mejor calidad de vida de los ciudadanos". Disponible en: http://www.conicet.gov.ar/el-conicet-festejo-sus-55anos-en-tecnopolis/
} 
hablar de la ciencia y la tecnología como motor de cambio y valor agregado a todas las instancias socioprodutivas. Así queda establecido en el Plan Nacional de Ciencia y Tecnología, Argentina 2020, creado por el Ministerio de Ciencia, Tecnología e Innovación Productiva de la Nación ${ }^{127}$.

Las implicaciones de los aportes del documento es un estado de conocimiento para sostener las necesidades de desarrollo del país, donde se inscribe centralmente el lugar del CONICET. Y desde la comunicación marca un enfoque integrador para contribuir desde el desarrollo de estrategias y en la consecución de objetivos: mejorar y fortalecer los programas de difusión de resultados de las investigaciones y la gestión, la transferencia de conocimiento y la innovación.

En este sentido, la herramienta consideró los lineamientos del Plan en cuanto a la política científica, tecnológica y de innovación para el país para los próximos años y fortalecer desde la comunicación la continuidad del crecimiento y la consolidación de estas áreas consideradas puntales estratégicos del desarrollo nacional.

Alcanzar estas evaluaciones permitió organizar, forjar y reforzar la comunicación sobre los pilares sobre los que se elaboró el Plan y alcanzar un mejor aprovechamiento pleno de las capacidades científicas nacionales; asistir en el desarrollo del impulso de la cultura emprendedora y la innovación productiva, inclusiva y sustentable; en el mejoramiento de la calidad de vida de la población; y fomento de la información y de datos científicos y tecnológicos referidos a una mejora de los procesos gubernamentales de consulta y de apoyo a los mecanismos de cooperación regionales e internacionales.

Si bien es necesario evitar las categorizaciones concluyentes, y teniendo en cuenta que este proceso político institucional donde se encuentra profundamente involucrado el CONICET, se plantea una comunicación de carácter regional y nacional involucrando a los CCT, con sus UE y a los CIT provinciales, que se propuso llevar adelante aspectos y cambios impulsados desde las políticas públicas de distinta profundidad según el caso que se analice.

\footnotetext{
${ }^{127}$ El Plan fue presentado el 12 de marzo de 2013 por el ministro de Ciencia y Tecnología, Lino Barañao, durante un acto presidido por le presidenta Cristina Fernández de Kirchner. Disponible en: http://www.argentinainnovadora2020.mincyt.gob.ar/

El discurso completo del ministro está disponible en: http://www.mincyt.gob.ar/noticias/la-presidenta-presento-el-plan-nacional-de-cienciatecnologia-e-innovacion-4775
} 
Estos cambios constituyeron la condición de posibilidad para el desarrollo de estas herramientas de comunicación que reconocen como denominador común, pudiéndose tener diferencias de matices, primero la recuperación y posteriormente la profundización del rol del comunicador en el Estado en el entendimiento y tratamiento de temáticas de ciencia y tecnología a través del papel que juega en el principal organismo del Sistema Nacional de Ciencia, Tecnología e Innovación.

La capacidad en establecer mapas de ruta para la toma de decisiones en políticas científicas respecto al organismo y darlas a conocer se fundó en estrategias, perspectivas y seguimiento de políticas, y la construcción de procesos de comunicación fundados bajo criterios de sustentabilidad.

Esta secuencia y con los indicativos señalados fue posible observar la relación ciencia y política y viceversa en un vínculo que evidencia dimensiones que tienen una alto grado de incidencia en y desde las prácticas sociales. Por tal motivo, desde la mejor acepción metodológica fue necesario no abstenerse a un sistema rígido y preconcebido. La manifestación permanente de decisiones con los decisores (presidente del CONICET -en primer lugar- y directorio) configuró el eje de discusión y reflexión de la comunicación ${ }^{128}$. Esto se convirtió en un requisito de partida al momento de planificar cada una de las herramientas y desde el punto de vista procedimental de la Herramienta Comunicación Pública fue el mayor intento por contener una multiplicidad de discursos, de criterios, posiciones, modalidades y argumentos divergentes.

Esto se expresó en la medida misma de no subsumir lo heterogéneo en la unicidad y en la contención de las pluralidades, sobre posiciones que otorgan las Grandes Áreas de conocimiento del CONICET y desde donde se expresan las posiciones de una parte del Directorio.

Aquí fue necesario componer las relaciones, el origen de los discursos y visualizar las diferentes percepciones y concepciones que tienen sobre determinados temas estos actores y las redes involucradas.

\footnotetext{
${ }^{128}$ Documento publicado por el CONICET con motivo de conmemorarse 30 Años de Democracia.

Disponible en: http://www.conicet.gov.ar/wp-content/uploads/2013/09/CONICET-55-a\%C3\%B1os-Discurso-Roberto-Salvarezza.pdf
} 
Se puede afirmar, entonces, que aquí necesariamente se conecta lo subjetivo, lo temporal, lo simbólico y lo socio cultural ${ }^{129}$. Que también es necesario un aprendizaje del lenguaje a partir de conocer los códigos, reconocer los supuestos y los propósitos de los usuarios, como contextualizar sentidos y significados.

Y lo señalado en este pasaje, entre lo deseado y lo realizado en cuanto a la producción de la información, sobre la que se ha dado cuenta y ha sido generada durante el trienio, está disponible en documentos y notas de prensa en la página Web del CONICET.

\section{Componente de comunicación}

Dentro de los componentes para la comunicación que involucra el desarrollo de la herramienta, se pensó en:

-Garantizar la articulación en aquellas instancias determinadas como procedimientos o procesos necesarios para impulsar y fortalecer la comunicación en las diversas unidades divisionales que integran la Red Institucional;

-desarrollar políticas y estrategias de comunicación para la articulación regional junto con la Red Institucional, y de esta con la comunidad;

-desarrollar políticas tendientes a difundir las acciones de gestión y las actividades de investigación, desarrollo tecnológico y vinculación con los sectores público y privado;

-impulsar y promover mecanismos de cooperación sobre aspectos comunicacionales de gestión con el sistema universitario argentino y sistemas e instituciones del exterior;

-generar instancias y organizar acciones de seguimiento y comunicación de programas y proyectos, en cuanto a la consecución de procesos de administración de las Carreras del

\footnotetext{
${ }^{129}$ Es posible pensar en la relación de campus y habitus de Bourdieu y, sobre la misma, señalar que puede constituirse como la base para la identificación de actores y diferentes imaginarios.
} 
Investigador Científico, del Personal de Apoyo a la Investigación y al Desarrollo, y el Programa de Becas;

-participar en los procesos de integración e intercambio a nivel nacional, regionales e internacional con organismos estatales y privados en la generación de convenios y acuerdos tendientes a promover la ciencia y la tecnología y conducir la implementación de instancias comunicacionales;

-establecer relaciones de trabajo comunicacional construidas y sostenidas en la ética profesional principalmente y en el reconocimiento, conocimiento, colaboración, cooperación y asociación con áreas de comunicación en los CCTs, Centros Multidisciplinarios y todas las Unidades que así lo requieran;

-propiciar estructuras administrativas y organizativas que permitan reconocer y abordar la agenda pública, no solo a través del establecimiento de temas sino en el seguimiento de los debates públicos que se generan en torno al CONICET;

-incorporar metodologías propicias para el monitoreos y evaluación de la comunicación generada desde la Institución, del seguimiento de la agenda científica y tecnológica y de los avances científicos presentados y sus alcances por los organismos del Sistema Nacional de Ciencia, Tecnología e Innovación.

Esta compleja perspectiva, que también hace al abordaje de los procesos sociales y de las organizaciones desde la comunicación, implicó asumir una referencia concreta para la acción, atendiendo a que la misma requiere pensar los procesos de comunicación desde la cultura. Este hecho no por menos significativo, significa establecer que el estudio no cae en el evidente reduccionismo de la problemática de comunicación a la de tecnologías ${ }^{130}$.

\footnotetext{
${ }^{130}$ MARTIN BARBERO, Jesús (1987). "De los medios a las mediaciones". Editorial Gustavo Gilli, Barcelona. España.
} 


\section{Comunicación Científica y Tecnológica}

En la última década la ciencia ganó un lugar preponderante en la agenda pública adquiriendo el rango de política de Estado. Esta jerarquización también fue acompañada de mañera dispar con presencia en los medios de comunicación del ámbito local acerca de temas que daban cuenta de la generación de conocimiento y de procesos de innovación.

En esta trama se inscriben la divulgación de la ciencia y la tecnología y sus conceptuaciones relacionadas que ayudan y aportan a describir procesos de conocimientos centrados en la explicación y difusión del contenido científico, los cuales incluyen a los medios de comunicación de masas.

En la construcción de esta herramienta comunicacional se tomo en cuenta el criterio de comunicación pública de la ciencia entendido como un proceso de construcción que, implica o se gesta, con otros actores. Esto requería ir más allá del entorno específico de la producción científica en sí misma que se generaba en el CONICET. Desde el concepto de otros había que trabajar desde la identificación de escenarios, individuos que lo componen, aspectos vinculantes, culturales; es decir, pensar en otros con saberes y prácticas propias entre los cuales se producen sentidos y exigen plantear nuevas modalidades comunicacionales.

En esta identificación era precisa la concurrencia de múltiples miradas (disciplinares) para poder integrar esa diversidad. Desde este punto de vista, la herramienta fue pensada desde el reconocimiento de este entramado con el fin de poder captar y brindar a la sociedad los procesos de conocimiento que en la Institución se gestaban.

El CONICET, al ser una organización compleja que incluye una extensa combinación de actores de distintos orígenes disciplinares, asegura una producción de conocimiento como resultado de las operaciones de investigación y desarrollo, con variaciones en su amplitud de problemáticas que están supeditadas además a las regiones, a lo social y cultural como a lo productivo como enfoque posible desde dónde abordarlo desde la comunicación. 
Estos problemas cambian según los espacios generando la necesidad de pensar en estrategias según cada lugar, lo cual se hace necesario incluirlo como caracterización necesaria para la articulación de campos de trabajo y abordajes de temas y casos a comunicar (las acciones de comunicación se pensaron desde una orientación que posibilitara acciones que promovieran encuentros, conversaciones y articulaciones cuyo productos reconocieran estos escenarios y características).

Así pues la comunicación pública de la ciencia y la tecnología permite contextualizar y comprender las relaciones que existen entre prácticas tales como la producción del conocimiento científico, su repercusión en diversas esferas de la vida social, el desarrollo tecnológico y las formas particulares con que este conocimiento se incorpora a la sociedad; así como el sentido que los actores sociales dan a estas relaciones en su práctica cotidiana ${ }^{131}$.

Para esta herramienta se requería trabajar en el desarrollo de habilidades y conocimientos que permitieran generar una mejor y mayor interrelación de la ciencia y la tecnología con la sociedad.

Desde la visión institucional fue necesario orientar la labor del grupo de comunicadores, encargados de la comunicación científica y tecnológica ${ }^{132}$, con una visión integradora del contexto socio cultural en que se ubica su público destinatario, lo cual les permitió situar y

\footnotetext{
${ }^{131}$ HERRERA LIMA, Susana (2007). "La profesionalización de la comunicación pública de la ciencia". Maestría en comunicación de la ITESO. Guadalajara, Jalisco, México.

${ }^{132}$ Las actividades de rutina asignadas a la coordinación de Divulgación Científica y Tecnológica se pueden reconocer en las siguientes tareas: redacción de notas de divulgación científica, orientadas a público general, que después se envían a los medios. Gestión de notas de prensa y solicitudes de entrevista de medios gráficos y audiovisuales para investigadores, personal de apoyo y becarios del CONICET. Redacción de notas de difusión de vinculación tecnológica. Incluyen diferentes instancias de aprobación: investigadores, empresa contraparte (si aplica), coordinadores de grupos de la Dirección de Vinculación Tecnológica, director de la DVT, presidencia del CONICET. Generación y diseño de material informativo de apoyo para actividades de divulgación. Coordinación con los comunicadores de los CCT e institutos para que las notas salgan en simultáneo, unificando criterios de redacción y edición. Desarrollo y diseño de infografías para ilustrar las notas de divulgación científica y vinculación tecnológica. Desarrollo de contenidos y diseño de folletería y materiales para las actividades de la Dirección de Vinculación Tecnológica. Diseño de stands para esas actividades. Desarrollo de contenidos y diseño de folletería y materiales para las actividades de organizadas por la Coordinación de Eventos, Ceremonial y Protocolo de la Dirección de Relaciones Institucionales. Cobertura de conferencias y actividades científicas. Redacción de notas en el día. Cobertura de actividades nacionales e internacionales de la Dirección de Vinculación Tecnológica y Social. Redacción de notas en el día. - De la Coordinación de Divulgación Científica y Tecnológica depende el Área de Traducciones, encargada de traducir al inglés no solo las notas publicadas en la página web del CONICET, sino además la traducción de diferentes materiales solicitados por otras áreas del CONICET como folletos, presentaciones, documentos, etc. El Área de Traducciones brinda además capacitación semanal a los miembros de la Dirección de Relaciones Institucionales en el uso de inglés científico. Generación de un banco de imágenes de divulgación científica, que incluye colecciones y trabajos a campo de diferentes investigadores. Desarrollo, diseño y ejecución de las carpetas de oferta tecnológica para la DVT. Colaboración con el sistema informático de fichas de oferta tecnológica (technology cards) y su diseño. Diseño y desarrollo de contenidos para folletos específicos para Vinculación Tecnológica, así como de los stands y cartelería, para ferias y congresos. Redacción de casos de transferencia y notas de vinculación tecnológica. Cobertura de congresos y exposiciones. Desarrollo del logo y seguimiento de marca para Transferencia Tecnológica. Desarrollo del Manuales de Marcas para Vinculación Tecnológica. Diseño y desarrollo de infografías para notas de Divulgación Científica y Vinculación Tecnológica. Diseño de diferentes materiales gráficos. Soporte en diseño para diferentes eventos de VT. Diseño de anotadores, prensa y divulgación científica. - Fotografía. Coberturas fotográficas para Comunicación Pública, Divulgación Científica y Tecnológica, y Eventos. Administración, identificación, tratamiento estético, clasificación y envío de fotografías. Constitución y renovación de fotografías del Banco Multimedia.
} 
situarse en la mirada del receptor y desarrollar las formas de representación que resulten significativas en este contexto.

Esto se alcanzó en un permanente ensayo en cuanto a la forma y los modos de narrar y a la construcción de vínculos que involucró el trabajo desde el permanente relacionamiento con el investigador, el profesional de apoyo a la investigación y el becario, en la construcción de las articulaciones y en un lugar de acuerdos sobre las diferentes conceptualizaciones e interpretaciones de la investigación a dar a conocer. Pero también están involucradas las epistemologías de las diversas disciplinas, como de las lógicas del hacer las tareas de cada oficio, profesión o disciplina que se involucraron en el proceso. Y las problematizaciones en cuanto al lenguaje, los prejuicios profesionales y aquello que se presenta como lo naturalizado acerca de lo que constituyen las decisiones al trabajar los temas, las restricciones institucionales, el tiempo de producción, las posturas ambivalentes referidas a los beneficios derivados de las aplicaciones tecnocientíficas, entre otras.

Fue necesario, no solo por el carácter y el lugar que ocupa el CONICET en el imaginario social, atender desde la producción de artículos periodísticos el planteo acerca de que la ciencia y la tecnología persigue fines que involucran bienestar de la sociedad hecho para el cual era necesario trascender las producciones que tuvieran un mero fin informativo.

En este sentido, la labor comunicacional ${ }^{133}$ llevó a plantear que la ciencia y la tecnología no se conciben como prácticas y conocimientos aislados como tampoco ajenos a la realidad social y al entorno cultural en que se desarrollan. Esta concepción se fundó en el reconocimiento de que la ciencia es parte constitutiva de la cultura y el conocimiento científico forma parte de una estructura social que lo sustenta y que a la vez se ve modificada por éste.

En la tarea por conocer la complejas dinámicas sociales en que se inserta la práctica científica y el desarrollo tecnológico que son su objeto de difusión hubo que considerar y analizar un

\footnotetext{
${ }^{133}$ Es importante traer a colación cuando se piensa el quehacer del comunicador como mediador en la cultura, lo que sobre éste destaca Jesús Martín Barbero. Si bien parece algo ya naturalizado ha sido de ayuda releerlo a fin de poder tenerlo presente de manera permanente frente a la práctica. Al respecto reconoce que "el trabajo del mediador en la cultura [parte de] hacer explícita la relación entre diferencia cultural y desigualdad social. No de la reducción de la diferencia a la desigualdad, sino de la imposibilidad de pensarlas completamente por separado en nuestra sociedad". Y agrega que "en esa perspectiva, el comunicador descubre que la difusión de una obra o la comprensión del sentido de una práctica no tiene como únicos límites la densidad o complejidad del texto sino la situación de lectura, y la imbricación en ella de factores sociales no puramente culturales. Asumir esta perspectiva no va en modo alguno en detrimento de la especificidad de la información o del trabajo cultural, es más bien asumir que esta especificidad no está hecha solo de diferencias formales sino también de referencias a los mundos de vida y a los modos de uso".

En MARTÍN BARBERO, Jesús (1990). "Comunicación, campo cultural y proyecto mediador". Diálogos de la Comunicación № 26. FELAFACS. Lima.
} 
conocimiento más profundo y acabado de los medios de comunicación a nivel local como global, especialmente aquellos medios especializados y específicos para la difusión de la investigación científica. Éstos cumplen un rol que es necesario desentrañar en sus diversas dimensiones: características técnicas, formas particulares de representación, ubicación en la estructura social, vínculos con diversas formas de poder, por considerar algunas.

\section{Dimensión científica y producción}

Por considerar solo un dato relevante en cuanto a la producción de conocimiento, en 2013 (según un relevamiento realizado por la DRI en Scopus, la mayor base de datos de resúmenes y citas de literatura revisada por pares, esto es revistas científicas, libros y actas de congresos) se identificaron 5.261 producciones del CONICET (en 2007 fueron algo más de 2.300) de los cuales más de 4.900 eran artículos científicos. El mayor número de producciones correspondían a: ciencias Agrarias y Biológicas con 1.553 artículos; Bioquímica, Genética y Biología Molecular con 924; Física y Astronomía con 766; Medicina con 737, por destacar solo los primeros lugres en número de producciones científicas publicados en revistas con referato internacional.

\section{Condiciones para el diálogo científico}

Respecto a qué temas tomar y acerca de qué desarrollos investigativos formular, elaborar y gestionar artículos en el orden de la divulgación científica, para diferentes medios de comunicación y soportes pero pensando esencialmente en diferentes públicos, fue en principio necesario tomar en cuenta: el análisis no solo del marco histórico e institucional de desarrollo de cada disciplina -de las cuatro Grandes Áreas de conocimiento-, sino de las 
dimensiones políticas que estas representaban frente a los objetivos institucionales, las implicancias en investigación y transferencia de conocimiento, el impacto sobre el desarrollo regional y nacional, como los vínculos y relaciones de intercambio y colaboración con otras instituciones y organismos.

A su vez, también constituyó una tarea no menor explorar frente a cada emergente temático el modo que impacta socialmente y se encausa en las prioridades de desarrollo propuesto por el Directorio del organismo, no solo en cuanto a los procesos de investigación en ciencia y tecnología consolidados sino a partir de los cambios y en especial aquellos que aportan de alguna u otra manera a modificar la calidad de vida de la sociedad.

Cualquier aproximación desde la producción de comunicación que tiene la intención de comunicar o de dar a entender las implicaciones de la relación entre ciencia y sociedad ${ }^{134}$, se encuentra con una dificultad de pretender que la distancia entre ciencia y sociedad es superable informando convenientemente a los ciudadanos. Pero el obstáculo a superar y que se presenta es negar o no considerar la desigualdad que existe entre científicos y públicos que impone una asimetría que aparece como un condicionamiento de base para el diálogo científico.

Este umbral de comunicabilidad es primeramente necesario considerarlo para el diálogo entre el comunicador y el científico, con el técnico de apoyo o el becario. Partir del mismo requiere de una aprendizaje de conceptos y entendimiento de la experiencia que se desea compartir acerca del objeto sobre el cual se busca dialogar, compartir y debatir a los fines de la construcción del artículo periodístico científico.

El conocimiento científico en esta relación no es el único que se juega, tampoco con el público, sino que también deben incluirse códigos, saberes y valores no científicos que toman parte de ella. Un punto central en esta relación es que los científicos o expertos se esfuercen en comprender y evaluar los argumentos y valores extracientíficos, y aún así quedarán un núcleo de conceptos, prácticas y valores científicos involucrados en torno al entendimiento del objeto que se pondrán en discusión o estarán en disputa y que, necesariamente, requerirán examinar los argumentos y perspectivas que aportan cada una de las partes.

\footnotetext{
${ }^{134}$ Esta conceptualización es retomada del trabajo de Carina Cortassa titulado "Del déficit al diálogo, ¿y después? Una reconstrucción crítica de los estudios de comprensión pública de la ciencia". En Revista CTS, №15, Vol. 5. Septiembre de 2010.
} 
Se trata pues de evitar que la comunicación del conocimiento científico desde la interpretación y producción de artículos de divulgación científica tenga presente los condicionamientos y pueda implícitamente explicar o aproximarse de la manera más adecuada a considerar el escenario en que se plantea la relación en la que se trabaja, entre el conocimiento de científicos, el proceso de circulación social de ese conocimiento, sobre los fundamentos en que se dan estas mediaciones, y los sentidos en que se dan los vínculos basados en la credibilidad y la confianza cuando se llega a la esfera pública.

Claramente aquí se trabaja con problemas ya que el comunicador se desempeña en un contexto que requiere por un lado reconocer aquellos temas clásicos de los estudios científicos, y por otro los prejuicios del público, las representaciones y actitudes ante la ciencia.

El acercamiento productivo que permitió esta herramienta comunicacional se dio en esta complejidad planteada entre ciencia y sociedad y en un escenario de cambio con fuerte intervención del Estado, hecho que facilitó la posibilidad de intervenir desde la reflexión conceptual y desde lo empírico, al compartir socialmente el conocimiento científico generado a través de la práctica desarrollada por la DRI del CONICET.

\section{El significado de la experiencia}

En la producción científica se evidencia tanto en el incremento sostenido de recursos destinados a la recomposición y ampliación de la investigación, como en las estrategias orientadas a articular los saberes científicos con las necesidades de desarrollo social, económico y cultural del país. Fue así que como parte inseparable de este proceso, emergieron nuevos desafíos que el campo científico argentino fueron identificando y asumiendo y al que se buscó contribuir desde la comunicación.

Aquí valen algunas referencias consideradas parte del reconocimiento y del contexto discursivo en el que se presentaron temas de investigación ante la opinión pública. Esta es 
una muestra de los más de 1.050 notas generadas en el período 2012 - 2014, que tuvieron como destino la propia página Web del CONICET y los medios masivos de comunicación desde un enfoque de cobertura nacional.

\section{Nuevo avance argentino en la lucha contra el cáncer}

Investigadores del CONICET describen un mecanismo que permite tratar tumores hasta ahora resistentes a las terapias convencionales.

http://www.conicet.gov.ar/nuevo-avance-argentino-en-la-lucha-contra-el-cancer/

\section{Retos para el futuro de los alimentos}

La doctora en bioquímica habla sobre la importancia de la investigación en materia de cultivos mejorados y su impacto en la producción de alimentos. "Hay que saber usar la tierra sin agotarla. En definitiva, todos nos alimentamos de plantas en los distintos eslabones de la cadena alimentaria", dice.

http://www.conicet.gov.ar/retos-para-el-futuro-de-los-alimentos/

\section{Investigación del CONICET destacada por Nature como una de las mejores de 2013}

La publicación seleccionó el artículo de científicos argentinos sobre los mecanismos que usa el ave para cantar.

http://www.conicet.gov.ar/investigacion-del-conicet-destacada-por-nature-como-una-de-lasmejores-de-2013/

\section{Identifican los mecanismos que usa el ave para cantar}


Un estudio reciente propone un novedoso código neuronal para la generación y procesamiento del canto de aves. Las herramientas desarrolladas en este trabajo podrían dar una clave para generar dispositivos de voz artificial.

http://www.conicet.gov.ar/identifican-los-mecanismos-que-usa-el-ave-para-cantar/

\section{Vacunas más efectivas}

En Córdoba estudian una alternativa para aumentar la eficacia de los inóculos de última generación.

http://www.conicet.gov.ar/vacunas-mas-efectivas/

"YOGURITO es un ejemplo de interacción multisectorial con impacto en la sociedad"

Profesionales del CONICET participan en un programa cientifico nutricional de transferencia tecnológica que consiste en el desarrollo de un yogur enriquecido.

http://www.conicet.gov.ar/yogurito-es-un-ejemplo-de-interaccion-multisectorial-conimpacto-en-la-sociedad/

Describen el genoma de una especie de tomate silvestre

Se trata de Solanum pennellii. Este hallazgo abre un camino para el mejoramiento del tomate doméstico.

http://www.conicet.gov.ar/describen-el-genoma-de-una-especie-de-tomate-silvestre/

El rol de microRNAs en el hígado graso no alcohólico 
Investigadores descubrieron su modo de acción y su relación con esta patología que afecta a cerca del 30\% de los argentinos. Su estudio permitiría avanzar en el desarrollo de nuevas técnicas de detección.

http://www.conicet.gov.ar/el-rol-de-micrornas-en-el-higado-graso-no-alcoholico/

\section{Las leyes de la mecánica cuántica inspiran un método para enviar mensajes confidenciales por internet}

El investigador del CONICET, Ezequiel Alvarez, habla sobre la creación de una nueva forma de enviar e-mails de manera segura.

http://www.conicet.gov.ar/las-leyes-de-la-mecanica-cuantica-inspiran-un-metodo-paraenviar-mensajes-confidenciales-por-internet/

\section{Avances en innovaciones con grafeno}

Por primera vez se logró controlar el flujo de esta cuasipartícula en grafeno. A futuro esto permitiría desarrollar dispositivos más pequeños, livianos y rápidos.

http://www.conicet.gov.ar/avances-en-innovaciones-con-grafeno/

\section{Microbios aportan colores naturales a los alimentos}

Levaduras patagónicas sirven para producir el pigmento característico de especies como el salmón de criadero.

http://www.conicet.gov.ar/microbios-aportan-colores-naturales-a-los-alimentos/

\section{La ciencia básica en el hospital}


Científicas de CONICET en Córdoba llevan sus estudios básicos al consultorio para colaborar en la lucha contra la artritis reumatoidea.

http://www.conicet.gov.ar/la-ciencia-basica-en-el-hospital/

\section{Descubren el mecanismo biofísico molecular de adaptación térmica en bacterias}

Investigadores del CONICET explican cómo una proteína convierte la temperatura ambiental en una señal intracelular y sus implicancias para la salud y la biotecnología.

http://www.conicet.gov.ar/descubren-el-mecanismo-biofisico-molecular-de-adaptaciontermica-en-bacterias/

\section{Leinkupal laticauda: el nuevo dinosaurio argentino}

Es el primer ejemplar de la familia de los diplodócidos encontrado hasta ahora en América del Sur.

http://www.conicet.gov.ar/leinkupal-laticauda-el-nuevo-dinosaurio-argentino/

\section{Animales que cuentan su vida ante las cámaras}

Cientificos de Puerto Madryn estudian el comportamiento de especies marinas gracias a diminutos instrumentos tecnológicos. Recientemente lograron seguir con una cámara a un ave hasta el fondo del mar

http://www.conicet.gov.ar/animales-que-cuentan-su-vida-ante-las-camaras/ 
Sin duda estas notas de divulgación se han trabajado a partir de diseñar la Herramienta de Comunicación Científica y Tecnológica brindando una accesibilidad del conocimiento científico al mayor público posible.

Es necesario mencionar para no pasarlo por alto que, además de las notas de divulgación científica confeccionadas por los comunicadores de la Dirección, se incluyó en la Web del CONICET un espacio denominado "Ciencia con voz propia", una columna destinada a los investigadores para que ensayaran, opinaran y expresaran los debates vigentes en torno a su campo disciplinar o los desarrollos de su línea de investigación ${ }^{135}$.

Paralelamente al desarrollo de las actividades de divulgación hubo un claro crecimiento de espacios para los debates en el mundo académico acerca del rol del periodismo científico. Desde el 2011, eventos como el Congreso Internacional de Comunicación Pública de la Ciencia (COPUCI) han tenido como objetivos profundizar y consolidar un espacio heterogéneo donde conviven miradas, intereses, valores y prácticas involucradas en la construcción de cultura científica.

Estos espacios tienen como fin recuperar aproximaciones y aportes desde diferentes puntos de vista. Pero así y todo estos debates están lejos de profundizar los procesos políticos en investigación y desarrollo (que algunos lo denominan de "gobernanza"136 científica) apuntando a las controversias que necesariamente estructuran estos procesos.

Desde otro punto, se observa que tampoco se ha profundizado el lugar de los medios masivos, más allá de recuperar y reconocer el campo de experiencias personales donde se han circunscripto los debates, dejándose de lado lo referente a la concentración de medios y su oposición a las nuevas políticas públicas inclusivas, de ampliación de derechos y del acceso al consumo y de redistribución de la riqueza donde la ciencia y la tecnología tiene aportes por

\footnotetext{
${ }^{135}$ Aquí se pueden ver algunos ejemplos de "Ciencia con voz propia":

Dinosaurios gigantes de la Argentina

Disponible en: http://www.conicet.gov.ar/dinosaurios-gigantes-de-la-argentina/

Las fascinantes rosquillas que rodean a los Agujeros Negros Activos

Disponible en: http://www.conicet.gov.ar/las-fascinantes-rosquillas-que-rodean-a-los-agujeros-negros-activos/

Estudios hidroacústicos en el Canal Beagle

Disponible en: http://www.conicet.gov.ar/estudios-hidroacusticos-en-el-canal-beagle/

Anteojos 4D y caleidoscopios: instrumentos para abordar el Chagas desde una nueva perspectiva

Disponible en: http://www.conicet.gov.ar/anteojos-4d-y-caleidoscopios-instrumentos-para-abordar-el-chagas-desde-una-nueva-perspectiva/

${ }^{136}$ El concepto de gobernanza, que es complementario con las nociones de buen gobierno, gobierno participativo y gobierno abierto, cobró en este tiempo diversas acepciones. Al respecto este término está sujeto al ideario liberal de libre mercado en el campo anglosajón, a los desafíos de reorganización del territorio y la integración en distintos niveles en el contexto europeo, y con estrategias de poder en el lenguaje de los organismos multilaterales cuando significaron la intervención por parte de estos sobre las políticas económicas y sociales en la región. En GAUDIN, Jean-Pierre (2002). "¿Pourquoi la gouvernance?". Ed. Presses de Sciences-Po. Paris.
} 
señalar. Más aún, aquí no está exento el lugar ocupado por la ciencia y la tecnología desde el 2003 en adelante.

Desde esta perspectiva quizás queda aún pendiente avanzar o profundizar en instancias de reflexión pública acerca de estas experiencias institucionales que apunten a potenciar lo logrado precisando la agenda político-científica y de esta manera contribuir a la construcción de estrategias y herramientas comunicacionales que permitan cubrir aspectos hasta ahora poco o nada atendidos.

En tal sentido, impulsar los debates públicos sobre cuestiones de desarrollo científico y tecnológicos es una forma de avanzar en la reflexión pública y el diseño de estrategias de divulgación científica en la Argentina para contribuir al acercamiento entre el saber científico y la sociedad.

\section{La discusión conceptual y metodológica en la capacitación}

En un proceso integrado por la reflexividad ${ }^{137}$ y el diálogo desde la DRI se generaron talleres de capacitación para comunicadores del CONICET y de organismos del sistema científico y tecnológico con la participación de científicos. El "Taller de Capacitación en Biotecnología y Biología Molecular para Divulgadores del Estado" realizado en 2012 en el Instituto de Biología Molecular y Celular de Rosario (IBR), se intercambiaron conocimientos y se profundizó en la sociabilización de estos temas, especialmente en el rol de la divulgación en la popularización del conocimiento.

\footnotetext{
${ }^{137}$ Es en estas instancias conduce a reconocer y escuchar. El modelo reflexivo, coincidiendo con lo que expresa Richard Milner desde sus aportes al tema, plantea las posibilidades que tiene este modelo para que, tanto el investigador como los participantes en la investigación, se impliquen en un proceso de construcción de ellos mismos. Este procedimiento permite en tal situación alcanzar una reflexión acerca de cómo cambiar las situaciones o los significados que les oprimen. Un modelo reflexivo que sirve para aportar criterios para asistir tanto al investigador como a los participantes a que mejoren lo que conocen y cómo lo conocen, y así beneficiar la teoría, la investigación y la práctica.

En MILNER, Richard (2006). "Culture, race and spirit: a reflextive model for the study of African-Americans". International Journal of Qualitative Studies in Education, 19 (3).
} 
En 2013 en el Centro Nacional Patagónico (CENPAT) tuvo lugar el "Taller de capacitación en biotecnología y biología marina para divulgadores" quienes junto a investigadores del Centro desarrollaron temas como manejo de recursos marinos, microbiología ambiental, genética forense y biotecnología; completándose la capacitación con avistaje de fauna marina junto a guías científicos.

Entre otras instancias generadas, se desarrolló junto a la Gerencia de Desarrollo Científico y Tecnológico la convocatoria de Proyectos de Divulgación Científico - Tecnológica en 2012. La iniciativa acompañó la política de fortalecimiento institucional del CONICET, tomando como instrumento la divulgación científica y tecnológica donde participaron equipos conformados por investigadores, personal de Apoyo y becarios del Conicet y de otras instituciones.

Los proyectos presentados fueron evaluados por científicos del CONICET especialistas en divulgación como los expertos externos en comunicación de universidades nacionales. Se financiaron 53 proyectos por 2 millones de pesos para las tres categorías de 10 mil, 30 mil y 100 mil pesos.

\section{El inicio de los debates}

La necesidad de comunicar al público general los resultados de investigación, líneas de trabajo y proyectos se enmarcó en una política integral de apertura de conocimientos por y hacia la sociedad. En ese contexto se creó Divulgación Científica y Tecnológica bajo una coordinación que desarrolló también una subárea de Comunicación Visual, orientada a la generación no solo a la producción de material de difusión e infografías, sino también de fotografías que ilustran diferentes trabajos.

Frente al volumen de material producido surgió la necesidad de reunirlo bajo un concepto o identidad que permitiera aunar todos los contenidos, imágenes y registros generados por el CONICET en relación a la divulgación del trabajo de sus investigadores, personal de apoyo y 
becarios, junto a los casos de transferencia y servicios que se enmarcan bajo la Dirección de Vinculación Tecnológica.

Así se constituyó la línea de trabajo CONICET Contenidos. Bajo esta identidad se reunieron las notas de divulgación científica, vinculación tecnológica, y su apoyo visual y fotográfico, así como nuevas propuestas de material de divulgación producidos para dar soporte a colegios y estudiantes, y libros generados por científicos del Consejo.

El trabajo que consolidó sobre lineamientos dispuestos por la coordinadora en diálogo con su director para cobijar dentro de una misma identidad los contenidos generados en materia de divulgación científica y tecnológica, y de comunicación visual por el CONICET. Esto incluyo: artículos de divulgación científica; de divulgación tecnológica; infografías; fotografías y videos de trabajos a campo, investigaciones, colecciones, etc.; material de divulgación científica de apoyo para docentes, y orientado a estudiantes; libros, cuadernillos y producción bibliográfica.

La creación de una identidad visual y conceptual permitió maximizar y amplificar el impacto de su comunicación.

\section{Abordaje a la Vinculación Tecnológica y Social}

El trabajo proyectado se situó sobre el conocimiento enmarcado en las Grandes Áreas como Exactas y Naturales, Agrarias, Ingeniería y de Materiales, Biológicas y de la Salud, y Sociales y Humanidades, sumado al seguimiento de las acciones de vinculación y soporte a la transferencia realizada por la Dirección de Vinculación Tecnológica y Social (DVTS) en todo lo referente a la promoción de la vinculación y al soporte a la transferencia tecnológica del CONICET, como fue el seguimiento y ofrecimiento de servicios a través de su red de profesionales con más de 100 integrantes y sus 15 oficinas de vinculación tecnológicas en el país. 
Para este desarrollo fue preciso incorporar y lograr el máximo aprovechamiento e impacto de los conocimientos generados por sus científicos, impulsando diversas actividades destinadas a dar a conocer sus conocimientos y capacidades.

Por esta razón y para no redundar en lo ya explicado respecto de las Grandes Áreas, el trabajo realizado con la Dirección de Vinculación Tecnológica tuvo al menos 4 ejes de ordenamiento que fueron propuesto por la vicepresidencia de Asuntos Tecnológicos a partir de enfoques que, lejos de presentarse como divergentes, se complementan mutuamente permitiendo una comprensión panorámica y analítica de la labor de la Dirección de Vinculación Tecnológica y Social. Estos ejes directrices son: desarrollo tecnológico, tecnologías disponibles, empresas de base tecnológicas y desarrollo de proyectos de desarrollo social; permitiendo así la posterior construcción de una nueva Web para la DVTS en base a estas categorías reconocidas para la arquitectura de la comunicación ${ }^{138}$.

En este orden el trabajo de comunicación también se consagró en un análisis positivo y puesta en conocimiento de dichas articulaciones a partir del relevamiento e indagación de las capacidades ofrecidas en las distintas regiones del país sobre una perspectiva general. Identificando estos ejes con lo regional y respondiendo a las políticas de gestión, modelos y tendencias de la DVTS a fin de ubicar la cuestión de la articulación no solo como un acontecimiento sino en cuanto a una tendencia de la Institución. La cual puso a disposición de los sectores socioeconómicos su experiencia en investigación y desarrollo. Hecho que

\footnotetext{
${ }^{138} \mathrm{La}$ arquitectura de la información precisa entender el entorno que modela a la Web y que no solo responde a estándares de diseño y producción de entornos virtuales. En el trabajo realizado entre la Gerencia de Organización y Sistemas y la DRI constituyó la puesta en común de conceptos para poder situar tanto a los ejes de ordenamiento como los estándares para construcción de un nueva Web (los estándares facilitan la elaboración de abstracciones de arquitecturas que representen a toda una gama diversa de implementaciones prácticas de las mismas). Este término es de uso común en el ambiente del diseño informático, y puede resultar recurrente en cuanto a la aplicación de nuevas plataformas empleadas en Instituciones que cuentan con un área específica.

La labor desarrollada junto a la Gerencia consistió en proponer, más allá de que aún predominan conceptos e imaginarios tecnológicos acuñados desde el estructural funcionalismo y que se prestan a discusiones en cuanto a los dispositivos y modelos presentes en un entorno web, proponer un espacio compartido de trabajo y análisis para rescatar conceptos comunicacionales sobre lenguaje multimedial y los elementos de su entorno (aquí deseamos mencionar el texto de Santiago Albarracín "Elementos del Entorno Multimedial". Documento del Taller de Producción de Mensajes. Facultad de Periodismo y Comunicación Social. UNLP) sobre referencias concretas y experiencias como recorridos producto del diagnóstico y sobre un conjunto de nuevos saberes. Según Albarracín "la tecnología multimedia, en su aspecto cultural, está borrando las fronteras entre la informática, las comunicaciones, los medios de comunicación masivos y personales, el ocio y los sistemas de representación visual a los que estábamos acostumbrados a suceder de manera aislada".

La producción de la Web del CONICET, de CCTs y UE que así lo solicitaron, y la Web de Vinculación Tecnológica, fueron pensadas desde la denominada arquitectura de la información para diseñar la metodología de organización de contenidos en sedes Web, y tratar la definición de éstas en cuanto a la gestión de contenidos, sistemas de navegación, rotulado y búsqueda. Pero también fue utilizada para organizar contenidos, en tanto que define metáforas, estructuras jerárquicas y horizontales, y taxonomías.

Desde la definición de la arquitectura de comunicación fue posible entender las relaciones de sus componentes básicos con otros sistemas relacionados. Este hecho permitió el diseño e implementación de estos componentes de forma reusable, económica y adaptable.

Resta una referencia, ya que si bien el concepto de arquitectura de la información fue acuñado por Saul Wurman en 1976, la misma se definió y fue configurando como especialidad de las ciencias de la información._De ahí que el arquitecto de la información sea aquel que crea la estructura o mapa de información que posibilita a otros encontrar sus propios caminos hacia el conocimiento, hecho que no escapa a los comunicadores como posibilidad.
} 
permitió configurarla -a su vez- en el campo de las políticas públicas y las organizaciones de Sistema Científico Tecnológico Nacional.

\section{Conocer, indagar e intercambiar experiencias}

Para el equipo abocado al desarrollo de la Herramienta Comunicación Científica y Vinculación fue una verdadera y real posibilidad observar y dar a conocer el tipo de articulaciones que se generan entre el Estado y las organizaciones de la sociedad civil en la Argentina, en particular en torno a la aplicación de las políticas de investigación y desarrollo. Capacidades del sistema científico nacional que plantea un modelo de país donde la ciencia y la tecnología constituyen un motor del desarrollo económico y de inclusión social.

Al emparentar las distintas realidades regionales se planteó una modalidad para la acción que tradujo el modo en que se acopló el sistema científico con las necesidades locales y regionales, pero especialmente permitió evaluar el impacto acerca de las políticas científicas y llevó a establecer referencias acerca de los grados de participación. Y conocer además los mecanismos según los cuales operó esta articulación y las características de dicha relación respecto a la capacidad institucional, conocimiento del tema y del área, organización interna, entre otros puntos.

La proyección de la herramienta y el conocimiento del campo, que involucró necesariamente a los comunicadores localizados en los Centros Científicos y Tecnológicos y Centros Multidisciplinarios, facilitó poner el énfasis en cada uno de los actores a la hora de encarar acciones de comunicación de manera articulada para generar los debates sobre la constitución de este espacio, su génesis, tanto como perfil y composición; y, en general, el rol que debe asumirse desde la Institución en la compleja trama social y política con la que se vincula.

En este sentido, hubo intercambios necesarios con los comunicadores sobre aspectos referidos a las políticas públicas en el área, las dinámicas del sector científico y tecnológico y los desafíos presentes, así como las oportunidades a las que se enfrenta la investigación 
científica. Y, además, se propuso la generación de líneas de diálogo con la DVTS para propender a fomentar la cooperación regional en puntos necesarios donde fue preciso comprender y poder afianzar un sector en plena construcción a nivel institucional.

Desde la DRI se eligió para todos los intercambios considerar a las instancias dentro de procesos históricos que aportan una mejor comprensión de las organizaciones, en la medida en que permiten superar o sortear las visiones reduccionistas respecto de la realidad del desarrollo científico y acceder a las diversas interacciones sociales que se producen entre todos los agentes e instituciones.

Por tanto, en lo que hace a la vinculación tecnológica, esta herramienta permitió vertebrar aprendizajes relevantes y familiarizarse con el sistema científico argentino, para acercarse a las mejores prácticas comunicacionales y abordajes para el reconocimiento y análisis de las lógicas de producción del conocimiento científico.

Y tener acceso directo y rescatar desde la vinculación tecnológica el enfoque, instrumentos implicados y servicios, y aquellos marcos que orientan las posibilidades para la investigación y el desarrollo, la innovación y la transferencia en temas como: biodiversidad, biología marina, biotecnología con aplicaciones farmacéuticas y con aplicaciones vegetales, tecnología nuclear con fines no bélicos, nanotecnología y tecnología aeroespacial, como de otras áreas disciplinarias.

Otros factores se orientaron a poner en perspectiva el conocimiento de los núcleos (salud, energía, agro-industria, desarrollo social, ambiente y desarrollo sustentable) de desarrollo nacional en investigación y desarrollo; promover y estimular el contacto directo desde los Centros Científicos y Tecnológicos ubicados en diversas provincias, con decidida participación de los comunicadores, con las realidades ecorregionales y el trabajo en los laboratorios de punta pertenecientes al Consejo Nacional (en la mayoría de los casos de doble dependencia con las Universidades) y de otras áreas temáticas como Sociales y Humanidades.

Al presentarse la herramienta sobre una serie de ejes dinámicos, la perspectiva pudo ser asumida como una de las partes interesadas para hablar de las actividades y con fundamento en cuanto conocimiento de los hechos que explican, sobre la complejidad, un espacio de transformación en la organización. 
La complejidad habla de la imposibilidad de ignorar la compleja naturaleza de las organizaciones, entre otras cosas porque cada vez van surgiendo formas más complejas de estructura organizacional sobre la cual la comunicación, o, el área de la comunicación, deja de tener una función meramente técnica y pasa a ser considerada estratégica. Esto lleva a precisar la cuestión de los recursos humanos y cómo se llevan adelante procesos de agregación de valor en la Institución.

Aquí resulta también válido recuperar lo que sostiene Edgar Morin ${ }^{139}$, en cuanto a que no se puede concebir a la estrategia como organización de la acción sin la comunicación ya que estos dos elementos interactúan entre sí y son partes inseparables.

Las prácticas y saberes de la comunicación en su genealogía están vinculadas con el diseño y vinculación en la instrumentación de políticas públicas. Lo comunicacional y las formas de lo institucional que hacen a los planteos, los diseños y la articulación de lo simple a lo complejo, de lo individual a lo colectivo, de lo particular a lo general, desde esta visión compleja, hacen posible valorizar y superar los aspectos meramente tecnicistas e instrumentales.

En el reconocimiento de la importancia y trascendencia que implica contar con las herramientas comunicacionales para la producción integral ${ }^{140}$ en la Institución, en torno a la creación y divulgación de las ideas, las experiencias, los debates, los análisis y las recomendaciones, responde tanto a la gestión como a los agentes institucionales en la voluntad de involucramiento bajo líneas de pensamiento y acción sobre la concepción de un Estado que es capaz de ejecutar políticas activas en muchos planos, entre ellos, el de la investigación y desarrollo.

\footnotetext{
${ }^{139}$ MORIN, Edgar (2011). "Introducción al pensamiento complejo". Gedisa, Barcelona.

$140 \mathrm{Al}$ señalarse la producción deben considerarse incluidos los procesos de creación, escritura, detección, compilación, evaluación, selección, puesta en soporte, edición, distribución y análisis de la implementación de las producciones en el medio en que se haya propuesto.
} 


\section{Relaciones con la Comunidad}

El reconocimiento de la Herramienta Comunicacional Relaciones con la Comunidad se pensó como un aporte que las áreas de comunicación en instituciones científicas debían considerar como paso necesario para profundizar y enriquecer los debates acerca del sentido formativo de las propuestas de promoción de la ciencia y la tecnología.

En el carácter de promover se configura y constituye el sentido de crear un amplio espectro de diferentes órdenes discursivos y simbólicos, para develar nuevos y viejos procesos reflexivos que tiendan a poner en evidencia y desentrañar el sentido de la ciencia y la tecnología y, en ese orden, comprender su construcción social.

Para tal fin se ponía de relieve la necesidad de alcanzar una articulación en diversos escenarios en el todo el territorio donde, en este caso puntual, ya contaba con presencia el CONICET. Por eso esta herramienta ${ }^{141}$, si bien partía de un delineamiento acerca de que era fundamental que contribuyera a lograr una mayor comprensión de la configuración del campo de la investigación y desarrollo, tenía como objetivo crear un programa que ayudara a repensar, indagar y problematizar los sentidos sociales de la ciencia y la tecnología y por ende cómo y desde qué lugar cada ciudadano se involucra desde la diversas propuestas.

Entendiéndose que a partir de la creación de un Programa de Promoción de Vocaciones Científicas (VocAr), en un campo de conocimiento complejo y en plena construcción desde la divulgación y promoción de las vocaciones científicas, poco explorado desde los organismos de ciencia y tecnología hasta el momento, que tenía y planteaba profundos debates epistemológicos, es que desde la constitución de la herramienta las preguntas se

\footnotetext{
${ }^{141}$ Las actividades de rutina asignadas a la coordinación de Relaciones con la Comunidad se pueden reconocer en las siguientes tareas: generación de agendas institucionales orientadas a facilitar la vinculación del CONICET con el sector público y privado. Promoción de las actividades del organismo en divulgación científica y acciones de interés para el sistema educativo con el fin de promover convenios y la generación de actividades en común. Redacción de proyectos de orden institucional para la firma de convenios. Seguimiento de la evolución de las acciones interinstitucionales. Promoción de actividades divulgativas y educativas de orden internacional en el país. Generación de acciones para la consolidación de VocAr en el ámbitos de ministerios de Educación y de Ciencia y Tecnologías provinciales. Elaboración de propuestas de intervención metodológica para eventos promovidos desde la Dirección. Generación de material conceptual para actividades en CCTs y UEs. Presentación en congresos, seminarios y jornadas de carácter educativos/académicos en ciencias sociales avances en la promoción y vinculación interinstitucional para la divulgación de la ciencia y la tecnología, desde acciones generadas desde el CONICET.
} 
orientaron en conocer acerca de cómo se gestaban los procesos científicos que, en el contexto de las prácticas, como tales, se constituían como procesos para el cambio social.

Desde aquí y sin olvidar que la herramienta surgía desde el lugar de comunicadores y con la premisa de la sustentabilidad comunicacional, hecho que llevó a cuestionar modelos de producción, distribución y consumo hegemónicos en cuanto al conocimiento de la ciencia y la tecnología, a cuestionar la idea de un campo contrario a la idea de lineal e inmutable y que era posible partir de pensar la realidad como dinámica y en proceso de construcción, cabía la posibilidad de posicionar la reflexión crítica desde el lugar de los distintos actores institucionales.

Ser por tanto un enlace para presentar saberes, ponerlos en común, producir y apropiarse de saberes y participar en pensar nuevos escenarios, gestionar en función de ello y alcanzar un compromiso político institucional deseado en interacciones donde se incorporen variables ligadas a las dimensiones sociales, educativas, culturales, tecnológicas, económicas, relacionadas en definitiva a los distintos sistemas de valores y creencias desde los cuales se sostiene, justifica y legitiman modos particulares de producción del conocimiento.

Desde este ámbito, que necesariamente se entrecruzaba con la educación, quedó evidenciado que se requería un esfuerzo para integrar a los diversos ámbitos institucionales y no reproducir respuestas meramente técnicas, sino comunicar desde perspectivas integradas y complejas a la realidad del otro y donde el investigador, el técnico de apoyo o el becario pudiese discutir sobre la forma en que se construye el conocimiento y las tramas que como tal se constituyen a nivel institucional. A su vez, la comprensión pública de la ciencia y el lugar que le ocupará al ciudadano en un futuro cercano al tener la posibilidad de poder optar sobre qué disciplina seguir, especialmente aquellas que se alejaron del común de la gente, a la vez que desnaturalizar la imagen pública de la práctica científica reconocida como algo inquietante y atemorizador y caracterizarla en función de la transformación a escala de la producción del conocimiento, de la estructura institucional cuyo objetivo es contribuir a consolidar un ámbito propicio para la reflexión y el debate del saber científico y técnico.

Se trata pues de una herramienta comunicacional que fue pensada y concebida para examinar las condiciones de posibilidad de un diálogo, discusión y debate entre ciencia y sociedad, 
acotado a la posición institucional del CONICET y a las alianzas que se constituyeron como tales, que tendieron a promover la circulación y apropiación social del conocimiento.

Por su parte, en todo momento se trató de reconocer y poner en invidencia la dificultad en la que se incurría en cuanto a pretender que la distancia entre ciencia y sociedad era superable informando adecuadamente a los ciudadanos. Y por tanto suponer que a partir de conceptualizaciones accesibles tendrían por sí mismas el efecto de promover no solo actitudes sino el interés y la capacidad de reflexionar para integrarse a las discusiones públicas.

Negar, como ya lo hemos dicho, la desigualdad entre expertos y públicos en lo que respecta a la disposición del conocimiento científico era uno de los mayores desafíos por trabajar. Pues si se trataba de incorporar el potencial renovador que había sido detectado en muchos discursos y planteos de investigadores, donde se manifestaba una actitud realista con respecto a condiciones de credibilidad y confianza, era necesario que éstos se vincularan desde la experiencia y el conocimiento cotidiano de los sujetos y de la confianza en las instituciones que la desarrollan.

Claramente los programas impulsados con apoyo en la herramienta se reconocían en estas dimensiones porque eran necesarias comprenderlas para la interacción entre científicos y públicos, y desde el lugar de estos últimos se revalorizaba la cultura y las competencias como mediaciones sustantivas e innegables de su relación con el conocimiento científico, como también en cuanto al impacto y las consecuencias para la circulación y apropiación social del conocimiento $^{142}$.

\footnotetext{
${ }^{142}$ En relación a estas reflexiones y para captar la naturaleza compleja de la vinculación entre expertos y públicos, se incorporó la lectura de CORTASSA, Carina (2012). "La ciencia ante el público. Dimensiones epistémicas y culturales de la comprensión pública de la ciencia". 1era. ed. Buenos Aires: Eudeba.
} 


\section{Programas y proyecciones}

En el plano de la comunicación institucional el enfoque sobre la promoción de vocaciones científicas estaba en clara referencia y recuperaba en parte las discusiones que en la esfera pública se venían ya generando en ámbitos de la nanotecnología, la biología molecular, la ingeniería genética, el desarrollo aeroespacial, las ciencias medioambientales vinculadas con el cambio climático; pero centralmente remitía en poner en contexto el proceso de apropiación pública de la ciencia respecto del futuro de ciertas disciplinas (aquí se corre el riesgo de cifrar el futuro de profesionales en respuesta a la creciente demanda laboral de un país privilegiando unas disciplinas por otras, tema que está sujeto a controversias; no solo en orientar para un demanda, sino también en no comprender la realidad de los sujetos y no poder distinguir las condiciones de los grupos sociales con los que se trabaja, en cuanto sensaciones de exclusión, temores y presiones que representa la ciencia cuando se identifica con conocimientos y disciplinas) y su vinculación desde el conocimiento cotidiano (práctica del deporte: fútbol, básquet, controles antidopaje; cuidado de la salud, cambio climático, medición de la velocidad de la luz, percepción y contacto con la fauna marina, entre otros) expresado en saberes, o desde el sentido común, en: física, química, matemática y biología.

Desde esta perspectiva asumida institucionalmente y destinada como propuesta a alumnos escolarizados de primaria y de nivel medio y técnico y terciarios, sin desconocer aquellos otros lugares posibles por fuera de los ámbitos educativos, se iniciaba la interacción bajo la posibilidad de que estos pudiesen formarse una opinión al respecto y ser considerados en el desarrollo de la discusión. Propuesta sustentada en que la circulación del conocimiento en los ámbitos no formales y sobre enfoques concentrados en las áreas científicas revisten un carácter de novedad, incertidumbre u aprensión y generan interfaces de cara al diálogo que hace posible la circulación y apropiación colectiva del conocimiento científico.

Y por otra parte, el enfoque debía constituir una línea de tratamiento donde el conocimiento científico no debía situarse únicamente desde los medios, sino desde condiciones iniciales de diálogo donde los científicos debían desplazarse y constituirse en el lugar donde los actores tienen sus intereses y desarrollan sus prácticas, relevando las expectativas recíprocas con las 
que se involucran en la interacción para construir simbólicamente lo que es la ciencia en cada uno de ellos.

El diseño de esta trama requirió la decisión y apoyo institucional en primer lugar, posteriormente repensar una planificación desde las prácticas comunicacionales, es decir, plantearla como un espacio de socialización, un encuentro donde se fomenta la circulación de las distintas voces, opiniones y decisiones, sobre la realidad en la cual se desenvuelve la comunidad científica, la escolarizada y no escolarizada, y así poder ampliar esta mirada. También la propuesta, como se desarrolla más adelante, acompaña el criterio de que todo proyecto que se orienta en una concepción social de los procesos de comunicación conlleva dos componentes ineludibles: el educativo y el político ${ }^{143}$.

En la misma línea, y en esta oportunidad recuperando a Paulo Freire ${ }^{144}$ trabajar e instar de manera consecuente en que la educación, en general, deje de ser una educación de respuestas, en lugar de ser una educación de preguntas. "Una educación de preguntas es la única educación creativa y apta para estimular la capacidad humana de asombrarse, de responder a su asombro y resolver sus verdaderos problemas esenciales, existenciales, y el propio conocimiento".

\section{El Programa de Promoción de Vocaciones Científicas}

El Programa de Promoción de Vocaciones Científicas (VocAr) ${ }^{145}$ como tal y desde sus orígenes, se reconocía la necesidad de generar estrategias de acercamiento entre el Sistema Científico y Tecnológico, el Sistema Educativo y la sociedad, fortaleciendo las capacidades de alumnos y profesores en el conocimiento e interés del trabajo científico, acompañando y promoviendo actividades de cultura científica a cargo de investigadores del organismo.

\footnotetext{
143 CARDOSO, Nelson (2000). "La Comunicación Comunitaria". Bibliografía Modulo 1. Taller Cuatrimestral de Comunicación Comunitaria. Universidad Nacional de La Matanza. Apunte de la Cátedra.

144 FREIRE, Paulo (1986). "Hacia una pedagogía de la pregunta. Conversaciones con Antonio Faundez". Buenos Aires. Ediciones la Aurora.

${ }^{145}$ El Programa de Promoción de Vocaciones Científicas (VocAr) se puso en funcionamiento en junio del 2013 y fue formalizado por el Directorio del CONICET bajo Resolución N²247, con fecha 25 de junio de 2014.
} 
En ese orden VocAr consideró lo postulado por el Ministerio de Ciencia y Tecnología, que advertía la necesidad de promover vocaciones creando a su vez el Programa Nacional de Popularización de la Ciencia y la Innovación, en 2013, con el fin de profundizar el acercamiento de la ciencia y la innovación a la sociedad con el propósito de contribuir a la apropiación social del conocimiento y a la formación de una ciudadanía responsable.

Desde su origen VocAr reconocía que el desarrollo sostenido de las políticas en ciencia, tecnología, e innovación durante más de una década fueron la clave para avanzar en un programa cuyo resultado debía ser profundizar la apropiación social del conocimiento por parte de la sociedad.

Se enfatiza así su aporte sustancial, al crearse en el marco de la DRI la herramienta Relaciones con la Comunidad, para trabajar en explicar y acercar a los alumnos, estudiantes, docentes y demás actores sociales, ese pasaje de lo abstracto a lo concreto fundado en la afirmación que se vive rodeado de ciencia y tecnología, o, más aún, bajo la sensación de que se está inmerso en ellas.

Y como tal aparecía en el plano de las representaciones y fue trabajado por el Ministerio de Ciencia y Tecnología, previo a la implementación de la herramienta, bajo el lema: "Tu vida tiene ciencia". Donde el conocimiento científico bajo la forma de bienes y procesos tecnológicos envuelve ámbitos íntimos de la vida cotidiana y hasta aparece integrada al propio cuerpo, constituyendo todas las imaginables formas (artefactos, electrodomésticos, teléfonos móviles, vegetales como tantas otros; pero ciertamente evidenciando el contexto se debe dar la aparición de los objetos) evidentes de la ciencia y la tecnología en el imaginario social.

A través del el carácter didáctico que tiene la enseñanza y aprendizaje del conocimiento científico, se buscó fortalecer espacios que habilitasen a promover la ciencia, la tecnología y la innovación con inclusión social. En una construcción conjunta aplicando las herramientas comunicacionales de Comunicación Pública; Científica y Vinculación Tecnológica; y Eventos, Ceremonial y Protocolos. 


\section{Aportes del Programa VocAr}

El Programa VocAr fue creado para estimular, reforzar e incrementar el interés en la investigación científica y tecnológica fortaleciendo los lazos con la sociedad y el sistema científico. Pero también en su propuesta consideraba las maneras en las que se modifica y transforma el conocimiento de los grupos de investigación, las estrategias que tienen incidencia en la práctica cotidiana, los comportamientos naturalizados por los investigadores y grupos de investigación, los diálogos con los saberes y experiencias de las comunidades, la articulación del conocimiento científico y tecnológico producido con las experiencias y los conocimientos de las grupos con los que interactúa.

Conocer al interior de la Institución fue la primera tarea que permitió detectar más de 250 investigadores (entre las categorías de la Carrera del Investigador Científico: Asistentes, Adjunto, Independiente, Principal y Superior) que venían generando desde diversas perspectivas pedagógicas y metodológicas instancias puntualizadas de divulgación de la ciencia.

Bajo diferentes concepciones sobre modelos de enseñanza y aprendizajes, alcances y limitaciones, en cada caso y en la medida que se iban integrando a VocAr de manera voluntaria se pudo discutir el lugar otorgado a la ciencia, el saber y el lugar de quienes participarían en estas propuestas. Así fue como sucedieron distintas aproximaciones y concepciones sobre el aprendizaje, donde hubo quienes plantearon los procesos de divulgación de la ciencia centrado en lugar de quien plantea la propuesta y con eje en la transmisión de conceptos en el marco de una disciplina científica bajo una concepción epistemológica positivista de la ciencia. Con conocimiento y saberes organizados en la lógica de la disciplina, sin articulación con el contexto al cual se dirige la experiencia, y con carencias en los contenidos a exponer o transmitir, al ser presentados de manera desarticulada y fragmentada acerca de las problemáticas a las que refieren o pretenden explicar. Y, si bien en el relevamiento los hubo, estos casos fueron los menos. 
Otras perspectivas, en las propuestas de divulgación relevadas, eran críticas y valorizaban el lugar del sujeto destinatario de la propuesta como parte activa, con experiencias, conocimientos y con diferentes perspectivas que se vinculaban con los contextos culturales o individuales que orientan sus acciones y interpretaciones. El actor social aquí era visto como un alguien que debía construir su conocimiento, donde funcionan esquemas o estructuras de de representación de los sujetos donde las actividades no están dirigidas a la transmisión de conceptos. Esta perspectiva integra la diferenciación entre ciencia y realidad donde la ciencia constituye modelos explicativos provisorios de este última que condicionan la observación. La ciencia es vista como una construcción cultural al interior de una sociedad y por tanto dinámica y atravesada por condiciones sociales, históricas y políticas.

VocAr buscó impulsar instancias nuevas formas de reflexión y participación de los alumnos, profesores y público en general, al generar de su capacidad de intervenir en la transformación de la realidad como posibilidad de construir alternativas desde el lugar desde donde cada actor social interviene ${ }^{146}$.

\footnotetext{
${ }^{146}$ Las actividades de VocAr estuvieron destinadas a adolescentes de los últimos años del colegio secundario, docentes de distintos niveles educativos y público en general. Durante este período se realizaron charlas y talleres para jóvenes, docentes y actividades destinadas a todo público. El detalle de las actividades generadas en 2013 y 2014 es fue el siguiente: Charlas de Divulgación Científica en el Buque Oceanográfico Puerto Deseado, ciudad de Mar del Plata (1500, $\mathrm{N}^{\circ}$ de asistentes); Charla de Divulgación Científica. Ciudad de Baradero, provincia de Buenos Aires (150); Tecnópolis, charlas con investigadores en los stand del Ministerio de Ciencia y Tecnología, provincia de Buenos Aires (25.000); "Ciencia, ¿Qué me contás?". Ciudades de Rosario, Granadero Baigorria, Funes y Capitán Bermúdez en la provincia de Santa Fe, Colón provincia de Buenos Aires y Villa 21-24 en Barracas, Ciudad Autónoma de Buenos Aires (3.000); Semana de actividades científicas. Centro Científico Tecnológico CCT CONICET La Plata, Instituto de Fisiología Vegetal (INFIVE, CONICETUNLP), Museo de Física de La Plata de la UNLP (500); "Hablemos de Chagas" en San Luis. Sede del Instituto de Matemática Aplicada San Luis - CCT San Luis (200); "Educando al Cerebro". Colegio Nacional Buenos Aires, Ciudad Autónoma de Buenos Aires (400); "La Ciencia en los Cuentos". Concurso que abarcó todo el país (200); "La Noche de los Museos". Sede central del CONICET, Ciudad Autónoma de Buenos Aires (1.500); "VI Encuentro de Jóvenes Investigadores en Neurociencias". Ciudad de Córdoba (700); Actividad de Divulgación Científica - Educación destinada a alumnos secundarios. Ciudad de Salta (350); actividad de Divulgación Científico - Educativa destinado a docentes. Ciudad de Salta (30); Actividad de Divulgación Científico - Educativa. Ciudad de Tandil (30); Actividad de Divulgación Científica - Educativa. "Año internacional de Cristalografía", Concurso para alumnos de nivel secundario: Crecimiento de Cristales. Charlas en las provincias (1.500); Capacitación sobre conservación y uso sustentable de la vicuña a cargo del grupo de investigación VICAM y CONICET. Ciudad de Nuevo Pirquitas, provincia de Jujuy (150); Lanzamiento de la Plataforma Federal para la Socialización de la Ciencia "País Ciencia". Escuela Técnica No 465 General Manuel Belgrano. Ciudad de Rosario, provincia de Santa Fe (400); Charla de la Plataforma Federal para la Socialización de la Ciencia "País Ciencia". Ciudad de Esperanza, provincia de Santa Fe (200); Investigadores del CONICET en la Feria del Libro. $39^{\circ}$ y $40^{\circ}$ Feria Internacional de Libro. Ciudad Autónoma de Buenos Aires (5.000); "Ciencia a Bordo". Actividad de Divulgación Científica en el Buque Oceanográfico Puerto Deseado. Ciudad Autónoma de Buenos Aires (3000); "Educando al Cerebro". Universidad Nacional del Comahue (400); Museo de la Universidad de General Sarmiento. General Sarmiento, provincia de Buenos Aires (200); "Hablemos de Ciencia y Jornadas Científicas". Ciudad de Lobos, provincia de Buenos Aires (800); "Ciencia a Bordo". Actividad de Divulgación Científica en el Buque Oceanográfico Puerto Deseado. Ciudad de Mar del Plata (700); Archivo Pedagógico de la Valija Olga Cossettini, Instituto de Formación Docente de la provincia de Buenos Aires (500); "La Noche de los Museos". Sede Central del CONICET. Ciudad Autónoma de Buenos Aires (3.000); Talleres científicos en escuelas, ciudades de Corrientes, Entre Ríos, Carmen de Areco provincia de Buenos Aires (200); Recorridos educativos en el CENPAT. Ciudad de Puerto Madryn, provincia de Chubut (150); Jornadas de Puertas Abiertas 2014 IBYME. Ciudad Autónoma de Buenos Aires (300); Charlas de divulgación científica en la Universidad Nacional de Lanús (UNLA). Charlas de "País Ciencia". Ciudad de Lanús, provincia de Buenos Aires (150); Taller de ciencia para docentes de profesorado del área de Ciencias Exactas y Naturales. "País Ciencia". Ciudad de Rojas, provincia de Buenos Aires (50); Ciclo de charlas Tecnología para quién. Ciudad de San Luis (200); Charlas de divulgación científica para docentes y alumnos de colegios secundarios. "País Ciencia". Ciudad de Ushuaia, provincia de Tierra del Fuego (300); Entrega de premios del Concurso Nacional de Crecimiento de Cristales para Colegios Secundarios. Ciudad de Mar del Plata (100); "¿Existen los monstruos?". Muestra temporaria en el Museo Argentino de Ciencias Naturales Bernardino Rivadavia. Ciudad Autónoma de Buenos Aires (10.000); Recorridos educativos en el CENPAT. Ciudad de Puerto Madryn, provincia de Chubut (300); Concurso de Arte Público "Murales de Ciencias". Ciudad de Salta (40); Charla de divulgación científica. Ciudad de La Plata, provincia de Buenos Aires (150); Charlas de divulgación científica de "País Ciencia". Ciudad de Mercedes, provincia de Buenos Aires (450); Charlas de divulgación científica para escuelas secundarias en el Museo Argentino de Ciencias Naturales "Bernardino Rivadavia". "País Ciencia". Ciudad Autónoma de Buenos Aires (150); Mosquitos, transmisores de enfermedades. Ciclo de
} 
Surgió entonces dinamizar en las nuevas instancias asumidas por VocAr, donde el investigador, el becario o el técnico de apoyo del CONICET tenía en su rol trabajar en el encuentro y la apropiación del conocimiento, de producción saberes y desarrollo de habilidades a partir de potenciar la capacidad de evaluación crítica de los participantes en las charlas, jornadas, visitas y talleres.

Las distintas propuestas que fueron integradas a VocAr se fueron adecuando a los contextos, los participantes y los objetivos perseguidos por el Programa. Y bajo la necesidad de modificar el modo de entender la realidad de la ciencia y la tecnología, se trabajó para dinamizar los procedimientos orientados a la divulgación científica, desde la participación, la comunicación y las actividades creativas que desde la DRI se podían generar y potenciar con impulso desde los CCT y las UE. Esta instancias y proyectos con características propias que incluían propuestas destinadas a emprender procesos científicos divulgativos bajo la incorporación de perspectivas diversas que permitieron avanzar no solo en la comprensión de la prácticas de los investigadores, técnicos y becarios, sino que estos se permitieron reflexionar sobre el lugar relativo de sus propios puntos de vista.

Desde estos lugares se fue construyendo VocAr, con más de 150 integrantes en todo el país entre investigadores, becarios y personal de apoyo, en línea con los comunicadores de los CCT. Y junto a los actores involucrados en un marco de interrelaciones todos los recursos estuvieron orientados en rescatar las acciones colectivas sobre las individuales, la participación acerca de la construcción del conocimiento y no en el reconocimiento de dogmas, en la articulación y la reflexión, la incorporación de perspectivas y el acercamiento a los objetos por conocer interviniendo, promoviendo y realizando distintas acciones en temáticas de orden estratégico para el país ${ }^{147}$.

charlas abiertas a la comunidad . Ciudad de La Plata, provincia de Buenos Aires (200); "Educando al Cerebro" Buenos Aires 2014. Facultad de Derecho de la Universidad de Buenos Aires (UBA). Ciudad Autónoma de Buenos Aires (1.500); La Ciencia en los Cuentos, premiación. Ciudad Autónoma de Buenos Aires (100).

${ }^{147}$ Durante el período analizado el Programa VocAr tuvo como principal objetivo la promoción de vocaciones científicas en jóvenes y adolescentes mediante distintas actividades de promoción de cultura científica con el fin de impactar positivamente en la elección de carreras científicas y tecnológicas. Fue así que impulsó acciones que fortalezcan los lazos entre el sistema científico y tecnológico y el sistema educativo, con el objetivo de mejorar y acompañar los procesos de enseñanza y aprendizaje de la ciencia y la tecnología. Se generaron actividades que difundieron el trabajo del investigador científico y tecnológico, el valor de su labor para la sociedad y para la toma de decisiones.

Se trabajó en promover y estimular el fomento de la cultura científica en el las comunidades locales, y apoyar como sostener diferentes proyectos de divulgación de la ciencia que desarrollen investigadores del organismo. A comienzos del 2014 desde VocAr se presentó la página web para mejorar la comunicación y visibilidad de las actividades con materiales exclusivos para ser descargados de http://www.conicet.gov.ar/vocar/. 


\section{El Buque Oceanográfico Puerto Deseado integrado a VocAr}

La propuesta "Ciencia a bordo" fue producto de un trabajo de observación, análisis y debate realizado durante el 2013-2014, donde se atendieron y registraron las respuestas del público a diferentes actividades de divulgación científica como charlas, encuentros y muestras realizadas en espacios como "Feria del Libro", Tecnópolis y actividades en colegios secundarios en distintas ciudades del país.

Por este motivo, se comenzó por indagar nuevas posibilidades de propuestas en diferentes espacios y surgió como propuesta integrar a VocAr al Buque Oceanográfico Puerto Deseado del CONICET. Amarrado en la ciudad de Mar del Plata, se logró realizar una serie de jornadas para escuelas secundarias en el espacio del buque e interactuar con los investigadores, becarios y personal de apoyo. Desde Relaciones con la Comunidad se identificaron con los investigadores los mensajes a transmitir, al igual que con los formatos seleccionados para llevar a cabo los encuentros, tanto las modalidades y soportes de comunicación utilizados.

A su vez, las experiencias permitieron expresar y conocer la diversidad de visiones de los estudiantes respecto de las actividades, y con recursos atractivos y motivadores donde los alumnos estuvieron próximos se logró mantener el interés y brindar sentido al proceso de investigación que en el buque se realiza, integrando de forma natural el conjunto de actividades realizadas y los contenidos puestos en juego durante la visita ${ }^{148}$.

\footnotetext{
${ }^{148}$ La docente Julia Larocca, directora de la Escuela Rural No 60 , del Partido de General Pueyrredón, envió una nota sobre la visita de la escuela al Buque Oceanográfico Puerto Deseado amarrado en la Base Naval Mar del Plata durante 2013, en la ciudad de Mar del Plata. Al respecto señaló:

Logrado el objetivo.

-Los alumnos pudieron escuchar, preguntar y entendieron. La profesora de matemática, frente a "¿para qué me sirve?" pudo desarrollar que mediante trigonometría podemos ubicar un buque en el medio del océano, ampliaron saberes sobre tratados, Antártida y está circulando el material, excelente.

- La visita cumplió altamente las expectativas de ellos y de los profesores: los alumnos se comportaron como esperábamos, plantearon cuestiones interesantes y las personas a cargo de la visita fueron muy claras en el recorrido de las temáticas abordadas.

- Al otro día de la visita vino una madre, que tiene 3 hijos en la escuela, a contarme lo siguiente: "Mauricio volvió muy contento del paseo, ¿usted le prestaría la enciclopedia?. Él tiene cabeza, tiene que seguir estudiando. Yo no entiendo mucho, pero él sí. Voy a tratar de no hacerlo faltar y arreglarme de otra forma para cuidar a los hermanos. Tiene que venir a la escuela siempre".

Ésta historia de vida cotidiana te ofrece un ejemplo de alguien que entendió que mediante el estudio puede armarse un proyecto de vida posible, con otro destino.
} 
La propuesta "Ciencia a bordo" se constituyó en una de las propuestas más importantes para explorar, a través de diferentes recursos, el trabajo efectuado por los investigadores, becarios y personal de apoyo del CONICET con la finalidad de convertir la visita en una actividad educativa, vivencial y enriquecedora, promoviendo espacios de intercambio, reflexión y participación activa. Además, acompaño el lanzamiento de la iniciativa nacional "Pampa Azul".

\section{País Ciencia}

En esta misma línea que VocAr el Consejo Nacional promovió la Plataforma País Ciencia. Creada a partir de un Proyecto de Desarrollo Tecnológico y Social (PDTS) ${ }^{149}$ formalizado en 2014, se encuentra enmarcado en el Programa VocAr que impulsa Relaciones con la Comunidad de la DRI y está conformada por actores del CONICET y de otras instituciones que tienen que ver con la generación de acciones científicas y educativas, tales como: el Ministerio de Educación de la Nación a través de la Subsecretaría de Gestión de Políticas Universitarias (SPU), la Universidad Nacional de Rosario, el Ministerio de Planificación Federal de la Nación, y el Centro de Estímulo al Desarrollo del Conocimiento (CEDEC) del municipio de Granadero Baigorria, de la provincia de Santa Fe.

Este proyecto federal que ha llegado a los jóvenes y que está integrado por investigadores, profesionales y técnicos de apoyo y becarios, apunta a la comunicación pública de la ciencia a partir de reconocer el problema de la brecha entre ciencia y sociedad en forma integral. Desde el CONICET esta Plataforma parte de la premisa de que los participantes de la relación son heterogéneos no solo en cuanto a sus capacidades, sino en los modos de dar sentido a la ciencia desde la diversidad, la cual incide en las percepciones, las identidades de

\footnotetext{
149 Los Proyectos de Desarrollo Tecnológico y Social (PDTS) surgen como parte de un acuerdo que renueva las posibilidades de los investigadores que realizan actividades de desarrollo y transferencia de conocimiento y que estaban limitados por la imposibilidad de poder llevar adelante proyectos de transferencia de tecnología de todas las Grandes Área incluida la Tecnología, cuyos investigadores no contaban con una normativa institucional que les diera un marco de trabajo para la ejecución de los mismos. Al permitirse los PDTS surgen proyectos a partir de acuerdos alcanzados por las instituciones del sistema científico y tecnológico nacional, las Universidades y el Ministerio de Ciencia, Tecnología e Innovación Productiva junto al CONICET. Este es el caso de la Plataforma País Ciencia.
} 
quienes participan, las expectativas depositadas en cada acontecimiento generado, y las actitudes que se ponen en juego en el curso de los vínculos establecidos.

En sus objetivos País Ciencia contribuye a ampliar la frontera del conocimiento, promover la participación activa de la comunidad científica en la tarea de comunicación pública de la ciencia, generar vocaciones científicas en niños y jóvenes, y estimular el pensamiento crítico de los ciudadanos en la toma de decisiones frente a situaciones de la vida cotidiana.

Definido como una oportunidad para atacar el problema de la brecha entre ciencia y sociedad a partir del trabajo llevado adelante por un equipo que conjuga los aportes de investigadores científicos y comunicadores de la ciencia, fue concebido como proyecto interinstitucional nacido a partir de una concepción social de la ciencia y la tecnología como bien público.

Desde esta definición se plantea que las preguntas la genere el "otro", un otro que son los chicos, los jóvenes, las familias, los trabajadores, los adultos mayores con quien es necesario pensar el presente para proyectar el futuro y analizar el pasado de la ciencia en el país.

Desde esa concepción se diseñaron y llevaron adelante experiencias ${ }^{150}$ para acercar la ciencia a las escuelas y barrios y también motivar, despertar el interés y por qué no, las vocaciones científicas en los jóvenes. Conjuga además como herramienta comunicacional, educativa y de formación, la inclusión y la federalización para lo cual ha creado una red de nodos en diversas ciudades del país con el fin de generar instancias de reflexión en torno del conocimiento científico situado en su contexto territorial.

La genuina importancia de País Ciencia se expresa en que la divulgación de la ciencia configura uno de los grandes retos de la sociedad tecnológica y como una necesidad de las sociedades democráticas. El desafío está puesto en desmitificar la figura del científico y pensar el conocimiento como un bien social, no como un privilegio de unos pocos.

\footnotetext{
${ }^{150}$ En el marco de la convocatoria de proyectos de innovación tecnológica con inclusión social para escuelas secundarias técnicas de la provincia de Santa Fe, organizado por el Consejo Nacional de Investigaciones Científicas y Técnicas (CONICET) y la Fundación Medifé, se seleccionaron diez proyectos cuyo fin estuvo en aportar soluciones tecnológicas realizables y aplicables a problemáticas medioambientales locales. Durante 2014 esta convocatoria ejecutado por la Dirección de Relaciones Institucionales, a través de País Ciencia y VocAr, seleccionó las propuestas que recibieron entre todas la suma de 100 mil pesos. Sobre diferentes soluciones y abordajes que van desde la construcción de un filtro doméstico de arsénico, la creación de un sistema de balizas viales LED con carga solar, hasta el armado de terrazas verdes, los proyectos seleccionados pudieron llevar adelante la etapa experimental con el financiamiento recibido.

Los 10 proyectos seleccionados corresponden a escuelas santafesinas de las localidades de Carcarañá, Esperanza, Rosario (2), Venado Tuerto, Helvecia, Cañada de Gómez y Santa Fe, a las que se sumaron una escuela de Concordia (Entre Ríos) y otra de General Rodríguez (Buenos Aires).

De la convocatoria general participación, producto del incentivo generado por charlas y visitas realizadas desde País Ciencia y VocAr, unos 300 alumnos y 100 docentes de 13 localidades de la provincia de Santa Fe que presentaron 32 proyectos.
} 
En la actualidad, el conocimiento científico permite robustecer la toma de decisiones en políticas públicas $\mathrm{y}$, consecuentemente, el desarrollo de la tecnología es el factor más determinante para la soberanía y la independencia de las naciones. En ese orden, la producción de conocimientos es uno de los indicadores que distingue a los países donde la ciencia y la tecnología es un instrumento que puede producir cambios sociales ${ }^{151}$.

\section{Eventos, Ceremonial y Protocolo}

La articulación de las necesidades y demandas de la estructura del CONICET en todo el país requería una estrategia de desarrollo y vinculación con las necesidades para ser abordada desde una herramienta que relacionara los distintos procesos organizacionales ${ }^{152}$. Fue así que al impulsar desde la DRI la Herramienta Eventos, Ceremonial y Protocolo la misma no aparece como una propuesta o condición direccionada a ese orden, sino como un concepto multidimensional con un significado comunicacional pero bajo una denominación que pudiese ser reconocida a nivel institucional.

Consistía en una construcción intencionada desde su propia formulación y desde los inicios de ejecución desde la DRI, donde se buscaba alcanzar grados de articulación institucionales, consolidación de las formas organizativas, reconocimiento de las concepciones y prácticas vigentes en CONICET Central, CCT y Centros Multidisciplinarios sobre diferentes procesos de organización de actividades, con un mayor despliegue de trabajo territorial a partir del

\footnotetext{
${ }^{151}$ Es preciso referir a la importancia que tienen estas definiciones en la formulación de los fines de la Plataforma País Ciencia, fruto de la iniciativa de Claudio Fernández junto a un grupo de investigadores y del trabajo conjunto con la Dirección de Relaciones Institucionales. Fernández es investigador Principal del CONICET, director del Laboratorio Max Planck de Biología Estructural, Química y Biofísica Molecular (MPLbioR), dependiente de la Universidad Nacional de Rosario y la Sociedad Max Planck de Alemania, y director de la Plataforma País Ciencia.

${ }^{152}$ Las actividades de rutina asignadas a la coordinación de Eventos, Ceremonial y Protocolo se pueden reconocer en las siguientes tareas: organización de eventos institucionales que requieren el seguimiento de las Normas de Ceremonial y Protocolo Argentino, como inauguraciones de Institutos, Centros de Estudios y otros. Generación de contactos y seguimiento para realizar las actividades de divulgación del Programa de Promoción de Vocaciones Científicas Voc.Ar. Organización de la actividad, folletería, señalética y materiales a utilizar en cada una. Generación, en conjunto con la Coordinación de Divulgación Científica y Tecnológica, de los contenidos de científicoscomunicacionales a utilizar en las actividades. Generación de un informe posterior de la actividad para evaluar impacto, resultado y progreso. Desarrollo y organización de actividades de VocAr y País Ciencia. Distribución de un dossier semestral de VocAr, orientado a público general. Participación en espacios de promoción de cultura científica. Al igual que años anteriores en estos espacios se busca promover el diálogo entre investigadores y público en general en temas que hacen a la vida cotidiana. Algunos de estos espacios son la Feria del Libro, la Noche de los Museos, Tecnópolis y Buque oceanográfico "Puerto Deseado", entre otros. La Coordinación está a cargo de la organización general de la actividad, logística de los transportes de participantes e investigadores, coordinación con otras áreas para desarrollar los materiales impresos, cartelería y folletería a utilizar, así como ambientar los espacios acorde a las necesidades de la actividad.
} 
surgimiento del Programa VocAr y País Ciencia, de la integración de espacios de reconocimiento del personal en trabajos integrados con la Gerencia de Recursos Humanos y consolidación de eventos de orden integrador como eran "Los Juegos Deportivos CONICET" con su última versión en 2014 que tuvo como anfitriona a la ciudad de Bahía Blanca (se trata del evento reconocido de mayor integración institucional que cuenta con un Comité Nacional de organización donde tiene voz la DRI y que dispone los mecanismos para que un CCT del país al año pueda llevar adelante esta iniciativa. Ya en su séptima edición contó un promedio de más de 600 asistentes entre administrativos, becarios, técnicos de apoyo e investigadores).

Con la incorporación de modalidades integrales para la acción y apoyada en la sustentabilidad de las herramientas comunicacionales, se consolidó en la organización de los acontecimientos de orden político institucional frente a inauguraciones, congresos de orden nacional e internacional, y seguimiento de convenios y proyectos incluyendo para la gestión la agenda pública y política institucional en su desempeño y desarrollo de actividades.

En la eficacia de las actividades de gestión de recursos y la diversificación de propuestas considerando las interacciones e intercambios sobre similitudes, diferencias y complementariedades en pro de propósitos comunes, sin dejar de lado los fines grupales o institucionales y manteniendo como premisa el concepto de Red Institucional, también su particular campo de abordaje tuvo como destino conformar ámbitos adecuados para la capacitación del personal de la DRI como en los CCT, con el fin de dejar capacidades instaladas de modo de permitir futuras acciones autónomas en conocimientos y de gestión asociada y bajo modos de trabajo intersectoriales, multiactorales, articulados y basados en acuerdos para una mayor desempeño en el uso de los recursos y democratización de los vínculos.

El Estado moderno requiere tener en cuenta no solo cómo comunica la gestión de sus acciones de gobierno, sino mantener una fluida comunicación entre ciudadanos y los actores institucionales y para ello requiere del uso de herramientas técnicas y conceptuales que deben ser claramente definidas. Como se ha podido verificar no solo en el caso de esta herramienta, sino en las diversas aplicaciones de los demás componentes, se fueron potenciando parar articularse en un contexto de complejidad y bajo una gestión institucional que impulsó y habilitó a la integración de las mismas. 
En la elaboración de las estrategias comunicacionales que se vinculan al punto de diagnóstico (dada su importancia, se le ha dedicado el Capítulo VII), se agrega el conocimiento de las respuestas institucionales o programáticas existentes y los recursos disponibles para afrontar las instancias en el territorio.

Imaginar el futuro deseado y reconocer dentro del CONICET la distancia o brecha existente entre la situación planteada y aquella deseable en el año 2012, implicó poner en claro los propósitos y objetivos de acción de la herramienta y asumir que era oportuna una programación sujeta a evaluación, para la toma de decisiones, y una reprogramación durante distintos períodos de la gestión de la DRI.

En este sentido, fue crucial la generación de informes al interior de la coordinación de la herramienta (como ha sucedido en los demás componentes comunicacionales) para advertir sobre las dificultades y hacer hincapié en la construcción de la viabilidad -sobre requerimientos y disponibilidad de recursos- que a partir de la misma se gestaban. Y aunque suele presentarse como una lógica de las secuencias propias del trabajo entre coordinaciones, fue preciso sostener un proceso de diálogo entre el director y los coordinadores de los componentes orientado en la reflexión, la sistematización y la evaluación donde surgieron aportes a la reprogramación en distintos momentos.

La articulación con otros dispositivos comunicacionales que se aplicaron desde la DRI, en un contexto institucional, social y político muy diferente al que existía en el momento en que se comenzó a pensar en la creación de estas herramientas, tiene que ver con la jerarquización y legitimación de la información que deja de ser privativa del orden institucional interno para convertirse en una cuestión del ámbito público en la que tanto la comunicación externa como la interna constituyen un proceso dinámico que se retroalimenta y donde resulta una tarea difícil (suscita discusiones vinculadas con diferentes concepciones y tendencias que indican que se fusiona con la comunicación externa o aquellas que la sostienen como algo diferenciado de la comunicación externa. En otro orden está quienes sostienen que la separación entre lo interno y lo externo ha resultado una perspectiva táctica y de orden operativo fundamentalmente en el uso de unas herramientas o técnicas de comunicación concretas y no centrada en los sujetos de la relación, la organización y su público) porque centralmente adquieren importancia los distintos actores para la Institución. 
Mencionar a Eventos, Ceremonial y Protocolo sirve como ejemplo para aludir a que los límites que ponen las definiciones institucionalizadas como "ceremonial y protocolo" permiten marcar nuevas líneas temáticas y estrategias de resolución ante las demandas y modos de resolución, y desde las orientaciones políticas institucionales que se promuevan.

En tal sentido, existe una relación coherente entre el discurso institucional y la puesta en práctica de esta herramienta, y el modelo de actuación resulta innovador y con posibilidades de replicarse en otros contextos con los ajustes necesarios de modo de poder transferir los conocimientos que se obtienen de la experiencia.

Las acciones de comunicación se identifican y tienden a formular respuestas congruentes a situaciones de diversa índole a partir de situar la caracterización y dimensionamiento de lo que enmarca el contexto, debiendo incorporar elementos de la dimensión territorial y lo productivo en lo concerniente a investigación y desarrollo, la variable de la constitución de los recursos humanos (destinatarios/involucrados de las acciones del componente), el relacionamiento con las organizaciones, la estructura gubernamental para el diálogo técnico y legal, los abordajes desde el enfoque adoptado que apunta a transformar la experiencia en conocimiento ordenado, fundamentado y transmisible (del sentido de acción a la acción para los sujetos. Un ejemplo ha sido la construcción de las condiciones de posibilidad que se dieron para celebrar los 55 Años del CONICET en Tecnópolis. Aquí se expresó la necesidad de compartir aquellos resultados que surgieron de la interpretación de los procesos en ciencia y tecnología, de colocar en un espacio a todos los actores para la recuperación de la memoria histórica crítica y en proceso de revisión, de testimonios y relatos sobre la Institución y, centralmente, desde lo que cada uno de los presente pudo vivenciar de forma particular y de manera valorativa el concepto de recuperación de la ciencia y tecnología para el país en la última década. Sobre esto último se fue instalando en el marco de la celebración que involucró a la historia, la reflexión y los debates mediatizados respecto de lo que aconteció en ese momento - las referencias a esto último se encuentran en el Capítulo II, "El sistema cientifico y sus instituciones"), y la comprensión, las condiciones y las capacidades de quienes se vinculan en llevar adelante la herramienta desde una diversidad de perspectivas epistemológicas respecto a los enfoques comprensivos e interpretativos de la realidad y al tipo de conocimiento resultante . 
Con seguridad, y con la necesidad de profundizar su desarrollo, el camino avizora que sus objetivos se identificaban con la orientación política institucional del momento, advirtiendo que no se puede situar como única alternativa la imagen institucional construida para los medios (razón ya sostenida y explicitada, amalgamada al concepto de sustentabilidad comunicacional al incorporar las políticas de Estado como referencias y como articuladoras de las iniciativas institucionales), sino que se debe operar sobre la comprensión de los modos tradicionales y facilitar la formulación de respuestas heterogéneas para la articulación, la gestión y la formulación de capacidades de los equipos técnicos y administrativos, grupos de investigación, y de comunicación que integran de la Red Institucional; junto a destinatarios múltiples, organizaciones públicas y de la sociedad civil.

\section{Comunicación Audiovisual}

Constituye una de las instancias fundamentales y una herramienta comunicacional indicativa de los estrategias de gestión que se dio la DRI para llevar adelante todas las experiencias en constante interacción.

Surgida de la necesidad de pensar la lógica de producción audiovisual ${ }^{153}$ para la construcción y de la gestión institucional, también debía fortalecer la producción de mensajes de los programas de divulgación científica. Bajo una noción que imprimía comprender nuevos criterios institucionales de difundir y divulgar desde el lenguaje audiovisual se generaba un recorrido que suponía la conformación de un grupo de profesionales de la comunicación que orientara la producción de nuevos discursos.

\footnotetext{
${ }^{153}$ Las actividades de rutina asignadas a la coordinación de Comunicación Audiovisual se pueden reconocer en las siguientes tareas: confección de materiales audiovisuales sobre convenios y anuncios de presidencia y directorio del CONICET. Material destinado la Web y enviado a medios de comunicación masivos como al sistema de medios públicos del Estado. Registro y edición de materiales requeridos a demanda por organismos del Estado Nacional para eventos presidenciales (Secretaría de Comunicación Pública). Desarrollo de corto informativos institucionales sobre las acciones de investigadores, profesionales y técnicos de apoyo y becarios. Soporte a CCT y UE. Armado y clasificación del archivo audiovisual según estándares del BACUA. Facilitación de paños de registro a CONICET Documental y Ministerio de Ciencia y Tecnología. Intercambio de materiales y apoyo en instancias de producción y postproducción. Elaboración de piezas institucionales para VocAr y País Ciencia. Edición de audio para radios. Generación de proyectos desde su guionado y registro. Constitución y renovación de audio y video del Banco Multimedia.
} 
Por tanto, se requería desde la experiencia de gestión una adecuación a los fines de intervenir de manera productiva en la dialéctica entre los programa de promoción de vocaciones científicas y también el sistema de medios.

En correspondencia a estas necesidades, distanciada de una versión mimética sin apelar a los mismos recursos que las producciones comerciales, se planteaba funciones de también debían considerarse como marca para la Institución. La circulación de mensajes institucionales audiovisuales se convertía en una forma de presentar al CONICET hacia la comunidad para ser identificada y percibida a través de la Web, las redes sociales y con la oportunidad inmejorables que se abrían a partir de nuevos espacios de aire en la televisión pública, del surgimiento de señales de Televisión Digital Abierta (TDA), la Ley de Servicios de Comunicación Audiovisual y, especialmente, con la creación de emisoras administradas por organismos del Estado, tal el caso del canal perteneciente al Ministerio de Ciencia y Tecnología de la Nación, TEC TV (Tecnópolis TV).

Frente a estos escenarios y de manera articulada desde sus inicios con el Área Audiovisual del Ministerio de Ciencia y Tecnología a mediados de 2013, fue consolidándose la herramienta para generar nuevas capacidades y perfeccionar aptitudes para posicionar mensajes sobre la gestión institucional, la consolidación de las políticas públicas, avances en investigación y desarrollo, transferencia y extensión y presencia a lo largo del territorio. En este aspecto, la orientación de las acciones debieron situarse sobre criterios que permitieran alcanzar productos destinados a públicos heterogéneos.

Desde su creación se generó la vinculación con la producción informativa y no de orden documental, con experiencias que situaron la crónica audiovisual como desarrollo propio del género en sus variantes, intentando despegar la producción de la exclusividad de la temática científica poniendo como lugar posible el relato de vida. Así concebida se sugirió la hibridación concebida como espacio donde se reflejaran las relaciones con los sujetos, actores e instituciones que producen sentido interactuando socialmente, promoviendo desde la guionización producciones que plantean la articulación de dos instancias: la externa, la vinculación con la sociedad, y la interna, partiendo de la relación con el ámbito de desarrollo científico en la Institución. 


\section{Las condiciones de producción}

En la construcción de mensajes, desde las etapas de pre-producción, producción y post producción se requirió contar con nuevas capacidades y conocimientos que permitieran a los comunicadores producir materiales de carácter informativo donde se introdujera el dialogo, el relato biográfico como el perfil, entre otros. Sumado a esto, se requería asegurar calidad para la emisión y crear las condiciones de operatividad para abastecer la demanda de material a emitirse en estos espacios como noticieros, presentaciones institucionales y de orden ministerial.

Resultado de esta política en comunicación, se planificó el trabajo en función de las dimensiones institucionales en base al crecimiento programado, en la capacidad de selección de contenidos, formatos y temas, sin olvidar al mismo tiempo las estrategias institucionales mediáticas que intervienen en dicho proceso. En este sentido pensamos en términos de Stuart $\mathrm{Hall}^{154}$, en cuanto proceso que debe pensarse en términos de una estructura producida y sostenida a través de la articulación de momentos relacionados pero distintivos: producción, circulación, distribución / consumo, reproducción.

Claramente a los destinatarios se le está proponiendo un recorrido. Tal como Umberto Eco ${ }^{155}$ trabaja la idea de lector, construido a raíz de un proceso en el que el texto postula y diseña a su destinatario como condición indispensables de su capacidad comunicativa y de su potencialidad significativa, se le está proponiendo al lector un recorrido como también una metodología para reconstruir y encontrar las marcas que en él están presentes.

Resultado por el cual fue necesario generar los debates apropiados acerca de la dimensión comunicacional, los debates presentes y la manera de abordarlos, la relación con la técnica y la relación con la cultura mediante para la construcción discursiva en base a argumentaciones, formatos y estéticas que identificaran al CONICET.

\footnotetext{
${ }^{154}$ HALL, Stuart (1980). "Codificar / decodificar". En Culture, Media y Lenguaje. Traducción Silvia Delfino. Londres, Inglaterra.

${ }^{155}$ ECO, Umberto (1987). "Lector modelo". En "Lector in fabula". Editorial Lumen. Barcelona.
} 
Por lo tanto, y más allá desde donde fueron concebidas, la herramienta debía incluir una estrategia que procurara su viabilidad inicial y política desde la Institución. Esto se logró básicamente promoviendo la participación del coordinador y los integrantes bajo el involucramiento directo en todas las etapas posibles. Pero también fue de importancia contar con la adecuación de los recursos técnicos (el contexto político institucional, del cual depende la sustentabilidad o institucionalización prevista de apoyo; como la previsión para promover productos audiovisuales y potenciar las capacidades instaladas) y críticos para llevar adelante las producciones: infraestructura física, equipos, insumos, etcétera.

\section{Conceptualizaciones y convergencia}

El trabajo de análisis llevado adelante desde Comunicación Audiovisual impuso las conceptualizaciones elaboradas para las demás herramientas comunicacionales en el campo de las políticas de comunicación, en cuyos principios se concibe la intención de propiciar herramientas comunicacionales de manera integrada a la Red Institucional.

Independientemente del aspecto comunicacional en lo referente al entendimiento de la producción de los sistemas de televisión, pero desde la observación de un organismo del Estado, desarrollar esta nueva herramienta requirió nuevas lecturas y considerar que estas producciones también están bajo normas al igual que insertas en un contexto político institucional y social que las determinan, por lo que necesariamente la producción audiovisual tiene que ser examinada en todas sus instancias.

Así como sucede frente el análisis de las políticas y decisiones institucionales a comunicar con el fin de identificar las acciones que tendrán como efecto aquellas situaciones sociales sobre las que la dirección de un organismo desea hacer públicas y que generen opinión, se considera también que el valor público de la producción audiovisual consiste en producir y validar conceptos, modelos y métodos científicos, instancias de desarrollo y de transferencia que sustenten la otra trama de legitimaciones para cumplir sus funciones públicas dirigidas hacia la sociedad. 
En el marco de la producción se profundizó en el detalle de ejes para las etapas de trabajo:

-Detectar y recuperar investigaciones existentes propias del CONICET y con otros organismos del sistema nacional de ciencia y tecnología, universidades y otras organizaciones sobre aquellos los aspectos vinculados con la transferencia de tecnología.

-Generar y consolidar un repositorio digital con toda la información validada audiovisual, gráfica y fotográfica con el fin de disponerlo para otras producciones y la comunidad científica que lo requiera, en especial otros organismos del Estado que cuentan con canales de televisión y para aquellas producciones generadas desde la Red Institucional.

-Desarrollar nuevos procesos más accesibles y en contextos propios de la convergencia digital. Vincular las producciones a las tecnologías y las redes sociales en una réplica hacia una mayor integración de estos lenguajes y de los procesos creativos ${ }^{156}$.

-Componer mapas para identificar áreas, disciplinas y proyectos específicos y en la medida que surjan artículos de divulgación científica y que requieran mayor desarrollo, se trabajen todas las instancias de producción de manera coordinada bajo el registro audiovisual, especialmente en los proyectos de investigación interdisciplinarios; y en marcos propios de procesos de transferencia conjunta con otros organismos y organizaciones en el territorio, y sobre experiencias consideradas de desarrollo con impacto social.

-Sobre la identificaron de áreas e instancias de innovación y transferencia, cada una de las cuales se podrá constituir en informes audiovisuales periodísticos, se establecerán las líneas de base de los proyectos a partir de las cuales avanzar en planes y proyectos concretos.

-La participación de investigadores, becarios y personal de apoyo, grupos de trabajo y beneficiarios tendrá lugar desde el inicio del desarrollo de la propuesta audiovisual para poder generar una comunicación acorde a las particularidades y a los alcances de la transferencia de tecnología generada, identificando sus impactos y beneficios para el sector, la comunidad y la región.

\footnotetext{
${ }^{156}$ Es preciso considerar como lo señala Néstor García Canclini que "los avances comunicacionales auspician conexiones globales e integraciones multimedia, pero no garantizan mayor diversidad, ni intercambio equilibrado entre las sociedades, ni combinación creativa de los lenguajes, ni ampliación de la participación ciudadana, sin políticas culturales y mediáticas de los organismos públicos nacionales e internacionales".

En GARCIA CANCLINI, Néstor ( 2007). "Comunicación y Cultura: encuentros y desencuentros". En BUSTAMANTE, Enrique (editor). "La Cooperación Cultura-Comunicación en Iberoamérica". Cultura y Desarrollo $\mathrm{N}^{\circ} 6$. Agencia Española de Cooperación Internacional para el Desarrollo. Dirección General de Relaciones Culturales y Científicas. España
} 


\section{Trabajo colaborativo}

Esta herramienta reconoce el particular sentido y la importancia del trabajo colaborativo con otras componentes comunicacionales, donde la complementariedad permite alcanzar sinergias y llegar a la plena utilización de los recursos tecnológicos disponibles, y al aprovechamiento de los conocimientos existentes tanto en la institución como entre los profesionales.

Como parte de sus objetivos se destaca la concreción del archivo audiovisual ${ }^{157}$ que sumó en un año unas 65 producciones, entre micros informativos y crónicas institucionales. Las producciones fueron catalogadas en función de normativas y procedimientos estandarizados y contemplando los requisitos del BACUA (Banco Audiovisual de Contenidos Universales Argentino, al que se asiste con materiales).

Entre otros funciones que hacen a la guionización, el registro y la edición, desde Comunicación Audiovisual se asiste audiovisualmente a las necesidades de los CCT habiéndose generado para tal fin un workflow que permite generar una mejor sincronización de las distintas propuestas de producción entre la agenda de gestión y las demás producciones institucionales (la unidad cuenta con un equipo de registro audiovisual y una editora).

Junto a este proyecto institucional de desarrollo comunicacional para acercar el conocimiento a la sociedad, se generan producciones audiovisuales de divulgación a través de la productora CONICET Documental dependiente de la Dirección de Vinculación Tecnológica y Social.

La apuesta de la productora en este género, con más de 6 años de funcionamiento, ha sido la de generar contenidos de interés social donde la pregunta la hacen los chicos, los jóvenes, los

\footnotetext{
${ }^{157}$ Todas las producciones se encuentran publicadas en el canal de YouTube: CONICET Dialoga.
} 
científicos y la gente que vive en cada una de las comunidades donde se genera el trabajo científico y tecnológico.

El principal desafío fue documentar audiovisualmente el crecimiento de la actividad científica durante los últimos años, en el marco de las nuevas políticas de ciencia y tecnología orientadas a una apertura del organismo a la sociedad. El objetivo trazado estuvo en dotar al CONICET de una productora que pudiera producir relatos científicos audiovisuales y, al mismo tiempo, narrar y comunicar bajo conceptos y aproximaciones propias de la divulgación científica las experiencias de la práctica y los procesos de investigación científica.

A través de las distintas señales como TEC TV, Pakapaka, Encuentro y la Televisión Pública, se han narrado historias científicas y tecnológicas: Juana y Mateo contra el Chagas; Diario de Viaje; Viajeros Ciencia Adentro; Micromundos; y Vida Científica. En este tiempo el objetivo estuvo en enfatizar la importancia que tiene para el país el desarrollo de la ciencia como herramienta fundamental y estratégica para mejorar la calidad de vida de toda la sociedad. 


\section{Capítulo IX}

\section{Conclusión}

El proceso de desarrollo alcanzado buscó reflejar y proponer el tránsito en este organismo de ciencia y tecnología y los aportes que desde el campo disciplinar se lograron como propuestas epistemológica y metodológica, que confluyeron en la proposición, organización y aplicación de las 5 herramientas comunicacionales. El orden alcanzado facilitó la consolidación de lecturas diagnósticas y espacios de reflexión e intercambio con los actores institucionales involucrados en la promoción, configuración y el desarrollo de las propuestas como las herramientas comunicacionales.

Esto permitió proceder sobre momentos e instancias que permitieron identificar temas críticos y desafíos hacia experiencias de gestión estratégica de la comunicación.

Los alcances, a partir de las preguntas y las necesidades relevadas, dieron lugar a un contexto para la gestión caracterizado por acciones concertadas con los actores institucionales, bajo un abordaje integral de las dimensiones comunicacionales y con el entendimiento de que era posible desarrollar un plan de acción de gestión continua que impulsara en la Red Institucional la incorporación de herramientas de cambio en manos de los actores.

Desde este enfoque se dieron elementos que no solo supusieron un mero ordenamiento técnico, sino que apuntaron a evaluar procesos (situando en éste a los sujetos) y no productos $\mathrm{y}$, en igual orden, llevaron a asumir y a organizar la incertidumbre por lo que no se trató de proceso predictivo pero sí prospectivo. Y que en todo momento interpretó y entendió como constitutivo los intereses plurales, contrapuestos y conflictivos en la institución.

Sobre las posibilidades de esta y otras experiencias se puede indicar una coincidencia en cuanto a que la planificación resulta central al momento de pensar la actividad del comunicador pero, asimismo, la emergencia de asumir situaciones y procesos dinámicos institucionales en ocasiones atenta contra esta posibilidad en toda su dimensión. 
El concepto de institución como estructura normativa y reguladora implica la existencia de diferencias de poder e intereses divergentes entre los actores involucrados en ella, lo cual hace emerger órdenes negociados que son construidos, mantenidos y transformados por la interacción social. Desde este lugar está vinculada a configuraciones de poder y con claras distinciones ideológicas y políticas en las cuales se reconoce. Donde la realidad institucional en toda su dimensión es mantenida y modificada por procesos de creación y promulgación de los acuerdos científicos y tecnológicos, donde también se crean valores y se expresan ideologías que llevan a un sentido de participación y pertenencia.

Bajo esta complejidad, sumadas a las paradójicas dificultades para comunicar, se ha podido observar que el comunicador debe reconocer e intentar explicar su relación con los propósitos de la comunicación organizacional. En estos abordajes ha sido oportuno apuntar al reconocimiento, la instalación y el diagnóstico preliminar cualificado, los pronósticos de decisores en cada caso y su interpretación en un marco contextual, la formulación de la estrategias desde el lugar de los actores; así como la implementación, monitoreo, evaluación y ajuste del proceso de gestión de la comunicación institucional.

Al retomarse el sentido de la dificultad de la planificación, bajo la emergencia de tiempo y frente a las dinámicas institucionales específicas, con programas y proyectos de desarrollo con dimensiones en plena tensión, fue importante una aproximación abierta y flexible que facilitara las necesidades de las Gerencias y las iniciativas de la Red Institucional, y que además contemplara los grupos e intereses diversos, dando lugar a espacios amplios de negociación abierta e inclusiva. Desde esta perspectiva fue importante definir las áreas, formas y niveles en que puede llevarse a cabo la intervención y dar respuestas desde la comunicación institucional.

La adecuación de herramientas comunicacionales para la gestión de la comunicación institucional consideró que el desarrollo de estrategias de intervención en estos procesos debía ser capaz de registrar, en cada problema o dificultad particular, oportunidades de diálogo y participación, ocasiones de construcción de sentidos que solo era posible cuando el problema se compartía.

A partir del análisis comparativo de las realidades regionales los procesos pudieron originarse sobre principios semejantes, al tomar en cada lugar y en cada situación sus particularidades 
para hallar la manera de participar de un proceso global con las comunidades con las que se vinculaban. Por este motivo, es posible reconocer en cada una de los 14 CCT y los 2 Centros Multidisciplinarios una identidad, procesos y productos como lineamientos similares y diversos de participación.

La necesidad de partir de su propia necesidad de cambio y no en el de seguir una receta e imponerla a cualquier contexto particular, hizo que los comunicadores como protagonistas produzcan y aprovechen una oportunidad de cambio en su propio contexto particular y que lleguen a reconocerse como co-protagonistas de un contexto mayor. A medida que se reconocieron en el conjunto de múltiples acciones, dieron lugar a una nueva fuente de sentido y de legitimación donde convergieron en una nueva trama.

Al respecto, en el caso de la DRI del CONICET, la cual comenzó a organizarse a partir de los componentes, las coordinaciones y los grupos de trabajo, se configuró como una alternativa al modelo instrumental que le asignaba a este momento a la comunicación desde la Institución. De ahí en adelante, la DRI quedó ubicada en una complejidad mayor a la de solo brindar información en una estructura que se conformaba con profesionales de la comunicación como nudos de su existencia. Fue así que se superó la imagen asociada a la idea de productor, en cuanto y en tanto éste aparecía como el indicador instrumental; y, si bien esta fue por años la manera elegida de comunicar, el lugar del comunicador dejó de ser el de un articulador y posibilitador de espacios en medios de comunicación en donde solo replicaba un modelo.

\section{Condiciones y aportes}

En un organismo que supera los 21.000 fue preciso hablar del indudable papel de la comunicación, cuyo desarrollo ha de pasar necesariamente por la generación de la instancias de acercar el avance del conocimiento a la sociedad. Para ello fue oportuno contar como protagonistas a los sectores que integran la estructura funcional (gerencias y direcciones) y la Red Institucional. Ámbitos donde se reconocieron las necesidades y demandas de los sujetos 
participantes, se imprimieron los rasgos identitarios de las institución y se pudo dar inicio a componer escenarios prospectivos. Las acciones comunicacionales destinados a la capacitación, formación y transferencia fueron eje de la DRI y la sistematización de las experiencias facilitó la posibilidad de determinar, como elementos centrales, los procesos de comunicación basado en el re-conocimiento y la sustentabilidad.

En otras palabras estos argumentos que hacen al debate y a la posición asumida desde la intervención de la comunicación determinaron: la imposibilidad de analizar hoy a la organización sin contar con la interpretación desde la comunicación y la transdisciplinariedad que exige la mirada de realidades complejas.

Esta perspectiva de abordaje de los procesos comunicacionales implicó también situar el encuentro en el terreno de la cultura. "Pensar en procesos de comunicación desde ahí, desde la cultura, significa dejar de pensarlos desde las disciplina y los medios. Significa romper con la seguridad que proporcionaba la reducción de la problemática de la comunicación a la de las tecnologías", según Jesús Martín Barbero ${ }^{158}$.

Otra afirmación, tal como lo propone Jorge González es entender que la cultura "es un modo de organizar el movimiento constante de la vida concreta, mundana y cotidianamente. La cultura es el principio organizador de la experiencia, mediante ella ordenamos y estructuramos nuestro presente a partir del sitio que ocupamos en las redes sociales. Es, en rigor, nuestro sentido práctico de la vida"159.

La importancia de contemplar las prácticas institucionales desde la cultura reside en que ella encarna la ligazón con el tiempo y el espacio. Lejos de constituirse en un mero organizador de las experiencias detalladas en esta tesis, la cultura nos hablas también de los sueños y la fantasía, de las utopías; también es ligadura y raíz con nuestro pasado, recuerdo de los sucesos y acciones que nos fueron constituyendo a lo largo de la historia. La cultura es, pues, memoria de lo que hemos sido; igualmente, constituye el registro imaginario y sedimento de lo que alguna vez pudimos ser y hacer. Es, en esta perspectiva lo que da espesor al presente y factibilidad al porvenir. Asimismo, la cultura es la que nos permite definir nuestra situación dentro de la vida social y colectiva.

\footnotetext{
${ }^{158}$ BARBERO, Jesús Martín (1987). "De los medios a las mediaciones". Editorial Gustavo Gilli. Barcelona.

${ }^{159}$ GONZÁLEZ, Jorge (1994). "MÁS (+) CULTURA(S). Ensayo sobre realidades plurales". Colección Pensar la Cultura, CNCA. México.
} 
En esta línea ha sido posible pensar en los sujetos inmersos en procesos comunicacionales que se desarrollan en su contexto más cercano, de los mitos y ritos que los constituyen, de los discursos en los que la cultura cobra materialidad, cualquiera sea su soporte.

Los sujetos así pensados dieron lugar a otras interpretaciones posibles desde concepciones como la de VocAr y País Ciencia que los constituyen individual y colectivamente enmarcados en un determinado "universo simbólico"160, una trama discursiva en la que ciertos sentidos institucionalizados aparecen operando en la forma del ser y actuar social. Por tanto, se hizo preciso adoptar una concepción del sujeto en relación con los discursos que éste construye y que lo construyen.

Uno de los principales elementos que hacen a la sustentabilidad comunicacional de esta Institución está en considerar, desde la perspectiva de la comunicación, la constitución de prácticas que también puedan ser objeto de análisis.

La sustentabilidad es comprender que la comunicación es una perspectiva de abordaje, una forma de posicionarse, lugar para el análisis pero también de construir modos de intervención que tiene como fin último el cambio. $\mathrm{Y}$ estos modos de intervención, encaminados hacia un horizonte, supone la acción ${ }^{161}$ comunicativa $\mathrm{y}$, al mismo tiempo, políticas y estrategias para llevarlas a cabo, es decir, gestión.

\footnotetext{
${ }^{160}$ Entendiendo que el universo simbólico es "la matriz de todos los significados objetivados socialmente y subjetivamente reales", de acuerdo a BERGER, Peter y LUCKMANN, Thomas (1997). "La construcción social de la realidad". Amorrortu. Buenos Aires.

${ }^{161}$ Este conjunto de acciones comunicativas supone conocer de antemano las características propias de cada grupo y su posicionamiento, crear instancias de motivación para integrarlos aumentando el sentido de pertenencia y generando la cohesión interna. Tienen que ser iniciativas y acciones coherentes, que se apoyan sobre lo existente, en un espacio de tiempo establecido.
} 


\section{Respuestas hacia la sustentabilidad comunicacional}

Este proceso comunicacional fue mucho más allá de la organización de acciones en las que intervinieron las gerencias y direcciones, los CCT, Centros Multidisciplinarios y UE. En tanto pensado desde la herramientas comunicacionales se trató de un desarrollo de comunicación para la movilización del conocimiento generado y como construcción de bienes públicos, en el cual desde la Institución se alimenta el circuito de sentido.

Se trató entonces de un proceso comunicacional que se inició con la aplicación de herramientas comunicacionales y con la finalidad de facilitar el diálogo público en el espacio público, entre actores diversos y plurales, donde estuvo la intención de construir nuevos consensos en torno a lo importancia y el lugar que toma hoy la ciencia y la tecnología, bajo un tema donde se generen sentidos colectivos que faciliten y consoliden las políticas públicas y la gestión del CONICET y del Ministerio de Ciencia y Tecnología.

Desde esta perspectiva, la gestión en la DRI implicó poner en juego una concepción y una práctica respecto del poder, de la administración del mismo y de la forma de construir consensos y hegemonías dentro de la organización. Y en todo lo que conllevó la acción de gestionar atravesó a toda la institución, en sus relaciones inmediatas, en la coordinación interna, en las maneras de establecer o de frustrar lazos de trabajo, en la selección de determinados medios, en el conjunto de opciones que se adoptaron a la hora de interactuar con otras instituciones.

Al ubicar estos procesos comunicacionales como centro de preocupación y objeto de análisis se pudo reconocer en ellos las interdeterminaciones fundamentales y proponer las soluciones que se consideraron adecuadas y que no implicaron respuestas uniformes.

Es así que las herramientas comunicacionales deben entenderse integradas a un proceso comunicacional en el que confluyeron y se coordinaron acciones con metas ya pautadas por los Consejos Directivos de los CCT y desde el Directorio del organismo. Hecho que permitió identificar tendencias y oportunidades para el posicionamiento, a los fines de situar a la institución en la comunidad adecuadamente en el contexto de aceleramiento, vertiginosidad y 
fluctuaciones permanentes, promoviendo un desarrollo de estas herramientas en todo el territorio.

Se instaló -consecuentemente- la anticipación, la lectura de escenarios, la mirada prospectiva como hecho a considerar por los integrantes de comunicación como cultura de la organización, en la cual las decisiones y quienes las promovieron fueron en la medida en que se dieron las condiciones por delante de las transformaciones; respondiendo a las crecientes exigencias de participación y coordinación de los agentes sociales, la administración, los diversos actores, las organizaciones del sistema nacional y las asociaciones públicas y privadas con la que se vincula el CONICET. Y alcanzaron una flexibilidad en su instrumentación que contemplaron e incluyeron los posibles cambios.

Estas herramientas comunicacionales superaron los propios límites que se tenían inicialmente, acerca de cómo resultarían desde la mirada prospectiva en la construcción de escenarios y como horizonte de las acciones a realizar. Estos escenarios, entre los cuales se hizo la apuesta y fueron horizonte a alcanzar, apuntaron a organizar acciones y fueron un marco de referencia que contempló también planes, programas y proyectos con sus metas, pero atendiendo al sentido de la complejidad.

Y no por ello fueron menos los problemas y dificultades, que los hubo y que fueron ejes de permanentes redefiniciones de las herramientas $y$, a su vez, permitieron incorporar equilibrios y dinámicas en torno de los distintos componentes institucionales.

\section{Comunicación en acto}

Esta tesis que en su recorrido tradujo las lógicas de funcionamiento de la comunicación institucional, el lugar de las herramientas comunicacionales para la gestión, repasó e identificó los modelos vigentes que, a la hora de pensar en comunicar, requirieron ser definidos para alcanzar claridad y no crear dependencias a modelos, y pasar de la comunicación como el mero sentido de informar a la comunicación estratégica. 
Desde un principio se pensó que la comunicación en las organizaciones y en las instituciones llevan a enfrentar al desafío de contemplar una mirada micro y una mirada macro, para poder entender la manera en que se genera el desarrollo y el amalgamiento entre lo individual y lo social. Y, al mismo tiempo, desde el entendimiento y discernimiento se pudo conceder que el estudio de la comunicación es, y debe ser, transdisciplinario, en cuanto a que las propuestas giran en repensar a las organizaciones y las instituciones desde la comunicación.

Por su parte, esta posición tiene la pretensión de escapar a las resistencias que el análisis organizacional e institucional se ha visto expuesto. Razón por la cual no ha sido tarea sencilla comprender las problemáticas enfrentadas, las cuales desde su complejidad requirieron de perspectivas sociológicas, filosóficas y comunicacionales.

Retomando los relevamientos alcanzados, se ha logrado fijar y definir la presencia de conceptualizaciones que operan sobre el organismo. Una de ellas y quizás la más citada, es la que reduce la comunicación a su dimensión informativa a partir de que se piensa y articula como transferencia de información. Esta idea se nutre de modelos lineales y funcionales emparentados con entidades de la década del '80, atravesadas por otros contextos socioculturales.

En este orden se suma la concepción de los canales de comunicación como trasvasamiento, junto a la de los medios de comunicación como articuladores de una única forma de diálogo posible para con la sociedad y no con ella. Esto último, implica pensar en procesos dinámicos donde la sociedad debe intervenir. Requiere conocer cuáles son esos actores sociales con quienes se completará el mensaje y dar el lugar al otro, donde cada persona ponga en juego un bagaje sociocultural, sus valoraciones, sus expectativas, sus experiencias, sus maneras de reconocer.

Estos actores sociales pueden ser categorizados en cuanto a sus intereses y necesidades, pero en el entendimiento de una estrategia de comunicación se asume a la comunicación como espacio de encuentro entre actores a partir de reconocer sus diferencias.

Como parte de una construcción intencionada se optó por el no involucramiento en una definición de manual sobre la identidad y la comunicación. Se apuntó a establecer posición desde la comunicación pero no forzar su entendimiento, en cuanto a los modelos narrados y los intercambios con los actores institucionales. 
Por otra parte, si se avanza en la idea de transformación de viejas estructuras vigentes en nuevas instituciones, y presentes no solo en los llamados decisores, identificadas en las representaciones acerca de cómo ven y cómo perciben la comunicación, al igual que en otros referentes del organismo como son aquellos afincados en las regiones, se llega a la necesidad de instalar fuertemente un nuevo criterio de comunicación.

La comunicación atraviesa a la organización porque es su forma de relación, porque es la manera en que la ésta trata con sus miembros, se relaciona con la sociedad y con las instituciones con las que interactúa. Pero sustancialmente porque la comunicación como se pensó para impulsarla desde la DRI estuvo vinculada a la calidad de las prácticas producto de la implementación de las herramientas propuestas. Y que sí considera a la sociedad, en el planteo de sus objetivos y en la promoción de la voluntad de diálogo y participación entre sus miembros. Sobre todo porque la comunicación es una dimensión presente en toda acción social y en tanto abarca a toda la vida del CONICET.

Desde esta función, que debe ser reconocida como la de articulación de la comunicación, se deberán generar aprendizajes necesarios para poder aplicar diferentes elementos que hacen a las herramientas de comunicación según las necesidades comunicacionales que surjan en la resolución de problemas que se definan como prioritarios. A más comunicación, conocimiento y consciencia de sus posibilidades mayor será el beneficio y el impacto que se alcanzará con las estrategias propuestas.

\section{Otras respuestas a las preguntas iniciales}

Esas primeras referencias o preguntas iniciáticas se constituyeron en el punto de partida para sostener la necesidad de que los cambios generados en ciencia y tecnología en más de una década deben seguir siendo comunicados y apropiados por la sociedad. Se trata de hablar y establecer situaciones vinculadas con acciones colectivas que facilitan el compromiso de la ciudadanía en cuestiones públicas, produciendo un capital social necesario para la democratización de las instituciones y la convivencia social. 
La sociedad civil anuncia direccionalidades y posibilidades, es decir, contextos políticos para integrar nuevas estrategias, actitudes, lenguajes y saberes con los cuales parece prefigurar nuevos mapas e historias posibles. Y es aquí donde pueden generarse y aprovecharse las condiciones para que una institución/organización del Estado pueda organizarse y entramar sus múltiples iniciativas con la sociedad.

A su vez, en este recorrido en más de una oportunidad surgió la pregunta acerca del rol del comunicador en instituciones de ciencia y tecnología, en función de este caso. Desde esta posición se asumió que como parte del sistema es un generador de estrategias de cambio, al concebirlas a partir de experiencias circunscriptas en el marco de su institución.

En este orden, aparece una dimensión que debe ser atravesada y es la necesidad de repensar la relación ciencia y tecnología y desarrollo considerando la dimensión política como factor fundamental para superar las ideas de neutralidad y de universalidad de la ciencia y la tecnología a las que históricamente se sometieron la formulación de las políticas ciencia y tecnología en Latinoamérica.

En la búsqueda de claridad y en la lectura hacia el desarrollo de las herramientas comunicacionales se atravesó la pregunta acerca del alcance y la efectividad de las políticas en ciencia y tecnología, en función de su real aporte a un proceso de desarrollo orientado por un proyecto político amplio e inclusivo donde las prioridades están centradas en las necesidades de la sociedad.

Desde la comunicación fue posible reconocer la entramado de las organizaciones que integran el sistema nacional. Las políticas públicas en el orden de la investigación y el desarrollo impulsaron a la comunidad científica en estos años a reconocer desde sus propios lugares los problemas asociados a las mayores dificultades sociales como la pobreza e inclusión, en todas sus líneas, y a orientar las prioridades de investigación en la satisfacción de las necesidades básicas para grandes sectores de la población.

Y desde aquí, desde esta experiencia comunicacional de intervención se observa que las políticas en ciencia y tecnología son necesarias para dar respuestas concretas a los problemas que históricamente han obstaculizado el desarrollo del país y la región, bajo desafíos que tiene implicancias en abordar problemáticas de la coyuntura. Pero asimismo los gestores de las políticas se enfrentan a un verdadero desafío: continuar su camino histórico en la 
reproducción de estilos científicos y tecnológicos disfuncionales para el país, o enfrentarse al desafío de definir la ciencia y tecnología a un proyecto nacional propio y que permita imaginar una ciencia y una tecnología al servicio de un proyecto político regional.

En este proceso de recuperación de la ciencia y la tecnología experimentado en más de una década y en la recuperación de los sentidos de las necesidades de la sociedad actual, se encuentra el verdadero aporte a los desafíos actuales. 


\section{Bibliografía}

-ALAIC (2002). "La Formación de Posgrado de la Facultad de Periodismo y Comunicación Social de La Plata". Boletín $N^{0} 7$ de la Asociación Latinoamericana de Investigación de la Comunicación (ALAIC). Año II, Noviembre de 2002. Disponible en: http://www.eca.usp.br/associa/alaic/boletin7/poslaplata.htm

-ALBORNOZ, Mario y GORDON, Ariel (2011). "La política de ciencia y tecnología en Argentina desde la recuperación de la democracias 1983-2009)". En ALBORNOZ, Mario y SEBASTIÁN, Jesús. "Trayectorias de políticas científicas y universitarias de Argentina y España". Madrid: CSIC.

(2011). "La política de ciencia y tecnología en Argentina desde la recuperación de la democracias 1983-2009)". En ALBORNOZ, Mario y SEBASTIÁN, Jesús. "Trayectorias de políticas científicas y universitarias de Argentina y España". Madrid: CSIC.

-ALBORNOZ, Mario, FERNÁNDEZ POLCUCH, Ernesto y ALFARAZ, Claudio. (2002). "Hacia una nueva estimación de la 'fuga de cerebros'". Buenos Aires: Centro Redes.

-ANDER-EGG, Ezequiel (1995). "Introducción a la Planificación". Editorial Lumen. Buenos Aires. Argentina.

-ARGUMEDO, Alcira (2005). "Crisis de las Ciencias Sociales de la Argentina en Crisis". Prometeo Libros. Buenos Aires.

-BARBERO, Jesús Martín (1987). "De los medios a las mediaciones". Editorial Gustavo Gilli. Barcelona.

-BEKERMAN, Fabiana (2009). "El campo científico argentino en los años de plomo: desplazamientos y reorientación de los recursos". Sociohistórica. Cuadernos del Centro de Investigaciones Sociohistóricas. $\mathrm{N}^{\circ}$ 26, segundo semestre. Facultad de Humanidades y Ciencias de la Educación. Universidad Nacional de La Plata. La Plata.

-BERGER, Peter y LUCKMANN, Thomas (1997). "La construcción social de la realidad". Amorrortu. Buenos Aires. 
-BOLMAN, Lee y DEAL, Terrence (1995). "Organización y liderazgo". Addison-Wesley Íbero América S.A Wilmington, Delawere, Estados Unidos. Traducción Centro para el Desarrollo de Recursos Humanos. Instituto de Estudios Superiores de Administración (IESA) Caracas, Venezuela.

-BOURDIEU, Pierre, CHAMBOREDON, Jean Claude y PASSERON Jean Claude (1990). "El oficio del sociólogo". México, Siglo Veintiuno.

-BRONSTEIN, Víctor y GAILLARD, Juan Carlos (1995). "La comunicación en las organizaciones". Instituto Nacional de Administración Pública - INAP . Jefatura de Gabinete de Ministros. Buenos Aires.

-CARDOSO, Nelson (2000). "La Comunicación Comunitaria". Bibliografía Modulo 1. Taller Cuatrimestral de Comunicación Comunitaria. Universidad Nacional de La Matanza. Apunte de la Cátedra.

-CARRIZO, Érica y ALFONSO, Victoria (2013). "Las políticas de CyT y el estilo de desarrollo: un proyecto inconcluso". En Voces en el Fénix. Año 4, Núm. 24.

-CERASO, Cecilia (2002). "El rol del planificador", en "Sembrando mi tierra de futuro. Comunicación, Planificación y Desarrollo Local". Ediciones de la Unidad de Prácticas y Producción de Conocimiento de la Facultad de Periodismo y Comunicación Social. UNLP.

-CERASO, Cecilia y ARRÚA, Vanesa (2006). "Aportes de la comunicación a la planificación de procesos de desarrollo". Ponencia X Jornadas Nacionales de Investigadores en Comunicación. Una Década de encuentros para (re)pensar los intercambios y consolidar la red. Red Nacional de Investigadores en Comunicación. San Juan.

-CONICET (2006). "Ciencia y tecnología para el desarrollo". 1ra. ed. Edición Nacional Editora \& Impresora. Buenos Aires.

-CORTASSA, Carina (2010). "Del déficit al diálogo, ¿y después? Una reconstrucción crítica de los estudios de comprensión pública de la ciencia". En Revista CTS, N¹5, Vol. 5. Septiembre.

(2012). "La ciencia ante el público. Dimensiones epistémicas y culturales de la comprensión pública de la ciencia". 1 era. ed. Buenos Aires: Eudeba. 
-CROZIER, Michel y FRIEDBERG, Erhard (1990). "El Actor y el sistema: Las restricciones de la acción colectiva". Alianza Editorial. México.

-DE CERTEAU, Michel. (1996). "La invención de lo cotidiano I". Artes de hacer. Universidad Iberoamericana. México D.F.

-DELFINO, Silvia (1998). "La relación entre producción e investigación de procesos comunicacionales en los planes de estudio de las carreras de comunicación social". Trabajo presentado en las Primeras Jornadas sobre Comunicación y Ciencias Sociales. Facultad de Ciencias Políticas y Relaciones Internacionales de la Universidad Nacional de Rosario. Rosario. Septiembre.

----------- (2009). "Investigación y activismo en el vínculo entre teorías de género, identidad de géneros y luchas políticas". № 66. julio-agosto. Revista Tram[p]as de la Comunicación y la Cultura. Facultad de Periodismo y Comunicación Social. UNLP. La Plata.

-DENZIN, Norman y LINCOLN, Yvonna (Eds.) (1994). "The Sage Handbook of Qualitative Research". Los Ángeles. SAGE.

-ECO, Umberto (1987). "Lector modelo". En "Lector in fabula". Editorial Lumen. Barcelona.

-ETKIN, Jorge (1989). "Administración hoy". Publicación de la Asociación de Docentes Nacionales de Administración General (ADENAG). XV Asamblea Nacional de Graduados en Ciencias Económicas. Tesis. Buenos Aires.

-ETKIN, Jorge y SCHVARSTEIN, Leonardo (1994). "Identidad de las organizaciones. Invariancia y cambio". Paidós. Buenos Aires.

-FERNÁNDEZ COLLADO, Carlos (1991). "La Comunicación en las Organizaciones". Editorial Trillas. México D.F.

-FREIRE, Paulo (1986). "Hacia una pedagogía de la pregunta. Conversaciones con Antonio Faundez". Buenos Aires. Ediciones la Aurora.

-GARCIA CANCLINI, Néstor (2007). "Comunicación y Cultura: encuentros y desencuentros". En BUSTAMANTE, Enrique (editor). "La Cooperación CulturaComunicación en Iberoamérica". Cultura y Desarrollo $\mathrm{N}^{\circ}$ 6. Agencia Española de 
Cooperación Internacional para el Desarrollo. Dirección General de Relaciones Culturales y Científicas. España

-GARGANO, Cecilia (2013). "Ciencia y dictadura: producción pública y apropiación privada de conocimiento científico-tecnológico. Dinámicas de cooptación y transferencia en el ámbito del Instituto Nacional de Tecnología Agropecuaria (INTA) durante la última dictadura cívico-militar". Crítica y Emancipación. Revista Latinoamericana de Ciencias Sociales.

-GAUDIN, Jean-Pierre (2002). “Pourquoi la gouvernance?”. Ed. Presses de Sciences-Po. Paris.

-GIORDANO, Carlos José (2009). "23 tesis sobre la tesis. La comunicación para la transformación de la gestión educativa". Tesis doctoral. Facultad de Periodismo y Comunicación Social. Universidad Nacional de La Plata. La Plata. Argentina.

-GODET, Michel. (1979). "The Crisis in Forecasting and the Emergence of the Prospective Approach. Pergamon Press". USA. (1985). Prospectivas y Planificación. CPE. Economía. París.

(2000). "La caja de herramientas de la prospectiva estratégica". Laboratoire d'Investigation Prospective et Stratégique.

-GODET, Michel y DURANCE, Philippe (2007). "Prospectiva Estratégica: problemas y métodos". Laboratoire d'Investigation Prospective et Stratégique. París.

-GONZÁLEZ, Jorge (1994). "MÁS (+) CULTURA(S). Ensayo sobre realidades plurales". Colección Pensar la Cultura, CNCA. México.

-GORDON, Ariel (2013). "El sistema de innovación argentino en perspectiva histórica. Historia institucional y políticas públicas". En SUAREZ, Diana (Comp.). "El sistema argentino de innovación: instituciones, empresa y redes: el desafio de la creación y apropiación de conocimiento". 1a. ed. Los Polvorines, Universidad Nacional de General Sarmiento.

-GUBER, Rosana (2001). "La etnografía, método, campo y reflexividad". Bogotá: Grupo Editorial Norma. 
-GUBER, Rosana y ROSATO, Ana. (1986). "La construcción del objeto de investigación en Antropología Social: una aproximación", Congreso Argentino de Antropología Social, Buenos Aires. Argentina.

-HALL, Richard (1996). "Organizaciones. Estructuras, procesos y resultados". 6ta. Ed. Prentice Hall. México.

-HALL, Stuart (1980). "Codificar / decodificar". En Culture, Media y Lenguaje. Traducción Silvia Delfino. Londres, Inglaterra.

-HERRERA LIMA, Susana (2007). "La profesionalización de la comunicación pública de la ciencia". Maestría en comunicación de la ITESO. Guadalajara, Jalisco, México.

-HURTADO, Diego (2010). "La ciencia Argentina: un proyecto inconcluso: 1930-2000". 1ra. ed. Buenos Aires, Edhasa.

(2010). "Organización de las instituciones cientificas en la Argentina (1933-1996).

Una Visión Panorámica". 1ra. ed. Cuadernos ICES 3. Buenos Aires.

(2014). "El sueño de la Argentina atómica: política, tecnología nuclear y desarrollo nacional. 1945-2006". 1era. ed. Edhasa. Ciudad Autónoma de Buenos Aires.

-IRVEN, Alberto. (2005). "Hacia una pedagogía de la reciprocidad". Ciudad Nueva. Buenos Aires. Argentina.

(2007). "Hacerlo posible: autoorganización y procesos de cambio social". 1era. ed. Editorial SB. Buenos Aires.

-KREPS, Gary (1995). "La comunicación en las organizaciones". Addison-Wesley Iberoamericana. Estados Unidos.

-MARTIN BARBERO, Jesús (1987). "De los medios a las mediaciones". Editorial Gustavo Gilli, Barcelona. España.

(1990). "Comunicación, campo cultural y proyecto mediador". Diálogos de la Comunicación $\mathrm{N}^{\circ} 26$. FELAFACS. Lima. 
-MASSONI, Sandra (2007). "Estrategias. Los desafios de la comunicación en un mundo fluido". Homo Sapiens Ediciones. Rosario, Argentina.

-MATA, María Cristina. (1990). "Nociones para pensar la comunicación y la cultura masiva". La Crujía, Buenos Aires. Argentina.

-MATUS, Carlos (1984). "Planificación, libertad y conflicto". Ponencia presentada ante el Ministerio de Sanidad y Asistencia Social de Venezuela. Caracas.

-MERELLO, Agustín (1973). "Prospectiva, teoría y práctica". Editorial Guadalupe. Buenos Aires.

-MIGLIORATI, Mario (2013). "La política transformó la ciencia y la tecnología". Ponencia leída en la mesa: "La comunicación de la ciencia como política pública". Congreso de Popularización de la Ciencia (COPUCI). Ciudad de Rosario, provincia de Santa Fe.

-MIKLOS, Tomás y TELlO, María Elena (1991). "Planeación Prospectiva. Centro de Estudios Prospectivos". Fundación Javier Barros Sierra, A.C. Edit. LIMUSA y Grupo Noriega Editores. México

-MILNER, Richard (2006). "Culture, race and spirit: a reflextive model for the study of African-Americans". International Journal of Qualitative Studies in Education, 19 (3).

-MINCyT (2006). "Plan estratégico nacional de Ciencia, Tecnología e Innovación 'bicentenario' (2006-2010)". Ministerio de Ciencia, Tecnología e Innovación Productiva de la Nación. Ciudad Autónoma de Buenos Aires.

-MINCyT (2011). "Plan Nacional de Ciencia, Tecnología e Innovación 2012-2015". Secretaría de Planeamiento y Políticas en CTIP. Ministerio de Ciencia, Tecnología e Innovación Productiva de la Nación. Ciudad Autónoma de Buenos Aires.

-MINCyT (2013). "Argentina Innovadora 2020. Plan Nacional de Ciencia, Tecnología e Innovación. Lineamientos Estratégicos 2012-2015". Secretaría de Planeamiento y Políticas en Ciencia, Tecnología e Innovación Productiva. Ministerio de Ciencia, Tecnología e Innovación Productiva de la Nación. Ciudad Autónoma de Buenos Aires. Disponible en: http://www.mincyt.gob.ar/adjuntos/archivos/000/022/0000022576.pdf 
-MINCyT (2014). "La percepción de los argentinos sobre la investigación científica en el país". Tercera Encuesta Nacional (2012), Ciudad Autónoma de Buenos Aires, MINCyT. Disponible en: http://www.mincyt.gob.ar/_post/descargar.php?idAdjuntoArchivo=35806

-MINTZBERG, Henry (1984). "La estructuración de la organizaciones". Editorial Ariel. Barcelona.

-MOJICA, Francisco José (2005). "La construcción del futuro. Concepto y modelo de prospectiva, estratégica, territorial y tecnológica". Convenio Andrés Bello - Universidad Externado de Colombia. Buenos Aires.

-MORGAN, Gareth (1990). "Imágenes de la organización". Ra-ma Editorial. Madrid. (1991). "Imágenes de la organización". Editorial Alfaomega S.A. de C.V, México. -MORIN, Edgar (2002). "El método. El conocimiento del conocimiento". 4ta. ed. Cátedra. Madrid.

(2005). "Epistemología de la complejidad". En "Nuevos paradigmas, cultura y subjetividad". 1er. ed. Editorial Paidós. Buenos Aires.

(2011). "Introducción al pensamiento complejo". Gedisa, Barcelona.

-OREGIONI, María Soledad y SARTHOU, Nerina (2013). "Dossier Ciencia, Tecnología y Sociedad. La dinámica de la relación entre CONICET y dos universidades nacionales argentinas". Revista Ciencia, Docencia y tecnología. $\mathrm{N}^{\circ} 46$ Concepción del Uruguay. Disponible en: http://www.scielo.org.ar/scielo.php?script=sci_arttext\&pid=S1851$17162013000100002 \& \operatorname{lng}=\mathrm{es} \& n r m=$ iso

-OROZCO GOMEZ, Guillermo (1994). "Al rescate de los medios. Desafío democrático para los comunicadores". Univ. Iberoamericana / Fundación Manuel Buendía: México.

-ORTIZ, Renato (2004). "Taquigrafiando lo social". 1er. ed. Siglo Veintiuno Editores. Buenos Aires, Argentina.

-OTEIZA, Enrique (1992). "La política de investigación cientifica y tecnológica en Argentina". Historias y Perspectivas. Centro Editor de América Latina. Buenos Aires. 
-PAGANO, Nora (2004). "Las ciencias sociales durante la dictadura argentina (19761981)". En DEVOTO, Fernando y PAGANO, Nora (Editores). "La historiografía académica y la historiografia militante en Argentina y Uruguay". Buenos Aires: Biblos.

-PETIT, Francois (1984). "Psicosociología de las organizaciones". Editorial Herder. Barcelona.

-PRIETO CASTILLO, Daniel (1985). "Diagnóstico de Comunicación". Editorial: Manuales Didácticos. CIESPAL. Ecuador.

(1993). "Planificación de la comunicación institucional". San Salvador: Universidad Centroamericana José Simeón Cañas. Mimeo.

-RICYT (2014). "Estado de la Ciencia 2014". Publicación de la Red de Indicadores de Ciencia y Tecnología - Iberoamericana e Interamericana (RICYT). Disponible en: http://www.ricyt.org/publicaciones

-ROZENWURCEL, Guillermo y BEZCHINSKY, Gabriel (2007). "Economía del conocimiento, innovación y políticas públicas en Argentina". Escuela de Gobierno y Política. Universidad Nacional de General San Martín. Buenos Aires. Documento de Trabajo № 25.

-SAINTOUT, Florencia (2004). "Abrir la comunicación, Tradición y movimiento en el campo académico". Ediciones de Periodismo y Comunicación. Facultad de Periodismo y Comunicación Social, Universidad Nacional de La Plata. La Plata.

(2008). "Los estudios socioculturales y la comunicación: un mapa desplazado". Revista Latinoamericana de Ciencias de la Comunicación.

-SCHEIN, Edgar (1982). "Psicología de la organización". Prentice-Hall Hispanoamericana S. A. México.

-SCHVARSTEIN, Leonardo (1997). "Psicología Social de las organizaciones". Nuevos Aportes. Paidós. Buenos Aires.

-SECyT (2005). "Bases para un Plan Estratégico de Mediano Plazo en Ciencia, Tecnología e Innovación 2005-2015". Ciudad Autónoma de Buenos Aires. 
-SOUZA, María Silvina (2005). "El espacio público como objeto transdisciplinarios. Cruces $y$ transversalidades". Anuario de investigaciones 2004. Editado por la Secretaría de Investigaciones Científicas y Posgrado de la Facultad de Periodismo y Comunicación Social. Universidad Nacional de La Plata.

-SOUZA, María Silvina, GIORDANO, Carlos y MIGLIORATI, Mario (Comp.) (2012). "Hacia la Tesis. Itinerarios conceptuales y metodológicos para la investigación en comunicación". En Cap. V: "El referente empírico". Verónica Vidarte Asorey. 1.a ed. - La Plata: Universidad Nacional de La Plata. Argentina.

-STAKE, Robert (1999). "La investigación con estudio de casos". 2da. ed. Ediciones Morata. Madrid.

-TAUBER, Fernando, DELUCCHI, Diego, MARTINO, Horacio y PINTOS, Patricia (2006). "La Planificación Estratégica Participativa. Para el desarrollo urbano y regional". Editorial de la Universidad Nacional de La Plata. La Plata, provincia de Buenos Aires.

-TAUBER, Fernando (2008). "La comunicación en la planificación y gestión para el desarrollo de las instituciones universitarias públicas argentinas: el caso de la Universidad Nacional de La Plata en el trienio junio 2004-mayo 2007". Tesis de doctorado. Facultad de Periodismo y Comunicación Social. Universidad Nacional de La Plata. La Plata.

-TELLO, María Elena y MIKLOS, Tomas (2004). "Planeación prospectiva. Una estrategia para el diseño del futuro". Editorial Limusa. México.

-TRÉSPIDI, Miguel Ángel (2009). "Universidad Nacional y Comunicación Institucional. Una gestión posible para alcanzar una universidad mejor comunicada". PLANGESCO. Facultad de Periodismo y Comunicación Social. Universidad Nacional de La Plata. La Plata.

-URANGA, Washington (2008). "Prospectiva estratégica desde la comunicación. Una propuesta de proceso metodológico de diagnóstico dinámico y planificación". Buenos Aires.

-VESSURI, Hebe (1992). "Las ciencias sociales en la Argentina: diagnóstico y perspectivas". En OTEIZA, Enrique (Dir.). "La política de investigación científica y tecnológica en Argentina. Historias y perspectivas". Buenos Aires, Centro Editor de América Latina (CEAL). 
-VINUESA, Juan Francisco (2012). "Política Agraria y Comunicación. El INTA y su propuesta de intervención rural". PLANGESCO. Facultad de Periodismo y Comunicación Social. Universidad Nacional de La Plata. La Plata.

-WEBER, Max (2002). "Economía y sociedad". 2da. reimpresión. Fondo de Cultura Económica. España. 


\section{Documentos Institucionales consultados}

-BAHÍA BLANCA (2012). "Informe de Evaluación Externa. Centro Científico y Tecnológico CCT Bahía Blanca". Programa de Evaluación Institucional (PEI). Junio. Secretaría de Articulación Científico Tecnológica. Ministerio de Ciencia, Tecnología e Innovación Productiva de la Nación.

-BAHÍA BLANCA (2011). "Informe de Autoevaluación Centro Científico y Tecnológico CCT Bahía Blanca". CONICET.

-BAHÍA BLANCA (2011). "Informe de Autoevaluación Centro Científico y Tecnológico CCT Bahía Blanca". Anexo. CONICET.

-CADIC (2011). "Informe de Evaluación Externa. Centro Austral de Investigaciones Cientificas CADIC - Ushuaia". Programa de Evaluación Institucional (PEI). Agosto. Secretaría de Articulación Científico Tecnológica. Ministerio de Ciencia, Tecnología e Innovación Productiva de la Nación.

-CADIC (2011). "Informe de Autoevaluación del Centro Austral de Investigaciones Cientificas CADIC - Ushuaia". Marzo. CONICET.

-CADIC (2012). "Evaluación Institucional y Planificación Estratégica Orientada al Mejoramiento. Centro Austral de Investigaciones Cientificas CADIC - Ushuaia". Septiembre. Convenio CONICET - MINCyT.

-CENPAT (2012). "Informe de Evaluación Externa. Centro Nacional Patagónico CENPAT Puerto Madryn". Programa de Evaluación Institucional (PEI). Abril. Secretaría de Articulación Científico Tecnológica. Ministerio de Ciencia, Tecnología e Innovación Productiva de la Nación.

-CENPAT (2011). "Informe de Autoevaluación del Centro Nacional Patagónico CENPAT Puerto Madryn". Agosto. CONICET

-CENPAT (2013). "Informe de Autoevaluación del Centro Nacional Patagónico CENPAT Puerto Madryn". Mayo. Convenio CONICET - MINCyT. 
-COMAHUE (2013). "Proceso de Autoevaluación del Centro Científico y Tecnológicos CCT Comahue". CONICET.

-CÓRDOBA (2013). "Informe Final de Autoevaluación Centro Científico y Tecnológico CCT Córdoba". CONICET. Agosto.

-LA PLATA (2013). "Informe de Evaluación Externa. Centro Científico y Tecnológico CCT La Plata". Programa de Evaluación Institucional (PEI). Mayo - Agosto. Secretaría de Articulación Científico Tecnológica. Ministerio de Ciencia, Tecnología e Innovación Productiva de la Nación.

-LA PLATA (2012). "Ejes del Plan de Desarrollo del CCT La Plata". CONICET.

-LA PLATA (2012). "Informe de Autoevaluación del Centro Científico y Tecnológico CONICET La Plata". Agosto. CONICET.

-MAR DEL PLATA (2012). "Informe de Evaluación Externa. Centro Científico y Tecnológico CCT Mar del Plata". Programa de Evaluación Institucional (PEI). Noviembre. Secretaría de Articulación Científico Tecnológica. Ministerio de Ciencia, Tecnología e Innovación Productiva de la Nación.

-MAR DEL PLATA (2012). " Informe de Autoevaluación del CCT Mar del Plata". Agosto. CONICET.

-NORDESTE (2013). "Informe de Evaluación Externa. Centro Científico y Tecnológico CCT Nordeste". Programa de Evaluación Institucional (PEI). Septiembre - noviembre. Secretaría de Articulación Científico Tecnológica. Ministerio de Ciencia, Tecnología e Innovación Productiva de la Nación.

-NORDESTE (2013) "Informe de Autoevaluación del Centro Científico y Tecnológico CCT Nordeste". CONICET.

-ROSARIO (2012). "Informe de Autoevaluación del Centro Científico y Tecnológico CCT Rosario". CONICET.

-SAN LUIS (2012). "Informe de Evaluación Externa. Centro Cientifico y Tecnológico CCT San Luis". Programa de Evaluación Institucional (PEI). Noviembre. Secretaría de 
Articulación Científico Tecnológica. Ministerio de Ciencia, Tecnología e Innovación Productiva de la Nación.

-SAN LUIS (2011). "Informe de Autoevaluación del Centro Científico y Tecnológico CCT San Luis". Diciembre. CONICET.

-SANTA FE (2013). "Informe de Autoevaluación del Centro Científico y Tecnológico Santa $F e^{\prime \prime}$. Septiembre. CONICET.

-TUCUMÁN (2012). "Informe de Evaluación Externa. Centro Científico y Tecnológico CCT Tucumán". Programa de Evaluación Institucional (PEI). Octubre. Secretaría de Articulación Científico Tecnológica. Ministerio de Ciencia, Tecnología e Innovación Productiva de la Nación.

-TUCUMÁN (2012). "Informe de Autoevaluación del Centro Científico y Tecnológico Tucumán". Marzo. CONICET. 